\title{
Report of the 75th National Conference on Weights and Measures
}

\section{0}

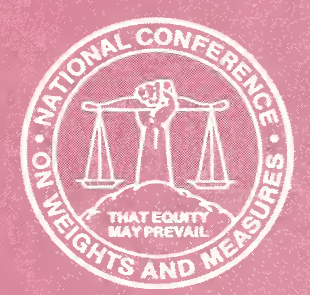



Report of the

\section{5th National Conference on Weights and Measures 1990}

Sponsored by the National Institute of Standards and Technology, Attended by Officials from the Various States, Counties, and Cities, and Representatives from U.S. Government, Industry, and Consumer Organizations Washington, DC July 9-13, 1990

Report Editors:
Albert D. Tholen
Carroll S. Brickenkamp Ann H. Turner

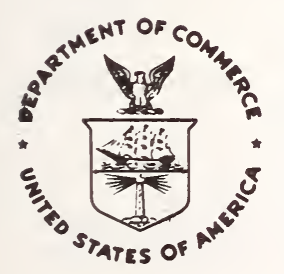

U.S. Department of Commerce

Robert A. Mosbacher, Secretary

National Institute of Standards and Technology John W. Lyons, Director

Issued September 1990

Natl. Inst. Stand. Technol. Spec. Publ. 793, 242 pages (Sept. 1990) CODEN:NSPUE2

U.S. GOVERNMENT PRINTING OFFICE

WASHINGTON: 1990

For sale by the Superintendent of Documents, U.S. Government Printing Office, Washington, DC 20402-9325 


\begin{abstract}
The 75th Annual Meeting of the National Conference on Weights and Measures (NCWM) was held at the J. W. Marriott Hotel in Washington, D. C. during the week of July 9 through 13, 1990. The theme of the meeting was "Progress Through Consensus Among Consumers, Regulators, \& Industry."
\end{abstract}

In his address to the delegates, Chairman Fred Gerk of New Mexico reflected on the progress made by the NCWM in the past year. In his address, Conference President John Lyons, Director, National Institute of Standards and Technology, provided a history of the founding of the National Bureau of Standards and the NCWM. In his keynote address, Congressman Tim Valentine noted the challenges to be met by the NCWM in the future.

The Conference set standards for equipment and sales practices in the area of cash/credit pricing of retail motor fuel and compressed gas cylinders. Progress in training program development and standards for moisture loss were also reported upon.

Special meetings included those of the Metrologists, the Associate Membership Committee, the Retired Officials Committee, the Scale Manufacturers' Association, the American Petroleum Institute, the Industry Committee on Packaging and Labeling, the State regional weights and measures associations, and the National Association of State Departments of Agriculture Weights and Measures Division.

Reports by the standing and annual committees of the Conference comprise the major portion of this publication, along with the addresses delivered by Conference officials and other authorities from government and industry.

Key words: motor fuel dispensers; legal metrology; railroad track scales; safety; specifications and tolerances; training; type evaluation; uniform laws and regulation; weights and measures.

Library of Congress Catalog Card Number 26-27766.

Note: Opinions expressed in non-NIST papers are those of the authors and not necessarily those of the National Institute of Standards and Technology. Non-NIST speakers are solely responsible for the content and quality of their material. 


\section{Contents}

Page

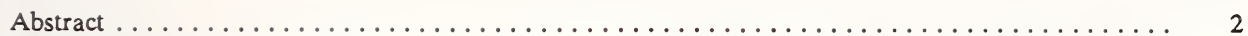

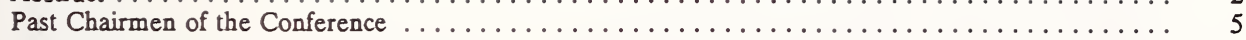

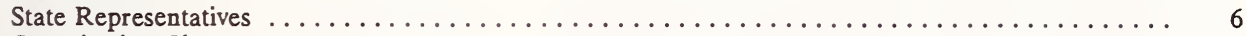

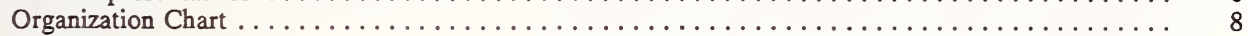

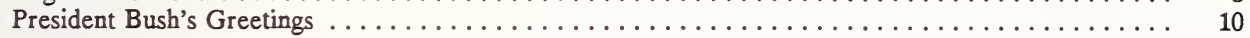

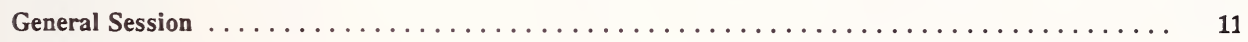

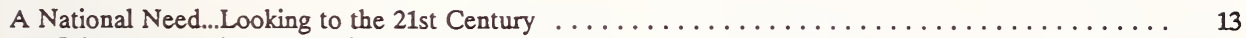

Dr. John Lyons, Director, National Institute of Standards and Technology

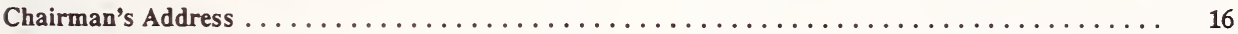

Fred A. Gerk, New Mexico

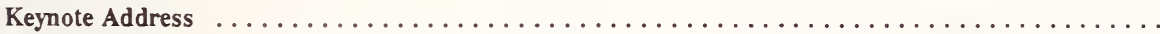

U.S. Representative Tim Valentine, North Carolina

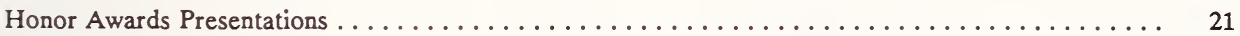

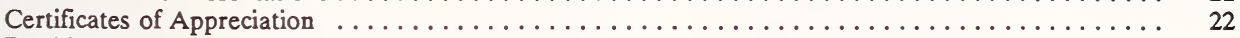

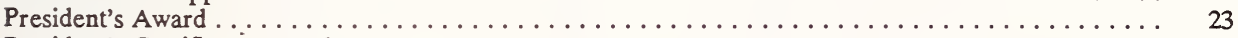

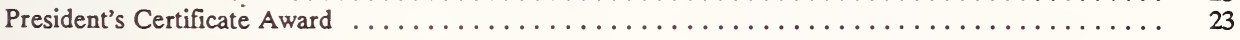

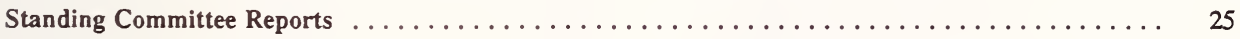

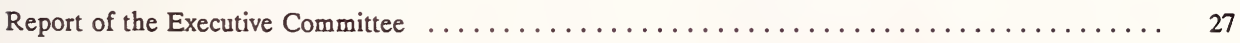

Appendix A - Policy, Interpretations, and Guidelines ................ 47

Appendix B - Proposed Changes to NTEP Administrative Procedures, Technical Policy,

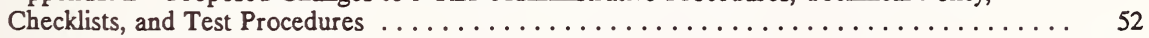

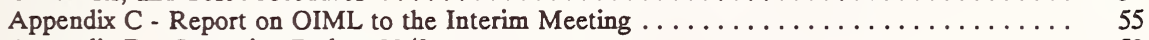

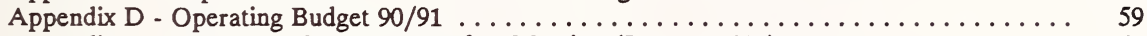

Appendix E - NCWM Task Force on Safety Meeting (January 1990) .............. 62

Appendix F - Summary, Questionaire on Conference Costs and Locations . . . . . . . . . . 69

Appendix G - Treasurer's Interim Report Fiscal Year 74 (1989-1990) . . . . . . . . . . 73

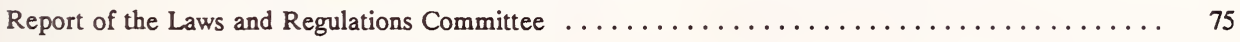

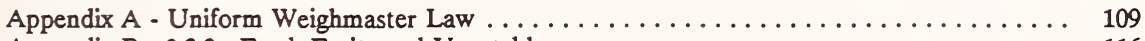

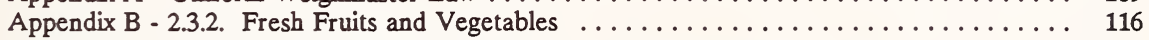

Appendix C - Meat and Poultry Products

A Consumer Guide to Content and Labeling Requirements .......... 119

Appendix D - Test Method for Compressed Gases ...................... 127 


\section{Contents (Continued)}

Report of the Specifications and Tolerances Committee $\ldots \ldots \ldots \ldots \ldots \ldots \ldots \ldots \ldots \ldots \ldots$

Report of the Committee on Education, Administration, and Consumer Affairs $\ldots \ldots \ldots \ldots \ldots$

Appendix A - NTP Certification Summary $\ldots \ldots \ldots \ldots \ldots \ldots \ldots \ldots \ldots \ldots \ldots \ldots \ldots \ldots \ldots \ldots$

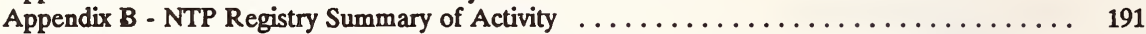

Appendix C - The NCWM Training Needs Survey . . . . . . . . . . . . . . . 197

Appendix D - Outines of Parts I and II of Module $23 \ldots \ldots \ldots \ldots \ldots \ldots \ldots \ldots \ldots \ldots \ldots \ldots$

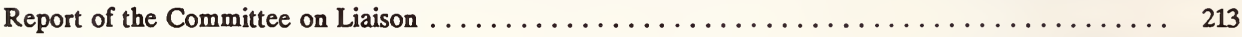

Annual Committee Reports ................................. 221

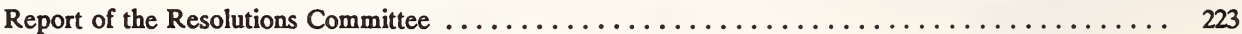

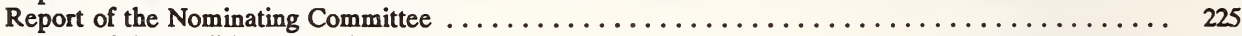

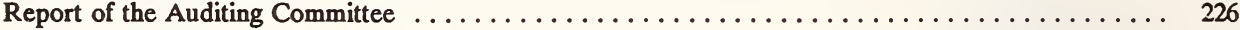

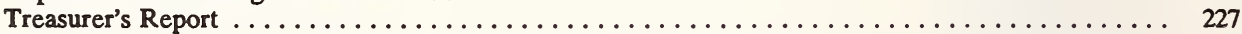

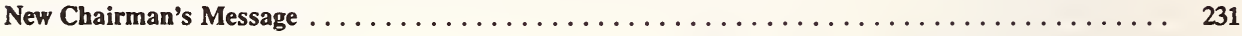

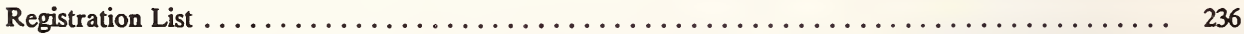




\section{Past Chairmen of the Conference}

$\begin{array}{lll}\text { CONFERENCE } & \text { YEAR } & \text { CHAIRMAN } \\ \text { 43rd } & 1958 & \text { J. P. McBride, MA } \\ \text { 44th } & 1959 & \text { C. M. Fuller, CA } \\ \text { 45th } & 1960 & \text { H. E. Crawford, FL } \\ \text { 46th } & 1961 & \text { R. E. Meek, IN } \\ \text { 47th } & 1962 & \text { Robert Williams, NY } \\ \text { 48th } & 1963 & \text { C. H. Stender, SC } \\ \text { 49th } & 1964 & \text { D. M. Turnbull, WA } \\ \text { 50th } & 1965 & \text { V. D. Campbell, OH } \\ \text { 51st } & 1966 & \text { J. F. True, KS } \\ \text { 52nd } & 1967 & \text { J. E. Bowen, MA } \\ \text { 53rd } & 1968 & \text { C. C. Morgan, IN } \\ \text { 54th } & 1969 & \text { S. H. Christie, NJ } \\ \text { 55th } & 1970 & \text { R. W. Searles, OH } \\ \text { 56th } & 1971 & \text { M. Jennings, TN } \\ \text { 57th } & 1972 & \text { E. H. Black, CA } \\ \text { 58th } & 1973 & \text { George L. Johnson, KY } \\ \text { 59th } & 1974 & \text { John H. Lewis, WA } \\ \text { 60th } & 1975 & \text { Sydney D. Andrews, FL } \\ \text { 61st } & 1976 & \text { Richard Thompson, MD } \\ \text { 62nd } & 1977 & \text { Earl Prideaux, CO } \\ \text { 63rd } & 1978 & \text { James F. Lyles, VA } \\ \text { 64th } & 1979 & \text { Kendrick J. Simila, OR } \\ \text { 65th } & 1980 & \text { Charles H. Vincent, TX } \\ \text { 66th } & 1981 & \text { Edward H. Stadolnik, MA } \\ \text { 67th } & 1982 & \text { Edward C. Heffron, MI } \\ \text { 68th } & 1983 & \text { Charles H. Greene, NM } \\ \text { 69th } & 1984 & \text { Sam F. Hindsman, AR } \\ \text { 70th } & 1985 & \text { Ezio F. Delfino, CA } \\ \text { 71st } & 1986 & \text { George E. Mattimoe, HI } \\ \text { 72nd } & 1987 & \text { Frank Nagele, MI } \\ \text { 73rd } & 1988 & \text { Darrell A. Guensler, CA } \\ \text { 74th } & 1989 & \text { John J. Bartfai, NY } \\ & & \end{array}$




\section{State Representatives}

The following designated State representatives were present and voted on reports presented by the Conference standing and annual committees:

\section{STATE}

Alabama
Alaska
American Samoa
Arizona
Arkansas
California
Colorado
Connecticut
Delaware
District of Columbia
Florida
Georgia
Guam
Hawaii
Idaho
Illinois
Indiana
Iowa
Kansas
Kentucky
Louisiana
Maine
Maryland
Massachusetts
Michigan
Minnesota
Mississippi
Missouri
Montana
Nebraska
Nevada
New Hampshire
New Jersey
New Mexico
New York

\section{REPRESENTATIVE}

Don E. Stagg

Aves Thompson

Arthur L. Young

Raymond Helmick

Sam Hindsman

Darrell Guensler

David Wallace

Allan Nelson

Eugene Keeley

None

Maxwell Gray

Martin Coile

None

James E. Maka

Glen Jex

Sid Colbrook

Sharon Rhoades

Jerry L. Bane

DeVern H. Phillips

Victor Page

Melvin Lyons, Jr.

Stanley K. Millay

M. Richard Shockley

Charles H. Carroll

Edward Heffron

Michael F. Blacik

William P. Eldridge

Lester H. Barrows

None

Steven A. Malone

None

None

Carl P. Conrad, Jr.

Fred Gerk

John Bartfai

\section{ALTERNATE}

John B. Rabb

David Cavender

None

Calvin F. Vance

None

Barbara Bloch

None

Raymond Kalentkowski

None

None

Jack Jeffries

George E. Jones

None

None

Thomas Schafer

Steve McGuire

None

None

Carl Gile

Randy Wise

None

None

Louis E. Straub

None

Celeste Bennett

None

None

R. Wittenberger

None

Michael Diesley

None

None

Joseph Silvestro

Charles H. Greene

Ross Andersen 
STATE

North Carolina

North Dakota

Ohio

Oklahoma

Oregon

Pennsylvania

Puerto Rico

Rhode Island

South Carolina

South Dakota

Tennessee

Texas

Utah

Vermont

Virginia

Virgin Islands

Washington

West Virginia

Wisconsin

Wyoming
REPRESENTATIVE

N. David Smith

None

James C. Truex

O. Ray Elliott

Kendrick J. Simila

Dean F. Ely

Heliodoro Lopez-Torres

None

Carol P. Fulmer

James A. Melgaard

Cathryn Pittman

Edwin J. Price

Robert Smoot

Bruce Martell

J. Alan Rogers

None

Sterling McFarlane

None

Donald J. Soberg

Victor Gerber
ALTERNATE

Ronald Murdock

None

None

Charles Carter

None

None

Jose A. Torres-Ferrer

None

John V. Pugh

None

None

James H. Eskew

None

None

G. Wes Diggs

None

None

None

Alan Porter

None 


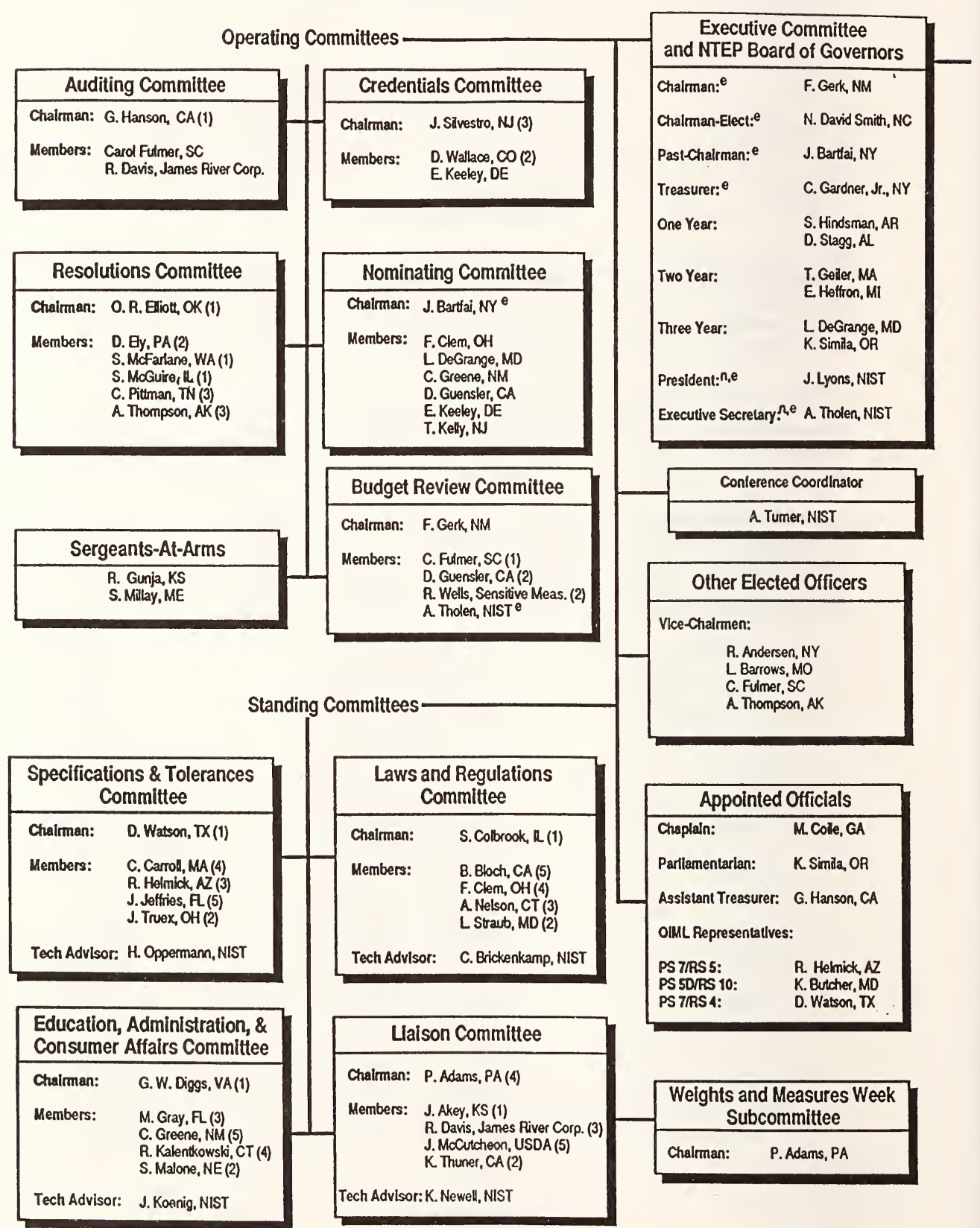




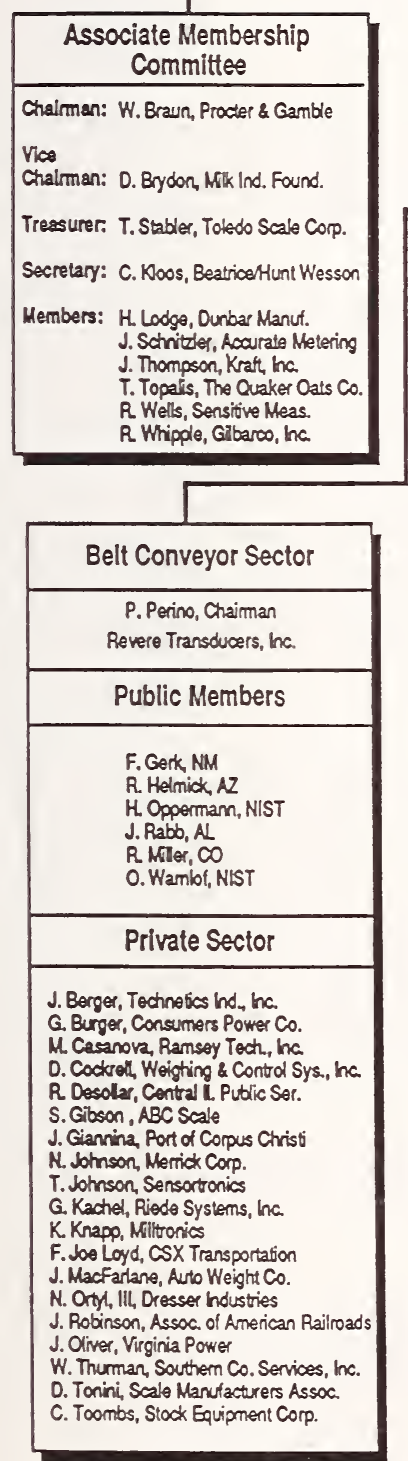

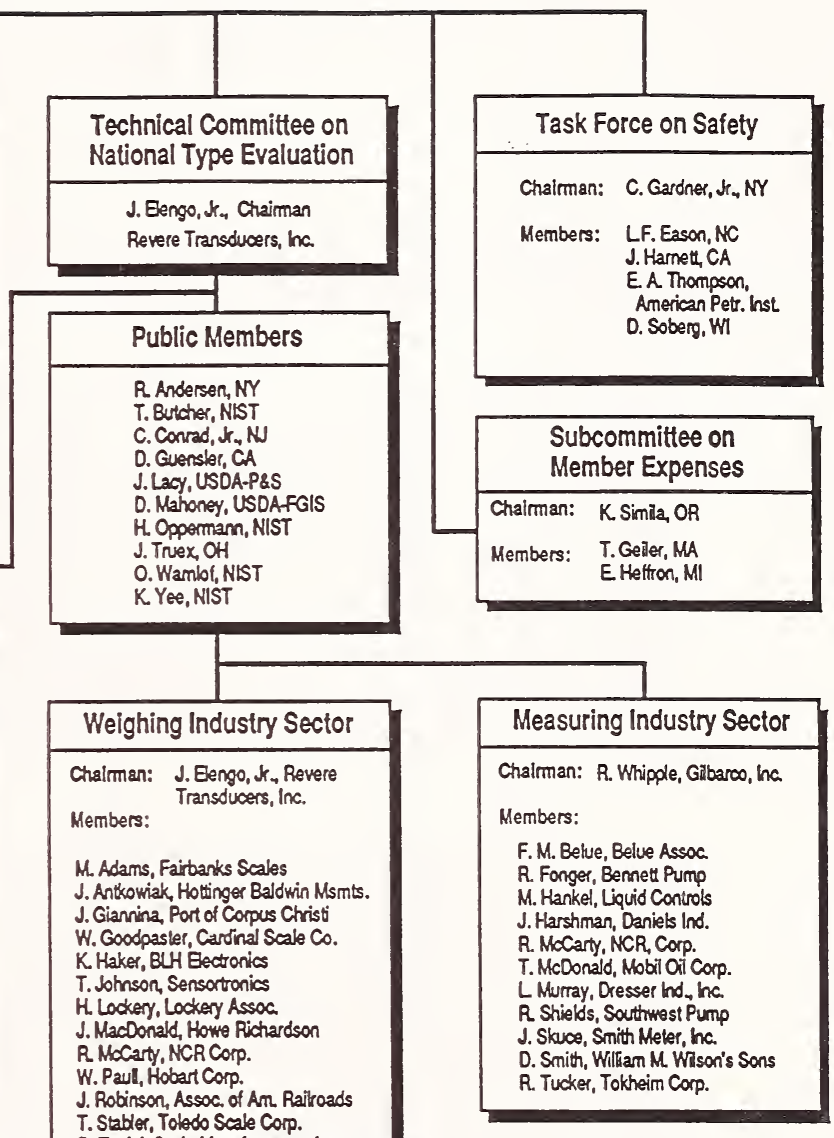


THE WHITE HOUSE

WASHINGTON

May 7, 1990

I am pleased to send my greetings to all those gathered in Washington, D.C., for the 75th Annual Meeting of the National Conference of Weights and Measures.

For three-quarters of a century, the National Conference has played a vital role in our marketplace by protecting the rights of consumers and business owners alike; by establishing uniform standards for retail trade; by promoting fair competition among businesses; and by facilitating trade across state and national borders. Today, the consensus-building approach taken by the regulatory officials and industry representatives participating in this conference is helping to assure an efficient and fair marketplace without excessive restrictions on technology or business operations.

The National Conference of Weights and Measures provides a model of cooperation between Federal, state, and local governments and the private sector. I applaud your efforts to promote equity in trade at both the national and international levels. With more free market systems emerging around the world, your work will continue to grow in importance. You have made significant contributions to the growth of American commerce since your first meeting in 1905, and I look forward to your continued success.

Barbara joins me in congratulating you on your Diamond Anniversary and in sending best wishes for a productive Annual Meeting.

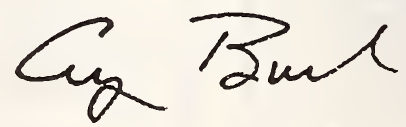


General Session 



\title{
A National Need....Looking to the 21st Century
}

\author{
Dr. John Lyons \\ Director, National Institute of Standards and Technology
}

I am very pleased to be here today to participate in celebrating the 75th Annual Meeting of this Conference. On this occasion, it is useful to revisit the origins of the National Institute of Standards and Technology (formerly the National Bureau of Standards) and the National Conference on Weights and Measures to gain important perspectives of the relative changes of our organizations in response to National needs in commerce and industry in the United States in the intervening 85 years. Of course, the evolution of the Conference has been, and remains today, inseparable from the historic changes to the National Institute of Standards and Technology during that same 85 years.

As the United States entered the 20th century, neither the National Institute of Standards and Technology nor the National Conference on Weights and Measures existed.

Quoting from "Measure for Progress, A History of the National Bureau of Standards,"

"A Federal Standards laboratory had been under discussion for almost 20 years before the burst of nationalism at the turn of the century and the surging growth of American industry together conspired to assure its serious consideration. As a result of the Spanish-American War we had, in a few short months, become a world power, intensely proud of the new respect with which the nations of the world now dealt with us. Our foreign and domestic commerce flourished as never before. In the decade before 1900 the export of American manufacturers almost doubled. Only Germany's overseas trade had exceeded this rate of increase in the same period, largely because, as our manufacturing and trade associations pointed out, she was able to guarantee the uniformity and quality of her exported goods."

Fortunately, the U.S. Congress responded to the rapid changes taking place a century ago. One of its responses was the establishment of the National Bureau of Standards (NBS) in 1901. Most of you know that the Office of Standard Weights and Measures, that had been established in 1836, was incorporated into the NBS.

Shortly after the establishment of the NBS, steps were taken to address a national problem that was getting in the way of growth in commerce among the States; this was, in the words of Dr. Stratton, first Director of the NBS, the need

"to bring about uniformity in the State laws referring to weights and measures, and also to effect a close cooperation between the State inspection services and the National Bureau of Standards."

These words are from his letter sent to each State in 1904 in which he invited representatives of the States to meet at the NBS to address this need. The first meeting in response to that letter was in 1905. In 1906, the holding of annual meetings was formalized under the name "The National Conference on Weights and Measures."

This week, we are holding the 75th such annual meeting. We, the National Institute of Standards and Technology (NIST) and the Conference, continue the work started nearly a century ago to ensure the integrity of the U.S. marketplace through foresight and hard work. I understand that you all received a special souvenir reproduction of the proceedings of that first meeting in 1905. Later, after all of the speeches this afternoon, you will see a filming of portions of that first meeting based on those proceedings. That was a truly historic meeting called and chaired by the first Director of the National Bureau of Standards. 
As the first Director of the National Institute of Standards and Technology, I want to lay the groundwork for what I hope will be an equally successful future for joint NIST/Conference cooperation.

In the 85 years since that first, historic Annual Meeting, the Office of Weights and Measures (OWM), handin-glove with the National Conference on Weights and Measures (NCWM), has continued to support that role of the NBS related to working with the States and business, first in establishing a uniform basis for regulation of the marketplace to all the States, and second, ensuring that the laws, regulations, codes, and standards continue to meet the needs of the marketplace. To say that we, together, have succeeded is a gross understatement. We should be proud of our achievements.

While the OWM and the NCWM continued to address their responsibilities, the National Bureau of Standards was constantly being challenged to serve the Nation's rapidly expanding scientific development. That challenge was described in a letter from the then Secretary of the Treasury Lyman Gage to the Congress in 1900. He stated that:

"The establishment of uniform standards, their maintenance, and the solution of problems connected with them, has until recent years been confined to standards of length, mass, capacity, and temperature; but the increased order of accuracy demanded in scientific and commercial measurements and the exceedingly rapid progress of pure and applied science have increased the scope of such work until it includes many important branches of physical and chemical research."

The National Bureau of Standards has met its many challenges since its creation. In fact, as the world moves toward the dawn of the 21st century, the challenges we are facing are, perhaps, more serious than those faced in 1900. In 1900, the United States was emerging onto the world arena as a strong aggressive trading competitor. Today, we are facing increasing competition from other countries that are emerging as strong aggressive trading competitors.

Again, as it did nearly a century ago, the U.S. Congress has expressed its concern for the economic future of our country. Again, as in 1901, the Congress concluded that the National Bureau of Standards should play a major role in addressing the new challenges. In 1988, the Congress passed the "Omnibus Trade and Competitiveness Act of 1988." Several features of that Bill affect us. Ray Kammer described the nature of the legislation to you last year in Seattle, including the change in our name to the National Institute of Standards and Technology.

He noted that while major concerns were discussed about the competitiveness of the U.S. industry, a healthy science and creativity continue to be U.S. strengths. Our problems are based on the fact that we are not meeting the competition of other nations in translating that science and creativity to products in the marketplace. Our competitors are viewed as introducing new products into commerce faster than we do, and their products are considered to be of higher quality and lower cost. Based on this evaluation of our competitiveness problem, the Omnibus Trade Bill assigns new tasks to the NIST.

We at NIST are responding to the need:

"To modernize and restructure (NIST) to augment its unique ability to enhance the competitiveness of American Industry while maintaining its traditional function as lead National Laboratory for providing the measurements, calibrations, and quality assurance techniques which underpin United States commerce, technological progress, improved product reliability and manufacturing processes, and public safety."

As stated here, I am committed to maintaining our traditional functions which include our support of the States, business and this Conference through the programs of the Office of Weights and Measures, the Force Division, and other NIST research efforts. 
General Session

In the new NIST role in the enhancement of competitiveness, we:

- must build on our strengths;

- continue our supporting services to the public and the private sectors;

- tie our programs to emerging technologies; and

- put growing emphasis on industrial processing, concurrent engineering, and ever improving quality.

As you can see, NIST has a broad range of new scientific research to address. We want to succeed; we need to succeed. Progress on our part is a major key to the economic health of the United States.

We also must be vigilant and protect the resources needed to keep our traditional work healthy. We intend to work closely with you through the National Conference to ensure that the U.S. marketplace keeps pace with the rapid changes appearing there constantly. We at NIST and you in the weights and measures community cannot sit on our hands, because important segments of the Nation's future are in our hands.

At the end of the 19th Century, our Nation had serious needs. We were given important work to do then. We did succeed.

At the end of this, the 20th Century, our Nation again has serious needs. We again have been given important work to do. We again intend to succeed.

Let us get on with this work, with the expectation that History will record that we also succeeded as did the National Bureau of Standards and the National Conference on Weights and Measures since their creations nearly a hundred years ago.

Thank you. 


\title{
Chairman's Address
}

\author{
Fred A. Gerk, Chairman \\ Director, New Mexico Division of Standards \& Consumer Services
}

\begin{abstract}
Thank you Ladies and Gentlemen for being here this week and allowing me to be before you today. I am most pleased that Dr. Lyons is here with us today and is continuing the support for the National Conference on Weights and Measures that we have enjoyed for many years with Dr. Ambler at the helm of the National Insititute of Standards and Technology. Dr. Lyons, I want to publicly thank you on behalf of the Conference for appointing Dr. Heffron to the NIST Visiting Committee. We in the Conference feel that his appointment will be of great benefit to the weights and measures community, the state and local businesses, and the government community in general. I think you will find him to be a valuable addition to the committee.
\end{abstract}

I hope you will take an active role in the conference in years to come and I assure you that you have the support of the NCWM.

I see today as "report card day" for the "Ol' Country Boy from New Mexico." I have found that the job of Chairman can be accomplished in half days, and it doesn't make any difference whether it's the first twelve hours or the last twelve hours. So please, judge me not only on what I did, but on what I didn't do. I am glad to report that when I told you last year, "if all else fails lower your standards," I don't feel we had to lower our standards. If I failed as Chairman, I will assume full responsibility. If I passed your standards as Chairman, many people are responsible. If you look in your conference announcement on the third and fourth pages, which is the organizational chart of the Conference, you will see a list of those people.

The NCWM has become such a dynamic organization, it is approaching perpetual motion status and its current 3,021 members are the driving force.

This year, our 75th Anniversary, was an exciting and fulfilling year for me as Chairman, speaking conservatively, I feel I have visited one on one with over 700 of our members. I have given advice and counsel and, you can be assured, I have received plenty of advice and counsel.

The staff at the Office of Weights and Measures has been enormously helpful and, I might add, very understanding. Carroll Brickenkamp was always ready and willing to pitch in when needed, and has served on many occasions as my personal counselor. Henry Oppermann's expertise and support was there as usual. He is one of the hardest working and brightest young men in the weights and measures profession. Joan Koenig in her usual professional manner was there to help and, I might add, keep my handwriting in order. Her job requires more signatures than a famous movie star! Computer whiz Karl Newell did his thing over and above, as you will see later on during our feature film. Tina Butcher, in her sweet quiet way, has come on like "gangbusters" in her role as advisor to the Task Force on Safety and numerous other duties. Joan Mindte did great all year -- she even scheduled a 7:00 A.M. breakfast in my suite this week and didn't tell me about it. The new kid on the block, Georgia Harris, has already taken the metrologist programs to the forefront and is accomplishing great things. I have to say something good about my two girlfriends in the Office of Weights and Measures, Elizabeth Begosh and Terry Grimes, better known as Trixi. Without question, they do the work and the rest of the OWM staff takes the credit.

I can't say enough about Ann Turner or, as she is sometimes called, "Crash Turner." She took care of every little detail in impeccable fashion and almost kept me on the straight and narrow.

Al Tholen always had a solution for any dilemma I encountered and was very responsive to my thoughts regardless of how "country" they were. He constantly strives to make the NCWM a better organization. His ideas are unlimited. The only fault I find with him is that his normal attire does not go well with "western boots." 
I owe a special thanks for all the guidance I received from my very good friend Otto Warnlof. He and Irene have tutored well. Otto has a philosophy that I learned early on in my years on the S \& $\mathrm{T}$ Committee. Do everything right and, if that's not good enough, do it again -- That's why I served two years as Chairman of that Committee.

I must also mention the outstanding work our metrologists have done this year. They are now formally organized and have become a positive contributory factor to the conference.

Charlie Greene has been my personal shrink for many years and has been extremely helpful this year. His brains and my B.S. have made us known as the "G-men of New Mexico."

My staff at home has been very understanding, and to them I owe much gratitude - without them I wouldn't be here today! Pat Avalos, my head secretary of $17+$ years, probably worked harder for the Conference this year than I did.

Last, but not least, a big thank you to my wife Verna; she kept my clothes clean, my bags packed, and my tummy full and was always there to listen and support!

This year's theme of "Progress through Consensus Among Consumers, Regulators and Industry," I feel, became a reality. As your Chairman, I traveled to all of the regional conferences, two meetings of the Scale Manufacturer's Association, a meeting of National Type Evaluation Technical Committee and the Board of Governors, and several meetings of the Retail Grocers Association, and the Petroleum Marketers. Consumers and industry were heavily involved in all of these meetings and played a key role in reaching consensus solutions.

I mentioned attending all four regional conferences. I can truly state that I was thoroughly impressed by each of the regional meetings. They are becoming more and more of a driving force for the National Conference. We still need a little more coordination between the regionals and the National to finalize the proper relationship, but I think the regionals are really moving forward in the right direction. They have convinced me that weights and measures is not only a profession, but has become a way of life! I might mention that on my trip to the Northeastern Conference, I was made a member of the airlines 100,000 mile club, and at the same time my luggage became a member of the 150,000 mile club!

To quote from the famous acceptance speech given by Fred A. Gerk on July 1989, "I didn't campaign for this office; thus, I didn't make any campaign promises." Therefore, I must have fulfilled all my campaign promises.

Seriously, I think the Conference had a great year and is alive and well.

The National Type Evaluation Program received considerable attention this year. For the first time ever, a certificate of conformance was revoked, others have been challenged. Many questions have been raised about how far NTEP goes, what changes need to be made and how NTEP effects weighing in the real world. Some solutions have been reached, others are under study. NTEP is in place and fine tuning has begun. The National Type Evaluation Technical Committee Chaired by John Elengo for the Weighing Industry Sector, Richard Whipple for the Measuring Industry Sector, and Peter Perino for the Belt Conveyor Sector are spending much time and effort in this fine tuning and they are to be commended for their efforts. NCWM Publication 5 that has recently been published, should be a real asset to the field inspector.

Next, the National Training Program has matured. All but one state have now signed up for the program and that one is coming around. Megabucks, namely over $\$ 500,000$, have been spent on module development, and 13 modules are currently in place. To date over 582 people have received formal training with these modules. This year we took it a step further and provided funding for regional "Train the Trainer" programs. Just two months ago the Northeastern Weights and Measures Association finalized plans for "train the trainer" courses for their members. They have contracted with the Institute for Weights and Measures to provide this training. This, hopefully, is another step in implementing our training program nationally for the benefit of both industry and regulators. We next have to look at ways of quickly revising the modules to track annual changes made to Handbooks 44 and 130 . We are even experimenting with training delivery sponsored by NCWM. 
The Task Force on Safety, formed just one year ago this month, hit the deck "a-running." Under the guidance of the incomparable Charles Gardner, of Suffolk County, New York, much has been accomplished. The Task Force has developed an outstanding library of safety material available to anyone interested. This will be the first comprehensive national effort in the safety arena and I think it will benefit the entire weights and measures community immensely. I strongly urge all weights and measures officials in attendance here today to take a look at the Task Force work and take it home with you and implement it. If we prevent one accident, it will be well worth our effort.

Next, if you look at the Conference announcement and read the committee reports, you will see full agendas for each committee. Much work and effort has gone into the development of each of the committee reports. I urge you to become familiar with each of the issues and vote your conscience the rest of the week.

One of my philosophies throughout my year as Chairman has been to try, during my travels, to take the Conference to the people that do not have the privilege or the resources to attend the Conference. My good friend, and our Chairman-Elect David Smith from North Carolina, and I have hosted a breakfast at each regional for persons that normally do not attend the Conference, the guys and gals in the trenches, so to speak. At these regional breakfasts, we have asked Daryl Tonini of Scale Manufacturers' Association, Dick Whipple of Gasoline Pump Manufacturers' Association, and Mike Belue of American Petroleum Institute to explain the role and functions of their respective organizations and how they interact with the NCWM. This has proven to be very informative and interesting and, as a result, I think the conference is better understood outside the realm of the regular attendees. I would be remiss if I didn't tell you more about your incoming Chairman. Dave and I have worked very closely together this year in representing the Conference. Dave has been a real asset and true ally during my term as Chairman. And as a result of his involvement, I can assure you, he is ready and competent to take over as Chairman later this week. You can rest assured anything I've broken, Dave will fix. Anything I accomplished Dave will make better. I only ask that you give him the enthusiastic support you gave me.

I will conclude with that positive note and bid you "Vaya Con Dios."

Thank You. 
Keynote Address

\author{
Honorable Tim Valentine (D-NC) \\ U.S. House of Representatives \\ Chairman, Subcommittee on Science, Research and Technology
}

It is an honor for me to appear before your organization, the National Conference on Weights and Measures, on the occasion of your diamond anniversary meeting. Your organization has a prestigious past and much to accomplish in the future. I also wish to compliment you on your farsightedness in choosing David Smith, the Director of North Carolina's Standards Division, as your chairman-elect. David is known in North Carolina as a highly able administrator and as one of our most dedicated public servants. I am sure that your organization will be as well-served by David as we in North Carolina have been.

The National Conference on Weights and Measures is one of our nation's best kept secrets, and I hope it remains that way. You are the reason that American customers get fair measure wherever and whenever we make purchases. When we buy 10 gallons of gasoline or five pounds of roast beef, whether we do it in Alaska or North Carolina, there is never any question that we are getting the volume or the mass we are paying for. You and the professionals you work with have done such a good job of standardizing weights and measures in American commerce that we can take for granted that we are being treated fairly.

The U.S. economy has come a long way in the seventy-five years since the National Conference on Weights and Measures was formed and in the 79 years since the National Bureau of Standards became the U.S.'s first national laboratory. At the turn of the century, the United States had the potential for greatness, but we were not there yet. Our country then stretched from coast to coast, but we were not unified. Not much time had passed since the Civil War, the closing of the frontier, or the establishment of rail service from coast to coast. This was a time of excitement and vision, a time of reformers, a time when there was great interest in building a society where all who would put forth the effort could prosper and enjoy the great natural wealth of our nation.

What more appropriate time could there be to establish a National Bureau of Standards and a National Conference on Weights and Measures to standardize weights and measures within the United States and to provide a forum for accomplishing these goals. These organizations over the last 75 years have complemented our free market system by giving it the accurate measurement framework it needs to exist. In a very real way, the National Bureau of Standards and the National Conference on Weights and Measures have provided the uniformity necessary for the United States to become one big marketplace. You have helped create and preserve a market system that is wide open to good ideas and products by providing the means of assuring that transactions are fair both to buyers and sellers. It was the National Bureau of Standards' support to industry that led the subcommittee I now chair to promote the legislation which transformed NBS into the National Institute of Standards and Technology and expanded its role of promoting the competitiveness of American industry.

The events in Eastern Europe over the past couple years have shown us just how lucky we are that our predecessors chose a free market approach. 1905, when your organization began its work, is not that far from 1917 when communism, the other great economic experiment, began in another emerging country which also spanned a continent. Both systems made great promises regarding the well-being and prosperity of the average citizen. Both promised to make great leaps forward, but only one delivered. Democracy with its free market produced outstanding results because, under the free market system, the good ideas of all could be factored into the rules and standards of the market. Communism lost because it gave only lip service to the people and assumed the government knows best. Seventy-five years after your founding, the East is seeing the light. Our economy is finally viewed as a model by these countries and others around the world which now yearn for free markets and the efficiency that comes from them. 
As your organization begins its second 75 years, measurements and standards are as important and newsworthy as they have been in recent memory. We are rapidly moving onto a world stage. More than ever before, the world is becoming one economy, and internationally-accepted measurements are the glue that will hold the world economy together. You are about to face challenges like never before, because traditional U.S. measurements are no longer accepted in the rest of the world, and because U.S. standards are being accepted as de facto world standards less and less. The metric systems of measurement is gaining international acceptance. International standards organizations are gaining new prominence. The European Community and other trading blocks are working towards integrated standards and systems of measurement. The world of measurement will never be the same again.

Some of the changes should be welcomed. Take metric, for instance. This system is inherently simpler and more rational. We are already used to thinking in terms of a width of 35 millimeters for film, a distance of 10 kilometers for a race, and a volume of two liters for Coke. The sooner we can do all our business in metric the better, because not being metric costs the United States dearly in world trade. The Federal Government is in the process of converting to metric over the next 3 years or so, and this change is bound to impact on your work as well.

Others of these changes present a challenge and will require patience and persistence on our part. The European Community's testing and certification procedures have the potential for limiting, as least temporarily, access of some American products to their markets. We are outvoted considerably in the international standards organizations. Other nations are aggressively promoting their standards to third world nations.

I am confident that we are now understanding the challenge we face and, as in the past, we will work to meet the challenge. We must make sure as a nation that any international system of measurement that we subscribe to makes sense, permits U.S. business to do business, and does not jeopardize the public health and safety aspects of our system. We will be challenged, but if we are vigilant and stick to our principles, we will help the world move towards a fairer and more efficient system for doing business worldwide and we will all be much the better for it.

We, of course, have much going for us in this endeavor. We can rely on the fact that our consensus system of establishing standards and our democratic ways of solving measurement issues are both rational and firmly grounded in the realities of the marketplace. We also have many outstanding men and women who, through organizations such as the National Conference on Weights and Measures, have dedicated their careers to making sure that commerce in America can run smoothly.

Therefore, I hope that business and government, at all levels, can continue to work together to meet the challenge. Let's begin now to lay the groundwork so that we have something really big to celebrate in 2015 at the centennial meeting of the National Conference on Weights and Measures. 


\section{Honor Awards Presentations}

Dr. Donald Johnson, Director of Technology Services, NIST, presented Honor Awards to members of the Conference who, by attending the 75th Annual Meeting this year, reach one of the attendance categories for which recognition is given - attendance at $10,15,20,25,30$, and 35 years.

\section{YEARS}

Don Stagg, State of Alabama Thomas Morrow, Tec America Martin Coile, State of Georgia Joseph Nagy, City of South Bend, Indiana

Robert Fonger, Bennett Pump Co.

Walter Kupper, Mettler Instrument

Charles Gardner, Suffolk County, NY

Fred Clem, City of Columbus, $\mathrm{OH}$

C. Thomas Picton, Conrail

\section{YEARS}

Darrell Guensler, State of California Claude Parent, Consultant

Allan Nelson, State of Connecticut John Robinson, Association of American Railroads Austin Rhoads, Northeast Ice Cream Association Steven Malone, State of Nebraska Charles Greene, State of New Mexico John Bartfai, State of New York

20 YEARS

Edwin Hanish, La Porte County, IN

\section{YEARS}

Eugene Keeley, State of Delaware Thomas Stabler, Toledo Scale Co.

30 YEARS

James Bird, Retired, State of New Jersey James Lyles, Retired, State of Virginia 
General Session

\section{Certificates of Appreciation}

Fred Gerk, Conference Chairman, presented Certificates of Appreciation to members of standing committees and annual committees who had completed their tenure on the following committees:

Specifications and Tolerances Committee

Laws and Regulations Committee

Liaison Committee

Education Committee

Executive Committee

Budget Review Committee

Associate Membership Committee

Auditing Committee

Resolutions Committee
David Watson, Fort Worth, Texas

Sidney Colbrook, State of Illinois

Peggy Adams, Bucks County, PA

James Akey, State of Wisconsin

G. Wes Diggs, State of Virginia

Sam Hindsman, State of Arkansas

Don Stagg, State of Alabama

Carol Fulmer, State of South Carolina

William Braun, Procter \& Gamble Co.

Gerald Hanson, San Bernardino County, CA

O. Ray Elliott, State of Oklahoma

Sterling McFarlane, City of Seattle, WA

Steve McGuire, State of Illinois 


\title{
President's Award
}

This special award is a banner presented to the State Director of each state having $100 \%$ of its weights and measures officials as members of the National Conference on Weights and Measures for the membership year July 1, 1988 - June 30, 1989.

\section{First Year Awards Banners}

State of Iowa

State of Montana

State of Oregon

State of Texas

State of Utah

State of Washington

State of Wyoming

Streamers for Second Year 100\% Membership

State of Arizona

State of Hawaii

State of Michigan

State of New Hampshire

Streamers for Third Year 100\% Membership

State of New Mexico

State of Vermont

Streamers for Fourth Year 100\% Membership

State of Alaska

State of Delaware

State of Idaha

State of Kasas

State of South Dakota

Streamers for Fifth Year 100\% Membership

State of Arkansas

State of Nebraska

\section{President's Certificate Award}

This award is given to States with $100 \%$ of their State office staff as members for the $1989-90$ year:

\author{
Colorado \\ Maine \\ Massachusetts \\ New York \\ Indiana \\ Wisconsin \\ Virginia
}



Standing Committee Reports 



\title{
Report of the Executive Committee
}

\author{
Fred A. Gerk, Chairman \\ Director, Division of Standards \& Consumer Services \\ New Mexico
}

Introduction

This is the Final Report of the Executive Committee for the 75th Annual Meeting of the National Conference on Weights and Measures (NCWM). The Report is based on the Interim Report offered in the Conference "Program and Committee Reports" (NCWM Publication 16), the Addendum Sheets issued at the Annual Meeting, and actions taken by the membership at the Voting Session.

Items are grouped into two parts: Part I - Executive Committee Business; and Part II - National Type Evaluation Program, Board of Governors' Business. Table A identifies all of the items contained in the Report by Reference Key Number, Item Title, and page number. Table B lists the Appendices to the Report. Table C reports the voting results.

Table A

Reference Key Items and Index

\section{Reference}

Key No.

\section{PART I - EXECUTIVE COMMITTEE}

$\begin{array}{ll}101-1 & \text { I } \\ 101-2 & \text { I } \\ 101-2 A & \text { I } \\ 101-2 B & \text { I } \\ 101-3 & \text { I } \\ 101-4 & \text { I } \\ 101-5 & \text { V } \\ 101-6 & \text { I } \\ 101-7 & \text { I } \\ 101-8 & \text { I } \\ 101-9 & \text { I } \\ 101-10 & \text { I } \\ 101-11 & \text { I } \\ 101-12 & \text { I } \\ 101-13 & \text { I } \\ 101-14 & \text { I } \\ 101-15 & \text { I } \\ 101-16 & \text { I } \\ 101-17 & \text { I } \\ 101-18 & \text { I } \\ 101-19 & \text { I } \\ 101-20 & \text { I } \\ 101-21 & \text { I } \\ 101-22 & \text { I } \\ 101-23 & \text { I }\end{array}$

Publications, Sale/Distribution ...................... 29

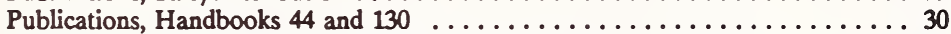

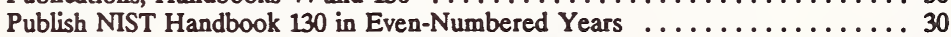

Publish NIST Handbook 44 in Odd-Numbered Years .............. 31

Mailing to Local Jurisdictions . ...................... 31

Membership, Status Report . . . . . . . . . . . . . . . . . . 31

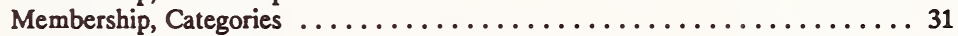

Organization, Appointments and Assignments $\ldots \ldots \ldots \ldots \ldots \ldots \ldots \ldots \ldots \ldots$

Organization, Role of Metrologists ..................... 33

Organization, Canadian Representation .................... 34

Organization, Change Name of NCWM $\ldots \ldots \ldots \ldots \ldots \ldots \ldots \ldots \ldots \ldots$

Finances, Treasurer's Report ...................... 34

Finances, Expenses of Conference Members . . . . . . . . . . . 35

Meetings, Annual \& Interim, Work Schedule ................ 35

Meetings, Annual, Time of Year ...................... 36

Meetings, Annual, President's Award .................... 36

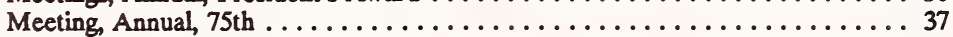

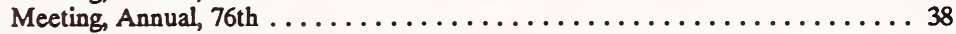

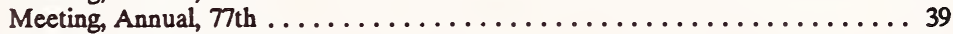

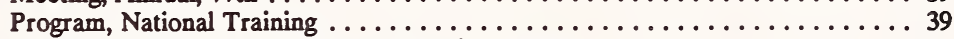

Program, Task Force on Energy Allocation Systems ............. 40

Program, Task Force on Workplace Safety $\ldots \ldots \ldots \ldots \ldots \ldots \ldots \ldots$

Program, International Organization of Legal Metrology ............ 40

Program, Office of Weights and Measures ................ 40

Program, National Uniformity ..................... 40 
Table A (Continued)

Reference

Key No.

Title of Item

Page

\section{PART II - BOARD OF GOVERNORS}

\begin{tabular}{|c|c|c|}
\hline $102-1$ & I & Publications, Status Report \\
\hline $102-2$ & I & Program, Acceptance by the States \\
\hline $102-3$ & I & Program, Participating Laboratories/Evaluation Report \\
\hline $102-4$ & I & Financial, Funding Resolution of Appeals ......... \\
\hline $102-5$ & I & Financial, NIST Administrative Expenses \\
\hline $102-6$ & I & Financial, Funding Meetings of NTEP Laboratory Representatives \\
\hline $102-7$ & I & Policy, Labeling Requirements . . . . . . . . . . . . . . . . . \\
\hline $102-8$ & I & Policy, Type Evaluation Criteria for Computers ............ \\
\hline $102-9$ & I & Policy, Load Cell Testing ................ \\
\hline $102-10$ & I & Policy, Belt-Conveyor Scales, Test Procedures \\
\hline $102-11$ & I & .............. \\
\hline
\end{tabular}

\section{Table B}

Appendices

\section{Appendix}

Title

Reference Key No.

Page

Appendix A Policy, Weights \& Measures Publications

101- 1

Proposed Changes to NTEP Administrative Procedures,

Technical, Policy, Checklists, and Test Procedures

$102-4$

Appendix C

Appendix D

Report on OIML to the Interim Meeting

101-21

Operating Budget $90 / 91$

101-10

Appendix E

Task Force on Safety - Meetings Held During Interim

Meetings, January 14-18, 1990

$101-20$

62

Appendix F

Summary of Questionnaire on Conference Costs and Locations

101-16

\section{Order of Presentation}

The Report was presented to the membership for voting as follows:

1.

A separate vote was taken on the one voting item:

\section{1-5 V Membership Categories}

A vote was taken on the entire Report with editorial privileges accorded to the Executive Secretary. 
Table C

Voting Results

\begin{tabular}{lllllll}
\hline $\begin{array}{l}\text { Reference } \\
\text { Key No. or } \\
\text { Subject }\end{array}$ & $\begin{array}{l}\text { House of State } \\
\text { Representatives }\end{array}$ & No & & $\begin{array}{l}\text { House of } \\
\text { Delegates }\end{array}$ & Results \\
\cline { 2 - 5 } \cline { 5 - 6 } & 44 & & Yes & No & \\
\hline $101-5$ & 44 & 71 & 0 & 0 & Passed \\
$\begin{array}{l}\text { Report in } \\
\text { its entirety }\end{array}$ & 44 & 0 & 73 & 0 & Passed \\
\hline
\end{tabular}

\section{Detail of All Items}

\section{Part I - Executive Committee}

\section{1-1 I Publications, Sale/Distribution}

As described in the membership brochure, NCWM members may receive complimentary copies of selected NIST and NCWM publications. Taking account of costs and availability of publications, a formal policy, 1.4.9, "Publications, Weights and Measures, Distribution Policy" has been implemented (See Appendix A).

Members. Members may, at their option, receive a complimentary copy of the latest version of any of the following publications that they need.

\section{COMPLIMENTARY PUBLICATIONS FOR MEMBERS}

\$15.00 NIST Handbook 44, Specifications, Tolerances, and Other Technical Requirements for Weighing and Measuring Devices, H. V. Oppermann, editor

\$10.00 NIST Handbook 130, Uniform Laws and Regulations, C. S. Brickenkamp, editor

\$16.00 NBS Handbook 133, - Checking the Net Contents of Packaged Goods, C.S. Brickenkamp, S. Hasko, and M.G. Natrella, editors

\$10.00 NIST Special Publication 793, Report of the Conference on Weights and Measures

$\$ 30.00$ NCWM Pub 2, Directories of State and Local Weights \& Measures Officials and All Members of the NCWM

$\$ 10.00$ NCWM Pub 15, Interim Meeting Agenda

$\$ 37.50$ NCWM Pub 16, Announcement Book

$\$ 128.50$ Cost to non-members for all of the above 
Members may purchase additional copies of the: (1) NIST publications listed above from the Government Printing Office; and (2) NCWM publications from the NCWM at the reduced prices listed in Appendix A.

The notice for renewal for membership in the Spring of 1990 provided a check list for use by members to identify the publications they desire. Many members have forgone requesting one or more publications (e.g., Associate Members who work in the commodity area do not need or use NIST Handbook 44). This is one of the benefits of the new policy that will accomplish two important objectives: (1) provide the documents needed by each member; and (2) avoid distribution of documents that are not needed, thereby helping to control the expenses associated with the printing and distribution of unneeded documents.

Non-Members. Non-members must purchase the documents from the Government Printing Office (GPO), the National Technical Information Service (NTIS), or the National Conference on Weights and Measures (NCWM) at the prices shown above or in Appendix A.

\section{1-2 I Publications, Handbooks 44 and 130}

This item was divided into three items prior to the Annual Meeting: (1) Item 101-2, a general discussion of the subject; (2) Item 101-2A, a voting item, that, if adopted, would have resulted in publication of NIST Handbook 130 every other year (in the even-numbered years); and (3) Item 101-2B, a voting item, that, if adopted, would have resulted in publication of NIST Handbook 44 every other year (in the odd-numbered years). The Executive Committee changed items 101-2A and 101-2B from voting to informational items prior to the Annual Meeting based on the conclusion that the pros and cons were not yet adequately understood by the membership. The impact of the proposed changes to the current procedures of the Standing Committees needs to be analyzed further.

Publication of NIST Handbooks 44 and 130 every 2 years (instead of annually) was proposed to provide the following benefits:

1. the States would have 2 years to adopt the changes and train their staffs;

2. the Regional and State Associations would have 2 years to address issues more thoroughly;

3. the industry would have more time to make product and marketing changes;

4. the training modules would go to a 2-year updating cycle; and

5. the OWM would reduce its publishing budget and redirect staff effort towards updating the modules.

An annual publishing cycle imposes demands on the membership and the NIST that seriously strain the system. Changes to the handbooks directly require that the training modules be updated (for example, seven modules must be updated whenever general requirements in the Scales Code change). This in turn leads to the need to publish updated training modules annually, as well as ensure that all instructors are conversant with the changes. Printing costs are escalating, overly taxing the OWM publishing budget and the NCWM budget for updating training modules.

Many States do not adopt the changes to the handbooks annually; it is impossible to update annually those officials who have taken the training modules; and almost all changes adopted by the NCWM could readily be delayed for 1 year.

\section{1-2A I Publish NIST Handbook 130 in Even-Numbered Years}

If this item had remained a voting item and were to have been adopted, NIST Handbook 130 would have been published following the 75th Annual Meeting (1990 Edition) and republished every second year thereafter instead of annually. The next edition would have been published following the 77th Annual Meeting (1992 Edition). 
If this item had remained a voting item and were to have had been adopted, NIST Handbook 44 would have been published following the 76st Annual Meeting (1991 Edition) and republished every second year thereafter instead of annually. The next edition would have been published following the 78th Annual Meeting (1993 Edition).

\section{1-3 I Mailing to Local Jurisdictions}

This item was printed as a voting item in the agenda for the Annual Meeting. Prior to the Annual Meeting, the OWM reworked the NCWM mailing list to accomplish the aims described in the proposal. It was therefore changed to an Informational Item.

The Northeastern Weights and Measures Association requested the Executive Committee to add major local jurisdictions to the Director's mailing list. They stated that: (1) many county and city jurisdictions have more equipment, personnel, problems, programs, and population than some States; (2) that these jurisdictions need to receive the informational reports, questionnaires, surveys, and decisions that the NCWM mails to State directors; and, (3) that many States do not automatically send this information to their local jurisdictions.

\section{1-4 I Membership, Status Report}

The membership of the NCWM at the end of June, 1990 was 2983 , nearly $120 \%$ growth in the past two years. This large increase resulted from an intensive mailing campaign to potential members identified by the States and the OWM. Even with this increase, less than half of the weights and measures officials in the country are members; a far smaller percentage of potential private sector representation are members.

The directors of State and local jurisdictions are requested to: (1) work toward 100\% membership of all officials in their jurisdictions, and (2) provide to the Executive Secretary the identity of potential private sector members (i.e., lists of licensees, sales and service employees, etc.). Associate members are requested to provide similar identification of their associates and organizations.

101-5 V Membership, Categories

(This item was adopted.)

Recommendation: Reclassify State and local government members (other than active weights and measures officials) and foreign government members from Associate to Advisory members by changing Article III of the Constitution to read as follows:

ADVISORY MEMBERSHIP. - Advisory membership is open to (1) representatives of agencies of the Federal Government who-are-concerned in any way with-regulatory weights and-meastres- officers- or their-official activities-or who are interested in the-objectives and aetivities- of the-Conference, (2) representatives of State and local governments other than weights and members officials, (3) foreign government members, and (4) persons who have retired from Federal, State, county, or city weights and measures employment who are concerned in any way with regulatory weights and measures officers or their official activities or who are interested in the objectives and activities of the Conference.

Discussion. The use of the NCWM mailing list suggested the need to change the classification of some State and local members, such as State police and department of agriculture employees other than weights and measures officials, from Associate to Advisory members. This reserves the Associate membership classification for business, industry, and consumer members and simplifies the decisions regarding mailing of materials of interest to each classification of membership.

\section{1-6 I Organization, Appointments and Assignments}

In the original Committee report, Chairman Gerk announced the following appointments.

Parliamentarian: $\quad$ Clayton F. Davis, State of Maine 
Task Force on Safety: Charles Gardner, Jr., Chairman

L. F. Eason, North Carolina

Jean Johnson, American Petroleum Institute

James D. Harnett, California Donald Soberg, Wisconsin

Technical Committee on National Type Evaluation: John Elengo, Jr., Chairman

Public Members:
R. Andersen, NY
T. Butcher, NIST
D. Guensler, CA
J. Lacy, USDA/P\&S
H. Oppermann, NIST
J. Truex, $\mathrm{OH}$
K. Yee, NIST

C. Conrad, Jr., NJ

D. Mahoney, USDA/FGIS

Belt Conveyor Sector: P. Perino, Revere Transducers, Inc., Chairman
Public Members: F. Gerk, NM
R. Helmick, AZ
H. Oppermann, NIST
J. Rabb, AL
R. Miller, CO
O. Warnlof, NIST

Private Sector:

\section{J. Berger, Technetics Industries}

G. Burger, Consultant

M. Casanova, Ramsey Technology, Inc.

R. Desollar, Central IL Public Service

D. Cockrell, Weighing \& Control Systems, Inc.

J. Giannina, Port of Corpus Christi

S. Gibson, ABC Scale

T. Johnson, Sensortronics

N. Johnson, Merrick Corp.

K. Knapp, Milltronics

J. MacFarlane, Auto Weight Co.

G. Kachel, Riede Systems, Inc.

F. Joe Loyd, CSX Transportation

J. Robinson, Assoc. of American RRs

N. Ortyl, III, Dresser Industries

W. Thurman, Southern Co. Services, Inc. D. Tonini, Scale Manufacturers Assoc.

C. Toombs, Stock Equipment Corp.

Weighing Industry Sector: J. Elengo, Jr., Revere Transducers, Inc., Chairman
M. Adams, Fairbanks Scales
J. Giannina, Port of Corpus Christi
K. Haker, BLH Electronics
J. MacDonald, Howe Richardson
W. Paull, Hobart Corp.
T. Stabler, Toledo Scale Corp.
T. Johnson, Sensortronics
J. Antkowiak, Hottinger Baldwin Measurements
W. Goodpaster, Cardinal Scale Co.
H. Lockery, Lockery Assoc.
R. McCarty, NCR Corp.
J. Robinson, Assoc. of American Railroads
D. Tonini, Scale Manufacturers Assoc.

Measuring Industry Sector: R. Whipple, Gilbarco, Inc., Chairman
F. M. Belue, Belue Associates
R. Fonger, Bennett Pump
M. Hankel, Liquid Controls
J. Harshman, Daniel Flow Products, Inc.
R. McCarty, NCR Corp.
T. McDonald, Mobil Oil Corp.
L. Murray, Dresser Industries, Inc.
R. Shields, Southwest Pump
J. Skuce, Smith Meter, Inc.
D. Smith, William M. Wilson's Sons
R. Tucker, Tokheim Corp.

At the Annual Meeting, Chairman Gerk announced the following additional appointments:

Acting Parliamentarian: Mr. Ken Simila, OR appointed for the 75th Annual Meeting, substituting for Mr. Clayton Davis, ME who could not attend the meeting because of personal reasons.

Acting Chaplain: Mr. Martin Coile, GA appointed for the 75th Annual Meeting, substituting for Mr. Cordell Robinson, who did not attend the meeting.

Task Force on Safety: Mr. Hap Thompson, API appointed to replace Ms. Jean Johnson, API based on reassignments of responsibilities within API. 
At the Interim and Annual Meetings, Ross Andersen, NY reported on the progress made by the metrologists at the 74th Annual Meeting and on present and future activities as follows.

The metrologists have tried to make better use of the Metrology Workshop time at the Conference by structuring their activities and using a steering committee to guide their work in relation to the NCWM, the NIST Office of Weights and Measures, and the Regional Measurement Assurance Programs (RMAPs).

The Steering Committee is made up of one representative from each of the five RMAPs. The Chairmanship of this Committee will rotate through the Regionals. The Committee will report to the Executive Committee and work closely with Georgia Harris, the OWM staff member in charge of the State Standards Program.

The metrologists are working toward changing their primary objective for the Workshops from training to a combination of training and planning, coordination and completion of projects in the following areas:

1. Plan Metrology Workshops - Work with OWM staff and the Executive Committee to plan the agenda for the workshops.

2. Liaison with the NCWM - Work with the committees and task forces to provide information and assistance where their expertise is beneficial.

3. Liaison with OWM - Work with OWM staff to improve the State Standards Program, particularly in the areas of metrologist training, the LAP program and laboratory certification, and review and revision of NIST handbooks used by metrologists (e.g., Handbooks 145, the 105 series, etc.) to keep them current with today's technology.

4. Coordination of RMMP Activities - Work with the RMMPS, much as the NCWM does with the regional associations, to resolve technical issues, share knowledge and experience and encourage interaction among metrologists.

5. Other Projects - Cover appropriate topics not included above.

The metrologists will identify needs and select a few priority projects for work each year. For $1989-90$ the projects included:

1. Review of Handbook $105-3$ on Metal Volumetric Field Standards. This handbook covers specifications and tolerances for test measures and provers used in the enforcement of Handbook 44. This handbook is out of date and in need of revision. All five of the RMMPs reviewed the document in 1989 at the regional meetings. The OWM compiled the comments and has sent them to API and industry representives for additional comment prior to preparing a draft revision.

2. Jim Clifford, metrologist (OR), has prepared a draft of a new handbook in the 105 series to cover specifications and tolerances for LPG provers. The draft has been reviewed by a group of metrologists and a third draft has been submitted to the OWM and circulated to State directors, metrologists, API, and industry for review.

3. The metrologists are working to validate computer software developed in the metrology laboratories. Because of the wide variability in computer hardware and software, a decision was made to define standard data sets so that metrologists can readily verify their own programs. A draft Quality Assurance Program was developed for computer systems and software, and initial data sets for air density calculations were presented at the Annual Meeting by Georgia Harris.

4. A narrative procedure for testing large capacity platform scales is being drafted for review by the S\&T Committee. It parallels Handbook 94 and reflects the recent changes regarding nominal and concentrated load capacities and test patterns. This draft, written by Ross Andersen, was presented to the S\&T Committee before the 75th Annual Meeting. 
5. The metrologists are working with the Education Committee to assist in the development of a new training module on weights and measures administration (Module 23). An outline covering the laboratory and its role in weights and measures enforcement was provided to the Education Committee. The writing of the metrology section is an ongoing project and Ross Andersen, metrologist (NY), has volunteered to write the first draft for review by the regional representatives and OWM.

L.F. Eason, metrologist (NC), was appointed to the Safety Task Force in 1989. He has assisted in collecting and organizing safety material from many sources including material from the metrologists. This is an ongoing project.

\section{Organization, Canadian Representation}

Three representatives of the Canadian Government attended and participated in the Annual Meeting: Mr. Robert Bruce, Mr. Renald Marceau, and Mr. Gilles Vinet.

Senior representatives of the Canadian Weights and Measures Office have been members of the NCWM for several years. The NIST Office of Weights and Measures, has recently been working with its Canadian counterparts to harmonize legal requirements. More recently, OWM staff have attended meetings of the Canadians as their guests to: (1) gain understanding of the Canadian program and (2) contribute technically and administratively to the Canadian program. In October and November of 1989, Canadian representatives attended meetings of the NTEP Technical Committee and the Committee on Specifications and Tolerances. Two Canadian representatives attended the Interim Meeting in January, 1990 and worked with the Committee on Specifications and Tolerances and the Committee on Laws and Regulations. The Executive Committee complimented the OWM for arranging this cooperative effort and endorsed the continuing coordination between the two countries.

\section{$101-9$}

\section{Organization, Change Name of NCWM}

Mr. Louis Sokol, NCWM member and metrication consultant, advocated changing the name of the Conference because the use of the term "weights and measures" is an anachronism and should be replaced. Of special significance is the misuse of the term "weight." Mr. Sokol reminded the Committee that "weight" is gravity force and use of the word "weight" instead of "mass" is scientifically and technically incorrect. He pointed out that many alternatives to the current name of the Conference are available, and that the name of the National Bureau of Standards has been changed to the National Institute of Standards and Technology without any apparent negative consequences. In more specific terms, Mr. Sokol provided a copy of NIST HB 44 which he had marked up to provide consistency and accuracy. The Committee expressed its appreciation to Mr. Sokol for the hard work and time spent to edit the handbook; they also expressed their understanding of his advocacy for changing the name of the Conference.

The Executive Committee discussed Mr. Sokol's recommendation and decided not to change the name of the Conference. They concluded that the current name has too much intrinsic importance and value derived from 85 years of exposure nationally and internationally to change now, especially with all of the changes occurring at NIST and the U.S. Department of Commerce. The current name also enjoys high visibility among the States and the National Association of State Departments of Agriculture.

\section{1-10 I Finances, Treasurer's Report}

The Treasurer reported on the end-of-year status of the budget. (See separate Treasurer's Report for details.) Primarily as a result of the growth in membership, (1) actual receipts exceeded budgeted receipts by $\$ 36,000$; (2) actual disbursements exceeded budgeted disbursements by $\$ 22,000$. Net assets therefore increased by approximately $\$ 14,000$ over the previous year-end balance.

The Treasurer and the Executive Secretary emphasized the growing resources of the NCWM resulting from the greatly increased membership. The proposed budget for FY $90-91$ is $\$ 158,000$, a significant increase from the $\$ 113,000$ for FY 89-90. The income from membership fees is projected to rise from $\$ 67,550$ (FY 89-90) to $\$ 92,500$ (FY 90 91). A $\$ 15,000$ reimbursable item reflects the anticipated income from the processing of NTEP appeals: this item is offset by a budget expense of $\$ 15,000$ to cover the anticipated cost of processing appeals. 
At the Interim Meeting, after making a few changes, the Executive Committee adopted the budget. (See Appendix D.) At the Annual Meeting, the Executive Committee authorized the Executive Secretary to purchase another Certificate of Deposit after all expenses of the Annual Meeting have been paid, requesting that the purchase and renewal of Certificates of Deposits be planned so that the maturity dates will be spread out during the year.

\section{1-11 I Finances, Expenses of Conference Members}

Over the past 10 years an informal policy has been followed to reimburse members for expenses incurred when on travel for the conduct of NCWM business. As the activity of the NCWM has grown, this expense continues to increase and now accounts for a large portion of the operating budget.

The Executive Committee established a subcommittee to draft a policy for reimbursing of members' expenses when they are on Conference business. The Executive Committee suggested guidelines for the subcommittee:

1. Travel qualifying for reimbursement should be held to the minimum consistent with the requirements of the business to be transacted.

2. The need for travel should be established only after alternative means for accomplishing the business (e.g., telephone, FAX) has been deemed inadequate.

3. The NCWM should be the reimburser of last resort (i.e., after it has been determined that the member's organization can not reimburse the individual fully or partially).

The policy should include the following topics: (1) what travel is authorized; (2) who has the authority to approve travel; (3) what expenses are reimbursable under what conditions; (4) specific allowances, such as per diem, hotel costs, transportation, advances, etc.; (4) and procedures for claiming and processing reimbursement.

The subcommittee was asked to evaluate related issues that affect the costs to the NCWM for travel, such as:

- To what extent are the increasing costs due to the inability of jurisdictions to pay these expenses?

- Should only the active members be reimbursed?

- Can more of the committee business be conducted by phone/FAX/mail ballot as is done by many standards bodies (e.g., ASTM, ANSI)?

- Should candidates for committee assignments determine the willingness of their jurisdictions to reimburse them for travel expenses before accepting assignment?

- Should consideration be given to combining the Annual and Interim Meetings into a once-a-year occasion if enough jurisdictions are able to fund attendance at only one NCWM meeting per year?

The Chairman appointed the following members to the subcommittee: Ken Simila, OR, Chairman; Ed Heffron, MI; Tom Geiler, MA. The Subcommittee has developed a first draft document which will be refined and presented for consideration by the Executive Committee at the Interim Meeting in January 1991.

\section{1-12 I Meetings, Annual \& Interim, Work Schedule}

Length of Meeting. Some members are concerned about the expenses associated with attending the Annual Meeting. The NCWM is incurring increasing costs for the reimbursement of members attending the Interim Meeting. Shortening each meeting by one day would save money for members, their jurisdictions, and the NCWM.

Days of Meeting. Increasingly, more members arrive on Saturday to get better air fares. Committees meet on Sunday to review/organize agendas. Members formerly arrived on Sunday and Monday was the first full work day. For the past several years, the Conference has officially ended on Thursday morning, followed by the "outing" and committee planning sessions on Friday morning. However, the attendance at the Friday meetings has been steadily dropping. 
It was suggested that the Annual Meeting could be rescheduled by making Sunday a full day (agenda review in the morning and sessions in the afternoon), thus saving at least a half day. All voting sessions could be held on Wednesday (since a half day was gained on Sunday), and the Conference work could be completed by close of business on Wednesday, eliminating the need for meetings on Friday. The Meeting would be 4 full days (arrival Saturday, work days Sunday through Wednesday, departure Thursday) instead of stretching nearly 7 days, from Saturday (arrival of many) through Friday noon (for committee members). A similar plan was proposed for the Interim Meeting.

The Executive Committee decided to continue the currently followed schedule for the Interim and Annual Meetings. The consensus is that the present format and schedule has worked extremely well and that individual members are free to adjust their attendance to meet their personal agendas.

\section{1-13 I Meetings, Annual, Time of Year}

The most intensive work period of the year for the staff of the OWM is the month following the Annual Meeting. There are only 5 weeks (end of Annual Meeting in July until September 1) to make all of the changes in NIST handbooks and complete the Proceedings in order for these publications to be printed and distributed prior to January 1 of the year in which the Handbook requirements become effective. Holding the Annual Meeting one month earlier would provide four additional weeks to get this work done.

The Executive Committee decided to continue to hold the Annual Meeting in July for the following reasons:

- The January/July meeting weeks are well known and accepted by the membership in general; changing would add a measure of confusion;

- Moving the Annual meeting into June or earlier would (1) result in having two Annual Meetings in the same year (in the first year of change); (2) interfere with school graduation ceremonies; and (3) adversely affect the ability of guests to attend.

\section{1-14 I Meetings, Annual, President's Award}

The President's Award was established by NIST and announced at the 71st Annual Meeting (See Proceedings, 71st Annual Meeting.) Two levels of recognition were included in the award:

"1. Banner. The top award will be a banner presented to any State in which all of the weights and measures officials (State and local jurisdictions) are members of the Conference. The banner will be accompanied with a certificate for a State to post in the office. The banner will be brought to the Annual Meeting each year to be displayed at the front of the general session room. A ribbon will be added each succeeding year that a State qualifies for this award.

2. Certificate. A certificate will be presented to any State in which all of the weights and measures officials on the State staff are members of the Conference. That State will become eligible for award of a banner when all of the members of its local jurisdictions become Conference members."

It has been stated that it is difficult for States with multiple jurisdictions, (such as California, Massachusetts, New York, and Pennsylvania,) to win this award, thereby diminishing the significance of the award. The Northeastern Weights and Measures Association recommended, for those states having both State and local jurisdictions, that a banner be presented if (a) all of the State staff and (b) at least one of the staff of every local jurisdiction are members.

\section{NIST Position}

1. NIST opposes this recommendation; the NIST goal was, and continues to be, $100 \%$ membership in the NCWM of EVERY weights and measures official in the United States. NIST does not wish to back off from that goal. 
2. NIST believes that each State Director should be committed to $100 \%$ membership in the NCWM of every weights and measures official in his/her State, just as the NIST Director is committed to $100 \%$ membership of all weights and measures officials in the United States.

Qualifying for the Award is a lofty goal, but one on which we should set our sights. To the extent membership is expanded, the effectiveness of State programs will be increased. Uniformity will spread, and equity will benefit because EVERY official will get the same information in a timely manner and will feel that he/she is "a part of the action."

\section{The Facts.}

The Award is achieving the intended goals!

Twenty States will have qualified for banner awards for the July 1, 1989 through June 30, 1990 membership year. They are: Alaska, Arizona, Arkansas, Delaware, Hawaii, Idaho, Iowa, Kansas, Michigan, Montana, Nebraska, New Hampshire, New Mexico, Oregon, South Dakota, Texas, Utah, Vermont, Washington, and Wyoming

In addition, the first certificate awards will be presented for $100 \%$ membership of the State office this year to Colorado, Indiana, Maine, Massachusetts, New York, Virginia, and Wisconsin.

This means that 27 States are eligible for one of the two levels of the President's Award for the 1989-90 membership year. This is extraordinary in the days of tight budgets for government programs across the Nation, and in only 5 years since the introduction of the President's Award!

NIST believes that changing the President's Award sends the wrong message to State and local officials alike. It implies that it is not as important for local officials to become members of the NCWM as for State employees. Yet, the message from Chairman Gerk is that there is a need for all weights and measures officials to become members. The proposal may also imply that it is not the responsibility for the State office to sell the need for membership in the NCWM.

NCWM data base records indicate:

- 54 out of 55 State directors are NCWM members;

- only $49 \%$ of State weights and measures officials are members;

- only $35 \%$ of county weights and measures officials are members; and

- only $38 \%$ of city officials are members.

\section{$101-15$}

\section{Meeting, Annual, 75th}

The 75th Anniversary Meeting of the National Conference on Weights and Measures was held at the J. W. Marriott Hotel, Washington, DC July $8-13,1990$. The meeting included a special celebration of the first weights and measures meeting held at the Bureau of Standards on January 16 and 17, 1905. A videotaped re-enactment of that first meeting (produced by the Liaison Committee) was played at the Opening General Session on Tuesday. A souvenir edition of the proceedings of the first conference was given to each delegate.

A total of 318 delegates were in attendance and 123 guests. There were 45 States represented, plus American Samoa and Puerto Rico. Not present were the District of Columbia, Guam, Montana, Nevada, New Hampshire, North Dakota, Rhode Island, Virgin Islands and West Virginia. Delegates from Belgium and Canada also attended.

This year, seven States received first year banners for $100 \%$ membership of their State and local weights and measures officials in the NCWM. This brings the total to 20 States that have $100 \%$ membership in the NCWM.

The "President's Certificate Award" was presented this year for the first time to seven States with $100 \%$ of their state office staff as members for the $1989-90$ conference year. 


\section{Chairman Gerk Says "Vaya con Dios"}

In his address to the Conference, Chairman Gerk reflected on his year as chairman. He reported that "the job of Chairman can be accomplished in haif days and it doesn't make any difference whether it's the first twelve hours or the last twelve hours." He said that the 75th anniversary year was exciting and fulfilling. During his year, the membership reached new heights - now exceeding 3,000. He asked that the members give Dave Smith the same enthusiastic support that he received, then bid the audience "Vaya con Dios." To Fred we say "muchas gracias" for a great job as Chairman.

\section{6th Theme: Weights and Measures for the 21st Century}

Chairman Smith has chosen "Weights and Measures for the 21st Century" as this year's theme. He also announced his appointments. (See Smith's address for details.)

Chairman Smith asked Darrell Guensler of California to chair a task force of wild-eyed dreamers. Their goal is to rock the boat and not be satisfied with the status quo, but to envision the future. Joining Darrell in this assignment are Bruce Martell of Vermont, Tom Geiler of the Town of Barnstable, MA, Chip Kloos of Beatrice/Hunt Wesson Foods, Inc., and a yet to be named representative from the Department of Commerce.

At the conclusion of a meeting, the usual ending is "sine die." Chairman Smith, with his North Carolina southern hospitality, preferred to end this meeting with "Y'all come back!"

\section{1-16 I Meeting, Annual, 76th}

The 76th Annual Meeting will be held in Philadelphia at the Four Seasons Hotel. Room rates are $\$ 90.00$ single, and $\$ 115.00$ double. It is appropriate to hold the 76th Annual Meeting in Philadelphia, the birthplace of the Declaration of Independence and the Constitution. The 76th can be linked with 1776, and the fact of Constitutional recognition of weights and measures will provide the basis for a very special meeting. Planning includes inviting participation of the ASTM whose offices are across the street from the hotel.

\section{Albany, New York, Original Choice}

Albany, NY had originally been selected by the Executive Committee as the location for the 76th Annual Meeting. As previously reported by the Committee, the Executive Secretary encountered difficulties in finding a hotel that combined the quality, sleeping rooms, and meeting space needed for the meeting. In terms of quality, the Marriott near the Albany airport was the best. However, the Marriott was not willing to block the sleeping rooms required; additionally, it lacked adequate meeting room facilities. The Executive Secretary began exploring alternative cities. Later, the Marriott announced plans to expand both its meeting space and the number of sleeping rooms.

Individual Conference members voiced dissatisfaction with Albany for the Annual Meeting. Other comments were made regarding the increasing costs associated with the Annual Meeting, especially room rates. The Executive Committee instructed the Executive Secretary to develop a questionnaire for completion by those attending the Tuesday General Session of the 74th Annual Meeting to "solicit opinions about site selection and costs related to attendance at the Annual Meetings." The questionnaire was developed and distributed to the membership at the General Session. The change of the meeting site from Albany to Philadelphia and the results of the membership questionnaire on meeting planning were reviewed. Mr. Bartfai requested that the results of the Survey be published in the proceedings of the 75th Annual Meeting. The Executive Committee concurred with Mr. Bartfai's request. A copy of the summary of the results is contained in Appendix F.

Question 6 asked the members to rate thirteen "possible" locations for future meetings on a scale of 1 to 5 . The results, extracted below, quite conclusively confirmed the comments that had been made regarding Albany. 
The following cities are being considered for the Annual Meeting. On a scale of 1 to 5 , where $1=$ avoid and $\mathbf{5}=$ excellent choice, rate the following possible locations for future meetings. (For purposes of the ranking reported below, the scorers gave the following values to the 1 through 5 ratings; $1=-10$ points, $2=-5$ points, $3=+5$ points, $4=+10$ points, $5=+15$ points).

$\begin{array}{ll}\text { New Orleans, Louisiana } & 1580 \text { points } \\ \text { Orlando, Florida } & 1540 \text { points } \\ \text { Phoenix, Arizona } & 1525 \text { points } \\ \text { Nashville, Tennessee } & 1510 \text { points } \\ \text { District of Columbia } & 1320 \text { points } \\ \text { Philadelphia, PA } & 1295 \text { points } \\ \text { Hawaii (non specific) } & 1020 \text { points }\end{array}$

$\begin{array}{lr}\text { Indianapolis, Indiana } & 910 \text { points } \\ \text { Chicago, Illinois } & 675 \text { points } \\ \text { Kansas City, Missouri } & 620 \text { points } \\ \text { Hartford, Connecticut } & 595 \text { points } \\ \text { Columbus, Ohio } & 350 \text { points } \\ \text { Albany, New York } & -24 \text { points }\end{array}$

Based on the results of the questionnaire and the general comments received, the Executive Committee decided: (1) against Albany, directing the Executive Secretary to proceed with Philadelphia, PA as the site for the 76th Annual Meeting; (2) to explore the possibilities of holding the January 1990 Interim Meetings in Phoenix, AZ; and (3) to continue efforts to hold the 77th Annual Meeting in Nashville.

\section{1-17 I Meeting, Annual, 77th}

The tentative plan for the 77th Annual Meeting was to hold a joint meeting of the National Conference on Weights and Measures and the International Society of Weighing and Measuring (ISWM).

The Opryland Hotel in Nashville, Tennessee, was selected as the location of the 77th Annual Meeting. The ISWM signed a contract with the Opryland Hotel at rates that were unacceptably high for the NCWM. The two organizations agreed to drop the plans for a joint meeting. Subsequently, the ISWM made arrangements with the Opryland Hotel to reschedule its 1992 meeting to May, its normal month.

The Executive Committee restated its desire to hold the 1992 meeting in Nashville, and requested the Executive Secretary to explore the possibilities of negotiating acceptable rates with a Nashville hotel.

\section{1-18 I Program, National Training}

Wes Diggs, Chairman of the Committee on Education, Administration, and Consumer Affairs reported on the work and program of the Committee in a joint session with the Executive Committee. He reviewed the status of many of the items contained in their report. (See report of the Committee on Education, Administration, and Consumer Affairs.) The joint session focused on the development and revisions of the Modules. Regarding module revisions, the current activities were reviewed. (See Table D of the Education Committee's report.) Wes Diggs emphasized the need to keep the existing modules as current as possible and offered the assistance of the Education Committee in that objective.

Chairman Gerk reported that he had written letters to the four states that had not signed an agreement to participate in the National Training Program. Three have responded by signing agreements; only Rhode Island has not signed up. [Editor's Note: On August 7, 1990, Rhode Island signed a letter of agreement.]

The Executive Committee provided $\$ 10,000$ for the Education Committee to use to establish "train-the-trainer" programs in each regional area. The Northeastern Weights and Measures Association has recommended approval of an Institute of Weights and Measures proposal to conduct two training sessions funded under this allocation. The other Regionals are making plans for the establishment of training sessions.

The Executive Committee expressed its collective appreciation to the Education Committee for its continuing hard work, dedication, and notable achievements. 


\section{1-19 I Program, Task Force on Energy Allocation Systems}

The wrap-up work of this Task Force was reported to the Committee at the Interim Meeting by Mr. Pat Nichols, CA, Chairman of the Task Force. The work of the Task Force has been completed, and the Committee on Liaison is going forward with the assignments made to them by the Executive Committee. See the Report of the Committee on Liaison for follow-up work to the Task Force.

\section{1-20 I Program, Task Force on Workplace Safety}

Mr. Charles Gardner, NY, Chairman of the newly established Task Force on Workplace Safety reported on the work plan of the Task Force. The Task Force has established a very ambitious plan. The Executive Committee was impressed with the accomplishments to date in defining the goals of the Task Force and emphasized its belief that safety is an issue of importance to every field inspector and laboratory metrologist in the country. (See Appendix E for detailed Report.)

\section{1-21 I Program, International Organization of Legal Metrology}

Sam Chappell, NIST, updated the Committee on the activities of OIML. He highlighted planned and anticipated activities during the next calendar year. (See Appendix C for the detailed report.) The next year will be a very busy one for OIML as it works toward special accomplishments in order to meet the needs of the European Community under the EC92 timetable.

\section{1-22 I Program, Office of Weights and Measures}

NIST Update. At the Interim Meeting, Dave Edgerly, Deputy Director of Technology Services, described reorganization activities at NIST, highlighting the change in the organizational positioning of OWM. He emphasized that OWM would not be affected in any negative manner as a result of the realignment. Dave also announced that NIST had awarded an additional $\$ 60,000$ add-on to the Grant to the NCWM. This is the third and last $\$ 60,000$ increment of the commitment made by Dr. Ambler.

OWM Update. Al Tholen, Chief of the Office of Weights and Measures, updated the Executive Committee on the status of the OWM Program, including the recent changes in staffing resulting from the retirement of Paul Krupenie and Dick Smith. OWM recruited Georgia Harris, the Minnesota State metrologist, to fill the Krupenie vacancy. The vacancy created by the retirement of Mr. Richard Smith has not been filled. A decision in this regard will not be made until the beginning of the next fiscal year (October, 1990). The NIST is meanwhile planning to upgrade the OWM computer system network to increase its overall efficiency and versatility.

The Executive Committee considers it urgent to fill the Smith vacancy as soon as possible. A reduction in the training program has already become evident.

Visiting Committee. Dr. Heffron reported on his participation on the NIST Visiting Committee. He expressed his appreciation for the support of the NCWM in gaining his appointment to the Committee. He said that he was very impressed with the other members of the Committee and their seriousness to make the Committee effective. He also concluded that the constituency of the NCWM is considered important to the Committee and that his participation will be active.

\section{1-23 I Program, National Uniformity}

Results of a recent questionnaire on the adoption of Handbook 44 and the NTEP Regulation reflected the fact that Handbook 44 has not been uniformly adopted by the States. Further review of the information in Handbook 130 provides evidence that much remains to be done regarding state adoption of the uniform laws and regulations recommended by the conference.

During the discussion of the results obtained from the questionnaire, several points were made, including one that the answers to the questionnaire do not necessarily report reality because the system in each State is often complicated and, consequently, that direct parallels cannot be drawn to the Uniform Laws and Regulations. It was the consensus 
of the Executive Committee that a State-by-State examination would lead to the conclusion that there is a far larger degree of uniformity than indicated by the table in NIST HB 130.

A recommendation was made that OWM identify those states that seem to be lagging in adopting the results of NCWM voting; determine whether these States are, in fact, lagging; and identify available options to assist these States in updating their statutes.

\section{Part II - NTEP Board of Governors}

$102-1$ I Publications, Status Report

NCWM Publication 14 "NTEP - Administrative Procedures, Technical Policy, Checklist, and Test Procedures." NTEP laboratories, State offices, and industry must have the latest NTEP policies, decisions, test criteria and procedures. OWM has updated this publication to include the changes reported at the 74th Annual Meeting. The OWM will continue to update Publication \#14 annually following the Annual Meeting. Reports of decisions by the Board of Governors between Annual Meetings will be mailed to interested parties as they are completed.

NCWM Publication 5 "NTEP Index of Evaluations." Since NTEP became operational, NBS Reports of Test and NTEP Certificates of Conformance (CofC) issued have been compiled in several documents (NCWM Publication 5 plus separate annual supplements). Since a single integrated report was needed by the States and industry, OWM updated NCWM Pub 5 to include records of all NBS Reports of Test and Certificates of Conformance issued through the end of December, 1989. Quarterly updates will be provided on the WAMIS Bulletin Board and by FAX to State Directors beginning October 1, 1990.

The updated Publication \#5 has been published and is being distributed: it is available in $81 / 2^{\prime \prime}$ by $11^{\prime \prime}$ format, $4^{\prime \prime}$ by $51 / 2^{n}$ (pocket) format, and on floppy disk (if customer provides one high density formatted disk or three low density formatted disks).

\section{2-2 I Program, Acceptance by the States}

The Board of Governors strongly urges that: (1) all states adopt the Uniform Regulation for National Type Evaluation; (2) all field inspectors be trained to enforce the code in the latest edition of Handbook 44; and (3) field inspectors routinely verify that all inspected devices have been issued a CofC.

Position of Board of Governors. The Board of Governors is very concerned about the reported lack of uniformity among the States in the enforcement of Handbook 44 and use of NTEP Certificates of Conformance as evidence that the devices under inspection meet the performance requirements under temperature variation. It was noted that no States other than those with NTEP laboratories have the capability to determine conformance of devices with temperature requirements.

Survey Results. In response to earlier reports of the industry, the Board of Governors requested that a survey "Questionnaire on Device Regulation" be sent to the fifty States, the District of Columbia, Puerto Rico, and the Virgin Islands on July 27, 1988. (Copies of the Survey results are available from the OWM.) The survey was conducted to determine: (1) the latest version of NIST Handbook 44 adopted by each State and (2) the status of adoption by each State of the Uniform Regulation for National Type Evaluation. The survey was remailed to the States following the Interim Meetings in January, 1989. A telephone follow-up was conducted by OWM in July, 1989. Results were:

Handbook 44. Forty-four jurisdictions had adopted the most current version of Handbook (1989). Nine jurisdictions were operating under the 1988 or earlier version. Nineteen jurisdictions reported that they automatically adopt the latest edition of Handbook 44 by reference. (Subsequent study of State laws and regulations by OWM staff indicates that as many as 36 States automatically adopt the most recent version of Handbook 44 .)

Uniform Regulation on NTE. Although fifty jurisdictions reported that they recognize the NTEP Certificate of Conformance as proof of type evaluation, only twelve jurisdictions have adopted the Uniform Regulation for National Type Evaluation. (Subsequent study of State laws and regulations by OWM staff indicates that 19 States 
have adopted regulations consistent with the Uniform Regulation.) Thirty-one jurisdictions have no type evaluation requirements.

Some State directors mistakenly thought that a State is expected to adopt the Uniform Regulation only if the State intends to operate an NTEP laboratory. Other reasons for not adopting the Uniform Regulation included: (1) it is too difficult to process it through the State system considering the slowness of the legislative process; and, (2) the NTEP did not meet all of the regulatory requirements of the States.

Position of Industry. Industry representatives met with the Board of Governors to reemphasize their earlier observations that enforcement of Handbook $\mathbf{4 4}$ code was far from uniform among the States. Their experience is that many field inspectors are not knowledgeable about the current requirements. Some industry members believe that those in industry who have attempted to meet the requirements of the Handbook and NTEP often discover that, in many jurisdictions, the code is not being enforced. They believe that this situation is unfair, putting them at a cost disadvantage with competitors who do not invest in facilities to meet the requirements.

Their comments are summarized below.

The NTEP Process. The front end of the system (i.e., NTEP evaluation) works well and the results are credible. A general erosion of industry respect for NTEP was reported because of the perception that there are no "teeth" in the process of revocation of Certificates of Conformance and improper advertising of products.

State Enforcement. Field enforcement is now being perceived as the weak link in the system.

1. Thirty-one States are not enforcing NTEP. This situation must be changed if participation by the industry in NTEP is to be meaningful.

2. The States are not getting the information on NTEP Certificates of Conformance to the field inspectors, nor are they training their staffs adequately regarding the requirements of NIST HB 44 and the criteria under NTEP.

3. Lack of enforcement undermines the investment of manufacturers (since it costs more to build NTEP equipment), resulting in unfair competition in favor of the manufacturers who do not build to NTEP criteria.

\section{2-3 I Program, Participating Laboratories/Evaluation Report}

Participating Laboratories and Evaluation Authority. The Participating Laboratories are authorized to conduct evaluations in the following areas: 
Laboratory

California

Kansas

New York

North Carolina

NIST

Ohio

USDA/Federal

Grain Inspection

Service (FGIS)
Areas of Authorization

Design and performance evaluation of scales, cash registers, metering devices, service station consoles, and taximeters.

Performance evaluation of largecapacity scales.

Design and performance evaluation of scales and cash registers. Expansion into liquid measuring devices is under discussion.

Performance testing of liquidmeasuring devices.

All NTEP evaluations, including load cells (NIST Force Group).

Design and performance evaluation of scales and cash registers.

Design and performance evaluation of automatic bulk-weighing systems, grain test scales, and performance testing of railway track scales.

Past Workload. The workload for the years 1985 through 1989 is shown in the following table.

\section{CERTIFICATES OF CONFORMANCE ISSUED}

\begin{tabular}{cccccc}
\hline & 1985 & 1986 & 1987 & 1988 & 1989 \\
\hline Total number of CofCs & 127 & 46 & 123 & 313 & 454 \\
Full CofCs & 127 & 37 & 80 & 227 & 319 \\
Provisional CofCs & & $9^{1}$ & $43^{2}$ & $21^{3}$ & 50 \\
Load cells & $9^{1}$ & $43^{2}$ & $20^{4}$ & $73^{5}$ \\
Pre-NTEP CofCs & & & 45 & 12 \\
\hline
\end{tabular}

Six provisional CofCs (all for load cells) upgraded to full in 1987 and 1988.

2 Sixteen provisional CofCs upgraded to full in 1988.

Excludes Load Cells.

${ }^{4}$ Thirteen provisional and seven full CofCs.

5 Included in totals for Full and Provisional CofCs. 


\section{Executive Committee}

About one third of the CofCs issued in 1989 were updates of CofCs issued in previous years, as shown below:

\begin{tabular}{ccc}
\hline New Certificates & 1989 & 303 \\
& & \\
Updated Certificates 1989 & 6 \\
& 1988 & 95 \\
& 1987 & 45 \\
& 1986 & 5 \\
Total & & 454 \\
\hline
\end{tabular}

Analysis of Workload Trends. The total workload of the Participating Laboratories has not changed much; the major change in the evaluation process has been associated with evaluation of load cells by the NIST Force Group. The Board expects the rate of growth in requests for evaluations to increase as additional States adopt the Uniform Regulation and require that devices installed for use have been issued CofCs. More businesses will need to conform with the latest version of Handbook 44 and obtain CofCs. In anticipation of growth, the Board plans to add one Participating Laboratory within the next 12 months. The OWM is working with other jurisdictions in order to add NTEP evaluation capability to their laboratories. An announcement will be made whenever a new Participating Laboratory is added to NTEP.

The Executive Secretary reported the following fee schedules of the NTEP Participating Laboratories.

$$
\text { Fee Schedules, Participating Laboratories }
$$

\begin{tabular}{|c|c|c|c|c|c|}
\hline & NIST & $\mathrm{CA}$ & NY & $\mathrm{OH}$ & FGIS \\
\hline Hourly Rate & $\$ 70.00$ & $\$ 50.00$ & $\$ 50.00$ & $\$ 60.00$ & $\$ 38.80$ \\
\hline Per Diem & $\begin{array}{l}\text { U.S. } \\
\text { Govt. } \\
\text { Rate }\end{array}$ & $\$ 82.00$ & $\begin{array}{l}\text { U.S. } \\
\text { Govt. } \\
\text { Rate }\end{array}$ & $\$ 75.00$ & None \\
\hline Environmental Chamber & $\$ 250.00$ & $\$ 250.00$ & * & $\$ 250.00$ & \\
\hline Water Meter Test Bench & & $\$ 26.50$ & & & \\
\hline $\begin{array}{l}\text { Weight Truck (per day) } \\
\text { Small Truck (pending) }\end{array}$ & & $\$ 150.00$ & $\begin{array}{l}\$ 150.00 \\
\$ 15.00\end{array}$ & $\$ 150.00$ & \\
\hline $\begin{array}{l}\text { Mileage } \\
\text { Large Truck (per mile) } \\
\text { Small Truck (per mile) }\end{array}$ & & $\begin{array}{l}\$ 1.50 \\
\$ 1.00\end{array}$ & $\begin{array}{l}\$ 2.00 \\
\$ .23\end{array}$ & $\begin{array}{l}\$ 1.00 \\
\$ .75\end{array}$ & \\
\hline
\end{tabular}

102-4

$$
\text { I Financial, Funding Resolution of Appeals }
$$

The NTEP has no policy or budget for meeting the expenses incurred in the resolution of appeals. The Executive Secretary drafted and proposed a policy to the Board of Governors in May 1989 (Appendix B). Although the proposal was adopted by the Board by letter ballot, it was not implemented because neither the Scale Manufacturers 
Association nor the Gas Pump Manufacturers Association fully agreed with the proposal of the Board of Governors. The Board has requested the two associations to provide their recommendations for the resolution of this problem.

The OWM has paid the appeal expenses when they occurred. However, the OWM is not budgeted for NTEP expenses and will no longer fund such activities. The Board anticipates that processing new appeals will require significant funding.

\section{2-5 I Financial, NIST Administrative Expenses}

Administrative expenses incurred by NTEP must be reimbursed. The following fees were established to cover expenses for processing NTEP applications, reviewing test results from participating laboratories, and processing of Certificates of Conformance.

$\$ 250.00$ per application if the Certificate of Conformance is prepared by OWM; or

$\$ 125.00$ per application if the Certificate of Conformance is prepared by another NTEP Participating Laboratory.

102-6

\section{Financial, Funding Meetings of NTEP Laboratory Representatives}

The evolution of the NTEP technical capability, including the development of checklists and procedures, has been very intensive over the past 4 years. Much was done through the NTEP Technical Committee, but some decisions must still be made on an ad hoc basis. The details of new technology and the rationale for the ad hoc decisions must be uniformly understood by the staff working in NTEP laboratories. The NTEP laboratories recommended that provisions be made to fund meetings of the participating laboratories representatives (at least annually) to ensure that NTEP criteria and procedures are understood and applied uniformly in all of the laboratories.

The Executive Committee: (1) approved the request; (2) recommended that $\$ 3000.00$ be added to the FY $90-91$ budget for this purpose; and (3) requested that these special meetings be held in conjunction with the meetings of the NTEP Technical Committee meetings. The Laboratory Representatives held one meeting in conjunction with the NTEC meeting in June 1990.

\section{2-7 I Policy, Labeling Requirements}

Handbook 130 defines requirements for labeling prepackaged standard pack and random weight items. These labels are generated by printers interfaced with computing scales used in direct sale and in prepackaging operations. The question has been raised: "Shouldn't these requirements be included in the NTEP checklist so that the Handbook 130 requirements can be evaluated at the same time as are the Handbook 44 requirements?"

Some reservations were raised about including the Handbook 130 requirements in the NTEP evaluation including the opinion that NTEP evaluations should be limited to requirements in Handbook 44. Offsetting this opinion is the efficiency of considering Handbook 130 requirements in the NTEP evaluation, thus avoiding problems "downstream" if the Handbook 130 requirements were not met.

The Board voted to: (1) include the legal requirements contained in Handbook 130 and other NIST and NCWM publications in the test procedures of NTEP Publication 14; (2) evaluate devices for all legal requirements at the time of the type evaluation; and (3) include appropriate comments on the Certificate of Conformance issued.

\section{$102-8$}

\section{Policy, Type Evaluation Criteria for Computers}

Computers are being used more frequently as integral elements in weighing and measuring systems. Agreement is needed on the procedures and criteria the NTEP is to follow when evaluating computers and their effects on the performance of systems being evaluated.

The Board decided that this issue is too complex to resolve now. The basic question is: "How far beyond the device should weights and measures regulation go?" The item was referred to the OWM for further development. 
As planned for in the NTEP administrative policy, the permanent program for evaluation of load cells has been implemented for load cells in the range from $30,000 \mathrm{lbf}$ to $100,000 \mathrm{lbf}$.

Mr. Oppermann, NIST, reported on the NIST experience and results of testing load cells under the NTEP. NIST has evaluated: (1) load cells provided by manufacturers for use by the NTEP in evaluation for issuance of CofCs; and (2) load cells procured from inventories of suppliers for comparison of performance with those provided by manufacturers. Generally, the load cells provided by manufacturers perform better than do those procured from inventories. These results cause questions to be raised, such as: (1) "Are production cells of equal quality to manufacturers' hand-picked cells?; or (2) "Is there a problem faced by NTEP related to the issuance of CofCs based on hand-picked cells if the production cells are proven to be inferior?"

The Board discussed the results developed by the NIST and expressed a general concern about the presented evidence. The Board of Governors voted to "authorize the Executive Secretary to spend up to $\$ 15,000$ to procure and test additional production cells off the shelf to gather additional information on this question." The Board further "encouraged the Executive Secretary to procure such cells on a loan basis to the extent possible in order to conserve the funds for use in reimbursement of the NIST Force Division's costs for evaluation."

\section{2-10}

\section{Policy, Belt-Conveyor Scales, Test Procedures}

The draft belt-conveyor test procedures have been completed. A meeting of the National Type Evaluation Technical Committee (NTETC) Belt-Conveyor Sector was held on June 28, 1990, to review the latest draft. Issues remaining to be resolved before the initiation of type evaluation of belt-conveyor scales were addressed at that meeting.

The Belt-Conveyor Sector has completed all of the work it is able to do prior to initiating the actual type evaluation of belt-conveyor scales. The Sector members recommend that NTEP implement the type evaluation of belt-conveyor scales gradually as the work schedule of the NTEP laboratories permits. If issues and problems are be identified during type evaluation, they will be addressed at future meetings of the Belt-Conveyor Scale Sector. It is expected that annual meetings of the Belt-Conveyor Scale Sector will be sufficient to resolve issues as they arise.

The Board of Governors concurs with this approach, and an announcement of the initiation of this program will be made when laboratories are prepared. First priority for type evaluation will be given to those companies that have requested type evaluations on belt-conveyor scales in the past. It is expected that two (perhaps three) evaluations will be conducted initially to test the procedure and determine the problems (if any) that may develop in the process.

\section{2-11 I Appeals}

The Board of Governors has met during the year to handle two appeals that it received. Final action was taken on both appeals and State Directors and the involved companies have been notified of the outcome.

F. Gerk, New Mexico, Chairman

N. David Smith, North Carolina, Chairman-Elect

J. Bartfai, New York, Past Chairman

L. DeGrange, Maryland

T. Geiler, Barnstable, Massachusetts

E. Heffron, Michigan

S. Hindsman, Arkansas

K. Simila, Oregon

D. Stagg, Alabama

C. Gardner, Suffolk County, NY, Treasurer

A. Tholen, NIST, Executive Secretary

\section{Executive Committee}




\begin{tabular}{|c|c|}
\hline National & on Weights and Measures \\
\hline \multirow{2}{*}{$\begin{array}{l}\text { POLICY, INTERPRETATIONS, } \\
\text { AND GUIDELINES }\end{array}$} & SECTION 1 - NCWM Management \\
\hline & SUBSECTION 4 - Publications \\
\hline eights and $M$ & Policy \\
\hline
\end{tabular}

Weights and measures publications will be sold and/or distributed according to this policy.

A. SPECLAL PROVISIONS FOR MEMBERS OF THE NATIONAL CONFERENCE. Members of the National Conference on Weights and Measures may elect to receive single copies of the most current editions of the following publications from the National Institute of Standards and Technology (NIST) and/or the National Conference on Weights and Measures (NCWM) at no cost. (Additional copies are available at the prices shown in Paragraph B, below.)

NIST Handbook 44, Specifications, Tolerances, and Other Technical Requirements for Weighing and Measuring Devices, H. V. Oppermann, editor

NIST Handbook 130, Uniform Laws and Regulations, C. S. Brickenkamp, editor

NBS Handbook 133, - Checking the Net Contents of Packaged Goods, C.S. Brickenkamp, S. Hasko, and M.G. Natrella, editors

NIST Special Publication xxx, Report of the Conference on Weights and Measures

NCWM Pub 2, Directories, State and Local Weights \& Measures Officials and All Members of the NCWM

NCWM Pub 15, Interim Meeting Agenda

NCWM Pub 16, Announcement Book

B. SOURCES OF PUBLICATIONS. Non-members (or members wanting additional copies) can purchase publications from the sources and at the prices noted below.

1. Superintendent of Documents, Government Printing Ofice, Washington, DC 20402 (202/783-3238).

\$15.00 NIST Handbook 44, Specifications, Tolerances, and Other Technical Requirements for Weighing and Measuring Devices, H. V. Oppermann, editor, 1990 Edition (Sept. 1989) SN003-003-02964-5

\$10.00 NIST Handbook 130, Uniform Laws and Regulations, C. S. Brickenkamp, editor, 1990 Edition (Sept. 1989) SN003-003-02962-7

\$16.00 NBS Handbook 133, Third Edition - Checking the Net Contents of Packaged Goods, C.S. Brickenkamp, S. Hasko, and M.G. Natrella, editors SN003-003-02885-1 
Call the Government Printing Office for the availability and price of the following publications.

NBS Handbook 105-3, Specifications and Tolerances for Graduated Neck Type Volumetric Field Standards - SN003-003-02044-3

NBS Special Publication 304, Metric Chart - SN003-003-02365-5

NBS Special Publication 304A, Brief History of Measurement Systems - SN003-003-02366-3

NBS Special Publication 345, A Metric America - A Decision Whose Time Has Come SN003-003-00884-2

NBS Special Publication 430, Household Weights and Measures - SN003-003-01542-3

NBS Special Publication 442, Report of the 60th National Conference on Weights and Measures (1975) - SN003-003-01614-4

NBS Special Publication 471, Report of the 61st National Conference on Weights and Measures (1976) - SN003-003-01806-6

NBS Special Publication 517, Report of the 62nd National Conference on Weights and Measures (1977) - SN003-003-01966-1

NBS Special Publication 532, Report of the 63rd National Conference on eights and Measures (1978) - SN003-003-02045-1

NBS Special Publication 566, Report of the 64th National Conference on Weights and Measures (1979) - SN003-003-02147-4

NBS Special Publication 599, Report of the 65th National Conference on Weights and Measures (1980) - SN003-003-02286-1

NBS Special Publication 684, Report of the 69th National Conference on Weights and Measures (1984) - SN003-003-02637-9

NBS Special Publication 704, Report of the 70th National Conference on Weights and Measures (1985) - SN003-003-02702-2

NBS Special Publication 725, Report of the 71st National Conference on Weights and Measures, A. D. Tholen, C. S. Brickenkamp, and A. P. Heffernan, editors, (1986) - SN003-003-02765-1

NBS Special Publication 734, Report of the 72nd National Conference on Weights and Measures, A. D. Tholen, C. S. Brickenkamp, and A. P. Heffernan, editors, (1987) - SN003-003-02828-2

NBS Special Publication 750, Report of the 73rd National Conference on Weights and Measures, A. D. Tholen, C.S. Brickenkamp, and A. P. Heffernan, editors, (1988) - SN003-003-02900-9

NIST Special Publication 771, Report of the 74th National Conference on Weights and Measures, A. D. Tholen, C. S. Brickenkamp, and A. H. Turner, editors, (1989) - 003-003-02977-7

NIST Special Publication 769, INDEX to the REPORTS of the National Conference on Weights and Measures - From the First to the Seventy-third (1905-1988), F. C. Bell, W. G. Mott, N. Chaconas, editors, (1989) - SN003-003-02649-2 
2. The National Conference on Weights and Measures, P.O. Box 4025, Gaithersburg, MD 20885 is the source for the following publications.

Number Title

Pub 1. NCWM Constitution and Bylaws, 1987

Pub 2. Directories, State and Local Weights \& Measures, 1989 Edition

Pub 3. NCWM Policy and Guidelines

Pub 4. National Type Evaluation Program . Administrative Procedures

Pub 5. National Type Evaluation Program Index of Evaluations (through 1988)

Pub 6. Brochure, NCWM Organization, Procedures, and Membership Plan Brochure, 1989

Pub 7. Weights \& Measures Week Guide

Pub 8. National Type Evaluation Program and Its Relationship to the Weights \& Measures Law, NBS Handbook 44, and the New Scales Code

Pub 9. Directory, Associate Members, 1989

Pub 10. Guide for Conduct of Annual Meeting

Pub 11. National Training Program 1989

Pub 12. Examination Procedure Outlines, 1989

Pub 13. Weights and Measures Information System (WAMIS) Guide

Pub 14. National Type Evaluation Program Administrative Procedures, Technical Policy, Checklists, and Test Procedures

Pub 15. Interim Meeting Agenda - Prepared annually

Pub 16. Announcement Book - Prepared Annually

Pub 17. Report, Task Force on Prevention of Fraud

Pub 18. National Training Program - Directory 1988

\section{Pembers
Non-members}

no cost 5.00

10.00 25.00

15.00

15.00

no cost

no cost

12.00

20.00

2.00

6.00

15.00

(not available; for Officers only)

5.00

10.00

10.00

20.00

5.00

10.00

15.00

30.00

5.00

10.00

10.00

37.50

5.00

10.00

5.00

10.00 
3. National Institute of Standards and Technology, Office of Weights and Measures, Administration Building A617, Gaithersburg, MD 20899. Telephone: (301) 975 4004. There is no charge for these publications as long as supplies remain.

NBS Handbook 105-1, Specifications and Tolerances for Field Standard Weights

NBS Handbook 105-2, Specifications and Tolerances for Field Measuring Flasks

NBS Handbook 137, Examination of Distance Measuring Devices

NBS Special Publication 447, Weights and Measures Standards of the United States, A Brief History

Letter Circular 1035, Units and Systems of Weights and Measures, Their Origin, Development, and Present Status

4. National Technical Information Service, 5285 Port Royal Road, Springfield, VA 22161 (703/487-4780 or 4650).

The proceedings of the first through the sixteenth NCWM annual meetings are available in paper copy form or in microfiche. The titles, prices, and NTIS accession numbers of all of the early proceedings that are currently available are listed below.

\section{TITLE}

First Conference on the Weights and Measures of the U.S.-1905 (NBS Misc. Pub. 4)

Second Conference on the Weights and Measures of the U.S.-1906 (NBS Misc. Pub. 5)

Third Conference on the Weights and Measures of the U.S.-1907 (NBS Misc. Pub. 6)

Fourth Conference on the Weights and Measures of the U.S.-1908 (NBS Misc. Pub. 7)

Fifth Conference on the Weights and Measures of the U.S.-1910 (NBS Misc. Pub. 8)

Sixth Conference on the Weights and Measures of the U.S.-1911 (NBS Misc. Pub. 9)

Seventh Conference on the Weights and Measures of the U.S.-1912 (NBS Misc. Pub. 10)

Eighth Conference on the Weights and Measures of the U.S.-1913 (NBS Misc. Pub. 11)

Ninth Conference on the Weights and Measures of the U.S.-1914 (NBS Misc. Pub. 12)

Tenth Conference on the Weights and Measures of the U.S.-1915 (NBS Misc. Pub. 13)

Eleventh Conference on the Weights and Measures of the U.S.-1916 (NBS Misc. Pub. 14)

\section{NTIS PRICES}

Paper Copy Microfiche Accession no.

$\begin{array}{lll}\$ 12.95 & \$ 6.95 & \text { PB87-232427 }\end{array}$

$\$ 14.95$

$\$ 6.95$

PB87-232435

$\$ 19.95$

$\$ 6.95$

PB87-232443

$\$ 14.95$

$\$ 6.95$

PB87-232450

$\$ 19.95$

$\$ 6.95$

PB87-232468

$\$ 19.95$

$\$ 6.95$

PB88-124219

$\$ 19.95$

$\$ 6.95$

PB88-124227

$\$ 25.95$

$\$ 6.95$

PB88-124201

$\$ 19.95$

$\$ 6.95$

PB88-124235

$\$ 25.95$

$\$ 6.95$

PB89-122055

$\$ 32.95$

$\$ 6.95$

PB89-122063 
Twelfth Conference on the Weights and Measures of the U.S.-1919 (NBS Misc. Pub. 41)

Thirteenth Conference on the Weights and Measures of the U.S.-1920 (NBS Misc. Pub. 43)

Fourteenth Conference on the Weights and Measures of the U.S.-1921 (NBS Misc. Pub. 48)

Fifteenth Conference on the Weights and Measures of the U.S.-1922 (NBS Misc. Pub. 51)

Sixteenth Conference on the Weights and Measures of the U.S.-1923 (NBS Misc. Pub. 55)
$\$ 25.95$

$\$ 25.95$

$\$ 19.95$

$\$ 6.95$

$\$ 19.95$

$\$ 6.95$

$\$ 19.95$

$\$ 6.95$
PB89-122071

PB89-12208

PB89-122097

PB89-122105

PB89-122113

Contact NTIS for current price information on the following publications; there is a charge per page for paper copies.

NBS Handbook 98, The Examination of Farm Milk Tanks - COM. No. 72-10619 (May 1964)

NBS Handbook 99, The Examination of Liquefied Petroleum Gas Liquid-Measuring Devices -- this has recently been replaced by National Training Program Module 21.

NBS Handbook 112, Examination Procedure Outlines for Commercial Weighing and Measuring Devices - COM. No. $73-50836$

NBS Handbook 117, Examination of Vapor-Measuring Devices for Liquefied Petroleum Gas, S. Hasko, - PB 248987

NBS Handbook 143, State Weights and Measures Laboratory Program Handbook, H. V. Oppermann and J. K. Taylor, (Feb. 1985) - PB85-183358

NBS Handbook 145, Handbook for the Quality Assurance of Metrological Measurements (1986) PB87140422NBS Handbook 94, The Examination of Weighing Equipment - COM. No. 73-10635

NBSIR 85-3172, Package Checking Field Manual, to accompany NBS Handbook 133, Checking the Net Contents of Packaged Goods, C. S. Brickenkamp, S. Hasko, and M. G. Natrella, editors, (Aug. 1985) PB86-108776/AS

NBS Special Publication 629, Report of the 66th National Conference on Weights and Measures (1981) - PB821-78997

NBS Special Publication 645, Report of the 67th National Conference on Weights and Measures (1982) - PB831-67148

NBS Special Publication 663, Report of the 68th National Conference on Weights and Measures (1983) - PB841-10998

NBS Special Publication 686, State Weights and Measures Laboratories Program Description and Directory, H. V. Oppermann, (Jan. 1985) - PB85-137651 


\section{Appendix B}

Proposed Changes to

\section{NTEP ADMINISTRATIVE PROCEDURES, TECHNICAL POLICY,} CHECKLISTS, AND TEST PROCEDURES

\section{Add the following paragraph to Section D. REQUEST FOR TYPE EVALUATION.}

To obtain a type evaluation, the applicant shall:

$\begin{array}{ll}1 . & \cdots \\ 2 . & --. \\ 3 . & --. \\ 4 . & --\end{array}$

5. submit a filing fee of $\$ 100.00$ payable to the National Conference on Weights and Measures. The filing fees will be deposited in a reserve account for use in offsetting unreimbursed costs incurred by the NTEP in the resolution of appeals.

Replace existing Section "O. APPEALS PROCESS" with the following.

\section{O. APPEALS PROCESS}

At any stage in the evaluation process, an appeal may be filed with the Board of Governors (hereafter referred to as "the Board").

This policy addresses three distinct appeals situations:

1. Applicant Appeal. In this case, the NTEP has concluded that a "type" does not meet the requirements and has decided not to issue either a Full or a Provisional Certificate of Conformance (hereafter referred to as a "Certificate"), or the NTEP has decided to withdraw for cause a previously issued Certificate. The manufacturer (applicant for NTEP evaluation) then files an appeal to either of these decisions.

2. Third Panty Appeal. In this case, a third party (other than the holder of the Certificate or the NTEP) files an appeal of the issuance of a Certificate based on evidence that the "type" does not conform with Handbook 44.

3. Regulatory Agency. This is a variation of the Third Party Appeal in which a Weights and Measures authority files an appeal of the issuance of a Certificate based on evidence that the "type" does not conform with Handbook 44 or has a history of unacceptable performance in use.

\section{APPLICANT APPEAL}

If a manufacturer appeals a decision of the NTEP NOT to issue a certificate or of the Board to WITHDRAW a Certificate, the steps in the appeals process follow.

a. A manufacturer (the applicant for a Certificate) files an appeal with the Board. The appeal must include (1) justification for reconsideration, (2) payment of a non-refundable $\$ 100.00$ filing fee, and (3) payment of a deposit prescribed by the NTEP based on its estimate of the expense for conducting a review of the Board's decision, including additional testing if required. 
b1. Board rejects appeal as not justified. The Board may decide that the appeal has inadequate justification for further action.

The original NTEP decision is reaffirmed and the deposit is retumed to the applicant. The applicant may appeal to the National Institute of Standards and Technology (hereafter referred to as NIST), the next level of appeal.

b2. Board accepts justification as adequate. The Board may decide that the appeal is convincing enough to uphold the appeal without additional testing.

The original NTEP decision is reversed, a Certificate is issued, and the applicant's deposit is returned.

b3. Board decides reevaluation is needed. If the justification provided by the applicant is not, in itself, convincing, the Board may request NTEP to reevaluate the "type."

If the "type" does not meet the requirements, the original decision of the NTEP is affirmed, and any part of the deposit remaining after costs have been offset will be returned to the applicant. In this case the applicant may still appeal to the NIST.

If the type meets the requirements, the original NTEP decision will be reversed, a Certificate will be issued, and any part of the deposit remaining after costs have been offset will be returned to the applicant.

\section{THIRD PARTY APPEAL}

If a Certificate has been issued by the NTEP and a third party (other than a Regulatory Agency) believes that the "type" does not meet the requirements of Handbook 44, that party (Appellant) may appeal the issuance of a Certificate to the Board. The steps in the appeals process follow.

a. A third party (hereafter referred to as the Appellant) other than a Regulatory Agency files an appeal with the Board. The appeal must include (1) justification for reconsideration, (2) payment of a non-refundable $\$ 100.00$ filing fee, and (3) payment of a deposit prescribed by the NTEP based on its estimate of the expense for conducting a review including additional testing.

b1. Board rejects appeal as not justified. The Board may decide that the appeal has inadequate justification for further action.

The original NTEP decision is reaffirmed and the deposit is returned to the appellant.

The appellant may appeal to the National Institute of Standards and Technology, the next level of appeal.

b2. Board accepts justification as adequate. The Board may decide that the appeal is convincing.

The Board will advise the holder of the Certificate of the pending action and offer the opportunity to present a defense to the Board.

If, after consideration of the defense, the Board concludes that the "type" does not meet requirements, it will withdraw the Certificate and return the appellant's deposit.

The Certificate holder may appeal to the NIST.

If the defense convinces the Board that the "type" meets requirements, the original Certificate will remain in effect, and the deposit of the appellant will be returned.

The appellant may appeal to the NIST.

b3. Board decides reevaluation is needed. If the justification provided by either the appellant or Certificate holder is not, in itself, convincing, the Board will request NTEP to reevaluate the "type."

Before the NTEP proceeds, the Centificate holder must make a deposit prescribed by the NTEP based on its estimate of the expense for conducting a review including additional testing. 
Executive Committee

If the holder of the Certificate refuses to make the deposit, the Board will conclude that the "type, ipso facto, does not meet the requirements, will uphold the appeal, withdraw the Certificate, and return the appellant's deposit.

If the holder of the Certificate makes the deposit, the "type" will be reevaluated.

If the "type" meets the requirements, the original decision of the NTEP is affirmed, and any part of the appellant's deposit remaining after costs have been offset will be retumed. All monies deposited by the holder of the Certificate will be retumed.

The appellant may appeal to the NIST.

If the type does not meet the requirements, the original NTEP decision will be reversed, the Certificate will be withdrawn, and any monies deposited by the holder of the Certificate, after costs have been offset, will be returned. The appellant's entire deposit will be retumed.

\section{REGULATORY AGENCY APPEAL}

If a Certificate has been issued by the NTEP and a Weights and Measures authority believes that the "type" does not meet the requirements of Handbook 44 or has a history of unacceptable performance in use, that party may appeal the issuance of a Certificate to the Board. The steps in the appeal process follow the same sequence as that for the Third Party Appeal except that the regulatory official will not be subject to any filing fees or deposit.

\section{SUBSEQUENT APPEAL OPTIONS}

If the resolution of the appeal by the Board is not acceptable by any party to the appeal, that party may appeal to the NIST. The NIST serves as a second level of review in its role as the issuer of NTEP Certificates of Conformance.

If the resolution of the appeal by the NIST is not acceptable to any party to the appeal, that party may appeal to the Federal Trade Commission through the established Federal Government process.

\section{RESERVE FUND}

Any unreimbursed expenses incurred by the NTEP in the resolution of appeals will be paid out of the NTEP Reserve Fund. (See Section D. REQUEST FOR TYPE EVALUATION, Paragraph 5.) 


\section{Appendix C}

\section{Report on OIML}

Samuel Chappell, NIST

\section{CIML Meeting}

A meeting of the International Committee of Legal Metrology (CIML) was held in Paris in September 1989.

OIML Certificate System for Measuring Instruments. Three drafts of this proposal had been prepared, and it was the intention to approve the proposal at this CIML meeting. Objections led by the United States and a few other CIML members were convincing enough to postpone the vote on it. Our main objection was that the proposal needed further clarification in order to be properly interpreted and implemented. All the latest drafts of this proposal have been sent to the members of the NCWM's Executive Committee for review, including the draft sent out officially to CIML members for review and vote by June 30,1990. The major elements of the proposal are as follows:

o It is voluntary.

o An Issuing Authority for each category of instruments will be established in participating member nations.

o Testing will be carried out at officially recognized laboratories according to the metrological and technical requirements of relevant OIML recommendations.

o The test report, which will accompany a Certificate, will be prepared according to the format prescribed in OIML recommendations.

o An owner of a Certificate may use it and the test report in support of an application for type approval of the instrument in any nation and may refer to the Certificate in marketing literature.

o A participating member nation must have an appeals process whereby its decisions may be challenged by a participating manufacturer, importer, or distributor of a measuring instrument affected. This appeals process is established according to national laws.

This proposal has implications for the NCWM. Through NTEP, the NCWM, if it chooses to participate, could become an Issuing Authority for instruments mutually covered by Handbook 44 and OIML Recommendations. On the other hand, it is a tacit assumption that OIML member states should consider OIML Certificates and accompanying test reports in their type approval programs. NCWM might therefore have to decide on what recognition would be given to such Certificates and test reports when presented by instrument manufacturers prior to type evaluation.

The benefits of the Certificate System for manufacturers could be a saving in time and expense in getting the approval in various nations in which they choose to market their products. The benefits to the legal authorities could also be in reduced time and expense associated with carrying out type evaluations of measuring instruments.

Evidence strongly indicates that this Certificate system will have a significant influence on the harmonization taking place in the European Community and subsequently in all of Europe. Further information on this point can be provided upon request.

Other Activities. Under the new authority provided to CIML by the International Conference of Legal Metrology, three Recommendations were approved covering the following topics: "Volume of Ships' Tanks," "Barometers," and "Volume of Measuring Bottles." 
A report was given by the Swedish CIML member on an intercomparison among the Nordic member Nations of tests of nonautomatic weighing instruments according to the requirements of OIML Recommendation 76. The results of this intercomparison may be helpful in the revision of that recommendation which is underway. OIML Recommendation 76 was approved at the last Conference in Sydney, Australia in October 1988.

The next CIML meeting is scheduled to be held in Porto, Portugal in October 1990.

\section{Presidential Council of CIML}

A meeting of the Presidential Council of CIML was be held in February at BIML in Paris. Sam Chappell, Vice President of CIML, participated. The primary subjects of discussion were: (1) the new draft of the proposed "OIML Certificate System for Measuring Instruments;" (2) a review of the quality of OIML recommendations with regard to their being included in the Certificate System; and (3) a revision of the "Working Methods of OIML Secretariats." An important aspect of the last subject is to provide a uniform style and content for OIML recommendations. At present, only a few of the existing OIML recommendations meet the requirements for being included in the proposed "Certificate System."

\section{Activities of OIML Secretariats}

This part of the report: (1) lists the Secretariats of interest to the NCWM and identifies draft recommendations and documents being developed; (2) provides a schedule of International Working Group (IWG) meetings completed or planned for that work (dates for U.S. National Working Group (USNWG) meetings for the work, which are more flexible, are not provided). More details on many of these activities were reported by Otto Warnlof to the Specifications and Tolerances Committee.

o PS5D "Dynamic Measurement of Liquids."

- $\quad$ RS1 on "Meters with Measuring Chambers or Turbines" (France). A second preliminary draft of a combined recommendation on this subject was distributed to the USNWG for comment. Comments were submitted in March 1990. An IWG meeting is scheduled at NIST during the week of October 22, 1990 to discuss this work.

RS3 on "Water Meters" (U.K.). A second preliminary draft recommendation on the subject was received and reviewed. Comments were sent in December 1989. An IWG meeting is scheduled to be held in West Berlin in October 1990.

RS6 on "Electronic Devices" (France). A first draft recommendation on this subject was distributed in June 1989 to the USNWG. Vote and comments were sent to the Secretariat in September. The U.S. voted no. This draft recommendation will also be discussed at the IWG meeting to be held at NIST in October 1990.

RS7 and RS9 on "Methods and Devices for Verification" and "Vortex Meters," respectively (Japan). Meetings of these two RSs were held in Japan in November 1989. The U.S. did not participate but did contribute comments on the following three preliminary drafts discussed at the meeting: (1) "Test Procedures for Gas Pumps," (2) "Pipe Provers," and (3) "Vortex Meters."

RS10 on "Direct Mass Flow Meters" (U.S.A.). A second preliminary draft prepared by the USNWG has been distributed to the IWG for review and comment. An IWG meeting is scheduled to be held at NIST during the week of October 22, 1990.

o PS5S on "Static Measurement of Liquids."

- RS12 "Static Direct Mass Measurement of Quantities of Liquids" (Australia). A first preliminary draft was received and distributed for review by the USNWG. Comments are requested by July 1990 . 
RS4 "Measurement of Hydrocarbon Gases Distributed by Pipeline" (U.S.S.R.). A second preliminary draft was distributed to the USNWG in August 1989. Comments were sent to the Secretariat in October 1989.

o PS7 on "Measurement of Mass."

- RS2 on "General Problems" (U.S.A.). R74 on "Electronic Weighing Instruments" is being revised and has been distributed for review. Comments were received from members of the USNWG and also from some OIML member nations participating in the IWG. A meeting of the IWG to discuss the revised R74 will be held at NIST during the week beginning July $16,1990$.

- RS4 on "Non-Automatic Weighing Instruments" (France-West Germany). A revision of R76 on the subject is being carried out by the Secretariat. The USNWG commented on proposals by the Secretariat in May 1989, and subsequently a draft revision of R74 was distributed. Comments by the USNWG were sent to the Secretariat in March 1990. A meeting of PS7/RS4 was be held in Braunschweig in May 1990 in which the U.S. participated. This meeting preceded by an OIML Seminar "Non-automatic Weighing Instruments." Two U.S. scale manufacturers presented papers at that Seminar.

- RS5 on "Automatic Weighing Instruments." Four draft recommendations are in various stages of development: (1.) 1st draft on "Hoppers Scales" has been approved recently by vote; (2.) 1st draft on "Rail Road Track Scales" was distributed for vote on which the U.S. voted no with all votes being 7 yes, 2 no, and 1 abstention; (3.) 3rd draft revision of R50 on "Belt Weighers" was reviewed by the USNWG with comments being submitted in March 1990; and (4.) 1st draft revision of R61 on "Gravimetric Filling Machines" was reviewed by the USNWG with comments being sent to the Secretariat March 1990. All four draft recommendations were discussed at an IWG meeting in the U.K. in May 1990 in which the U.S. participated.

- RS8 on "Load Cells." The revised R60 on "Load Cells" was prepared by the USNWG and submitted to CIML for vote. The votes were 30 yes and 1 no (FRG) with 6 countries providing comments. The Secretariat has responded to all comments. This revised $\mathrm{R} 60$ is expected to be considered for approval at the next CIML meeting in October 1990.

o PS8 "Weights."

- Belgium has prepared a combined draft recommendation on "Weights" that was distributed for review and comment to the USNWG in October 1989. Comments were sent to Secretariat in December 1990. A meeting is scheduled to discuss this combined draft recommendation on July 19, 1990 at NIST.

o PS20 on "Packaged Products."

A draft recommendation was prepared by West Germany on "Drained Weight" of packaged goods. It was distributed to the USNWG and IWG for review and comment. A meeting of the Secretariat was held in Wabern, Switzerland in June 1990 to discuss this draft along with an IWG meeting of PS2/RS5 on "Sampling." The U.S. was represented at these meetings at which the decision was to take no further action on the proposed draft recommendation on the "Drained Weight." In addition, no new work was proposed for "sampling."

o PS22 on "Metrological Controls" (U.S.A.).

RS4 on "Initial and Subsequent Verification" (U.S.A.). A draft document is being prepared on "Quality Assurance as Applied to Metrological Controls." This has been distributed to the USNWG and IWG for review and comment. Briefly, this document outlines procedures whereby legal officials may allow a manufacturer, which has obtained pattern approval, to declare that instruments produced meet the requirements for initial verification based on quality control procedures used in production. An IWG meeting to discuss this draft document is scheduled to be held at BIML in Paris in October 1990. At the same meeting, an effort to combine other documents on metrological control produced under PS22 will be discussed. 


\section{Summary}

The overall activity of OIML has increased significantly. A similar increase in work is being experienced by other national and international standardization organizations. Much of this increase reflects the impact of the globalization of trade on measuring instruments and related products along with the need or requirement for testing and certification of products. In addition, regional economic and trade agreements and arrangements among various nations are having an influence. Most notable is the agreement within the European Community (EC) to harmonize administrative and technical requirements for products traded within the EC by the end of 1992 . This will directly affect the 12 member nations of the EC; however, close cooperation of the EC with the nations of European Free Trade Association (EFTA) will in effect include six more nations for a combination of 18 nations in this regional agreement. All of Western Europe would therefore be affected by this harmonization within the EC. As we watch the news of the demise of the existing communist governments in the Eastern European block nations, it appears evident that stronger commercial ties will soon be established between those nations and Western Europe. These efforts have already begun; therefore, the principles of EC92 are spreading throughout Europe and, in time, may include the Soviet Union. 


\section{Appendix D \\ Operating Budget 90/91 \\ (July 1, 1990 to June 30, 1991)}

The major change occurring with respect to the budget is the growth in membership. At this time, the membership is over 2600. The $90-91$ budget is based on a membership of 2643 .

Several items on the Executive Committee Agenda are related to expenses:

101-1 Publications, Sale/Distribution (Account \# 8.0 and new Account \# 1.8)

101-11 Finances, Expenses of Committee Members (Account \#'s 4.0 and 5.0)

101-18 Program, National Training (Account \# 12)

102-4 Financial, Funding Resolution of Appeals (new Account \#'s 1.X and 5.3)

102-6 Financial, Funding Meetings of NTEP Laboratory Representatives (new Account \# 5.2)

INCOME

\begin{tabular}{|c|c|c|c|c|c|}
\hline $\begin{array}{l}\text { Number } \\
\text { (a) }\end{array}$ & $\begin{array}{l}\text { Name } \\
\text { (b) }\end{array}$ & $\begin{array}{l}\text { FY90-91 } \\
\text { Proposed } \\
\text { (c) }\end{array}$ & $\begin{array}{l}\text { FY89-90 } \\
\text { Budget } \\
\text { (d) }\end{array}$ & $\begin{array}{l}\text { FY88-89 } \\
\text { Actual } \\
\text { (e) }\end{array}$ & $\begin{array}{l}\text { FY87-88 } \\
\text { Actual } \\
\text { (f) }\end{array}$ \\
\hline $\begin{array}{l}1.1 \\
1.2\end{array}$ & $\begin{array}{l}\text { Registration Fees } \\
\text { Membership Fees }\end{array}$ & $\begin{array}{r}\$ 30,000 \\
92,500\end{array}$ & $\begin{array}{c}\$ 30,000 \\
67,550\end{array}$ & $\begin{array}{r}\$ 28,265 \\
73,650\end{array}$ & $\begin{array}{r}\$ 31,305 \\
61,402\end{array}$ \\
\hline 1.3 & $\begin{array}{l}\text { Training Modules } \\
1.3 \quad \text { NTP Modules } \\
1.3 \mathrm{a} \quad \text { HB } 133 \text { Field }\end{array}$ & 6,500 & 6,500 & 3,805 & 7,420 \\
\hline $\begin{array}{l}1.4 \\
1.5 \\
1.6 \\
1.8 \\
1.9 \\
1 . X\end{array}$ & $\begin{array}{l}\text { Interest } \\
\text { Promotional } \\
\text { Special Events } \\
\text { Publications, Sale } \\
\text { Miscellaneous } \\
\text { NTEP, Operations }\end{array}$ & $\begin{array}{r}3,700 \\
1,000 \\
8,000 \\
1,000 \\
300 \\
15,000\end{array}$ & $\begin{array}{r}3,000 \\
1,000 \\
5,000 \\
300\end{array}$ & $\begin{array}{r}4,506 \\
361 \\
7,696 \\
\\
25\end{array}$ & $\begin{array}{r}3,192 \\
668 \\
3,790 \\
250\end{array}$ \\
\hline & Total & $\$ 158,000$ & $\$ 113,350$ & $\$ 118,308$ & $\$ 108,027$ \\
\hline
\end{tabular}

\section{Footnotes (INCOME):}

$1.1 \quad$ No change. Based on registration of $300 @ \$ 100$.

1.2 As noted above; $2643 @ \$ 35$ (rounded to $\$ 92,500$ ).

1.3 No change.

1.4 Higher because of purchase of an additional Certificate of Deposit

1.5 No change.

1.6 Estimate based on 88-89 actual.

1.8 Estimate based on implementation of new policy (Item 101-1)

1.X Based on costs incurred with one load cell appeal. 


\section{Expenses}

\begin{tabular}{|c|c|c|c|c|c|c|}
\hline $\begin{array}{l}\text { Number } \\
\text { (a) }\end{array}$ & & $\begin{array}{l}\text { Name } \\
\text { (b) }\end{array}$ & $\begin{array}{c}\text { FY90-91 } \\
\text { Budget } \\
\text { (c) }\end{array}$ & $\begin{array}{l}\text { FY89-90 } \\
\text { Budget } \\
\text { (d) }\end{array}$ & $\begin{array}{l}\text { FY88-89 } \\
\text { Actual } \\
\text { (e) }\end{array}$ & $\begin{array}{l}\text { FY87-88 } \\
\text { Actual } \\
\text { (f) }\end{array}$ \\
\hline 2.0 & \multicolumn{2}{|c|}{ Annual Meeting } & $\$ 15,000$ & $\$ 14,000$ & $\$ 13,627$ & $\$ 9,880$ \\
\hline 3.0 & \multicolumn{2}{|c|}{ Interim Meeting } & 5,000 & 4,000 & 2,672 & 2,383 \\
\hline \multirow[t]{9}{*}{4.0} & \multicolumn{2}{|c|}{ Committee Meetings } & 20,000 & 20,000 & 24,344 & 19,242 \\
\hline & 4.1 & Executive & {$[5,000]$} & {$[5,000]$} & {$[7,406]$} & {$[3,690]$} \\
\hline & 4.2 & Laws and Regs & {$[3,000]$} & {$[3,000]$} & {$[3,361]$} & {$[5,920]$} \\
\hline & 4.3 & Specs \& Tol & {$[3,500]$} & {$[3,500]$} & {$[4,753]$} & {$[1,639]$} \\
\hline & 4.4 & Education & {$[3,500]$} & {$[3,500]$} & {$[6,112]$} & {$[1,606]$} \\
\hline & 4.5 & Liaison & {$[3,000]$} & {$[3,000]$} & {$[2,101]$} & {$[1,059]$} \\
\hline & 4.6 & Resolutions & & & 298] & \\
\hline & 4.7 & Nominations & & & 312] & \\
\hline & 4.9 & Misc & {$[2,000]$} & {$[2,000]$} & & {$[5,328]$} \\
\hline \multirow[t]{10}{*}{5.0} & \multicolumn{2}{|c|}{ Special Programs } & 43,000 & 18,000 & 14,633 & 16,060 \\
\hline & 5.1 & NTEP, Bd of Governors & {$[7,000]$} & {$[6,000]$} & {$[8,074]$} & {$[7,400]$} \\
\hline & 5.2 & NTEP, Coordination & {$[3,000]$} & & & \\
\hline & 5.3 & NTEP, Operations & {$[15,000]$} & & & \\
\hline & 5.4 & OIML & {$[5,000]$} & {$[4,000]$} & & {$[1,432]$} \\
\hline & 5.7 & TF on Belt Conveyor & {$[2,000]$} & {$[2,000]$} & & {$[1,192]$} \\
\hline & 5.8 & TF on Energy Systems & & {$[2,000]$} & {$[5,841]$} & {$[1,996]$} \\
\hline & 5.9 & TF on Safety & {$[7,000]$} & {$[4,000]$} & & \\
\hline & $5 . X$ & \multicolumn{2}{|c|}{ TF on Commodity Rqmnts } & & $717]$ & \\
\hline & $5 . \mathrm{XX}$ & TF on 21ST Century & {$[4,000]$} & & & \\
\hline 6.0 & \multirow{2}{*}{\multicolumn{2}{|c|}{$\begin{array}{l}\text { Chairman/Chairman Elect } \\
\text { Membership Program }\end{array}$}} & 12,500 & 12,550 & 13,852 & 7,972 \\
\hline 7.0 & & & 6,000 & 6,000 & 9,321 & 7,106 \\
\hline 8.0 & \multicolumn{2}{|c|}{ Printing/Pubs } & 12,000 & 6,000 & 5,345 & 3,859 \\
\hline 9.0 & \multicolumn{2}{|c|}{ Administration } & 10,500 & 12,500 & 4,555 & 10,203 \\
\hline 10.0 & \multicolumn{2}{|c|}{ Special Events } & 8,000 & 5,000 & 9,793 & 6,058 \\
\hline 11.0 & \multicolumn{2}{|c|}{ Promotion } & 2,000 & 1,300 & 1,151 & 962 \\
\hline \multirow[t]{6}{*}{12.0} & \multicolumn{2}{|c|}{ Training Modules } & 24,000 & 14,000 & 4,117 & 3,958 \\
\hline & 12.4 & Printing Existing & {$[4,000]$} & {$[4,000]$} & & \\
\hline & 12.5 & $\begin{array}{l}\text { Materials, Module } \\
\text { Implementation }\end{array}$ & {$[20,000]$} & {$[10,000]$} & & \\
\hline & & Total Disbursements & $\$ 158,000$ & $\$ 113,550$ & $\$ 103,410$ & $\$ 87,683$ \\
\hline & & Surplus: & & & 14,898 & 20.344 \\
\hline & & Totals & $\$ 158,000$ & $\$ 113,550$ & $\$ 118,308$ & $\overline{\$ 108,027}$ \\
\hline
\end{tabular}

\section{Footnotes (EXPENSES):}

2.0 Inflation, mostly hotel costs.

3.0 Inflation, mostly hotel costs.

4.0 This is primarily the expenses of committee members attending the Interim Meeting.

5.0 Increases include: (1) $\$ 3,000$ for travel expenses of NTEP lab chiefs to hold one meeting for cross training; (2) $\$ 15,000$ to cover expenses incurred in resolving appeals - this is a wash with 1.X on the assumption that the NCWM will establish a policy to provide needed appeals testing funds, (3) increase for operation of TF on Safety, and (4) provision of $\$ 4,000$ for additional Task Force. 
$6.0 \quad 6.01$ - Chairman $\$ 8,000$

6.02 - Chairman-Elect $\quad 4,500$

7.0 The significant reduction from the $88-89$ year is due to moving the Conference database in-house at OWM, thereby saving contract costs for services.

8.0 Larger number of NCWM publications results in added expenses to provide to members.

9.0 The significant increase over the $88-89$ year is due to the success of the Training Program, which adds expenses of registering participants in the National Register. The National Register maintains the records of the modules taken, completed, and the CEUs awarded by individual.

10.0 This is a wash with 1.6 above.

11.0 Increase to provide ability to promote new members.

12.0 Provides funding for conversion of modules into a common format for updating. 


\section{Appendix E \\ National Conference on Weights and Measures \\ Task Force on Safety \\ Progress Report}

This report is in two sections: (1) January 1990 meeting: and (2) April 1990 Meeting.

January 1990 Meeting.

The Task Force on Safety held its first meetings during the National Conference on Weights and Measures (NCWM) Interim Meetings in Scottsdale, Arizona. The Task Force was able to establish its objectives and identify specific tasks to be accomplished by the group.

Primary Objectives.

1. Update each Examination Procedure Outline (EPO) found in NCWM Publication 12 (EPO's for Weighing and Measuring Devices) to include basic safety information.

2. Incorporate safety information into the training modules of the National Training Program (NTP).

3. Make additions to National Institute of Standards and Technology (NIST) Handbook 145 to include safety information for the metrology laboratories.

4. Establish a library of safety information.

5. Establish an NCWM Subcommittee on Safety when the Task Force is disbanded and encourage similar subcommittees at the regional level.

6. Develop a separate publication detailing the work of the Task Force upon completion of its work.

The Task Force also met with the NCWM Liaison, Education, and Executive Committees. During its meetings with each standing Committee, the Task Force presented its goals and requested appropriate support from each Committee.

The Task Force recognizes that safety in the work place is an important issue which affects everyone, especially those individuals who handle heavy weights and equipment on a routine basis. Weights and measures field inspectors and laboratory metrologists are routinely exposed to potential safety hazards: these hazards are present in the equipment they use, the products with which they work, and the locations in which they work. The Task Force believes that dangerous situations can be avoided only through recognition of these potential hazards and the establishment of good safety practices.

While a number of weights and measures jurisdictions already have safety programs in place, many other jurisdictions have few or no established safety policies or procedures. The Task Force recognizes that the establishment of a safety program in a jurisdiction that has no safety program in place may seem overwhelming in terms of time and staff. The Task Force hopes that the objectives outlined above will facilitate incorporation of safety practices into all phases of weights and measures activities.

\section{The First Priority - EPO's}

The Task Force recognizes that a step-by-step approach is the most effective means to ensure the promotion of safety awareness in routine weights and measures activities. Training modules are often presented only to inspectors who are just beginning to learn about a particular testing activity and not to those inspectors who have actively performed that type of testing for a long period of time. Because the issue of safety should reach all inspectors, not just beginners to a test procedure, the Task Force targeted the EPO's as its first priority in getting safety information out 
to the various States. Almost every weights and measures inspector has access to and regularly makes use of the Examination Procedure Outlines (EPO's) found in NCWM Publication 12. Similarly, laboratory metrologists make frequent use and reference to the Standard Operations Procedures (SOP's), Good Laboratory Practices (GLP's), and Good Measurement Practices (GMP's) found in NCWM Handbook 145. By incorporating safety information into the EPO's and equivalent procedures in HB 145, the Task Force hopes to reach both lab and field personnel and to raise the level of safety consciousness in the everyday routine of weights and measures activities.

Each Task Force member will review the EPO's in NCWM Publication 12 prior to the next meeting of the Task Force to identify safety considerations which should be incorporated. At its next meeting the Task Force will discuss the work done by the members and will review the EPO's to summarize the safety information to be included. At the beginning of each EPO, a list of potential safety hazards will be identified using key words such as "electrical hazards," "location of testing," or "toxic substances." These key words will serve to warn the inspector prior to beginning an inspection of the potential safety hazards involved and of the preventive measures which can be taken. The Task Force will also incorporate safety information into the body of the EPO when a particular aspect of safety must be emphasized. For example, in the EPO for testing LPG meters, the need for protective gloves will be noted by use of a key word at the beginning and emphasized again in the body at the point that the inspector begins to set up the testing equipment.

The Task Force will develop a glossary containing the key words used at the beginning of each EPO. The glossary will be included in the back of Publication 12 and will define and elaborate on each key word, giving examples of the potential safety hazards implied by each term. For example, the glossary might include the following:

This glossary defines the key words which are used at the beginning of each EPO to identify potential safety hazards. Following each key word is a brief list of the most common hazards associated with that particular category of safety risk; the inspector is reminded that other associated hazards may exist and should be considered for each individual device and installation. Inspectors should follow those safety procedures established by their jurisdiction, including use of protective clothing and equipment. In all examination procedures, care should be taken to minimize safety risks and to remove potential safety hazards before the inspection begins.

electrical hazards

improper maintenance of equipment such as:

worn or faulty electrical cords

faulty electrical outlets

too many extension cords

exposed or loose electrical wiring or circuitry, especially when sealing the device

scale not designed for wet environments being used in an area frequently exposed to water or used to weigh wet products.

location of testing

grain mills or elevators:

inhalation of airborne grain dust -- use of dust masks

overhead bins -- use of hard hats

slick floor surfaces due to dust -- proper footwear with adequate traction and protection from falling objects; caution when moving about facility

chemical plants:

check with plant manager to determine products to which you will be exposed and what precautions must be taken

exposure to chemicals and caustic materials -- proper protective clothing and equipment such as coveralls, respirators, gloves, eye protection, protective shoes

slaughterhouse/meat packing facility:

slick, wet surfaces -- proper footwear with adequate traction and protection from falling objects; caution when moving about facility

hanging meat hooks with sharp prongs -- protective headgear and eye protection, caution when moving about facility... 
hanging meat hooks with sharp prongs -- protective headgear and eye protection, caution when moving about facility...

An approach similar to that described for the EPO's might also be used in NIST Handbook 145. Prior to its next meeting, the Task Force will request assistance from NIST in incorporating safety information into the SOP's, GLP's, and GMP's of NIST Handbook 145.

\section{Training Modules}

In a meeting with the Education Committee, the Task Force suggested incorporating safety information into the modules of the NTP as each is updated and revised. The Education Committee responded favorably and agreed to assist the Task Force in this area by reviewing any suggested changes and additions to the EPO's and training modules.

The Task Force specifically requested that the Education Committee:

1. Incorporate the revised EPO's into appropriate training modules as each module is revised.

Upon completion of its review of the EPO's, the Task Force will provide members of the Education Committee with copies for their review and input. Once agreement on revisions has been reached, the Task Force will request that the EPO be incorporated into the next revision of the appropriate training module.

2. Include additional and detailed safety information in training modules as they are revised at the discretion of the Education Committee.

The Task Force believes that training modules should expand specific safety issues to review potential hazards and preventive measures in each module. A separate chapter on safety (such as is currently found in Module 21, LPG Liquid Measuring Devices) is most desirable to emphasize the importance of safety awareness as a routine part of inspection.

As it progresses in its work, the Task Force will make specific recommendations for the existing training modules. Upon completion of its work, the Task Force hopes to provide guidelines to the Committee for ensuring that appropriate safety information is incorporated into future modules.

3. Provide copies of revised EPO's to instructors and students participating in the presentation of a module which has not been revised to include extensive safety information. This will ensure that safety information is included in the instruction program until such time as the module is scheduled for revision.

4. Include in the NTP's current library of audiovisual materials (which are available to the State and local jurisdictions for training) any available audiovisual materials concerning safety.

The Task Force has already identified some available audiovisual materials concerning safety which can be provided to the Education Committee for inclusion in their audiovisual library. It is anticipated that additional sources of material will be identified as the Task Force develops its safety library. The Task Force will prepare a list of information concerning sources of this material and provide it to the Education Committee for review. The list might be used for purchasing or simply to serve as a source of information for additional audiovisual materials for inquiries received by the Education Committee.

\section{Safety Library}

A great deal of information about safety in the work place has been gathered by Task Force members and a great deal more information is available from sources such as the American Petroleum Institute, the National Propane Gas Association (NPGA), Occupational Safety and Health Association (OSHA), Consumer Product Safety Commission (CPSC), and industry groups. The Task Force will not make formal recommendations concerning safety to the NCWM until its work has been completed; however, until such time as recommendations are made, the Task Force believes that the information that has been gathered should be made easily accessible to weights and measures jurisdictions. 
The Task Force believes that this information might be useful to weights and measures jurisdictions in establishing their own safety programs and can assist the weights and measures community in developing safe work habits. Although not expert in the area of safety, the Task Force does believe that it can assist jurisdictions in obtaining the information needed to implement safety practices in many of the routine activities of a weights and measures jurisdiction. By categorizing the information that is available and making it accessible to jurisdictions along with a list of expert contacts, the Task Force hopes to ease the burden of beginning a safety program from scratch, as well as providing an additional source of information for those jurisdictions with safety programs already in place.

The Task Force will organize the information that has been gathered into a "library" of safety information. A list of the information will be developed as the material is collected and will contain the title, a brief summary, the source, and the number of pages of each piece of information. The list will be divided into main subject categories (e.g., Safety Equipment and Clothing), with subcategories according to the type of inspection to which it applies. A preliminary list of categories is as follows:

1. Safety Philosophies and Good Work Practices

2. Safety Programs Already in Place

3. Safety Training and Education

4. Safety Gear and Clothing

5. Suitability of Vehicles for Weights and Measures Functions

6. Results of Tests To Establish Exposure Levels to Toxic Substances

7. Adaptation of Weights and Measures Equipment to Reduce Safety Risks

8. Accidents During Weights and Measures Testing

9. Changes to Policies and Procedures to Address Safety Concerns

10. Actions Taken by Federal, State, or Local OSHA Groups Relating to Weights and Measures Activities

11. Miscellaneous Safety Information

The Task Force will review the listing of information at its next meeting to determine if any revisions to the list of categories are required and will continue to develop the safety library as it proceeds with its work. At the present time the Task Force plans to have the NIST technical advisor to the Task Force maintain this "library" of safety information at NIST. A listing of information in the safety library will be distributed to NCWM members, along with instructions on how to obtain the information when the list has been further developed and the information catalogued.

The Task Force will continue to search for and gather information which might assist weights and measures jurisdictions in the area of safety. A letter will be sent to the State and active local weights and measures jurisdictions and to industry groups to request any additional safety information which they might provide to the Task Force. $\mathbf{A}$ similar letter will be sent to the chairperson of each regional weights and measures conference. Task Force members attending regional conferences will encourage members to submit information to the Task Force. An article has also been submitted for publication in the NCWM newsletter, W\&M Today, requesting NCWM members to forward pertinent information to the Task Force. The Task Force also recognizes the importance of including information about means that inspectors have devised to address a particular safety concern in their everyday activity and about accidents which have occurred; issues such as these serve to provide examples of how some jurisdictions have responded to hazardous situations.

\section{Safety Subcommittee}

The Task Force discussed various means which might be used to ensure that the issue of safety will be carried on even after the Task Force is disbanded. It is hoped that the importance of safety will continue to be emphasized by the NCWM. The Task Force recognizes that a mechanism must be provided by which members will continue to be made 
aware of areas of safety concern, ways to improve safety practices, and means by which to obtain information about a specific area of safety.

It was initially suggested that a person be designated at NIST to receive inquiries and to provide assistance to Conference members in resolving safety concerns after the Task Force is disbanded. After discussion with the other Committees, it was determined that a more effective approach might be to establish a NCWM standing committee or subcommittee. A standing subcommittee will provide a permanent mechanism by which safety issues and concerns are reviewed by the NCWM on a regular basis. Such a subcommittee would also facilitate the submission of safety issues to the NCWM by providing a direction for Conference members to focus their questions and concerns about safety in the weights and measures community.

It was suggested that a subcommittee on safety under the Education, Administration, and Consumer Affairs Committee would be most appropriate since training provides an ideal mechanism for conveying the general importance of safety and specific safety precautions for inspection activities. The Task Force will complete its work prior to making specific recommendations to the NCWM concerning the establishment of a separate committee or subcommittee; the Task Force would be more informed and would be in a better position to evaluate the continued needs of NCWM members and to recommend the best way to meet those needs.

\section{NCWM Publication on Safety}

The Task Force discussed the various means by which safety information can be disseminated to the members of the NCWM. Inclusion of information in the EPO's, the procedures of Handbook 145, and the NTP Training Modules will provide a means to reach the field inspector and the laboratory metrologist. The library of safety information can be used by NCWM members to gain access to information in specific areas of safety. The Task Force also hopes to identify a means of incorporating safety information into the procedures for other weights and measures activities not identified in the EPO's or Handbook 145 (e.g., package checking, testing of grain moisture meters) and other areas of safety, such as in testing equipment (e.g., use of an explosion-proof pump or wiring on an LPG prover).

The objectives identified by the Task Force will serve to provide information concerning the incorporation of safety into weights and measures activities to specific groups of Conference members; however, there should be some source of information that presents an overview of the issue of the issue of safety as it applies to the weights and measures community. The Task Force determined that an effective approach might be to develop a separate NCWM publication that presents an overview of safety, discusses current methods for resolving safety concerns that might be associated with weights and measures activities, and indicates means to obtain information and assistance. The Task Force intends to develop this separate publication as it proceeds with its work and plans to complete the document upon the conclusion of its work.

\section{Next Meeting}

The Task Force plans to hold a meeting in April 1990 at NIST in Gaithersburg, Maryland. Prior to this meeting, members of the Task Force will review and summarize any gathered safety information and forward it to the Task Force technical advisor. Members will also study the existing EPO's in NCWM Publication 12 for inclusion of specific safety information. At its next meeting, the Task Force plans to review the EPO's to identify safety concerns for each EPO and to develop a glossary of key words for inclusion in NCWM Publication 12. The Task Force will also review the information that has been catalogued into the safety library up to that time, and will evaluate the list of categories to determine that it adequately presents the information. The Task Force also plans to investigate the legal ramifications of any recommendations made by the Task Force so that the legal concerns of the NCWM are adequately addressed.

\section{April 1990 Meeting}

The NCWM Task Force on Safety held meetings April 24-25, 1990 at the National Institute of Standards and Technology (NIST) in Gaithersburg, Maryland. Some of the activities during that meeting were as follows:

\section{(1) Safety Library}

The Task Force revised the main categories in the Safety Library from the original categories established during its January 1990 meetings. The categories were revised in accordance with the subject areas of the information received by the Task Force since January. 
The Task Force continues to gather and compile information pertaining to safety in the workplace, particularly information pertaining to safety in the weights and measures workplace.

The Task Force plans to make a listing of the categories of information which will be distributed to NCWM members in September 1990 along with instructions on how to obtain the information.

\section{(2) Examination Procedure Outlines}

The Task Force performed a review of the EPO's found in NCWM Publication 12:

Key areas of safety concern were identified in each EPO. Key words and phrases were developed to identify safety hazards/concerns; these key words will be included at the beginning of each EPO.

A glossary of key words will be developed for inclusion at the back of Publication 12.

A section will be included at the beginning of Publication 12 which will provide a basic safety reminder to the weights and measures official.

A statement will be included at the beginning of each EPO to remind the inspector to read and be familiar with the safety section at the beginning of Publication 12 .

The Task Force continues to work on the EPO's and plans to review final drafts at its next meeting in Fall 1990.

(3) Subcommittee on Safety

The Task Force believes that the most appropriate mechanism to ensure the continuance of safety awareness in the weights and measures community is to establish a permanent body within the NCWM to address safety. The Task Force will recommend that a subcommittee be established under the Education Committee to address safety concerns in the NCWM.

(4) Projected Lifespan of the Task Force

The projected lifespan of the Task Force remains consistent with that estimated in January 1990. The Task Force will hold a meeting in Fall 1990 and an additional meeting in Spring 1991. An update of the work of the Task Force will be provided for the interim meetings. The Task Force plans to finish its work by the July 1991 NCWM, at which time its final recommendations will be presented to the Executive Committee.

(5) Reference to Safety in NIST Handbook 44

The Task Force discussed the general lack of understanding of the weights and measures official of the safety regulations in place at a particular inspection location. By revising the EPO's to include safety information, the Task Force hopes to impress the importance of safety upon the weights and measures official. To further emphasize the importance of safe work practices and an awareness of existing safety requirements, the Task Force will recommend an addition to each code of Handbook 44, to consist of a brief statement to remind the inspector to review the safety procedures for the inspection process and to be aware of the safety regulations in place at the place of inspection.

\section{Current Activities}

At the request of the Task Force, the Liaison Committee arranged a meeting with a representative of the Occupational Safety and Health Administration. Representatives of the Task Force and the Liaison Committee met with OSHA representatives on July 9, 1990 at the Department of Labor. OSHA has indicated an initial willingness to provide assistance to the Task Force by providing input on the revisions of the EPO's. OSHA may send a representative to 
the next meeting of the Task Force. In addition to guidance in the revision of the EPO's, it is hoped that arrangements can be made with OSHA to perform an analysis of each inspection procedure.

The Task Force is pleased to note that interest and awareness in workplace safety continues to increase in the weights and measures community. Information pertaining to safety in the workplace continues to trickle in from various sources. The Task Force would like to make NCWM members aware that safety information is still welcome.

The Task Force plans to finalize the revisions to the EPO's and perform a review of the Standard Operating Procedures in NIST Handbook 145 at its meeting in Fall 1990. 


\section{Appendix F \\ SUMMARY, QUESTIONNAIRE ON CONFERENCE COSTS AND LOCATIONS}

Responses to the questions in the Questionnaire may be generally summarized as follows:

Question \#1 - Categories of respondents.

For purposes of analysis, four categories were considered: State Officials, Local Officials, Associate Members, and Guests.

The Guests' answers to questions \#3, \#4, and \#5 were not included in the analysis.

Question \#2 - Are you staying at the Westin?

In spite of the room rate, about $90 \%$ stayed at the Westin. We have no statistics on past years, but the data on the room pickup and registration (page seven) are fairly consistent.

Question \#3 - If you are not staying at the Westin, why not?

In effect, the room rate was considered two high. However, the answers and comments on both the hotel and the city changed toward the end of the week. Written comments were to the effect that both choices were good, the hotel was first class, the lobby setup with lots of seating was great, lots to do in terms of restaurants and shopping.

Although Seattle was ranked fifth of the nine past meetings, the respondents who turned in their Questionnaires later in the week ranked Seattle 1st, 2 nd, or $3 r d$ in the past nine Annual meetings (there was a single low ranking). Had the earlier respondents' answers been similar to the later respondents, Seattle would have been second or third in the ranking.

Question \#4 - Will you be reimbursed for expenses?

The vast majority of attenders are reimbursed for all expenses. The major problem seemed to be reimbursement for meals; however, those who answered "no" on this expense, the comments written in clearly showed that most attenders received $\$ 20$ or more per day.

Question \#5 - Raise the registration fee as a step to getting lower room rates?

Nearly $62 \%$ answered no. Others wrote in comments to the effect that we should do what is best for the NCWM or continue doing what we are doing.

Question \#6 - Rating of proposed future meeting locations - locations currently being considered.

Respondents appear to prefer popular tourist cities (e.g., Orlando, New Orleans, Nashville, Phoenix, D.C.) and generally rate northeastern cities low. It is clear that there is considerable opposition to Albany.

Hawaii was a dichotomy; it received either "excellent choice" or "avoid" votes. The comments clearly indicated that Hawaii is a preferred location except for the problems with cost (transportation) and perceived "vacation image as seen by bosses." "Avoids" tended to nullify "excellent choices."

What other locations do you recommend for future meetings?

This turned out to be a poor question because it was too general. The result is a scattering of selections with no clear "popular" locations unless the votes for Denver and San Diego are considered significant. 
Executive Committee

Question \#7 - Rankings of past Annual Meeting locations/hotels.

Albuquerque came out clearly on top; sample comments included: a popular and unique vacation area, a very good hotel, and an interesting program.

Sacramento and Boston were close in second and third, followed by Washington and Seattle in fourth and fifth.

QUESTIONNAIRE ON CONFERENCE COSTS AND LOCATIONS

SUMMARY

\begin{tabular}{|c|c|c|c|}
\hline & & Yes & No \\
\hline \multirow[t]{4}{*}{ Are you staying at the Westin Hotel? } & $\begin{array}{l}\text { State Officials } \\
\text { Local Officials } \\
\text { Associate Members }\end{array}$ & $\begin{array}{l}45 \\
35 \\
76\end{array}$ & $\begin{array}{r}12 \\
2 \\
3\end{array}$ \\
\hline & Subtotal & 156 & 17 \\
\hline & Guests & 19 & 17 \\
\hline & Total & 175 & 20 \\
\hline
\end{tabular}

Will you be reimbursed for the entire

a. cost of your registration Fee? State Officials

Local Officials

Associate Members

2

34

79

2

Total

165

4

b. cost of your hotel?

State Officials

Local Officials

Associate Members

45

28

78

9

Total

151

c. cost of meals/other?

State Officials

Local Officials

Associate Members

37

18

Total

138

17

28

73

8

8
1

d. cost of transportation?

State Officials

Local Officials

Associate Members

50

26

Total

161

6 
In order to get a lower sleeping room rate for the meeting, the Conference would have to pay separately for the meeting room space. The cost for meeting rooms might approximate $\$ 2000.00$ per day. One way of offsetting the meeting room costs would be to raise the registration fee for the meeting.

$\begin{array}{rlrr} & \text { Yes } & \text { No } \\ \text { Raise the registration fee? } & & 20 & 33 \\ & \text { State Officials } & 7 & 29 \\ & \text { Local Officials } & 35 & 38 \\ \text { Associate Members } & 62 & 100\end{array}$

The following cities are being considered for the Annual Meeting. On a scale of 1 to 5 , where $1=$ avoid and $\mathbf{5}=$ excellent choice, rate the following possible locations for future meetings. (For purposes of the ranking reported below, the scorers gave the following values to the 1 through 5 ratings; $1=-10$ points, $2=-5$ points, $3=+5$ points, $4=+10$ points, $5=+15$ points).

\begin{tabular}{ll} 
New Orleans, Louisiana & 1580 points \\
Orlando, Florida & 1540 points \\
Phoenix, Arizona & 1525 points \\
Nashville, Tennessee & 1510 points \\
District of Columbia & 1320 points \\
Philadelphia, Penna & 1295 points \\
Hawaii (non specific) & 1020 points \\
\hline
\end{tabular}

$\begin{array}{lr}\text { Indianapolis, Indiana } & 910 \text { points } \\ \text { Chicago, Illinois } & 675 \text { points } \\ \text { Kansas City, Missouri } & 620 \text { points } \\ \text { Hartford, Connecticut } & 595 \text { points } \\ \text { Columbus, Ohio } & 350 \text { points } \\ \text { Albany, New York } & -24 \text { points }\end{array}$

Please rank the city/hotel combinations of past Annual Meetings. (For purposes of scoring, values were given to ranking as follows: \#1 (best) $=40$ points, $2=35$ points, $3=30$ points, $4=25$ points, $5=20$ points, $6=$ 15 points, $7=10$ points, $8=5$ points, $9=0$ points.

\begin{tabular}{llllllllllll}
\hline City * & 1 & 2 & 3 & 4 & 5 & 6 & 7 & 8 & 9 & $\begin{array}{l}\text { Total } \\
\text { points }\end{array}$ \\
\hline Seattle, WA(140) & 24 & 27 & 14 & 15 & 21 & 14 & 13 & 0 & 6 & 3490 \\
Albuquerque, NM(104) & 32 & 14 & 16 & 16 & 7 & 9 & 4 & 5 & 1 & 3365 \\
Washington, DC (108) & 22 & 20 & 14 & 15 & 10 & 13 & 7 & 5 & 2 & 2865 \\
Grand Rapids, MI(139) & 18 & 15 & 10 & 14 & 25 & 13 & 11 & 29 & 4 & 2795 \\
Boston, MA(95) & 30 & 24 & 16 & 8 & 5 & 4 & 3 & 3 & 2 & 2750 \\
Sacramento, CA(85) & 16 & 17 & 29 & 5 & 9 & 3 & 5 & 0 & 1 & 2505 \\
Atlanta, GA(83) & 1 & 2 & 7 & 16 & 12 & 16 & 12 & 16 & 1 & 1405 \\
Little Rock, AK(117) & 2 & 4 & 9 & 7 & 10 & 8 & 5 & 11 & 61 & 1090 \\
St. Louis, MO(69) & 4 & 2 & 3 & 5 & 6 & 14 & 13 & 12 & 10 & 1075 \\
& & & & & & & & & & & \\
\hline
\end{tabular}

Not all respondents were in attendance at all of the nine past Annual Meetings. Note that the number rating generally was less for each past year (i.e., 140 ranked Seattle, 139 ranked Grand Rapids, 117 ranked Little Rock, 108 ranked Washington, etc). If the rankings are adjusted to match the number of respondents ranking Seattle, 140 , the relative rankings change. For example, since the total points for Seattle is 3490 based on 140 responders, the adjusted total points for Albuquerque is then 140/104 times $3365=4530$. Making the same adjustments for the others, the adjusted rankings are:

$\begin{array}{llllll}\text { 1. Albuquerque } & 4530 & \text { 4. Washington } & 3714 & \text { 7. Atlanta } & 2370 \\ \text { 2. Sacramento } & 4125 & \text { 5. Seattle } & 3490 & \text { 8. St. Louis } & 2181 \\ \text { 3. Boston } & 4053 & \text { 6. Grand Rapids } & 2815 & \text { 9. Little Rock } & 1304\end{array}$


ADDITIONAL RECOMMENDED LOCATIONS FOR ANNUAL MEETING

\begin{tabular}{|c|c|c|c|c|}
\hline Anchorage, AK & 5 & Jackson Hole, WY & 2 & Puerto Rico \\
\hline Altanta, GA & 5 & Kansas. MO & 3 & Reno, NV \\
\hline Amelia Island, FL & 1 & Las Vegas, NV & 4 & Richmond, VA \\
\hline Baltimore, MD & 4 & Little Rock & 1 & Salt Lake City, UT \\
\hline Boise, ID & 1 & $\begin{array}{l}\text { Los Angeles/ } \\
\text { Anaheim, CA }\end{array}$ & 1 & San Antonio, TX \\
\hline Boston, MA & 8 & & & San Diego, CA \\
\hline Bozeman, MT & 1 & Memphis, TN & 1 & San Francisco, CA \\
\hline Cape Cod, MA & 2 & Milwaukee, WI & 1 & Santa Fe, NM \\
\hline Charlestown, SC & 7 & Minneapolis, MN & 6 & St. Louis, MO \\
\hline Charlotte, NC & 2 & $\begin{array}{l}\text { Monterey, CA } \\
\text { Nashville, TN }\end{array}$ & $\begin{array}{l}3 \\
6\end{array}$ & Tucson, AZ \\
\hline Chicago, IL & 3 & & & Virgin Islands \\
\hline Cincinnati, $\mathrm{OH}$ & 4 & New Orleans, LA & 1 & Washington, DC \\
\hline Clearwater, FL & 2 & North Carolina & 1 & Williamsburg, VA \\
\hline Dallas/Ft. Worth & 5 & Nome, AK & 2 & \\
\hline Denver, CO & 13 & $\begin{array}{l}\text { Omaha, NE } \\
\text { Orlando, FL }\end{array}$ & $\begin{array}{l}1 \\
1\end{array}$ & \\
\hline Ft. Lauderdale, FL & 1 & & & \\
\hline Hartford, CN & 3 & Palm Springs, CA & 1 & \\
\hline Hawaii & 2 & Phila., PA & 2 & \\
\hline Hilton Head, SC & 3 & Phoenix, AZ & 4 & \\
\hline \multirow[t]{2}{*}{ Indianapolis, IN } & 2 & Portland, ME & 5 & \\
\hline & & Portland, OR & 5 & \\
\hline
\end{tabular}


Appendix G

\section{TREASURER'S INTERIM REPORT FISCAL YEAR 74 (1989-1990)}

\section{CASH ON HAND June 30, 1989}

$\$ 90,942.70$

\section{BUDGET RECEIPTS:}

\begin{tabular}{|c|c|c|c|}
\hline$\$ 30,000$ & 1.1 & Registrations & $\$ 17.385 .00$ \\
\hline 67,550 & 1.2 & Memberships & $46,520.00$ \\
\hline 6,500 & 1.3 & Training Modules & $6,517.00$ \\
\hline 3,000 & 1.4 & Interest & $2,089.69$ \\
\hline 1,000 & 1.5 & Promotional & -0 \\
\hline 5,000 & 1.6 & Special Events & 5.777 .00 \\
\hline 300 & 1.9 & Miscellaneous & -0 \\
\hline 113,350 & & Total Receipts & \\
\hline
\end{tabular}

Total Income

\section{DISBURSEMENTS:}

$\begin{array}{cll}\$ 14,000 & 2.0 & \text { Annual Meeting } \\ 4,000 & 3.0 & \text { Interim Meeting } \\ 20,000 & 4.0 & \text { Committee Ops. } \\ 18,000 & 5.0 & \text { Special Programs } \\ 12,550 & 6.0 & \text { Chmns. Expenses } \\ 6,000 & 7.0 & \text { Membership Prog. } \\ 6,000 & 8.0 & \text { Printing \& Pubs. } \\ 12,500 & 9.0 & \text { Administration } \\ 5,000 & 10.0 & \text { Special Events } \\ 1,300 & 11.0 & \text { Promotional } \\ 14,000 & 12.0 & \text { Training Modules } \\ 113,350 & & \text { Total Disbursements }\end{array}$

11.285 .94

329.00

$7,091.92$

$6,326.16$

$6,705.92$

1.900 .65

$9,945.07$

4.060 .49

$8,036.18$

684.25

$12,204.43$

\section{BALANCE}

$\$ 68,570.01$

$\$ 100,661.38$

Bank Accounts

New York

Maryland

$\$ 47.222 .50$

314.24

CD \#1

22.451 .12

$\mathrm{CD} \# 2$

$\mathrm{CD} \# 3$

10.673 .52

$20,000.00$

BALANCE

$\$ 100,661.38$

GRANT ACCOUNT

$\$ \quad 2.482 .42$

SUBMITTED:

Charles A. Gardner, Treasurer 



\title{
Report of the Laws and Regulations Committee
}

\author{
Sidney A. Colbrook, Chairman \\ Weights and Measures Program Manager \\ Illinois Department of Agriculture
}

This is the final report of the Laws and Regulations Committee for the 75th Annual Meeting of the National Conference on Weights and Measures (NCWM). It is based on the Interim Report (NCWM Publication 16), the Addendum Sheets issued at the meeting, and the actions taken by the membership at the meeting.

Table A identifies items in the Report by Reference Key Number, item title, and page number. The first three digits of the Reference Key Numbers of the items in the Committee's report are assigned from the subject series listed below. Not all subject series will appear in the report. The digits after the hyphen are assigned at the time of assembly of the Interim Meeting agenda in the order of the appearance of the subject of the proposal in the handbooks. Several item numbers are out of sequence with their appearance in the Final Report because the Committee recommended revisions or additions to sections or paragraphs other than those originally proposed. In addition, several items were divided into parts after their numbers were assigned: these are delineated with the letters "A," "B," and so on, after the number, for example "221-1A." The titles of voting items are indicated with a "V" after the item number. At the Annual Meeting, the committee grouped the less controversial voting items into a consent calendar. These are marked with "VC." In the Report, the key text upon which a vote is to be taken is also highlighted by bold face print. Items marked with an " $\mathrm{I}$ " after the reference key number are information items. The items marked with a "W" were withdrawn by the Committee.

The Committee was assisted by Ms. Janice Oliver, representing the U.S. Food and Drug Administration, and Mr. Bret Smart, representing the Federal Trade Commission. Mr. Gilles Vinet, from the Legal Metrology Branch of Canada's Consumer and Corporate Affairs, also participated in all the Committee's deliberations. The Committee wishes to express its appreciation for their contributions.

Much of the Report contains recommendations to revise or amend National Institute of Standards and Technology (NIST) Handbook 130, 1990 edition, "Uniform Laws and Regulations;" NIST Handbook 133, Third Edition, "Checking the Net Contents of Packaged Goods;" or NCWM Publication 3, "NCWM Policy, Interpretations, and Guidelines." Proposed revisions are shown in bold face print by crossing out (crossing out) what is to be deleted, and underlining what is to be added. Entirely new paragraphs proposed are designated as such and also are shown in bold face print.

\section{Subject Series}

HANDBOOK 130 - General

210 Series

LAWS

220 Series

Uniform Weights \& Measures Law (UWML)

Uniform Weighmaster Law (UWL)

221 Series

Uniform Motor Fuel Inspection Law (UMFIL)

222 Series

223 Series

\section{REGULATIONS}

230 Series

Uniform Packaging and Labeling Regulation (UPLR)

231 Series

Uniform Regulation for the Method of Sale of

Commodities (UMSCR)

232 Series

Uniform Unit Pricing Regulation (UUPR)

233 Series

Uniform Regulation for the Voluntary Registration of

Servicepersons \& Service Agencies for Commercial Weighing \&

Measuring Devices (URVRS)

234 Series 


\section{Subject Series (Continued)}

\section{REGULATIONS}

Uniform Open Dating Regulation (UODR)

Uniform Regulation for National Type Evaluation (URNTE)

235 Series

Uniform Regulation for Motor Fuel (URMF)

Table A

Reference Key Items and Index

I Other Sections That Should Refer to Services ................. 79

VC 1.2. Weight; Drained Weight for Packages .................. 80

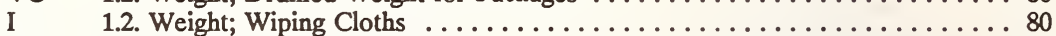

VC $\quad 1.2$. Weight; Primary Mill Paper ....................... 81

VC $\quad$ 1.X. Random Weight Package ......................... 81

222 I Uniform Weighmaster Law $\ldots \ldots \ldots \ldots \ldots \ldots \ldots \ldots \ldots \ldots$

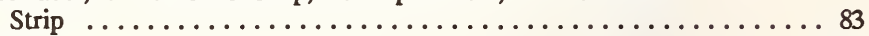

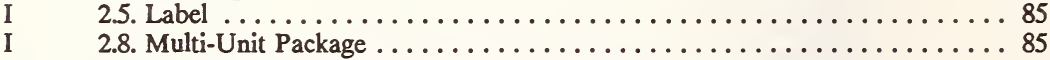

VC 3.1. Declaration of Identity: Consumer Package; 4. Declaration of Identity: Nonconsumer Package; Clarification of "Identity" . . . . . . 85

6.1. General ................................ 86

I 6.5.(b) Inch-Pound Units: Weight, Measure; Reference Temperature

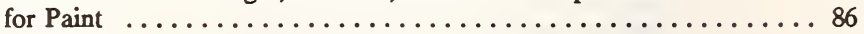

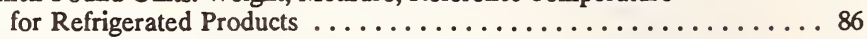

6.5.1. Symbols and Abbreviations; Add Abbreviations ............ 87

I 6.11.3. Rounding; How to Round for the Net Weight Declaration . . . . . . 87

VC 2.13.4. Declaration of Weight/Polyethylene Sheeting and Film .......... 88

I 10.5. Combination Packages and 10.6. Variety Packages .............. 89

I 10.X. Mechanical Pump Dispensers $\ldots \ldots \ldots \ldots \ldots \ldots \ldots \ldots \ldots \ldots \ldots \ldots \ldots . \ldots \ldots$ 


\section{Table A (Continued)}

\section{Reference}

Key No.

VC

11.23. Camera Film ............................. 90

11.28. Commodities' Variable Weights and Sizes ............... 91

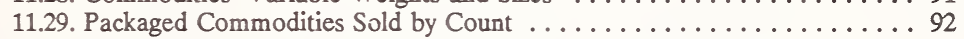

\section{Uniform Regulation for the Method of Sale of} Commodities ........................... 92

1.1. Berries and Small Fruits; Define "Small Fruits" .............. 92

1.5.1. In Combination with Other Foods . ................. 93

1.5.2.3. Fresh Oysters, Clams, Mussels, or Other Mollusks Removed from the Shell $\ldots \ldots \ldots \ldots \ldots \ldots \ldots \ldots \ldots \ldots \ldots \ldots \ldots$

1.5.X. Meat, Poultry, Fish, and Seafood -- Packaged with Other

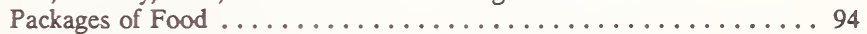

1.7.1. Factory Packaged and Hand-Packed Ice Cream and Similar Frozen Products. ........................ 94

I 1.9. Advertising and Price Computing of Bulk Food Commodities ........... 96

W 1.12 . Ready-to-Eat Food ............................. 96

I $\quad 1 . X$. Method of Sale for Fresh Fruits and Vegetables . . . . . . . . . . 97

W 1.X. Method of Sale for Salads . . . . . . . . . . . . . . . 97

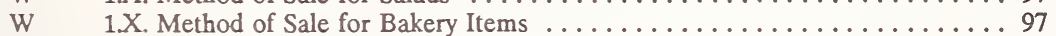

I Method of Sale Requirements in the U.S. and in Canada ............ 97

I Vacuum-Packed Cans of Coffee .......................... 99

VC 2.10.3.(a) and (b) Quantity (of Softwood Lumber) .................. 99

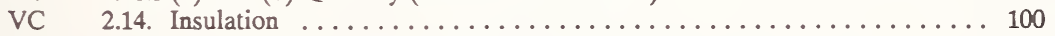

VC 2.16. Liquefied Petroleum Gas Cylinder Tare Weights; Compressed or Liquefied Gases in Cylinders ................... 100

2.16. Liquefied Petroleum Gas Cylinder Tare Weights; Acetylene . . . . . . 102

2.20. Gasoline-Alcohol Blends; Add Labeling of All Oxygenates ......... 102

2.22. Liquid Oxygen Used for Respiration .................. 104

2.X. Products Dispensed from Mechanical Devices ............... 104

2.X. Animal Bedding .......................... 104

Handbook 133: Package Testing ................ 105

Proposed Sampling Plans and Smaller MAV's ............... 105

VC 3.11.4. Exhausting the Aerosol Container; Clarify Instructions . . . . . . . . 105

I Moisture Loss for Ice-Packed Poultry and Other Meat and Poultry

Items ................................ 106

Moisture Loss for Pet Foods ........................ 106

Moisture Loss for Pasta . ......................... 107

Section 4.X. Hand-Packed Ice Cream ... . . . . . . . . . . . . . . . . 107

Polyethylene/Test Methods for Bags . .................. 108 


\section{Table B Appendices}

\begin{tabular}{llll}
\hline Appendix & Title & Reference Key No. & Page \\
\hline & & \\
A & Uniform Weighmaster Law & 222 & 109 \\
B & NCWM Publication 3, 2.3.2. Fresh Fruits & $231-10$, & 116 \\
& $\quad$ and Vegetables & $232-1$ & 119 \\
C & Meat and Poultry Products & $232-2 \mathrm{~A}$ & 127 \\
\hline
\end{tabular}

\section{Order of Presentation}

The report was presented to the membership as follows:

1. The Consent Calendar was presented. Item 232-4 had been proposed by the Committee as a Consent Calendar item, but was subsequently made a separate voting item by the Committee. The Consent Calendar was then adopted.

2. Item 232-4 was voted upon.

3. The report in its entirety was then ratified.

Table C

Voting Results

\begin{tabular}{llllll}
\hline $\begin{array}{l}\text { Reference } \\
\text { Key No. }\end{array}$ & $\begin{array}{l}\text { House of State } \\
\text { Representatives }\end{array}$ & House of Delegates & Resuits \\
& Yes & No & Yes & No & \\
\hline Consent Calendar & 46 & 0 & 63 & 0 & Passed \\
$232-4$ & 45 & 0 & 67 & 0 & Passed \\
Entire Report & 46 & 0 & 71 & 0 & Passed \\
\hline
\end{tabular}

\section{Details of All Items}

\section{VC Section V. Interpretations and Guidelines}

(This item was adopted as part of the consent calendar.)

Background: The guidelines that appear as Section 2 of NCWM Publication 3 were originally part of H130. It had 
been thought that States could adopt H130 in its entirety by reference (as States were already doing with Handbook 44) if it contained only legal requirements, not guidelines or interpretations. The guidelines section was therefore removed from $\mathrm{H} 130$. It was later determined that State executive agencies could not adopt laws by reference, but could adopt regulations by reference if a law permitted it. Several sections (rather than one encompassing section) were therefore added to the Uniform Weights and Measures Law in order to empower State Weights and Measures agencies to adopt specific regulations in $\mathrm{H} 130$ by reference. States do not adopt the entire Handbook 130 by reference because the document consists both of laws (needing legislative adoption) and regulations (which can be adopted by reference).

Having to consult Publication 3 for further information on legislative history or interpretation of specific sections is an unnecessary complication; ease of use and reference can be enhanced by including the guidelines in Handbook 130.

Committee Recommendation: Publish Section 2, "Uniform Laws, Regulations and Commodity Control," of NCWM Publication 3, "NCWM Policy, Interpretations, and Guidelines," as an appendix in NIST Handbook 130 (H130).

\section{Uniform Weights and Measures Law}

\section{1-1A VC 1.2. Weight; Include Services in Definition}

(This item was adopted as part of the consent calendar.)

Background: Section 1.2. is a fundamental definition in the Uniform Weights and Measure Law. It defines weight as meaning net weight "in connection with any commodity." The question has been asked whether this definition applies to services when charged on the basis of weight, for example, by moving companies, laundries, or package shippers. The Committee is unanimous in its opinion that this definition is also intended to encompass services. For example, if a laundry charges by weight, to be in compliance it may charge only for the weight of the clothing to be cleaned (and not for the wrapping or bag into which the clothes are placed). A moving service, when charging by weight, may charge only for the weight of the goods placed into the truck (and not for the tare weight of the truck). Similarly, a shipping or mailing service charging by weight may charge only for the weight of the package to be shipped.

The pricing practices of services are not required to be by weight, measure, or count. Furthermore, the term "net weight" when used in conjunction with services does not mean that a service (such as a shipper) may charge only for the goods inside a package: the service is the transportation of a total package, not just the goods inside the package; that is, the service of shipping includes the shipping of the packing materials. Charging for the total weight of the package does not mean that they are selling a service by gross weight.

Black's Law Dictionary (Fifth Edition) defines commodities as "those things which are useful or serviceable, particularly articles of merchandise movable in trade; goods, wares, and merchandise of any kind; movables, articles of trade or commerce; movable articles of value; things that are bought and sold..." Random House College Dictionary defines commodity as "1. something of use, advantage, or value; 2 . an article or trade or commerce, esp. a product as distinguished from a service." These definitions require that the Committee specifically add the performance of labor (service) in all transactions by measure in the UWML. The Committee was not able to reach consensus on appropriate wording for sections other than 1.2. Therefore, see Item 221-1B, which reports on further work that the Committee intends to address at future meetings.

Committee Recommendation:

Revise the UWML to clarify that weights and measures regulation applies to both things and services, when a quantity is determined:

12. Weight. - The term "weight" as used in connection with any commodity or service means net weight.

221-1B I Other Sections That Should Refer to Services

In its study of the UWML, the Committee notes that several of its sections already specifically refer to "service": 
Section 11.(b) "...unfair or deceptive dealing by weight or measure in any commodity or service..."

Section 12.(j)(1) "...in determining the weight, measure, or count of commodities or things sold..." (2) "...in computing the basic charge or payment for services..."

Section 16. "no person shall misrepresent the price of any commodity or service sold, offered,..."

Other sections are silent as to service, but have often been interpreted as including service even though not specifically mentioned. For example, Section 18. Sale from Bulk has been used to require a receipt in a waste-hauling service charging by weight when neither party to the transaction is present when the weighing is made.

In addition, Section 12. Powers and Duties of the Director is silent in subsection (n) concerning the power to prescribe by regulation methods of sale for services when those services are priced by weight, measure, or count.

The Committee will therefore discuss the following preliminary drafts of revisions to the UWML. Regional weights and measures associations are encouraged to provide their recommendations and suggestions.

1.8. Sale from Bulk. -- The term "sale from bulk" means the sale of commodities or services when the quantity is determined at the time of sale.

\subsection{Net Weight. --}

(a) Commodities. -. The term "net weight" means the weight of a commodity excluding any materials, substances, or items not considered to be part of the commodity. Materials, substances, or items not considered to be part of the commodity include, but are not limited to, containers, conveyances, bags, wrappers, packaging materials, labels, individual piece covering, decorative accompaniments, and coupons.

(b) Services. -- Materials considered to be part of a service may or may not include packaging materials, depending upon the type of service that is being purchased. It shall in no instance include the weight of the conveyance used to transport goods if the service is transportation of goods.

12(n) Prescribe, by regulation, the appropriate term or unit of weight or measure to be used, whenever he or she determines in the ease of a specifie-commodity that an existing practice of declaring the quantity by weight, measure, numerical count, or combination thereof, does not facilitate value comparisons by consumer, or offers an opportunity for consumer confusion.

\section{1-1C VC 1.2. Weight; Drained Weight for Packages}

(This item was adopted as part of the consent calendar.)

Background: Section 1.2. needs clarification because it mixes the general concept of sale by net weight, which could be of a commodity or service (see Item 221-1A), with the concept of drained weight for packages. The clause beginning with "...except where..." should be separated from the first part of the sentence. After some study, the Committee believes that the term "label" in Section 1.2 defining "weight" makes this clause apply only to packaged products; however, items could be sold from bulk by drained weight.

Committee Recommendation: Revise Section 1.2. as follows:

1.2. Weight. - The term "weight" as used in connection with any commodity means net weight. When a commodity except-where the tabet-dectares that the product is sold by drained weight, the term means net drained weight.

\section{1-1D I 1.2. Weight; Wiping Cloths}

Background: The Conference has been on record since the 1950's concerning the illegal practice of selling wiping cloths by gross weight. Several State weights and measures agencies have recently discovered that the practice of selling wiping cloths by gross weight continues in this industry. Section 1.2. of the Uniform Weights and Measure Law defines weight as meaning net weight in any transaction. In addition, Section 7.2. of the UPLR requires that 
nonconsumer packages bear a declaration of the net quantity of contents. All States have laws which similarly require net weight. The Committee has transmitted this information to the International Association of Wiping Cloth Manufacturers. The net weight of wiping cloths must appear on package labels, invoices, and any other sales literature that refer to the quantity of wiping cloths, if the quantity is by weight. (Some nonwoven wiping cloths are sold by count and dimensions.) It is not appropriate to label or sell by the gross weight of the box or bale (that is, the weight of the box or bale combining the weight of the wiping cloths with the weight of the container), nor to provide the percentage of the gross weight that is tare without also declaring the net weight of the wiping cloths.

Committee Recommendation: No change to existing requirements; transmit letter to wiping cloth manufacturers informing them of applicable State weights and measures requirements.

\section{1-1E VC 1.2. Weight; Primary Mill Paper}

(This item was adopted as part of the consent calendar.)

Interpretation: Nonconsumer sales of "primary mill paper" were discovered by weights and measures officials to be labeled and invoiced on what was called a "gross weight" basis. Primary mill paper is produced for commercial or industrial companies for subsequent additional processing, such as paper for newspaper or magazine publishers, or sanitary tissue manufacturers. The primary mill paper is cut from "parent rolls", but is still a commercial-sized item weighing from several hundred to several thousands of pounds.

The key to understanding the longstanding trade practice is that the purchaser of such paper specifies not only the quality of the paper being purchased, such as the thickness, surface coating, etc., but the purchaser also specifies the core around which the paper is to be wound, the type of overwrap, the number of overwraps, and such other requirements that will ensure receipt of the primary mill paper in proper condition for subsequent processing. The weight of the core and wrapping is approximately one percent of the gross weight. It is recycled by the purchaser in his own or other paper recovery or reuse systems.

Having reviewed the practices in the industry in the specification and purchasing of primary mill paper, the Committee concludes that the true product is the paper plus the packaging (in order to assure maintenance of quality) and an appropriate core (to ensure a fit on the recipient's equipment). Therefore, in the opinion of the Committee, the sale of primary mill paper is not at all on a gross weight basis. This is and has been a misnomer. The true identity of the purchased product has been misunderstood by weights and measures authorities and further compounded by industry use of the term "gross weight". The product is the primary mill paper plus the core and overwrap specified by the purchaser.

The Committee therefore believes that the industry should review its invoicing and labeling to clarify that the weight of the specified product is the weight of the primary mill paper, core, and overwrap. Although this weight is the gross weight of the entire item as produced and shipped, it is the net weight of the item as specified by the purchaser.

This interpretation applies only to primary mill paper and is not intended to be applied to other nonconsumer products ordered by specification: it is a narrow interpretation applying to the specific method of sale in this trade, where the service of packaging and the packaging is part of the purchase.

Committee Recommendation: Add the above interpretation to NCWM Publication 3, "Policy, Interpretations, and Guidelines."

221-2

\section{VC 1.X. Random Weight Package}

(This item was adopted as part of the consent calendar.)

Background: The term "random weight package" is used in UWML Section 20. Declarations of Unit Price on Random Weight Packages, but is not separately defined. (It is defined in Section 20 using the same words: "random weight.") There should be a definition for random weight package in the UWML and it should be consistent with that for "random package" in the UPLR. The definition for "random package" in the UPLR tracks federal regulations which define it only as applying to consumer packages. 
Committee Recommendation: Add a definition for "random weight package" to the UWML using the definition of "random package" in the UPLR as its basis (but generalizing the definition to include more than consumer packages):

1.X. Random Weight Package. - A package that is one of a lot, shipment, or delivery of packages of the same commodity with no fixed pattern of weights.

In addition, revise Section 2.4. of the UPLR editorially, to track the wording recommended above. Modification to Section 2.4. is as follows:

2.4. Random Package. - A package that is one of a lot, shipment, or delivery of packages of the same consumer commodity with various weights, that is, packages of the same consumer commodity with no fixed pattern of weights.

\section{1-3}

\section{VC 15. Misrepresentation of Quantity}

(This item was adopted as part of the consent calendar.)

Background: Section 16. Misrepresentation of Pricing prohibits misrepresenting the price "in any manner calculated or tending to mislead or in any way deceive a person." This is important language that does not exist in Section 15. Many States have commented that Section 16 is much more useful to cite to prevent obviously misleading trade practices, and have said that it would be very useful to have this tool in Section 15, which is the section prohibiting misrepresentation of quantity.

Committee Recommendation: Amend Section 15 as follows:

No person shall:

(a) sell, offer, or expose for sale less than the quantity he represents represented, nor

(b) take any more than the represented quantity he represents when as buyer, he/she he furnishes the weight or measure by means of which the quantity is determined, nor

(c) represent the quantity in any manner calculated or tending to mislead or in any way deceive another person.

Background: At the 74th Annual Meeting, the NCWM adopted a revised Uniform Weighmaster Law. The Executive Secretary, in his capacity as editor, subsequently recommended significant rewording of the rather archaic language that still remained. The Committee has reviewed these recommendations in detail and made a few necessary modifications to the Executive Secretary's draft so that the Uniform Weighmaster Law that appears in Appendix A is a significant editorial improvement, but represents no substantive change to the Law.

Committee Recommendation: Replace the Uniform Weighmaster Law as printed in the 1990 edition of Handbook 130 with the editorially revised version in Appendix A.

\section{Uniform Packaging and Labeling Regulation}

\section{1-1 I 2.X. Package}

Background: Although "commodity in package form" is defined in the UPLR, "package" is not. "Package" is defined in the UWML consistent with the definition of commodity in package form in the UPLR. However, weights and measures officials have found it difficult to guide the layman who must comply with the UPLR to look in several places for the definitions. It would be useful if the UPLR were a more self-contained document. 
Committee Recommendation: As a result of the discussion at the Interim Meeting, it was the recommendation of the Committee to add the definition for "package" that appears in the Uniform Weights and Measures Law to the UPLR Section 2. Definitions as follows:

2X. Package. -- Any commodity put up or packaged in any manner in advance of sale in units suitable for either wholesale or retail sale.

Material provided to the Committee before the Annual Meeting suggested that the definition in the Interim Report could be improved. For example, the Northeastern Weights and Measures Association recommended that the word "packaged" not be used in the definition for package. In addition, the Committee believes that the term "put up" needs defining. It was not the original intent of the Committee to revise the definition of package, but merely to add the definition from the Uniform Weights and Measures Law to the Uniform Packaging and Labeling Regulation. This item will therefore be carried over. Two recommendations have been provided. The Northeastern Weights and Measures Association suggested (and the Committee further revised) the following:

2.X. Package. -- Any commodity premeasured, wrapped or unwrapped, in any manner in advance of sale in units suitable for either wholesale or retail sale.

Ohio provided the following alternative:

2.X. Package. -- Any commodity whose quantity is determined in any manner in advance of sale in units suitable for either wholesale or retail sale.

Any changes in the definition would have to be incorporated in the Uniform Weights and Measures Law. The regional weights and measures associations are encouraged to discuss these alternatives and provide their own opinions concerning the best definition.

\section{1-2 VC 2.X. Spot Label; 2.XX. Header Strip; 11.X. Spot Label; 11.XX. Header Strip}

(This item was adopted as part of the consent calendar.)

Background: Both the Food and Drug Administration (FDA) and the Federal Trade Commission (FTC) have issued interpretations and guidelines concerning the special types of labels called "spot labels" and "header strips." The Committee recommends that the NCWM incorporate these interpretations into the UPLR so that States may also adopt these definitions for national uniformity. New paragraphs under Section 11. Exemptions are also proposed. These definitions have been reviewed by both FDA and FTC, to which the Committee wishes to express its appreciation for their assistance. The definition for spot label was editorially reworded by the Central Weights and Measures Association.

Committee Recommendation: Add definitions for spot label and header strip to Section 2. and labeling exemptions for spot labels and header strips to Section 11.:

2.X. Spot Label. - A spot label is a label that covers only a small portion of the surface of a principal display panel of a package; the entire portion of the principal display panel outside the area of the label contains no printed or graphic matter of any kind. A spot label may contain all required labeling information on it (identity, responsibility, and net contents), but it must have the identity and net contents. See Section 11.X. for net contents placement exemption for a spot label. Also see figure below.

2.XX. Header Strip. - A header label or header strip is a label that is attached across the top of a transparent or opaque bag or other container that bears no other printed or graphic material. See Section 11.XX. for net contents placement exemptions. See also the figure below.

11.X. Spot Label. - The declaration of quantity of the contents of a package is exempt from Section 8.1.1. Location, requiring the quantity declaration to appear in the bottom $\mathbf{3 0}$ percent of the principal display panel, as long as the declaration of quantity appears in the lower 30 percent of the spot label. In no case may the size of the spot label be used to determine the minimum type size; see Section 8.2. for this determination. 


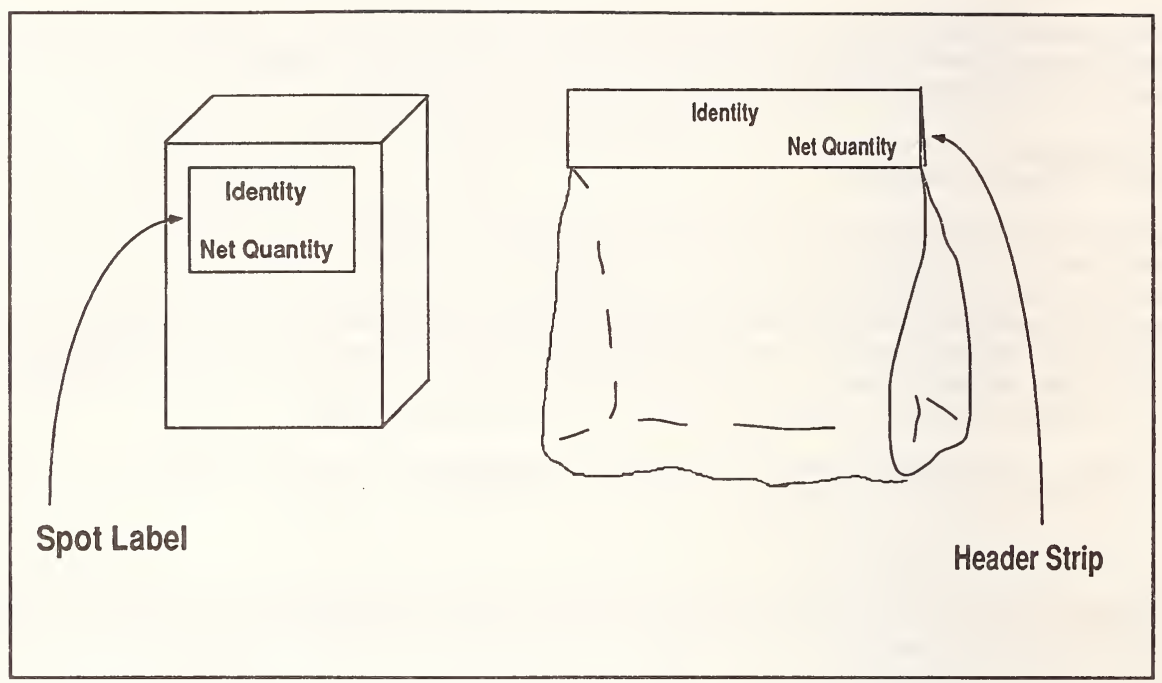

11.XX. Header Strip. - The declaration of quantity of the contents of a package is exempt from Section 8.1.1. Location, requiring the quantity declaration to appear in the bottom 30 percent of the principal display panel, as long as the declaration of quantity appears in the lower 30 percent of the header strip or header label. In no case may the size of the header strip be used to determine the minimum type size; see Section 8.2. for this determination.

231-3 I 2.5. Label

Background: The Northeastern Weights and Measures Association recommended that the definition of label be modified to remove the phrase "adjacent to:"

Label. -- Any written, printed, or graphic matter affixed to, applied to, attached to, blown into, formed, molded into, embossed on, or appearing upon or adjacent to a consumer commodity, or a package containing any consumer commodity...

The present definition permits a sign to be posted with required label information. The Association contended that it is not reasonable for required information to be separated from the commodity since the purchaser carries the package away from the sign. For example, the present definition allows a gift package to appear with a sign declaring the net contents, rather than requiring the net contents declaration to be affixed to the package.

Committee Recommendation: Although the criticism outlined by the Northeastern Association is valid, the Committee members recognize reasons to preserve the present definition. For example, farmers' markets vending produce in bags can post a sign with all required declarations, rather than affix a label to each bag. A department store selling linens can post a sign with dimensions and other label requirements without affixing a label to each linen item. Since the definition of commodity in package form encompasses items that are not enclosed in a package, there is a need to permit an adjacent label, not just one affixed to the item. The Committee believes that weights and measures officials would prefer the option of permitting additional signage with required labeling information, rather than have to declare a packaged product off-sale because its labeling is incomplete. The Committee therefore recommends no change. 


\section{1-4 I 2.8. Multi-Unit Package}

This was Item 231-4 in the Report of the 74th NCWM 1989.

Background: Bags of Halloween candy containing multiple packages of single-serving candies are labeled by weight. At least one packager labels a count on the back of its packages as a supplemental statement of quantity. This permits the purchaser to know how many servings are contained in the package. These bags of candy are not multiunit packages because the individual serving-size packages are not labeled for individual sale.

The Committee explored two possibilities: (1) require that a declaration of quantity in terms of weight be combined with an appropriate declaration of count unless a declaration of weight alone is fully informative (already in Section 6.4.1. of the UPLR). The argument in favor of this interpretation is that, since these candies are purchased to give away to numbers of children, count is required. However, since the packager controls the total package quantity by weight, only an approximate count can be provided; (2) petition the Food and Drug Administration to change the definition of multi-unit package.

It was generally agreed that the addition of count either as a net contents declaration on the principal display panel or as a supplemental statement should be encouraged, but should remain voluntary. Declaration by count is not required for sale of other foods competing for purchase for Halloween giving, such as oranges or apples. In addition, special labeling should not be required for the consumer for only one specific holiday. The Committee welcomes additional comments or consumer survey data suggesting whether additional net contents information is needed.

Committee Recommendation: No change to the existing definitions and requirements.

\section{1-5 VC 3.1. Declaration of Identity: Consumer Package; 4. Declaration of Identity: Nonconsumer Package; Clarification of "Identity"}

(This item was adopted as part of the consent calendar.)

Items 231-5 and 231-6 as they appeared in the agenda for the Interim Meeting have been combined into a single voting item. Therefore, there is no Item 231-6.

Background: At the present time, the UPLR only requires that a statement of identity appear on the principal display panel identifying the commodity "by its common or usual name, description, generic term, or the like." In order to specifically prohibit such practices as labeling a package containing a soil amendment with less than $5 \%$ cow manure as "cow manure," requirements such as those contained in FTC regulations (16CFR 500.4) prohibiting misleading or deceptive names should be incorporated.

Moreover, both FDA and FTC regulations for consumer commodities specify that the identity and quantity be declared separately. For example, if no change were made to State requirements, a problem might arise if a packager followed State requirements as presently written and listed both the identity and count of paper napkins in a single statement on the principal display panel, such as : "250 soft white paper napkins." This is prohibited under FTC requirements.

Committee Recommendation: Revise Sections 3.1. and 4. as follows:

3.1. Declaration of Identity: Consumer Package. - A separate declaration of identity on a consumer package shall appear on the principal display panel, and shall positively identity the commodity in the paekage-by its common- or ustat name, deseription, generie term, or the like: not be misleading or deceptive. The identity shall be in terms of:

(a) the name specified in or required by any applicable Federal or State law or regulation, or in the absence of this,

(b) the common or usual name, or in the absence of this, 
(c) the generic name or other appropriate description, including a statement of function (such as "cleaning powder").

4. Declaration of Identity; Nonconsumer Package. - A declaration of identity on a nonconsumer package shall appear on the outside of a package and shall positively identify the commodity in the package by its common or ustrat name, deseription, generie term, or the like: not be misleading or deceptive. The identity shall be in terms of:

(a) the name specified in or required by any applicable Federal or State law or regulation, or in the absence of this,

(b) the common or usual name, or in the absence of this,

(c) the generic name or other appropriate description, including a statement of function (such as "cleaning powder").

(This item was adopted as part of the consent calendar.)

Background: A "dual declaration of quantity" in Section 6.1. is a misleading term since there is also a "dual quantity declaration" in other sections of the UPLR. A combined metric and inch-pound quantity statement is not a "dual quantity declaration" as described in other sections of the UPLR and in Federal requirements; therefore, the current terminology needs to be revised.

Committee Recommendation: Revise Section 6.1. as follows:

6.1. General. -- The metric and inch-pound systems of weights and measures are recognized as proper systems to be used in the declaration of quantity. Units of both systems may be presented in a duat declaration of quantity. Paint

Background: The Committee was informed that an ASTM standard D16-84, "Standard Definitions of Terms Relating to Paint, Varnish, Lacquer, and Related Products," has been developed by the paint industry, and that it defines the U.S. gallon as "a volume equal to $231 \mathrm{cu}$ in. Paint, varnish, lacquer, and related products are measured at $77^{\circ} \mathrm{F}(25$ $\left.{ }^{\circ} \mathrm{C}\right)$." Section 6.5.(b) of the UPLR defines the declaration of quantity in terms of the U.S. gallon "...and shall express the volume at $68^{\circ} \mathrm{F}^{\prime \prime}\left[\left(20^{\circ} \mathrm{C}\right)\right.$ in Section 6.6.(b)]. Forty-seven States have adopted these sections of the UPLR. Since this is a regulation in 47 States, any paint manufacturer who uses the ASTM D16-84 definition at $77^{\circ} \mathrm{F}$ could find his product ordered off-sale for short measure. (As much as a $15 \mathrm{~mL}$ difference in volume will result for compounds formulated with certain solvents.)

Committee Recommendation: No change to the UPLR. The Committee's position has been transmitted to members of the National Paint and Coatings Association and the Chairman of ASTM D-1 Subcommittee on Definitions.

231-9

\section{VC 6.5.(b) Inch-Pound Units: Weight, Measure; Reference Temperature for Refrigerated Products}

(This item was adopted as part of the consent calendar.)

Background: The State of California and the Office of Weights and Measures requested an interpretation from the FDA concerning the meaning of the reference temperatures for refrigerated products [in Section 6.5.(b) and 6.6.(b) in the UPLR and 21CFR 101.105 (b)(2)(ii) in FDA regulations]. FDA's interpretation, with which the Committee concurs, is that the reference temperature of $40^{\circ} \mathrm{F}\left(4^{\circ} \mathrm{C}\right)$ applies only to products that must be refrigerated in order 
to maintain product quality, rather than to items, such as carbonated soft drinks, that are refrigerated for the convenience of the purchaser.

Committee Recommendation: Revise Section 6.5.(b) and 6.6.(b) as follows:

..except also in the case of a commodity that is mormally sotd must be maintained in the refrigerated state...

Also add the following guideline to NCWM Publication 3:

Guideline: The Committee also discussed how an inspector could decide whether a product under refrigeration is required to be maintained under refrigeration. The following guidelines are provided:

1. The traditional food items that normally require refrigeration and are found in refrigerated cases will not ordinarily have any statement about requiring refrigeration. These items include milk, orange juice, and similar products. They may be tested at any temperature at, above, or below their reference temperature of $40^{\circ} \mathrm{F}\left(4^{\circ} \mathrm{C}\right)$ because such products are at their maximum density at their reference temperature, and the volume of such products will always increase at higher or lower temperatures. Thus any errors made by not measuring at the exact reference temperature will be in the favor of the packer.

2. Food items that normally require refrigeration, but which are processed so as not to require refrigeration prior to opening, will have "refrigerate after opening" or similar wording on the label. Such items as milk and orange juice can be found in this category as well as in the "refrigeration required" category. The two categories can be distinguished by the "refrigerate after opening" statement, which calls for testing at or above their reference temperature of $68^{\circ} \mathrm{F}\left(20^{\circ} \mathrm{C}\right)$.

3. Food items that are not expected to require refrigeration, but which may be refrigerated for the convenience of the consumer (such as carbonated beverages), are to be tested at temperatures of $68^{\circ} \mathrm{F}\left(20^{\circ} \mathrm{C}\right)$ or above even when found refrigerated for the convenience of the consumer.

231-10 VC 6.5.1. Symbols and Abbreviations; Add Abbreviations

(This item was adopted as part of the consent calendar.)

Background: At the 74th Annual Meeting, the NCWM adopted a change to the UPLR permitting random labels to be used for the packaging and labeling of fresh fruits and vegetables that are sold by count rather than weight. It is now necessary to add abbreviations for count that may appear on the label.

Committee Recommendation: Add the abbreviations "ea", "pc", and "ct" for "each," "piece," and "count" to Section 6.5.1.:

6.5.1. Symbols and Abbreviations. - Any of the following symbols and abbreviations, and none other, shall be employed in the quantity statement on a package of commodity:

$\begin{array}{llll}\text { avoirdupois } & \text { avdp } & \text { ounce } & \text { oz } \\ \text { cubic } & \text { cu } & \text { pint } & \text { pt } \\ \text { feet or foot } & \text { ft } & \text { pound } & \text { lb } \\ \text { fluid } & \text { f } & \text { quart } & \text { qt } \\ \text { gallon } & \text { gal } & \text { square } & \text { sq } \\ \text { inch } & \text { in } & \text { weight } & \text { wt } \\ \text { liquid } & \text { liq } & \text { yard } & \text { yd } \\ \text { each } & \text { ea } & \text { piece } & \text { pc }\end{array}$

\section{1-11A I 6.11.3. Rounding; How to Round for the Net Weight Declaration}

Background: Several weights and measures agencies and packagers have sought the assistance of the Office of Weights and Measures concerning how to declare the net weight on their packages. Section 6.11.3. covers rounding rules to convert from inch-pound to metric declarations, but does not discuss how to round in other situations. 
In a related question concerning Section 6.11.3., a weights and measures jurisdiction inquired about the number of digits that should be used when declaring the net contents if both metric and inch-pound declarations are present. In particular, a U.S. baker had designed his label for use in both the U.S. and in Canada. The inch-pound declaration was $2 \mathrm{lb}$. The baker found that the particular product (cookies) was required to be sold in 100 gram multiples in Canada; therefore, instead of labeling his product 907 grams, the cookies were labeled 900 grams. In the Committee's Final Report, as it appeared in the 67th NCWM 1982, page 148, and in Section 2.2.4. of NCWM Publication 3, a discussion of this issue pointed out that the first sentence, stating that "...the number of significant digits retained should be such that accuracy is neither sacrificed nor exaggerated" should take precedence over the second: "As a general rule, converted values should be rounded down by dropping any digit beyond the first three." This is the reason for the phrase "as a general rule" and for the use of the word "should" rather than "shall." The packager must decide whether the accuracy of the net contents declaration is exaggerated by declaring three significant digits. In the case of the cookie packager, the number of digits in the inch-pound declaration (that is, $32 \mathrm{oz}$ ) is 2; thus, the equivalent $(0.907 \mathrm{~kg})$ or 907 grams, rounded down to two significant digits, is 900 grams (because $0.90 \mathrm{~kg}$ is not permitted.) ("9" and the first " 0 " are significant. The final " 0 " is not.)

The Committee has reviewed the requirements contained in the UPLR and recommends that Section 12.1.1. be used as the basis for further interpretations or requirements. Since Section 12.1.1. prohibits the average of the quantity in the packages from being below the declared net quantity, any calculated value to be declared on the label of a package must be rounded down (also known as truncating.)

Committee Recommendation: On the basis of its deliberations at the Interim Meeting, the Committee recommended clarifying Section 6.11.3. of the UPLR as follows:

6.11.3. Rounding. -- In all conversions for the purpose of showing an equivalent metric or inch-pound quantity to a rounded inch-pound or metric quantity, or in calculated values to be declared in the net quantity statement the number of significant digits retained should be such that accuracy is neither sacrificed nor exaggerated. As a general rule, converted values should be rounded down by dropping any digit beyond the first three. (Example: 196.4 grams becomes 196 grams or 1.759 feet becomes 1.75 feet.)

It became apparent after the Interim Meeting that several problems with Section 6.11.3. still remain; therefore, the Committee will carry this item over. The last two sentences of Section 6.11.3. read "As a general rule, converted values should be rounded down by dropping any digit beyond the first three (Example: 196.4 grams becomes 196 grams or 1.759 feet becomes 1.75 feet.) ${ }^{n}$ The issues are:

1. This sentence must be read in context with the previous sentence in order to understand that the guideline refers to significant digits, not to the actual number of digits; therefore, $2000 \mathrm{lb}$ is expressed as 4 digits, but there may be only 1 significant digit (the " 2 "), 2 significant digits ("20"), 3 significant digits ("200"), or 4 significant digits ("2000"). The regulatory official has no way of knowing how many of the digits are significant: this is for the packager to decide.

2. The Committee does not believe that a packager should be constrained to round down especially if he/she must label in round metric units for export to other countries; for example $7 \mathrm{oz}$ might also be declared as $200 \mathrm{~g}$ (rather than $198 \mathrm{~g})$ as long as the packager puts the larger amount $(200 \mathrm{~g})$ in the package.

3. Item 2 raises a question about uniformity of enforcement. Many weights and measures agencies only test the customary or inch-pound declaration; others test the larger of the declarations, whether metric or inch-pound; others test the "rational" declaration, for example, the 2-liter carbonated beverage or the 1-quart beverage, because they have both metric and inch-pound testing equipment.

The Committee intends to enlist the assistance of packagers, and in particular the Industry Committee on Packaging and Labeling for their assistance on this issue.

\section{1-11B VC 2.13.4. Declaration of Weight/Polyethylene Sheeting and Film}

(This item was adopted as part of the consent calendar.)

Background: Section 2.13.4. (polyethylene) requires that the labeled net weight for polyethylene sheeting and film 
not be less than the weight calculated using a formula. It was asked if Section 6.11.3. that covers rounding rules should be used to guide the packager in how to declare the net weight on the label. Section 6.11.3. covers rounding "for the purpose of showing an equivalent metric or inch-pound quantity...", not for how to round the results of other net quantity declarations.

It was also asked how many digits should be declared on a label of polyethylene sheeting or film. The Committee believes that a uniform approach to the label declaration for polyethylene products is useful. Specific rounding rules are therefore recommended in Section 2.13.4.:

2.13.4. Declaration of Weight. - The labeled statement of weight for polyethylene sheeting and film products under sections 2.13.1.1., and 2.13.3.2. shall be not equal to or greater than the weight calculated by using the fottowing formula below. The final value shall be calculated to four digits, and declared to three digits, dropping the final digit as calculated (for example, if the calculated value is $2.078 \mathrm{lb}$, then the declared net weight shall be $2.07 \mathrm{lb}$.)

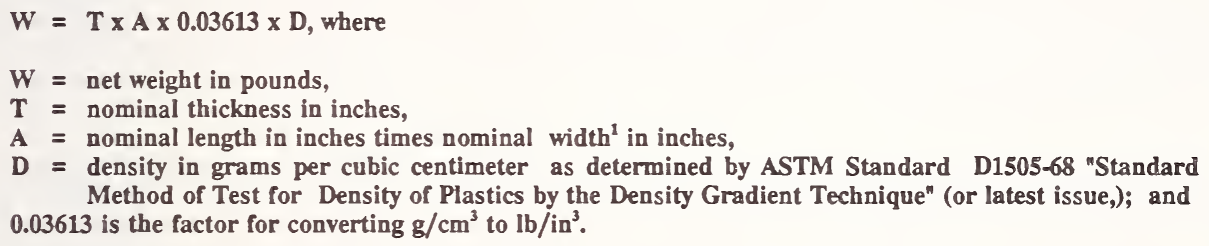

For the purpose of this regulation, the minimum density shall be $0.92 \mathrm{~g} / \mathrm{cm}^{3}$.

\section{1-12 I 10.5. Combination Packages and 10.6. Variety Packages}

(This carry-over item was Item 231-5C in the Report of the 74th NCWM 1989.)

Last year, the Committee proposed that the requirements promulgated by the FTC concerning variety and combination packages be adopted because (1) they are more specific than existing requirements in the UPLR; and (2) the FTC requirements are essentially the same for combination and variety packages. Such a change would consequently eliminate the need to make judgments concerning packages composed of "dissimilar" (combination) or "similar" (variety) commodities. Unfortunately, the FDA has no definitions or requirements for combination or for variety packages. Thus, consumers see packages of "variety" meats or cereals labeled only with a total net weight; if State requirements tracked the FTC regulations for variety packages, the net weights of each style or type of product in a variety package would also have to be labeled. The Committee will write FDA for a formal interpretation as to whether State regulations patterned after FTC's requirements could be imposed on products under FDA jurisdiction. The final objective would be to reach an agreement among FDA, FTC, and the NCWM on the appropriate requirements for variety and combination packages.

\section{1-13 I 10.X. Mechanical Pump Dispensers}

Sealed mechanical pumps are a relatively new dispensing mechanism for toothpaste. They dispense dentifrice through a sealed mechanism that will always retain a minimum amount of product. Only on aerosol containers must the net contents declaration be the amount that is delivered to the purchaser (see Section 10.3 of the UPLR). The Western Weights and Measures Association recommended that a new section be added to the UPLR requiring these new types of packages to declare on their labels the total weight of product that will be delivered. The proposal was:

10.X. Mechanical Pump Dispensers. -- The declaration of quantity on packages that deliver product through a nonremovable mechanical pump shall disclose the net quantity of the commodity that will be expelled when the instructions for use, as shown on the container, are followed.

At the present time, two problems are associated with this type of container: 
(1) The dispensing head will always retain a certain amount of product in it, which cannot be obtained using normal dispensing methods. However, the package label declares the contained net weight, not the delivered net weight.

(2) Compliance testing officials are not sure what method to use to determine the amount of product contained (as opposed to the amount delivered). Unlike aerosol packages, there are no warning statements on the package prohibiting the opening of the package. However, if emptied in the manner simulating use, the net weight will be less than the net weight determined by means which bypass the mechanical pump head.

The Cosmetics, Toiletries, and Fragrance Association (CTFA) met with the Committee and outlined how the mechanical pumps could be tested by regulatory officials to determine the amount of product contained. They also pointed out that studies showed mechanical pumps delivered comparable amounts of product as compared with tubes or other dispensing mechanisms, such as plastic squeeze bottles or hand pumps. (CTFA member firms found that other types of containers retain from 4.2 to $10.1 \%$ of labeled amounts without resorting to such extraordinary measures as cutting the containers apart, disassembling them, or waiting excessive periods of time for them to empty.) Another study showed that when consumers were asked to return tubes and mechanical pumps of toothpaste that they thought were "empty," pumps retained 4 to 5 percent of the labeled contents, while tubes retained 8 to 9 percent. Even though aggressive consumers can cut into a tube (but cannot do that to a pump), this study showed that they did not cut into the tube.

CTFA expressed concern that another declaration indicating the amount delivered in addition to the declaration presently on the packages (the amount contained) would be confusing. The Committee had not intended to require two declarations, but had interpreted the proposal as changing the net contents declaration, rather than adding one. Since such a requirement would be at variance with the traditional interpretation of the required net contents declaration (except for aerosols), the Committee is aware that the proposed section might be a solution that might require changes or additions to FDA regulations. However, it should be pointed out that certain segments of industry already provide a net contents statement that is the delivered amount; for example, many stick deoderant packages are labeled on the back declaring "(so many) ounces plus enough extra to secure the product to the base (of the dispenser)." The Committee will be carrying this item over for further study. See also Item 232-18 for further discussion.

Data collected in California indicated that mechanical pumps delivered from 89.5 to 100 percent of their declared net weights. The CTFA acknowledged that the various pumps now on the market have somewhat different dispensing characteristics. Mr. Ken Appell, Colgate-Palmolive Co., presented information concerning the possible causes of difference between California's and CTFA's data. They included the temperature at the time of measurement, the age of the product, the rate of use (fast, total dispensing vs. normal unit daily dosing), and container size (the size of the reservoir on the mechanical pump head compared with the size of the container, as well as the particular mechanical pump design). Other jurisdictions are urged to test both mechanical pumps and tubes and report their findings to the Committee. Data should include lot code information, temperature of test, and method of emptying the container, as well as container and package information, such as brand, product, and container net contents. It would be useful for the jurisdiction to test two samples of the same product, one to determine the delivered contents and one to determine the contained contents. Please contact the Office of Weights and Measures, Carroll Brickenkamp, 301-975-4005, for information on determining the contained net contents.

\section{1-14 VC 11.23. Camera Film}

(This item was adopted as part of the consent calendar.)

(This carry-over item was Item 231-6 in the Report of the 74th NCWM 1989.)

Background: The Western Weights and Measures Association had recommended that Section 11.23 of the Uniform Packaging and Labeling Regulation be broadened to provide for new products in the film industry beyond "camera film," "movie film," and "bulk still film." The recommendation was to add language to cover audio tapes, video film, and magnetic film. After consultation with members of the American National Standards Institute Image Board, the Committee published the following revision in its report to the 74th NCWM. Due to lack of time for the membership to study the extensive revisions and for the industry to comment, the Committee carried the item over. No comments were received. 
Committee Recommendation: Revise Section 11.23. as follows:

11.23. Camera Film, Video Recording Tape, Audio Recording Tape and Other Image and Audio Recording Media Intended for Retail Sale and Consumer Use.

Image and audio media Camera fitm packaged and labeled for retail sale are exempt from the net quantity statement requirements of this regulation that specify how measurement of commodities should be expressed, provided that:

(a) Unexposed or Unrecorded Media. - The net quantity of contents of unexposed or unrecorded image and audio media on packages of movie fitm and butk-stittfitm is expressed in-terms- of

(1) for still film, tape, or other still image media, in terms of the usable or guaranteed number of available still image exposures. The length and width measurements of the individual exposures expressed in millimeters or inches, are authorized as an optional statement. (Example, " 36 exposures, 36 millimeters x 24 millimeters" or "12 exposures, $2-1 / 4$ inches $\times 2-1 / 4$ inches.")

(2) for bulk or movie film, in terms of length (in meters or feet) of film available for exposure.

(3) for all other image and/or audio media, in terms of length of time of electronic media available for recording, together with recording and/or playing speed or other machine settings as necessary. Supplemental information concerning the length of the media may be provided.

Supplemental information may be provided on other than the principal display panel. number of tinear meters or feet of usable film contained therein.

Note: Size, length of media, and format details to ensure interchangeability and other characteristics of audio and imaging media are available in the applicable American National Standards.

(b) Exposed, Recorded, or Processed Media. . The net quantity of contents of exposed or processed film or prerecorded electronic media shall be on packages of movie fitm is expressed in terms of the length of running time that is of entertainment value. of the exposed film for that portion- of fitm that is of entertainment value.

"Entertainment value" is defined as that portion of a film, tape, or other media, that commences with the first frame of sound or picture, whichever comes first after the countdown sequence (if any), and ends with either. (a) the last frame of credits; or (b) the last frame of the phrase "The End," or (c) the end of sound, whichever is last.

(c) The net-quantity of contents on packages of still fitm is expressed in terms of the number of exposures the contents will provide. The tength and width-measurements of the individuat exposures, expressed in millimeters or inehes, are authorized as an optional-statement. (Example. "36-exposures, 36 millimeters $x 24$ millimeters" or "12 exposures, $2-1 / 4$ inches $x-2-1 / 4$ inches")

The Federal Trade Commission permits film to be labeled in metric declarations only (for example, $35 \mathrm{~mm}$ film). Revise the footnote at the bottom of page IV-12 as follows:

Packages subject to the Federal Fair Packaging and Labeling Act (except for camera film) must be labeled in inchpound units of measure. Metric units may also be declared on the principal display panel and may even appear first.

\subsection{11.28. Commodities' Variable Weights and Sizes}

(This carry-over item was Item 231-7 in the Report of the 74th NCWM 1989.)

Background: Under present U.S. Department of Agriculture (USDA) requirements, only poultry product shipping containers are required to be labeled with the tare weight of consumer packages inside them (if the poultry packages 
do not already have net weights on them). Several weights and measures agencies have reported that the tare weights printed on the shipping containers are often incorrect. The Central Weights and Measures Association and Southern Weights and Measures Association contend that the tare weight marked on the shipping container may not be entirely accurate, but it can be used to screen the packages; if an error is found, an official test using Handbook 133 procedures can be performed. The retailer should be responsible for labeling an accurate net weight according to the associations, but should not be expected to open packages to determine an accurate tare and final net weight. The Committee members had mixed feelings about this proposal; one member reflected that the printed tare weights on shipping containers can no more be relied upon than the net weights. Another member said that the printed information on the shipping container is lost when the container is thrown away. Discussions with Mr. McCutcheon, USDA's representative to the NCWM, revealed that the Conference would have to petition USDA for such a change to existing regulations. The Committee does not want to hamper progress in this area, so it will assist the Liaison Committee in petitioning USDA to require that the tare weight be printed on shipping containers of meat products, similar to the information required for poultry products and, in addition, request that this information be checked for accuracy by USDA.

Committee Recommendation: Assist the Liaison Committee in petitioning the USDA to require the tare weight of consumer packages to be verified and printed on the shipping container.

\section{1-16 VC 11.29. Packaged Commodities Sold by Count}

(This item was adopted as part of the consent calendar.)

Background: The Office of Weights and Measures pointed out that Section 11.29. adopted in 1973 was at variance with FTC and FDA regulations, which do not exempt packages containing 6 or fewer items from including a statement of count when the individual items are fully visible. However, the Committee believes that there is merit in retaining the exemption given in Section 11.29. for adoption and use by State and local weights and measures agencies. Many produce items sold by count are fully visible to the consumer; requiring the packager to label the count appears to the Committee to be unnecessary.

Committee Recommendation: Make no change to this Section, but add a footnote as follows:

When the net contents declaration of a package that may enter interstate commerce includes count, Federal regulations under the Federal Fair Packaging and Labeling Act provide no exemption from declaring the count unless the count is one (1).

\section{2-1 I 1.1. Berries and Small Fruits; Define "Small Fruits"}

Background: One jurisdiction has classified grapes as small fruit even though they are sold attached to the stem in a "bunch." It has been assumed that all jurisdictions are aware that tomatoes are fruit, and that cherry tomatoes may be sold by measure. It has been asked whether very small plums are small fruit. These issues can be addressed depending upon whether the fruit to be sold in the small measure containers of $1 / 2$ dry pint to 1 dry quart can fill the containers without a large amount of empty space left in the container (otherwise the method of sale is inappropriate). (Picture an apple in a pint container with a large amount of unfilled space in the corners.) The Central Weights and Measures Association had proposed that the diameter of the fruit might be used as a criterion for determining whether the fruit may be sold in measure containers of the sizes listed in Section 1.1. However, they were unable to recommend a suitable diameter or method of test. The Committee reviewed the existing NCWM recommendations for the method of sale of fresh fruits and vegetables (see Guideline 2.3.2. of NCWM Publication 3 "Policy, Interpretations, and Guidelines"). This section is reprinted in Appendix B. Only three commodities are recommended for sale by measure as defined in the Measure Container Code of Handbook 44: cherries, currants, and cherry tomatoes. The Committee therefore recommended in its Interim Report that these three become the definition of small fruit. It was thought that other items can be added as needed.

A member of the American Bunch Grape industry pointed out to the Committee that southern grapes, such as muscadines and nobles, are picked from the stem and sold by volume, but that they were not listed as "small fruit" in the Committee's Interim Report. Several comments were also received that if small fruits were defined, berries 
should also be defined (for example, all fruit with the name "berry" as part of their names).

After further deliberations, some members of the Committee expressed the belief that, since the title of Section 1.1. is "Berries and Small Fruits," there are no required methods of sale for large fruit, such as grapes on the bunch, or apples, or plums.

Committee Recommendation: Because of these several unresolved issues, the Committee has elected to make this item informational and to devote time to their resolution next year. The Committee's Interim proposal was to add a definition for the term "small fruits" and make other editorial modifications as follows:

1.1. Berries and Small Fruits. --

1.1.1. Definition of "Small Fruit." -. For the purposes of this regulation, only cherries, currants, or cherry tomatoes are "small fruits."

1.1.2. Methods of Sale. -- Shall be offered and exposed for sale and sold by weight, or by volume if in measure containers that are either open or else covered by uncolored transparent lids or other wrappings that do not obscure the contents and have capacities per subsection 1.1.2.(a) or subsection 1.1.2.(b). When selling berries and small fruits by volume in measure containers, whether or not covered, the measure containers themselves shall not be packages for labeling purposes.

(a) Inch-Pound Capacities - 1/2 dry pint, 1 dry pint, or 1 dry quart.

(b) Metric Capacities - 250 milliliters, 500 milliliters, or 1 liter.

1.1.3. Marking Requirements for Shipping Containers. -- If two or more measure containers are placed in a shipping package, the crate or package shall show the number of measure containers and the quantity of contents of each.

232-2A

\section{1.5.1. In Combination with Other Foods}

(This carry-over item was Item 232-3 in the Report of the 74th NCWM 1989.)

Background: Many food products are formulated and packaged by the retail store and labeled with names that may or may not have standards of identity or standards of composition in Federal regulation or policy (for example, "chicken cordon bleu"). Weights and measures officials need to know which names have standards of identity that must be followed in formulating the product and, therefore, in providing the ingredient statement.

Committee Recommendation: Reproduce the USDA Meat and Poultry Products Guide to Content and Labeling Requirements (Home and Garden Bulletin No. 236) in NCWM Publication 3 "Policy, Interpretations, and Guidelines" so that weights and measures officials will be better informed concerning packaged and unpackaged food identity statements. See Appendix C.

1.5.2.3. Fresh Oysters, Clams, Mussels, or Other Mollusks Removed from the Shell

The State of Maine alerted the Committee at the Interim Meeting that this subsection required fresh mollusks, including scallops, that are removed from the shell "and placed in a container [to] be sold by fluid volume." This subsection needs to be clarified: it was never the intent of the Committee to forbid direct sale from bulk of these items by drained weight. "Placed in a container" means prepackaged. Nevertheless, the Committee does not believe that the industry and weights and measures officials have been given enough time to respond to the Committee's position and to provide input for this item. The Committee intends to clarify this subsection next year. Weights and measures officials may want to survey the method of sale from bulk of fresh scallops, oysters, clams, and mussels removed from the shell and inform the Committee what legitimate practices are being followed. The following modification is being considered: 
1.5.2.3. Fresh oysters, clams, mussels, or other mollusks removed from the shell and ptacentaner sold prepackaged shall be sold by fluid volume. A maximum of 15 percent free liquid by weight is permitted. When sold from bulk, such items may be sold by drained weight.

\section{1.5.X. Meat, Poultry, Fish, and Seafood -- Packaged with Other Packages of Food}

(This carry-over item was Item $232-5$ in the Report of the 74th NCWM 1989.)

Background: On behalf of the NCWM, the Liaison Committee petitioned USDA to require separate labeling of the net weight of meat and poultry products packaged with packages of other commodities. This petition was included by USDA along with other comments on its net weight regulations that are currently being revised. It was expected that USDA would issue its final rules before the Annual Meeting. If the USDA answered affirmatively, then the NCWM would immediately recommend modifications to State requirements for meat, poultry, fish, and seafood. If USDA declined the petition, the Conference voting membership could have been polled in order to determine what priority weights and measures officials put on this issue and could, if warranted, petition the USDA again with new information.

Committee Recommendation: Since USDA has not yet issued its final rule, the Committee is making this an information item. Its plan is to adopt the following new section only if USDA accepts the NCWM petition:

1.5.X. Packaged with Packages of Other Foods. -- When meat, poultry, fish, or seafood is packaged with other packages of food, (for example, pork with a separate packet of barbecue sauce, or turkey with a separate package of gravy), the net weight of the meat, poultry, fish, or seafood portion in the combination package must be declared separately. If the total selling price is computed from the net weight of the meat, poultry, fish, or seafood portion only, then only the net weight of meat, poultry, fish or seafood portion must be declared. In such instance, a separate declaration of the net contents of the other packages included with the meat, poultry, fish, or seafood is permitted, but not required.

\section{1.7.1. Factory Packaged and Hand-Packed Ice Cream and Similar Frozen} Products.

(This item was adopted.)

Background: The Central Weights and Measures Association asked the National Conference to alert jurisdictions to a practice of selling soft-serve frozen desserts by weight. The Association contended that many jurisdictions are not aware that Section 1.7.1. requires that such items as hand-packed ice cream or self-serve frozen yogurt be sold by volume.

Prior to the Interim Meeting, but after the deadline for submission of agenda items, the Committee received a proposal from industry that the following definition of the term "hand-packed" be adoped by the Conference:

"Hand-Packed," as used in this section, refers to the filling of a container for the consumer by a third party. It does not include the sale of self-serve frozen products when the amount to be purchased is determined by the consumer and dispensed by the consumer.

This proposal would permit self-serve frozen products to be sold by any method, that is, by weight, volume, or by "each."

The proposal was based on two arguments:

(1) Consumers are best served if States permit self-serve frozen yogurt to be sold by weight because many consumers are unable to fill a volumetric measure container without air pockets. They may want peaks and swirls not measurable by means of a measure container, and they may want to buy random amounts, not necessarily the discrete sizes dictated by commonly available measure containers. 
(2) States do not uniformly require that self-serve frozen yogurt be sold by volume; therefore, the term "handpacked" must be defined to exclude self-serve from sale by volume.

The Committee assumed that the Central Weights and Measures Association had asked that this item be placed on the agenda because it wanted more uniform enforcement of the existing regulation; the association had not asked that the subsection be revised. However, at the Interim Meeting, two of the four Central Association members present at the Committee meeting stated that they had not adopted Section 1.7.1.

For many years, many weights and measures officials have wanted to change the method of sale of ice cream and similar products to weight rather than volume. Arguments against this change have centered on a trade custom of selling by volume. The Conference has maintained the requirements in Section 1.7.1. so that consumers can make quantity comparisons. Arguments in favor of retaining this position are that consumers do not know how many servings of frozen yogurt there are in a pound, nor can they compare a self-served portion sold by weight with a package of frozen yogurt labeled by volume. Many retailers now sell some types of soft-frozen desserts by weight, negating the argument that the only trade custom is to sell by volume.

In further investigation of this issue, the Committee found that a State of Maryland law requires that self-serve frozen yogurt be sold only by weight. They also found that some jurisdictions, even though they had adopted the Uniform Regulation for the Method of Sale of Commodities, permitted methods of sale other than volume. Jurisdictions may, for example, interpret sales of this commodity as falling under Section 1.12. Ready-to-Eat Food. Subsection (a) permits "items sold for consumption on the premises" to be sold by weight, measure, or count. This paragraph permits retail operations furnishing spoons, napkins, etc., to sell by measure container, weight, or even by "small," "medium," or "large." This section does not, however, cover sales of large portions of commodity that are obviously not intended to be consumed on the premises. Thus, there is already a lack of uniformity in methods of sale of this commodity.

If it is true that consumers have difficulty delivering accurate volume, it is similarly true when retailers hand-pack frozen desserts and ice cream. Item 240-6 discusses testing procedures proposed by the International Association of Ice Cream Manufacturers due to the difficulty their members have in delivering full volume by hand packing.

Although the Conference has been unable to require a complete switch from volume to weight, the Committee believes that it is worth permitting the sale of all hand-packed, whether self-serve or not, ice cream and similar frozen desserts by either weight or volume. The Committee stresses that retailers of these products must use Class III scales if they choose to sell by weight. If there appears to be any consumer confusion or complaints because of the mixture of methods of sale, the Committee will investigate the need for a single method of sale; at the present time, several methods of sale are tolerated across the country.

In its Interim Report, the Committee had proposed permitting hand-packed ice cream to be sold by weight or volume:

\subsubsection{Factory Packaged and Ifand-Packed Ice Cream and Similar Frozen Products. --}

(a) Factory packaged ice cream, ice milk, frozen yogurt, and similar products shall be kept, offered, or exposed for sale, or sold in terms of fluid volume.

\section{(b) Hand-packed ice cream, ice milk, frozen yogurt, and similar products shall be sold by weight or by fluid volume. See also Section 1.12.(a) Ready-to-Eat Food for other provisions if the product is sold for consumption on the premises.}

Based on correspondence since the Interim Meeting, it was determined that this proposal did not adequately deal with the long-standing practice of selling by the scoop or small/medium/large for ready-to-eat sales from bulk. Section 1.12. of the Uniform Method of Sale of Commodities Regulation permits ready-to-eat food to be sold by count (or by the number of scoops in this instance) only when sold for consumption on the premises.

The Committee was asked whether a grocer who packages frozen yogurt at the end of the day from his/her selfserve machines is packaging "factory packaged" frozen yogurt. "Factory packaged" ice cream does not mean grocery packed items. but refers to those standard-pack ice cream and similar commodities put up in measure container, usually in dairies. No consensus among the Committee members could be reached on the definition for "factory packed," but the term has been in the Uniform Regulation since the section was written and had not been questioned until the issue of self-serve and sale from bulk was raised. If the Regionals feel the need to propose a definition for "factory packaged," they are invited to submit their proposals as new work for the NCWM. 
Committee Recommendation: The revision recommended below will have the effect of permitting all sales from bulk, whether or not self-serve, and all packaged products not "factory packaged" to be sold by weight, measure, or count (for example, by the scoop, small/medium/large, etc.):

1.7.1. Factory packaged and-Hand-Packed Ice Cream and Similar Frozen Products. ${ }^{1}$-- Ice cream, ice milk, frozen yogurt, and similar products shall be kept, offered, or exposed for sale, or sold in terms of fluid volume.

\section{2-5}

\section{1.9. Advertising and Price Computing of Bulk Food Commodities}

(This item was Item 232-10 in the Report of the 74th NCWM 1989 and was withdrawn by the Committee as a voting item last year.)

Background: Subsection 1.9.2. Price Advertising now requires that the price of bulk food commodities be advertised or displayed in terms of whole units of pounds or kilograms. The subsection has been interpreted as applying only if prices are advertised, not requiring the display of price at the point of sale. In addition, the subsection does not address display of identity when the product and the price display are not close together. Utah weights and measures officials pointed out that many stores post no prices at all for bulk food commodities, or post the prices in such a way that they are unreadable (too small print, too far from the consumer, or hidden by equipment). There is often no clear information about which product is being offered at what price. Since these stores are not self-serve, the customer must ask for the product and can ask the price. The problem is that the customer has no idea about the price per pound of many items sold from bulk, for example, in a candy store or a boutique cookie store. It is argued that the absence of posted pricing is in itself deceptive; for example, purchasers may select one or two cookies costing $\$ 1.00$ without realizing that they are priced at $\$ 6.95$ per pound. Purchases are often on impulse; the consumer cannot make a value comparison without knowing the price per pound. When many customers are in line, a person may wait a long time before being able to ask the price of a product and to decide whether to make the purchase. Customers may be embarrassed to refuse the product when it costs more than expected. If the price is clearly posted, they can readily decide whether or not to buy. Utah weights and measures recommended requiring that the unit price be posted. The wording recommended last year (see Item 232-10) was considered a problem because it also required that the identity of the commodity be displayed; however, the extent of identification was not clearly defined. It was also determined that a price should be posted even if the commodity is sold by a method other than weight. The recommendation below was believed to take care of all these concerns:

1.9.1. Price Posting. -- The price of bulk food commodities or food commodities not in package form, whether sold by weight, measure, or count, shall be prominently displayed. When the price is not displayed adjacent to or on each commodity or each tray or bin of such commodity, a fully descriptive identity must also be provided along with the price.

Several issues were raised as a result of the Committee's Interim Report on this item. Some weights and measures jurisdictions were of the opinion that Section 1.9. already requires unit price posting. Other jurisdictions believed that the recommendation would go too far in that certain types of businesses selling from bulk, such as pubs selling draft beer, would be required under the proposed revision to post their prices for beer (selling by "each" or by count). California officials contend that the proposed revision would still not take care of the problems confronting consumers if cookies, for example, were sold by weight and a unit price per pound were posted. The consumer would still be unable to determine the price of a cookie without asking to have a cookie weighed. Some officials expressed the opinion that it is not necessary to post the unit price for food commodities sold by count.

Committee Recommendation: The Committee recommends carrying this item over.

(This carry-over item was Item 232-11 in the Report of the 74th NCWM 1989.)

No input was provided by any regional association or other party, the Committee is therefore withdrawing this item. It is recommended that any regional weights and measures association wishing to pursue this item develop a specific 
proposal for the Committee's consideration.

Background: As part of the Laws and Regulations 1989 Committee Report (Item 231-3), the Conference adopted a change to the Uniform Packaging and Labeling Regulation that permits random labels to be used for fresh fruits or vegetables labeled by count. It was noted in the report that the Conference adopted guidelines for appropriate methods of sale for fresh fruits and vegetables in 1979. (See NCWM Publication 3, "Policy, Interpretations, and Guidelines" 2.3.2. Fresh Fruits and Vegetables and Appendix B.)

The Office of Weights and Measures recommended that this guideline be added to the UMSCR as a new section. The Committee did not believe that this guideline should be proposed as a regulation this year because several "quantities" in the list need to be defined, including "head" and "bunch;" some dry measure quantities should be reviewed; and many common items are not in the list. However, the Committee agrees that this guideline should be more widely distributed and used. See Appendix B for a first draft of an update to this guideline.

Committee Recommendation: Reprint the recommended guidelines on the method of sale for fresh fruits and vegetables with some additions and modifications as proposed by the Committee and ask for recommendations for additions or changes to this list for further updating. No recommendation for change this year.

\section{$232-8$}

\section{W 1.X. Method of Sale for Salads}

The Central Weights and Measures Association informed the NCWM that salad items are offered for sale by weight and by volume. They contend that there should be a uniform method of sale for these types of items, enforced not only at the grocery store, but also at the fast food restaurant. Items to be considered include: potato salad, cucumber salad, lettuce salad, and macaroni salad. No specific recommendation was made, nor were any supporting data submitted. The Committee is therefore withdrawing this item from its report and returning it to the Regional Associations for further development and specific recommendations.

\section{W 1.X. Method of Sale for Bakery Items}

The Central and Northeastern Weights and Measures Associations alerted the Committee to a long-standing trade practice of selling unpackaged bakery items by count. Supermarkets often incorporate an in-store bakery that may sell unpackaged bakery items, most often by count. Such supermarket items compete directly with packaged products that must be labeled and sold by weight. The purchaser cannot make a price and quantity comparison between similar products. The Regional Associations note that the trade practice of selling bakery goods by count should either be acknowledged or eliminated in the UMSCR. Since no specific proposal was provided, nor were there specific recommendations as to which type of bakery products should be sold by what method, the Committee is withdrawing this item from its report and sending the item back to the Regional Associations for further development. It should be noted by the Regionals that FDA specifically permits hot dog rolls and buns made with unenriched flour to be sold by count; however, that agency already recommends that donuts and rolls and buns made with enriched flour be sold by weight. In addition, the Regionals should study how any recommendation will impact Section 1.2. BREAD of the UMSCR.

\section{2-10 \\ I Method of Sale Requirements in the U.S. and in Canada}

At the Interim Meeting, the Committee explored the differences between Canadian and U.S. method of sale requirements in anticipation of future efforts to make requirements for both nations more compatible. In the interests of free trade, the Committee will study ways that the U.S. and Canada can ease the burden for packagers to comply with each nation's requirements. A bilateral group, called the Free Trade Committee for Food, has representatives from both countries; FDA is represented on that group. No comments were received from industry prior to or at the Interim Meeting on specific problems that have resulted from conflicting U.S. and Canadian requirements.

Mr. Gilles Vinet, Canadian Weights and Measures, provided insight into several aspects of labeling for both countries. One problem that many U.S. packagers must avoid is declaring gallons without also declaring that they are U.S. 
gallons; an Imperial gallon is larger and will be assumed in Canada unless the declaration is clearly "U.S. gallons." Consumer packaged products are required to be labeled in metric units in Canada. Other packages are required to be labeled in metric or Canadian units of measurement. It is illegal to sell product on the basis of U.S. units only. Mr. Vinet provided a table (see below) showing examples of dual U.S. and metric quantity declaration that are not exact equivalents.

\section{Examples of Declarations (U.S. - Metric)}

In general, these dual declarations are accepted in Canada as long as both quantity declarations are met. Specific products may also have size restrictions, for example, skin lotion cannot be packaged in a $125 \mathrm{ml}$ size. Example 1: Cookies
Fact
Label
$2 \mathrm{lb}=907.2 \mathrm{~g}$
$2 \mathrm{lb} 900 \mathrm{~g}$
$-0.79 \%$
$1 \mathrm{lb}=453.6 \mathrm{~g}$
$1 \mathrm{lb} 450 \mathrm{~g}$
$-0.79 \%$
$8 \mathrm{oz}=226.8 \mathrm{~g}$
8 oz $225 \mathrm{~g}$
$-0.79 \%$

$\%$ Overpack

Other Examples

5 U.S. $\mathrm{fl} \mathrm{oz}=147.86 \mathrm{ml}$

5 U.S. fl oz $125 \mathrm{ml}$

$-15.46 \%$

5 U.S. fl oz $150 \mathrm{ml}$

$+1.45 \%$

4 U.S. $\mathrm{fl} \mathrm{oz}=118.29 \mathrm{ml}$

4 U.S. $\mathrm{fl} \mathrm{oz} 100 \mathrm{ml}$

$-15.46 \%$

4 U.S. fl oz $125 \mathrm{ml}$

$+5.67 \%$

3 U.S. $\mathrm{fl} \mathrm{oz}=88.72 \mathrm{ml}$

3 U.S. $\mathrm{fl} \mathrm{oz} 75 \mathrm{ml}$

$-15.46 \%$

3 U.S. fl oz $100 \mathrm{ml}$

$+11.28 \%$

8 U.S. $\mathrm{fl} \mathrm{oz}=236.58 \mathrm{ml}$

$$
\begin{aligned}
& 8 \text { U.S. } \mathrm{fl} \mathrm{oz} 200 \mathrm{ml} \\
& \text { or } \\
& 8 \text { U.S. } \mathrm{fl} \mathrm{oz} 225 \mathrm{ml} \\
& 8 \text { U.S. } \mathrm{fl} \mathrm{oz} \quad 250 \mathrm{ml}
\end{aligned}
$$

$-15.46 \%$

$-4.89 \%$

$+5.67 \%$

\% Overpack:

$(-)$ if U.S. quantity is exact, metric declaration is less than real content by listed $\%$.

$(+)$ in regard to U.S. quantity declaration, packages must be overpacked by listed $\%$ to equal metric declaration.

Examples of differing methods of sale are (1) powdered laundry detergents that are permitted only in certain weights and box sizes (volumes) in Canada; (2) toothpaste that must be labeled by volume in Canada, but by weight in the U.S.

One problem that arose this past year concerned the sale of cookies. A U.S. manufacturer who wanted to market cookies in both the United States and Canada labeled his cookies with a net weight declaration of $2 \mathrm{lb}(900 \mathrm{~g})$. This declaration was acceptable in Canada, which requires metric declarations in the range of 600 to 1000 grams to be rounded to the nearest $100 \mathrm{~g}$; however, a U.S. weights and measures jurisdiction objected to the metric declaration because it believed the $900 \mathrm{~g}$ was not a close enough equivalent to $2 \mathrm{lb}$ (using the conversion factor given in Handbook 44 , the gram equivalent of $2 \mathrm{lb}$ given to one decimal place is 907.2 grams.) 
There have been many consumer complaints to the Federal Trade Commission, FDA, and State Weights and Measures officials concerning the lack of fixed or required sizes for vacuum-packed coffee. No recommendation has been made by consumers or regulatory officials that coffee be standardized in one-pound increments, nor does the Committee believe that a method of sale is needed for vacuum-packed coffee.

The National Coffee Association has offered the following explanation concerning net weight declarations on vacuumpacked coffee containers. The Association states that a new "fast roast" process at higher speeds and temperatures is much more effective than the traditional roasting process. The increase in roasting speed and higher temperatures result in a larger bean size with a more expanded intracellular structure. When the customary 401 x 508 can size is filled with this coffee, the resulting net weight is $13 \mathrm{oz}$ rather than $16 \mathrm{oz}$, the net weight of coffee roasted in the traditional manner. According to industry representatives, 13 ounces of fast-roast product, when measured out by volume (fox example, using a scoop), yields the same quantity and quality of brewed coffee as does 16 ounces of the traditional roast. The same size can, labeled by net weight, is used for both 13-oz and 16-oz quantities due to the existing packing equipment. However, a new 11-oz size with a smaller diameter has now been introduced.

One of the consumer letters forwarded to the Committee complained about the supplemental statement appearing on certain cans that claims that the product "made the same amount of coffee as the old 1-pound size." The consumer apparently misunderstood this statement because she went on to say: "When I went to school, it took $16 \mathrm{oz}$, not 13 oz, to make a pound." Enforcement officials should note problems with supplemental statements on these packages and direct their and consumer complaints to the Food and Drug Administration (Division of Regulatory Compliance, HFF 310, FDA, 200 C St SW, Washington DC 20035).

\section{2-12 VC 2.10.3.(a) and (b) Quantity (of Softwood Lumber)}

(This item was adopted as part of the consent calendar.)

Background: Section 2.10.3. now requires that all receipts or invoices for sales of softwood lumber by nominal dimensions be accompanied by declaration of the actual dimensions. The Committee believes that this information is no longer necessary with all invoices and other sales documents because it is fairly well known that nominal $2 \times 4$ lumber is not 2 inches by 4 inches. It also appears that this requirement is not being enforced. The Committee recommends that the invoicing requirement be replaced with a posting requirement: that the minimum actual dimensions be posted so that purchasers can determine what the nominal dimensions mean depending upon purchase of seasoned or unseasoned lumber.

In addition, the Committee would like to alert weights and measures enforcement officials that the minimum dressed dimensions given in Table 1 of the Uniform Regulation for the Method of Sale of Commodities may not actually be offered for sale: many officials have found lumber of smaller dimensions than the minimums. Enforcement action should be taken in these instances.

Committee Recommendation: (1) Delete the requirement that any sales receipt or invoice stating nominal dimensions must also have printed on it the actual sizes (as delineated in parts (a) and (b)), and (2) make it mandatory to post Table 1. Softwood Lumber Sizes. The revision is as follows:

\subsection{Quantity - representations shall be in terms of}

(a) the number of pieces, the-minimum-dressed width-and thiekness;

(b) the length of individual pieces, or the lineal footage, exeept-that:

(c) the minimum dressed width and thickness, except that

$(a)$

the use of nominal dimensions shall be allowed when used in-enjunetion-with the required-minimum-dressed sizes-and actual tength; as long as a table of minimum dressed sizes is displayed prominently and the term "nominal" or "nom" is also used in conjunction with any representation of dimensions. 
(b) with-respect-to-alt-invoices, a-table- of minimum-dressed-sizes-may-appear-on-the-reverse-side-of-the invoice, so tong as appropriate-reference-to the-table-is prominently and conspictroushy-shown-on-the-face of the invoice.

\section{$232-13$}

\section{VC 2.14. Insulation}

(This item was adopted as part of the consent calendar.)

Background: This section should be amended to track the most recent version of Federal requirements for insulation: FTC regulations in 16 CFR Part 460 "Labeling and Advertising of Home Insulation." The Committee also recommends that references to the minimum net weight that were in Section 2.14. and that are also part of the Federal requirements be deleted. The Committee believes that this requirement is confusing to the weights and measures inspector and that the average requirement should be retained as the standard for all packaged goods.

Committee Recommendation: Revise this section as follows:

2.14.1. Packaged Loose-Fill Insulation Except Cellulose. - The label shall declare: (1) Packaged-toose-fiH insulation, exeept-eltutose, shatt-declare the type of insulation and the net weight with no qualifying statement; each-package must contain-at - feast the stated weight. In-addition, the following information-shat be-supplied-on the package: and (2) the minimum thickness, maximum net coverage area, number-of bags per-1000-syuare-feet, and minimum weight per square foot at $R$-values of 11, 19, and 22 . This information shall also be supplied for any additional $\mathbf{R}$-values listed.

\subsection{Packaged Loose-Fill Cellulose Insulation. - The label shall declare: (1) The prineipat-disptay-panet of} packaged-toose-fitt-eeltutose-insulation-shatt-dectare the type of insulation and the net weight with no qualifying statement; each-package-must-contain-at-least-the-stated-weight. In-addition, the-fothowing information-shaH be supplied on the-package: and (2) the minimum thickness, maximum net coverage area, number of bags per 1001000 square feet, and minimum weight per square foot at R-values of $13,19,24,32$, and 40. This information shall also be supplied for any additional R-values listed.

\section{VC 2.16. Liquefied Petroleum Gas Cylinder Tare Weights; Compressed or Liquefied Gases in Cylinders}

(This item was adopted as part of the consent calendar.)

(This carry-over item was Item 232-12A in the Report of the 74th NCWM 1989.)

Background: See the Report of the 72nd NCWM 1987 (page 134), Report of the 73rd NCWM 1988 (page 160), and Report of the 74th NCWM 1989 (page 107). The Committee developed substantial revisions to Section 2.16 in 1987. The Committee delayed recommending changes until a complete test procedure was available for incorporation into Handbook 133 to permit safe testing of cylinders. A test procedure was developed by the Committee in 1988 (see the 73rd NCWM Report) and reviewed by the Compressed Gas Association (CGA), which proposed additional precautions and procedures to protect the less experienced testing official. The committee wishes to thank CGA for its help in this important matter. This is an area in which many weights and measures officials are not well informed and it appears to be poorly monitored. The Committee urges weights and measures officials to visit cylinder refilling operations in their jurisdictions during the coming year to become familiar with the practices for the measurement and sale of these commodities. Officials should note the amounts charged for these important and widely used systems.

The proposed requirement permits the use of either the stamped or stenciled tare weight or the actual tare weight in net contents determinations. The proposed text clarifies the two permitted methods of fill: (a) to use the stamped tare weight (at which time tighter tolerances than those recommended for safety purposes would have to be maintained), or (b) to determine the actual tare weight whenever a cylinder is filled (additional markings on the cylinder or attached to the cylinder are then required). Stamped tare weights are required for safety purposes under U.S. Department of Transportation regulations. These Federal regulations permit a 1 percent tolerance between the actual tare weight and the stamped tare weight. This tolerance, although acceptable for safety purposes (for example, 
to avoid overfilling a cylinder and for determining if the cylinder is empty prior to refilling), is not precise enough for use in determining the net contents to arrive at a final charge for the cylinder of compressed gas. For example, a $200-$ pound tare weight cylinder of acetylene contains about $20 \mathrm{lb}$ of acetylene and costs about $\$ 75-100$. If the stamped tare were permitted to be used and if it were permitted to differ from the actual tare by 1 percent $(2 \mathrm{lb}$ on the $200 \mathrm{lb}$ cylinder), this would amount to a potential error of $2 \mathrm{lb}$ in $20 \mathrm{lb}$, (i.e., 10 percent of acetylene product) or $\$ 7.50$ to $\$ 10.00$ in product cost. The potential error in smaller cylinders is even more significant. California Weights and Measures recommended reducing the current allowable difference (1 percent) between the actual tare weight and the stamped tare weight of cylinders (Section 2.16.) to $1 / 4$ percent and to apply this to all cylinders of compressed gases. The Committee broadened the California recommendation of $1 / 4$ percent for this proposal to $1 / 2$ percent for small tanks of under $20 \mathrm{lb}$ tare weight.

Committee Recommendation: Replace Section 2.16. with the text below and incorporate Appendix D into NIST Handbook 133:

\subsection{Compressed or Liquefied Gases in Refillable Cylinders}

2.16.1. Application. - This Section does not apply to disposable cylinders of compressed or liquefied gases.

2.16.2. Net Contents. - The net contents shall be expressed in terms of cubic feet or cubic meters; pounds and ounces; or kilograms. See Section 2.21. for permitted net contents for liqueñed petroleum gas. A standard cubic foot of gas is defined as a cubic foot at a temperature of $70^{\circ} \mathrm{F}$ and a pressure of $14.696 \mathrm{psia}$ (or metric equivalent) except for liquefied petroleum gas as stated in Section $\mathbf{2 . 2 1}$.

2.16.3. Cylinder Labeling. - Whenever cylinders are used for the sale of compressed or liquefied gases by weight, or are filled by weight and converted to volume, the following shall apply:

2.16.3.1. Tare Weights. --

(a) Stamped or Stenciled Tare Weight. - For safety purposes, the tare weight shall be legibly and permanently stamped or stenciled on the cylinder. All tare weight values shall be preceded by the letters "TW" or the words "tare weight." The tare weight shall include the weight of the cylinder (including paint), valve, and other permanent attachments. The weight of a protective cap shall not be included in tare or gross weights. The Code of Federal Regulations Title 49, Section 178.50-22 requires the maker of cylinders to retain test reports verifying the cylinder tare weight accuracy to a tolerance of 1 percent.

(b) Tare Weight for Purposes of Determining the Net Contents. - The tare weight used in the determination of the final net contents may be either:

(1) the stamped or stenciled tare weight or

(2) the actual tare determined at the time of filling the cylinder. If the actual tare is determined at the time of filling the cylinder, it must be legibly marked on the cylinder or on a tag attached to the cylinder at the time of filling.

(c) Allowable Difference. - If the stamped or stenciled tare is used to determine the net contents of the cylinder, the allowable difference between the actual tare weight and the stamped (or stenciled) tare weight, or the tare weight on a tag attached to the cylinder, for a new or used cylinder shall be:

(1) $1 / 2$ percent for tare weights of $20 \mathrm{lb}$ or less or

(2) $1 / 4$ percent for tare weights of more than $20 \mathrm{lb}$.

(c) Average Requirement.- When used to determine the net contents of cylinders, the stamped or stenciled tare weights of cylinders at a single place of business found to be in error predominantly in a direction favorable to the seller and near the allowable difference limit shall be considered to be not in conformance with these requirements.

2.16.3.2. Acetylene Gas Cylinder Tare Weights. - Acetone in the cylinder shall be included as part of the tare weight.

2.163.3. Acetylene Gas Cylinder Volumes. - The volumes of acetylene shall be determined from the product weight using approved tables such as those published in NIST Handbook 133 or those developed using $70^{\circ} \mathrm{F}$ and $14.7 \mathrm{cu}$ ft per pound at one atmosphere as conversion factors.

2.163.4. Compressed Gases such as Oxygen, Argon, Nitrogen, Helium, and Hydrogen. - The volumes of compressed gases such as oxygen, argon, nitrogen, helium, or hydrogen shall be determined using the 
tables and procedures given in NIST Technical Note 1079, Tables of Industrial Gas Container Contents and Density for Oxygen, Argon, Nitrogen, Helium, and Hydrogen and supplemented by additional procedures and tables in NIST Handbook 133.

\section{2-15 \\ 2.16. Liquefied Petroleum Gas Cylinder Tare Weights; Acetylene}

(This carry-over item was Item 232-12C in the Report of the 74th NCWM 1989.)

The Committee received no input on this item from regional weights and measures associations. Kansas City, Kansas, Weights and Measures and Maryland Weights and Measures responded to the questions asked in the Committee's report to the 74th NCWM. A survey will be conducted to get answers to the questions posed in the Committee's final report before any recommendations are made.

\section{2-16 I 2.20. Gasoline-Alcohol Blends; Add Labeling of All Oxygenates}

Background: Eighteen spokespersons provided testimony on a proposal to broaden the labeling requirement for gasoline-alcohol blends to all gasoline containing any oxygenate above 1 percent by volume. An "oxygenate" is any oxygen-containing chemical compound, including alcohols (such as ethanol or methanol) and ethers (such as methylt-butyl ether (MTBE), another common additive to gasoline). The proposal was as follows:

2.20.1. Method of Retail Sale. -- All motor fuel kept, offered, or exposed for sale, or sold, at retail containing at least 1 percent by volume of oxygenates ethanol, methanol, or a combination shall be labeled by the maximum percentage of the oxygenate, by common name of the oxygenate (ethanol, methanol, MTBE, etc), and shall be identified as "with" or "containing" (or similar wording) "ethanot" "methanot" or "ethanol/methanol" on the upper 50 percent of the dispenser front panet in a position clear and conspicuous to the driver from the-driver's position, in a type at least $1 / 2$ inch in height, $1 / 16$ inch stroke (width of type).

2.20.2. Documentation for Dispenser Labeling Purposes. -- The retailer must be provided, at the time of delivery of the fuel, on an invoice, bill of lading, shipping paper, or other documentation, the presence and maximum amount of any oxygenate ethanol, methanol, or any combination of oxygenate of ethrnol/methanol/fin terms of percent by volume) contained in the fuel. This documentation is only for dispenser labeling purposes; it is the responsibility of any potential blender to determine the total oxygen content of the motor fuel before blending.

The reasons for this proposal provided by the Central Weights \& Measures Association and the National Association of State Directors of Agriculture were:

1. Greater use of ethanol fuel has major national benefits for the environment, U.S. agriculture, and national security.

a. The President has announced a comprehensive program supporting the use of ethanol and other oxygenated fuels to help meet air quality standards.

b. To facilitate attainment of these standards, current retail motor-fuel dispenser labeling requirements for ethanol need to be reviewed.

2. Requiring only ethanol/methanol blended fuels, instead of all oxygenated fuels, to be labeled is discriminatory.

a. Because alcohol is the only ingredient other than lead required to be labeled on retail motor-fuel dispensers, such labeling is viewed by many consumers as a warning statement against the use of ethanol-blended fuels.

b. With the increasing use of oxygenated fuels, some automobile manufacturers in their owner's manuals specifically limit the maximum amount of such other oxygenates as MTBE.

3. As long as there is a need for alcohol labeling, the requirements for alcohol labeling should be expanded to include other oxygenated fuel components. 
The American Petroleum Institute and some of its members were opposed to the proposal. Their arguments included:

1. MTBE has been added in small amounts at the refineries for many years to boost the octane without raising the concern of automobile manufacturers. These amounts often range from 2 to 7 percent by volume.

2. Oil companies do not know whether the gasoline that they receive through common-carrier pipelines has MTBE in it, nor how much. The MTBE has traditionally been added to gasoline to meet minimum specifications in octane; MTBE is expensive so that only the minimum amounts to raise the base gasoline to the prescribed octane are added.

3. If small volume amounts of MTBE in gasoline must be labeled, all gasoline suppliers will have to begin extensive testing.

The issue arises now because:

1. large amounts of an oxygenate (either ethanol or MTBE) must be added to gasoline in some Southwestera U.S. localities in the winter months in order to reduce pollution from emissions of carbon monoxide; and

2. gasoline refiners are producing gasoline blends with very high MTBE concentrations (e.g., 15 percent blends).

Automobile manufacturers recommend that owners purchase gas with no more than 10 percent ethanol ("gasohol") and to watch for drivability problems when using any gasoline-alcohol mixture. Older cars may not operate properly with gasoline-alcohol blends. (Due to tax incentives, mixtures of 10 percent are the universal norm for gasolineethanol). Some boat, airplane, and small engine manufacturers warn against the use of any gasoline-alcohol blend. Automobile owners manuals now recommend limits concerning high concentrations of MTBE (11 or 15 percent), but do not caution about gasoline-MTBE blends of lower levels.

The Motor Vehicle Manufacturers Association and the Automobile Importers of America recommend labeling of the presence of oxygenates when the gasoline contains more than $51 / 2$ percent by volume of ethanol or more than 11 percent by volume of MTBE. (These amounts are equivalent in terms of the amount by weight of oxygen in the blends.) The Committee does not know if manufacturers of small engines or airplane engines are also concerned about high levels of MTBE in gasoline to be used in their engines.

Some agricultural interests expressed a desire that no lableing of gasohol be required. There was also some interest in broadening the labeling requirements, but retaining the requirement that labeling appear on the dispenser front panel. Finally, there were alternative proposals that (1) labeling be required if alcohol content is greater than 1 percent by volume or if oxygenate content is 2 percent by weight or greater of oxygen (equivalent to 11 percent MTBE); or (2) labeling be required if alcohol content is greater than 1 percent by volume or if oxygenate content is above 2.7 percent by weight (equivalent to 15 percent MTBE).

Part of the proposal was to allow the alcohol label to be placed on the side of the dispenser. Several persons at the Interim Meeting commented that the label should remain on the front of the dispenser; one person suggested that the label be required where it can best be seen, on the front or on the side, depending upon the location of the dispenser nozzle.

Additional complications are:

1. MTBE in any concentration cannot be detected with a field screening test method as ethanol or methanol can be.

2. In 1988, 19 percent of all gasoline contained concentrations of MTBE at or above 1 percent. Ninety-five percent of MTBE blended gasoline contains less than 11 percent MTBE by volume.

3. The U.S. Congress is expected to revise the Clean Air Act, which may affect the use of oxygenated fuels in unforeseen ways. Bills in both the Senate and House of Representatives contain proposals to require certain types of motor fuel for environmental purposes that would affect the usefulness of any labeling proposal before the National Conference.

Committee Recommendation: No action at this time. The item will be open for discussion at the Annual Meeting. Comments are welcome. 


\section{2.22. Liquid Oxygen Used for Respiration}

Background: At the 74th Annual Meeting a new section was adopted concerning the sale of liquid oxygen for respiration. It currently requires in part:

(a) If sold by weight, liquid oxygen must be weighed on an appropriate, sealed commercial scale. A pressure or other type of gauge may not be used to determine weight.

There is no similar requirement for metering liquid oxygen. Since liquid oxygen must be weighed on an appropriate, sealed commercial scale, it was proposed that appropriate measuring methods be required when selling by other measure. The Committee did not have time to address this proposal in any depth. It is possible that the new Health Care Finance Administration (HCFA) rules for reimbursement of medical oxygen providers have nearly eliminated the sale of respiration oxygen by weight or by volume. The HCFA rules provide for reimbursement based on a flow rate schedule, rather than on a final quantitative amount. In addition, one medical oxygen provider said that hospitals and other large customers of liquid oxygen will not accept a metered value from the oxygen supplier as a basis for payment. Because a large volume of oxygen evaporates after the product has been metered during the filling of the tank, many oxygen customers require in their contracts that the volume be determined by means of a gauge rod in the holding tank.

Committee Recommendation: No action at this time. These practices will have to be investigated before the Committee can make final recommendations as was proposed in the agenda: to revise subsection (4b) to permit only sealed meters for use in dispensing liquid oxygen by measure and to prohibit use of gauge rods or similar methods.

\section{2-18 I 2.X. Products Dispensed from Mechanical Devices}

Background: It was proposed to add a new section for solid or liquid products dispensed from mechanical devices to require that the "delivered" weight or volume be the net contents declaration, rather than the "contained" weight or volume. Reason: the consumer does not usually receive all of the net contents of containers (e.g., toothpaste, deodorant sticks, or hair spray pumps). The container label should declare the net contents that will actually be delivered when the device is operated as indicated on the label. See the discussion under Item 231-13.

Committee Recommendation: The Committee will not make a recommendation concerning this issue this year, but it generally endorses the concept of labeling commodities on a "to deliver" basis. As several consumers at the meeting pointed out, there is some precedent in declaring a delivered weight in the stick deodorant industry: on stick deodorant packages, the label states that there are so many ounces of product "plus enough extra to secure the product to the base [of the dispenser]."

\section{VC 2.X. Animal Bedding}

(This item was adopted as part of the consent calendar.)

Background: Animal bedding is sold by weight or by volume, the latter by dry measure or cubic measure. Some packages are labeled by compressed volume, while others are labeled by the "loose" or "usable" quantity. Value comparison is difficult.

Committee Recommendation: Add the guideline adopted by the Conference at the 73rd NCWM as a new section in the UMSCR:

Section 2.X. Animal Bedding. - Packaged animal bedding of all kinds, except for baled straw, shall be sold by volume, that is, by the cubic yard, cubic foot, cubic inch, or cubic meter. If the commodity is packaged in a compressed state, the quantity declaration shall include both the quantity in the compressed state and the usable quantity that can be recovered. Example: "500 cu in. Expands to $1000 \mathrm{cu}$ in."

The recommended test method is Section 4.11. Peat Moss from Handbook 133. The test official may need to "fluff up" the product prior to testing by pulling the particles apart by hand or by sieving the product (selecting the sieve 
size according to the size of the individual particles) so that the material may be reconstituted from a compressed state or to compensate for compacting that may occur under ordinary packaging and distribution processes. The recommended test method will be noted in NCWM Publication 3 and added to the index of the next edition of NIST Handbook 133.

Handbook 133: Package Testing

240-1 I Proposed Sampling Plans and Smaller MAV's

(This carry-over item was Item 240-1A in the Report of the 74th NCWM 1989.)

Background: At the January 1989 Interim Meetings, the Committee did not think that enough information had been submitted with the New York proposal for changes to Handbook 133 to make a decision or recommendation, nor was there enough time between the 1989 Interim Meetings and the 74th Annual Meeting for weights and measures officials or industry representatives to determine the effects of the proposal on their operations. It was subsequently found that the New York proposal needed modification to permit concurrent jurisdiction with USDA on meat and poultry products. No further data or information on this proposal has been submitted by New York or other parties since that time.

At the 74th Annual Meeting, the Western Weights and Measures Association Meeting, and the Southern Weights and Measures Association Meeting, requests were made from the floor to withhold action on this item because weights and measures and industry representatives needed time to assimilate and work with Handbook 133 in its present form before they could decide whether changes should be made. The Committee therefore announced in its agenda for the 1990 Interim Meetings plans to table the item. However, at the Interim Meeting, the Industry Committee on Packaging and Labeling (ICPL) raised the issue of their planning to propose other modifications to Handbook 133, specifically to add a sampling allowance to Category B sampling plans similar to the sampling factor that must be computed when using a Category A sampling plan. They requested time at the Annual Meeting to make a presentation from the floor concerning this issue. The Committee would like to stress that ICPL made it clear they had no quarrel with Handbook 133 as written, but they felt that regulatory agencies have taken liberties with the procedures and, consequently, a new approach may be needed. In addition, New York discussed its plans to submit further data concerning the proposal to change both the sampling plans and MAV's.

Committee Recommendation: No action at this time. The Committee is aware that the New York proposal has been modeled in some part after the European Community sampling plans. In the interests of international uniformity, the Committee believes that it may be beneficial to compare these procedures with Handbook 133 prior to making any further modifications to the basic sampling plans. (One of the authors of Handbook 133 advised the Committee that the EC plans had been considered for weights and measures field use in the early 70's, but were not acceptable to field inspectors at that time.)

\subsubsection{Exhausting the Aerosol Container; Clarify Instructions}

(This item was adopted as part of the consent calendar.)

Background: This section instructs testing officials to follow emptying instructions provided on the container label. When testing aerosol cans of whipped cream that had no instructions printed on the cans, weights and measures officials shook the test containers for 1 minute. This turned the whipped cream into butter inside the can and it could not then be dispensed. The packager of the whipped cream will print shaking and emptying instructions on his containers. He has also requested that further instructions be included in the section on emptying aerosol containers to warn the testing official that shaking and emptying instructions may differ greatly from a 1-minute shake. Also, when the test stand is not available to the testing official, an exhausting time less rigorous than 30 minutes should be permitted.

Committee Recommendation: Revise subsection (a) as follows:

a. Foam Products: Shake container according to directions on the can. Placing selected container in the position specified in the instructions on the package, exhaust it by holding the valve wide open until visible 
spray is interrupted. Continue exhausting container for 30 seconds. If using portable test stand (see Figures 3-11 and 3-12), exhaust container following the above procedures. However, hold valve wide open for 30 minutes.

\section{0-3 I Moisture Loss for Ice-Packed Poultry and Other Meat and Poultry Items}

(This carry-over item was Item 240-5A in the Report of the 74th NCWM 1989.)

Further Information: The Task Force on Commodity Requirements completed its work at the 73rd Annual Meeting. Ongoing efforts to refine test methods and define specific approaches for different commodities subject to moisture loss were left to the Laws and Regulations Committee and the Liaison Committee. The Task Force recommended that the Committee take up the issue of moisture-loss for ice-packed poultry shipped in bulk for repackaging by retail stores. Weights and measures agencies have repeatedly found large shortages in bulk shipments of ice-packed poultry and have been frustrated in their efforts to decrease the occurrences of shortages. The Task Force was unable within the time allotted to it to design a data collection study that would shed light on the shortages caused by the loss of moisture during shipping. The U.S. Department of Agriculture (USDA), Food Safety and Inspection Service (FSIS), volunteered its help in collecting the necessary data.

USDA proposed five product categories in addition to ice-packed poultry for which to determine gray areas: (1) cured pork products (hams, shoulders, loins, and picnics); (2) cured beef products (corned beef, corned beef brisket, and tongues); (3) raw meat products (chopped beef, ground beef, hamburger, and beef patties); (4) ham patties, chopped ham, pressed ham, spiced ham, and similar products; and (5) meat and poultry products that are cooked in vacuum packaging. USDA has again volunteered to obtain data for moisture loss by tracking products from selected Federal establishments. This recommendation and offer of assistance from USDA are evidence of the USDA's strong commitment to improve net weight compliance procedures and achieve uniformity in net weight compliance test results.

The Committee met with Mr. John McCutcheon, FSIS, USDA, and Mr. George Wilson, representing the American Meat Institute (AMI) during the Interim Meetings. AMI is conducting its own tests to determine the amount of moisture loss in corned beef and will transmit their data to the NCWM.

Concerning ice-packed poultry, FSIS and the NIST Office of Weights and Measures designed a test protocol for weighing cases of poultry on the packing line, in the plant, at the point of shipping, and as received by the purchaser. A pilot study was planned for the spring of 1990 in order to finalize the test method prior to asking other States and manufacturing plants to participate. The study sought to determine the amount of moisture lost at each point in the manufacturing and distribution system for a wide variety of products, distribution distances, and times.

A pilot study on ice-packed bulk poultry was conducted by the States of Maryland, Delaware, and Connecticut. The Committee expresses its appreciation to these jurisdictions for their fine work. Moisture loss on whole chicken was as high as $9 \%$ in a little over 24 hours. The Committee must decide whether moisture loss of this magnitude can in any way lend itself to the gray area approach. Perhaps a more viable solution would be to help retailers with their contracts with their suppliers, who may not be the poultry packagers themselves, but could be middlemen.

The American Meat Institute is not only conducting studies on cured pork products and cured beef products, but assessing certain unanticipated problems with the types of products used as models to determine the size of the gray areas for bacon and for luncheon meats. They will provide the Conference their results and recommendations when completed.

\section{0-4 I Moisture Loss for Pet Foods}

(This carry-over item was Item 240-5B in the Report of the 74th NCWM 1989.)

Further Information: Members of the Pet Food Institute are collaborating with selected weights and measures jurisdictions in the conduct of a study of moisture loss for dry pet foods. Their objective is to provide moisture loss data that can be used to determine the amount of weight loss that may be experienced from the time of packaging. 
All regions of the country, as well as all representative types and sizes of dry pet foods and packaging materials, are represented in the study. Weights and Measures officials have been asked to visit the packaging plants and warehouses where the weight loss studies are being conducted, test the scales used to determine the amount of weight loss, and become acquainted with the net weight and other quality control aspects of the packager. The study began in January 1990 and is expected to end in June 1990; a second study to determine the effects of different seasonal variations will begin in May and end in November 1990.

Four companies are in the midst of collecting data on moisture loss for dry pet food: Alpo, Nabisco, Quaker, and Ralston Purina. The first 6-month collection period will end about August, 1990. The second phase will begin in July, 1990 and continue until January or February of 1991. Heinz Pet Products will participate with the other 4 companies in the second phase. The preliminary results of their work will be reviewed at the Interim Meeting in January 1991.

\section{0-5 I Moisture Loss for Pasta}

(This carry-over item was Item 240-5C in the Report of the 74th NCWM 1989.)

Further Information: The National Pasta Association would like to use the gray area approach adopted by the NCWM for flour as a model for moisture loss in pasta. They have provided the NCWM with a list of all U.S. packagers to act as contacts with the packaging plant. A round robin will have to be conducted to make sure that all laboratories obtain the same moisture content on the pasta. The association has agreed to sponsor the round robin; weights and measures officials will be kept informed and asked to participate in a pilot study when a final details have been worked out.

\section{0-6 I Section 4.X. Hand-Packed Ice Cream}

Background: Companies that deliver hand-packed ice cream by volume report that it is impossible to deliver the volume using brim-full measure containers and the current test methods for ice cream as specified in Handbook 133. Section 4.13. of Handbook 133 tests the volume of ice cream by measuring the displacement of ice water. The industry contends that this test method is satisfactory for testing factory-filled ice cream packages, but that the displacement test method applied to hand-packed ice cream does not adequately recognize the nature of the product. Hand-packing does not always eliminate air pockets, no matter how skilled or trained the store clerk is, resulting in failure to comply when the current test method is used. The presence of air pockets in hand-packed containers of ice cream sold by volume has led to complaints by some consumers, who argue that they receive less than the quantity of product indicated by the container size. The International Ice Cream Association therefore proposed adding the following new test method:

\section{X. Hand-Packed Ice Cream}

The following test method is for hand-packed ice cream only. Prepacked/factory packaged ice cream and related products should be tested according to Section 4.14.

\section{X.1. Equipment}

Scales and weights recommended in Section 3.1.

\section{X.2. Procedure}

1. Determine inspection lot, fill out the standard pack report form heading, and select the random sample and tare sample. Place the sample in the freezer or ice chest until ready to test. Remove packages from the freezer one at a time.

2. Remove the first package from the freezer and gross weigh it. Record the weight.

3. Note the appearance of the container and record - does it appear visibly full?

4. Clean and air-dry the tare materials (container, lid, etc.). Weigh and record the weight of these materials for the first package. 
5. Subtract the tare weight from the gross weight and record.

6. Repeat steps $2-5$ for the rest of the sample.

7. Weight of every package in the sample set must equal or exceed 4.5 pounds/gallon or appropriate subdivisions thereof.

\title{
4.X.3. Action
}

If the criterion in either step 3 or step 7 is not met, the lot fails to comply with the requirements; if both criteria are met, the lot conforms with the requirements.

Committee Position: The Committee believes that the proposed procedure can be only a screening procedure, not an enforcement test method. If the method of sale is by volume (as recommended by the Conference), then the enforcement test procedure must determine volume. The actual weight of ice cream ranges from 4.5 to 6 pounds per gallon. Thus a measure container with ice cream weighing 6 pounds per gallon that "looks full" will have 25 percent of air space in the container (that is, 1.5 pounds of missing product divided by 6 pounds per gallon), yet will be found "full measure" by means of the test procedure above. Weights and measures officials at the Interim Meeting asked whether the typical brim-full measure containers were suitable devices for the delivery of hand-packed ice cream; they suggested that larger containers than the measure containers intended for use in factory-filled operations be obtained by hand-packaging operators in order to accommodate the air space that they know packers will introduce. This situation is similar to that discovered in the sale of oysters by the gallon. One-gallon ice cream measure containers were used by oyster packers. The containers would contain 1 gallon only when filled to the brim; their design did not allow for the head space needed when filling the container with a watery fluid. The measuring devices were therefore inappropriate for the product being measured. Retailers who sell ice cream and similar frozen products by volume must deliver the stated volume; they should determine the size of container needed to deliver this volume. Brimfull measure containers are not required and may not even be appropriate for hand-packing operations.

The Committee is recommending a change to Section 1.7.1. of the Uniform Regulation for the Method of Sale of Commodities that will permit the sale of hand-packed ice cream and similar frozen desserts by weight or by volume. The industry must be warned, however, that if Item 232-4 is adopted, and if a retailer wishes to sell by weight, Class III scales must be used for such sales.

\section{0-7 I Polyethylene/Test Methods for Bags}

This carry-over item was Item 240-4C in the Report of the 73rd NCWM, 1988.

Background: The recommended test procedure needs further modification. The State of California is investigating alternatives to using vermiculite that (1) would not require that the inspector wear a dust mask when using it (recommended in the test procedure) and (2) would not break up during use and would reliably retain its volume. The use of styrofoam balls is being investigated. In addition, the method must be supplemented; the present recommendation only tests for tie-off volume; it does not test the capacity of bags labeled "fits X-gallon can."

Committee Recommendation: No action at this time.

\author{
S. Colbrook, Illinois, Chairman \\ B. Bloch, California \\ F. Clem, Columbus, Ohio \\ A. Nelson, Connecticut \\ L. Straub, Maryland \\ C. Brickenkamp, Technical Advisor
}

\section{Committee on Laws and Regulations}




\section{Appendix A}

\section{Uniform Weighmaster Law}

\section{Section 1. Purpose}

The purpose of this Act is to ensure accurate measurements by public weighmasters.

\section{Section 2. Scope}

This Act:

(a) establishes a registration, licensing, and enforcement program;

(b) provides authority for license fee collection;

(c) empowers the state to promulgate regulations as needed to carry out the provisions of the Act;

(d) provides for optional or voluntary licensing when the employing organization or other organizations require it as part of the condition for employment;

(e) provides for civil and criminal penalties.

\section{Section 3. Definitions}

As used in this Act:

3.1. Public Weighing means the weighing, measuring, or counting, upon request, of vehicles, property, produce, commodities, or articles other than those that the weigher or his/her employer, if any, is either buying or selling.

3.2. Public Weighmaster means any person who performs public weighing as defined in 3.1.

3.3. Vehicle means any device (except railroad freight cars) in, upon, or by which any property, produce, commodity, or article is or may be transported or drawn.

3.4. Director means the of the Department of

\section{Section 4. Enforcing Officer: Rules and Regulations}

The Director is authorized to:

(a) enforce the provisions of this Act; 
Laws and Regulations Committee

(b) issue reasonable regulations for the enforcement of this Act that shall have the force and effect of law; and

(c) adopt rules that include, but are not limited to, determining:

(1) the qualifications of the applicant for a license as a public weighmaster;

(2) renewal or refusal of a license;

(3) the period of license validity;

(4) measurement practices that must be followed, including the measurement or recording of tare;

(5) the required information to be submitted with or as part of a certificate;

(6) the period of recordkeeping.

\section{Section 5. Qualifications for Weighmaster}

To receive authorization to act as a public weighmaster, a person must receive a license from the Director. In order to qualify for a license, a person must:

(a) be able to weigh or measure accurately;

(b) be able to make correct certificates; and

(c) possess other qualifications required by regulations promulgated under the Act.

\section{Section 6. License Application}

Using a form provided by the Director, the applicant for a license as a public weighmaster shall furnish evidence that he/she has the qualifications required by Section 5 of this Act and regulations promulgated under the Act.

\section{Section 7. Evaluation of Qualifications of Applicants}

The Director will determine the qualifications of the applicant based on:

(a) the information provided on the application; and

(b) supplementary information as determined by the Director.

The Director may also determine the qualifications of the applicant based on the results of an examination of the applicant's knowledge.

\section{Section 8. Issuance and Records of Licenses}

The Director will:

(a) grant licenses as public weighmasters to qualified applicants;

(b) keep a record of all applications submitted and of all licenses issued. 


\section{Section 9. License Fees}

The Director shall have the authority to set fees for the administration and effective enforcement of the provisions of this Act. Before the issuance of a new license or renewal of a license as a public weighmaster, the applicant must pay a fee of $\$$ to the Director.

\section{Section 10. Certificate: Required Entries}

(a) The certificate, when properly filled out and signed shall be prima facie evidence of the accuracy of the measurements shown.

(b) The design of and the information to be furnished on a weight certificate shall be prescribed by the Director and will include, but not be limited to, the following.

(1) The name and license number of the public weighmaster.

(2) The kind of commodity weighed, measured, or counted.

(3) The name of the owner, agent, or consignee of the commodity.

(4) The name of the recipient of the commodity, if applicable.

(5) The date the certificate is issued.

(6) The consecutive number of the certificate.

(7) The identification, including the identification number, if any, of the carrier transporting the commodity, and the identification number or license number of the vehicle.

(8) Other information needed to distinguish or identify the commodity from a like kind.

(9) The number of units of the commodity, if applicable.

(10)The measure of the commodity, if applicable.

(11) The weight of the commodity and the vehicle or container (if applicable) broken down as follows:

(i) the gross weight of the commodity and the associated vehicle or container;

(ii) the tare weight of the unladened vehicle or container; or

(iii) both the gross and tare weight and the resultant net weight of the commodity.

(12) Signature of the public weighmaster who determined the weight, measure, or count. 


\section{Section 11. Certificate: Execution, Requirements}

(a) When filling out a certificate, a public weighmaster shall:

(1) enter the measurement values to clearly show that the measurements were actually determined;

(2) enter only the measurement values personally determined;

(3) not enter measurement values determined by other persons.

(b) If the certificate provides for entries of gross, tare, or net, the public weighmaster shall:

(1) strike out or otherwise cancel the printed entries for the values not determined; or

(2) enter the scale and date on which the values were determined on the certificate if the values were not determined on the same scale or on the same date shown on the certificate.

\section{Section 12. Measurement Practices \& Equipment Used}

A public weighmaster shall use measurement practices and equipment:

(a) in accordance with the requirements of the latest edition of NIST Handbook 44, "Specifications, Tolerances, and Other Technical Requirements for Weighing and Measuring Devices;"

(b) examined, tested, and approved for use by a weights and measures officer of this State.

\section{Section 13. Scale Used: Capacity, Platform Size, One-Draft Weighing}

(a) A public weighmaster shall not weigh a vehicle, or combination of vehicles, when part of the vehicle or connected combination, is not resting fully, completely, and as one entire unit on the scale.

(b) When weighing a combination of vehicles that will not rest fully, completely, and as one complete unit on the scale platform,

(1) the combination shall be disconnected and weighed in single drafts; and

(2) the weights of the single drafts may be combined in order to issue a single certificate for the combination, provided that the certificate indicates that the total represents a combination of single draft weighings.

\section{Section 14. Copies of Certificates}

A public weighmaster shall keep and preserve for the period specified in the regulations a legible copy of each certificate issued by him or her. The certificates shall be available for inspection by any weights and measures officer of this State during normal office hours.

\section{Section 15. Reciprocal Acceptance of Certificates}

The Director is authorized to recognize and accept certificates issued by licensed public weighmasters of other States that recognize and accept certificates issued by licensed weighmasters of this State. 


\section{Section 16. Optional Licensing}

The following persons shall be authorized, but are not required, to obtain licenses as public weighmasters:

(a) a law enforcement or weights and measures officer, or other qualified employee of a State, city, or county agency or institution when acting within the scope of his/her official duties;

(b) a person weighing property, produce, commodities, or articles:

(1) that he or his employer is either buying or selling; or

(2) in conformity with the requirements of Federal statutes or the statutes of this State relative to warehousemen or processors.

\section{Section 17. Prohibited Acts}

It is a prohibited act for any person

(a) without a valid license to:

(1) assume the title of public weighmaster, or any title of similar import;

(2) perform the duties or acts to be performed by a public weighmaster;

(3) hold himself or herself out as a public weighmaster;

(4) issue any certificate, ticket, memorandum, or statement for which a fee is charged;

(5) engage in full-time or part-time business of measuring for hire.

(b) to use or operate any device for certification purposes that does not meet, nor in a manner not in accordance with, the requirements of the latest edition of NIST Handbook 44, "Specifications, Tolerances, and Other Technical Requirements for Weighing and Measuring Devices;"

(c) to falsify a certificate or to falsely certify any gross, tare, or net weight or measure required by the Act to be on the certificate;

(d) to refuse without cause to weigh or measure any article or thing which it is his/her duty to weigh or measure, or refuse to state in any certificate anything required to be therein;

(e) to hinder or obstruct in any way the Director or his/her authorized agent in the performance of the Director's official duties under this Act;

(f) to violate any provision of this Act or any regulation promulgated under this Act;

(g) to delegate his/her authority to any person not licensed as a public weighmaster;

(h) to request a false certificate or to request a public weighmaster to weigh, measure, or count any vehicle, property, produce, commodity, or article falsely or incorrectly;

(i) to issue a certificate simulating the certificate in the Act;

(j) to use or have in his/her possession a device which has been altered to facilitate fraud. 


\section{Section 18. Suspension and Revocation of License}

The Director is authorized to suspend or revoke the license of any public weighmaster:

(a) when, after a hearing held following 10 days notice to the licensee, he/she is satisfied that the licensee has violated any provision of this Act or of any regulation under this Act;

(b) when the licensee has been convicted in any court of competent jurisdiction of violating any provision of this Act or of any regulation under this Act; or

(c) when the licensee is convicted of any felony.

\section{Section 19. Civil Penalties}

Any person who by him/herself, by his/her servant or agent, or as the servant or agent of another person commits any of the acts enumerated in Section 17 may be subject to a civil penalty.

19.1. Civil Action. A civil action may be brought by the Director in any court of competent jurisdiction to recover a civil penalty of:

(a) not less than $\$ \_$nor more than $\$$ _ for a first violation,

(b) not less than $\$ \_$nor more than $\$ \_$for a second violation within 2 years from the date of the first violation, and for a third violation within 2 years from the date of the first

(c) not less than $\$$ nor more than $\$$ violation.

19.2. Administrative Hearing. Upon a finding of a violation of any provision of this Act, the Director or his/her designee shall be authorized to conduct an administrative hearing and, upon notice and an opportunity to be heard, may assess a civil penalty of

(a) not less than $\$ \_$nor more than $\$$ _ for a first violation,

(b) not less than $\$ \_$nor more than $\$ \_$for a second violation within 2 years from the date of the first violation, and

(c) not less than $\$$ violation. for a third violation within 2 years from the date of the first

19.3. Judicial Review.The final decision of the Director shall be subject to appropriate judicial review.

19.4. Transmittal of Monies. Any civil penalty collected under this Act shall be transmitted to the state treasurer, who shall credit the same to the fund. 


\section{Section 20. Criminal Penalties}

20.1. Misdemeanor. Any person who, by him/herself by his/her servant or agent, or as the servant or agent of another person commits any of the acts enumerated in Section 17 or violates any other provision of this Act shall be guilty of a Class _ misdemeanor and upon conviction shall be punished by a fine not less than \$ nor more than $\$$ or by imprisonment for not less than nor more than or both fine and imprisonment.

20.2. Felony. Any person who by him/herself by his/her servant or agent, or as the servant or agent of another person intentionally commits any of the acts enumerated in Section 17 or repeatedly violates any other provision of this Act shall be guilty of a Class $\$$ _ and/or by imprisonment for not less than felony and upon conviction shall be punished by a fine not less than nor more than or more than

\section{Section 21. Restraining Order and Injunction}

The Director is authorized to apply to any court of competent jurisdiction for a restraining order, or a temporary or permanent injunction, restraining any person from violating any provision of this Act.

\section{Section 22. Validity of Prosecutions}

Prosecutions for violation of any provision of this Act are declared to be valid and proper notwithstanding the existence of any other valid general or specific Act of this State dealing with matters that may be the same as or similar to those covered by this Act.

\section{Section 23. Separability Provision}

If any provision of this Act is declared unconstitutional, or the applicability thereof to any person or circumstance is held invalid, the constitutionality of the remainder of the Act and the applicability thereof to other persons and circumstances shall not be affected.

\section{Section 24. Repeal of Conflicting Laws}

All laws and parts of laws contrary to or inconsistent with the provisions of this Act, and specifically are repealed insofar as they might operate in the future; but as to offenses committed, liabilities incurred, and claims now existing thereunder, the existing law shall remain in full force and effect.

\section{Section 25. Citation}

This Act may be cited as the "Public Weighmaster Act of

Section 26. Effective Date

This Act shall become effective on 


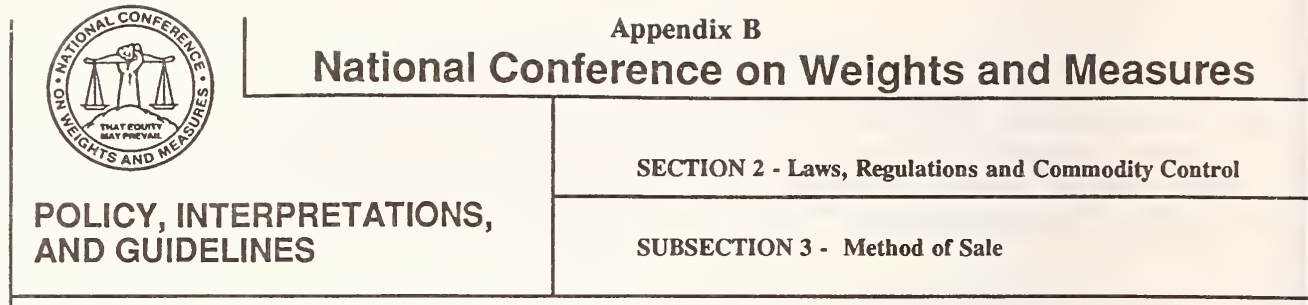

\subsubsection{Fresh Fruits and Vegetables}

(L\&R, 1979, p. 176; 1980; 1982, p. 152)

\section{Guideline}

Recognizing the difficulty faced by consumers when more than one method of sale is employed in the same outlet for the same product, noncomparable methods of sale (e.g., weight and measure) for the same produce item in the same outlet should be minimized.

The methods of retail sale for fresh fruits and vegetables should be:

$\begin{array}{ll}\text { Commodity } & \text { Method of Sale } \\ \text { Apples } & \text { Weight or count, or by dry measure in units not less than } 7 \\ & \frac{1 / 2}{2} \text { peck } \\ \text { Apricots } & \text { Weight } \\ \text { Artichokes } & \text { Weight or count } \\ \text { Asparagus } & \text { Weight or bunch } \\ \text { Avocados } & \text { Count } \\ \text { Bananas } & \text { Weight } \\ \text { Beans } & \text { Weight or dry measure, in units not less than } \pm 1 / 2 \text { peck } \\ \text { Beets } & \text { Weight or bunch } \\ \text { Berries (all) }{ }^{1} & \text { Weight or measure } \\ \text { Broccoli } & \text { Weight or bunch } \\ \text { Brussels sprouts } & \text { Weight } \\ \text { Cabbage } & \text { Weight } \\ \text { Cantaloupes } & \text { Weight or count } \\ \text { Carrots } & \text { Weight or bunch } \\ \text { Cauliflower } & \text { Weight or bunch } \\ \text { Celery } & \text { Weight or count } \\ \text { Cherries } & \text { Weight or measure } \\ \text { Coconuts } & \text { Weight or count } \\ \text { Corn on cob } & \text { Count } \\ \text { Cranberries } & \text { Weight or measure } \\ \end{array}$

${ }^{1}$ Commodities sold by measure must be sold in containers standardized by the Berry Basket and Box Code in Handbook 44. 
2.32. Fresh Fruits and Vegetables

\section{Commodity \\ Cucumbers \\ Currants $^{1}$ \\ Dates \\ Eggplant \\ Endive \\ Escarole}

Figs

Garlic

Ginger root

Grapefruits

Grapes

Greens (all)

Horseradish root

Kale

Kohlrabi

Kiwi fruit

Kumquats

Leeks

Lemons

Lettuce

Limes

Mangoes

Melons (whole)

Melons (cut or pieces)

Mushrooms

Nectarines

Nuts

Okra

Onions (spring or green)

Onions (dry)

Oranges

Papaya

Parsley

Parsnips

Peaches

Pears

Peas

Peppers

Persimmons

Plums

Pineapples

\section{Method of Sale}

Weight or count

Weight or measure

Weight

Weight or count

Weight or bunch

Weight or bunch

Weight

Weight or count

Weight or count

Weight or count

Weight

Weight

Weight or bunch

Weight

Weight

Weight or count

Weight or count

Weight

Weight or count

Weight or count

Weight or count

Weight or count

Weight or count

Weight

Weight or measure

Weight or count

Weight

Weight

Weight or bunch

Weight

Weight or count

Weight or count

Weight or bunch

Weight

Weight or count, or by dry measure in units not less than \pm $1 / 2$ peck

Weight or count, or by dry measure in units not less than 1 $1 / 2$ peck

Weight

Weight or count

Weight or count

Weight or dry measure, in units not less than $₫ 1 / 2$ peck

Weight or count

\footnotetext{
${ }^{1}$ Commodities sold by measure must be sold in containers standardized by the Berry Basket and Box Code in Handbook 44.
} 
Laws and Regulations Committee

2.3.2. Fresh Fruits and Vegetables

Commodity
Pomegranates
Potatoes (Irish or sweet)
Prunes
Pumpkins
Quinces
Radishes
Rhubarb
Rutabagas
Spinach
Sprouts
Squash
Tangelos
Tangerines
Tomatoes
Tomatoes (cherry)
Turnips

Method of Sale

Weight or count

Weight

Weight

Weight or count

Weight or count

Weight

Weight

Weight

Weight or bunch

Weight

Weight

\section{Weight or count}

Weight or count

Weight or dry measure, in units not less than $¥ 1 / 2$ peck

Weight or measure

Weight or bunch

${ }^{1}$ Commodities sold by measure must be sold in containers standardized by the Berry Basket and Box Code in Handbook 44. 


\title{
Appendix C
}

\author{
Meat and Poultry Products \\ A Consumer Guide to Content and Labeling Requirements ${ }^{1}$
}

Food Standards

The U.S. Department of Agriculture's Food Safety and Inspection Service (FSIS) and the U.S. Department of Health and Human Services' Food and Drug Administration (FDA) share the responsibility of assuring truthful and accurate information on product labels. FSIS has authority over all products containing more than 3 percent fresh meat or at least 2 percent cooked poultry meat. FDA oversees the labeling of most other food products.

Both agencies use a system of "food standards." These standards set requirements on the kinds and amounts of ingredients used in the manufacture of processed foods. Basically, these standards assure consumers that, if a product goes by a particular name, it will have certain characteristics.

USDA Standards of Identity and Composition

Almost all standards enforced by FSIS are called "standards of composition." These standards identify the minimum amount of meat or poultry required in a product's recipe. For example, the standard of composition for "chicken a la king" states that, if a product carries this name on its label, at least 20 percent cooked poultry meat must be used in the recipe.

But standards of composition don't prevent a manufacturer from increasing the meat or poultry content or adding other ingredients, to increase a product's appeal. For instance, a processor has the option of using more than the required amount of chicken in chicken a la king and adding other ingredients to make the product unique.

"Standards of identity," on the other hand, set specific requirements for a food's makeup: the kind and minimum amount of meat or poultry; maximum amount of fat or moisture; and any other ingredients allowed. Corned beef hash and chopped ham are two FSIS-regulated products that have standards of identity.

\section{Label Approval}

Before a product may be marketed, its label must be examined and approved by FSIS staff specialists. Food manufacturers submit over 100,000 labels a year for agency review. Label approval applications must include the product name, formula, method of preparation, type of container, and how the label is to be used.

A number of labeling regulations apply across-the-board to all meat and poultry products. These include: appropriate product name; ingredients, listed from most to least, by weight in the product recipe; net quantity of the package contents; name and address of the manufacturer, packer, or distributor; the USDA mark of inspection; and any special care or handling instructions, such as "keep refrigerated." In addition, label photographs or artwork depicting a product must not be misleading.

To assure consumers that the names of meat and poultry products accurately reflect the contents of these products, label reviewers evaluate product formulas and methods of preparation by comparing them with official standards in the meat and poultry inspection regulations. Because unpublished standards are used to evaluate some products, FSIS labeling policies also provide guidance.

Sometimes, no standard exists for a certain product. In these cases, a manufacturer can either give the product a "descriptive" name, such as "Chopped and Formed Cured Pork Product," or use a "fanciful" name accompanied by a descriptive name-"Breakfast Strips: Chopped and Formed Cured Pork Product." A manufacturer may also submit a proposal to FSIS, requesting a standard for the product.

Why You Should Know About Content and Labeling Requirements

\footnotetext{
${ }^{1}$ Home and Garden Bulletin No. 236
} 
Although Federal labeling laws and regulations are established to protect the public consumers are sometimes unaware of how to use the information on product labels. FSIS content and labeling requirements provide a simple means by which consumers can learn what to expect from a product if it is labeled with a particular name.

If you know that product names are required to truthfully reflect product content, much can be learned just by noting the order in which major ingredients appear. For example, the name "Beef with Gravy" tells you that there is more beef in that product than in one called "Gravy with Beef."

This guide includes listings for over 250 popular meat and poultry products-from baby food to won ton soup.

For your convenience, the list of meat and poultry product content and labeling requirements is divided into two sections"Meat Products" and "Poultry Products." Some product definitions include terms that are further defined elsewhere in the guide. For example, the "meatballs" in "spaghetti and meatballs" (page 124) is defined on page 123. The term byproducts is explained on pages 126, in the DEFINITIONS section.

\section{Meat Products}

All percentages of meat are on the basis of fresh uncooked weight unless otherwise indicated. Keep in mind the meat may shrink in weight after cooking because fat and water cook away.

\section{Baby Food}

High Meat Dinner-At least $26 \%$ meat.

Meat and Broth-At least $61 \%$ meat.

Vegetable with Meat-At least $8 \%$ meat.

Bacon (Cooked)-Weight of cooked bacon is $40 \%$ of uncooked, cured, smoked bacon.

Bacon and Tomato Spread-At least 20\% cooked bacon.

Bacon Dressing-At least $8 \%$ cured, smoked bacon.

Barbecue Sauce with Meat-At least $35 \%$ meat (cooked basis).

Barbecued Meat-Weight of meat when barbecued can't exceed $70 \%$ of the fresh uncooked meat. Must have barbecued (crusted) appearance and be prepared over burning or smoldering hardwood or its sawdust. If cooked by other drying means, product name must mention the method of cooking.

Beans with Bacon or Ham in Sauce-At least $12 \%$ bacon or ham (cooked basis).

Beans with Frankfurters in Sauce-At least 20\% franks.

Beans with Meat in Sauce-At least $12 \%$ meat.

Beans with Meatballs in Sauce-At least $20 \%$ meatballs.

Beef a la King-At least $20 \%$ beef (cooked basis).

Beef a la Mode-At least $50 \%$ beef.

Beef Almandine with Vegetables-At least $18 \%$ beef (cooked basis). Product must contain almonds.

Beef and Dumplings with Gravy or Beef and Gravy with Dumplings-At least $25 \%$ beef.
Beef Burgundy-At least $50 \%$ beef; enough wine to characterize the sauce.

Beef Carbonade-At least $50 \%$ beef.

Beef Roulade-At least $50 \%$ beef (cooked basis).

Beef Sausage (raw)-No more than $30 \%$ fat. No byproducts, no extenders and no more than $3 \%$ water.

Beef Stroganoff-At least $45 \%$ fresh, uncooked beef or $30 \%$ cooked beef and one of the following: at least $10 \%$ sour cream; or a combination of at least $71 / 2 \%$ sour cream and $5 \%$ wine; or $9 \frac{1}{2} \%$ whole milk, $2 \%$ sour cream, and $2 \frac{1}{2} \%$ wine.

Beef with Barbecue Sauce-At least $50 \%$ beef (cooked basis).

Beef with Gravy-At least 50\% beef (cooked basis).

Breaded Steaks, Chops, etc.-Breading can't exceed 30\% of finished product weight.

Breakfast (frozen product containing meat)-At least $15 \%$ cooked meat based on total net weight of breakfast.

Breakfast Sausage-No more than $50 \%$ fat. May contain $3 \frac{1}{2} \%$ binders and extenders, and $3 \%$ water.

Brown and Serve Sausage-No more than 35\% fat and no more than $10 \%$ added water.

Brunswick Stew-At least $25 \%$ meat, made up of at least two kinds of meat, including poultry meat. Must contain corn as one of the vegetables.

Burgundy Sauce with Beef and Noodles-At least $25 \%$ beef (cooked basis) and up to $20 \%$ noodles; enough wine to characterize the sauce. 
Burrito-At least $15 \%$ meat.

Cabbage Rolls with Meat in Sauce-At least $12 \%$ meat.

Cannelloni with Meat and Sauce-At least $10 \%$ meat.

Cappelletti with Meat in Sauce-At least $12 \%$ meat.

Cheesefurter-Shall contain sufficient cheese to characterize the product.

Chili con Carne-At least $40 \%$ meat.

Chili con Carne with Beans-At least 25\% meat.

Chili Hot Dog with Meat-At least $40 \%$

Chili Mac-At least $16 \%$ meat. Must be qualified with true product name: "Beans, Macaroni, and Beef in Sauce."

Chili Sauce with Meat-At least $6 \%$ meat.

Chop Suey (American Style) with Macaroni and MeatAt least $25 \%$ meat.

Chop Suey Vegetables with Meat-At least $12 \%$ meat.

Chopped Ham-Must be prepared from fresh, cured, or smoked ham, plus certain kinds of curing agents and seasonings. May contain dehydrated onions, dehydrated garlic, corn syrup, and not more than $3 \%$ water to dissolve the curing agents.

Chow Mein Vegetables with Meat-At least $12 \%$ meat.

Chow Mein Vegetables with Meat and Noodles-At least $8 \%$ meat and the noodles must equal no more than $1 / 3$ of the product.

Corn Dog-Must be accompanied by true product name, "Batter Wrapped Franks on a Stick." Limited to $65 \%$ batter and a minimum of $35 \%$ frankfurter.

Corned Beef and Cabbage-At least 25\% corned beef (cooked basis).

Corned Beef Hash-At least 35\% beef (cooked basis). Must contain potatoes, curing agents, and seasonings. May contain onions, garlic, beef broth, beef fat, or others. No more than $15 \%$ fat; no more than $72 \%$ moisture.

Country Ham-A dry-cured product frequently coated with spices. Minimum $4 \%$ salt content.

Creamed Meat Products or Creamed Sauce with Meat Products (Chipped Beef, Cooked Beef, Cured Beef, Ham, Franks, Meatballs, etc.)-At least $18 \%$ meat product (cooked basis).
Crepe with Meat-Based on total net weight of product; at least $20 \%$ meat (cooked basis) if filling has no other major characterizing ingredient, or $10 \%$ meat (cooked basis) if one other major characterizing ingredient ("Crepe with Meat and Cheese," for example).

Croquettes-At least 35\% meat (cooked basis); $50 \%$ fresh basis.

Curried Sauce with Meat and Rice (casserole)-At least $35 \%$ meat (cooked basis) in the sauce and meat part. No more than $50 \%$ cooked rice.

Deviled Ham-No more than 35\% fat; no added moisture; no cereal.

Dinner (frozen product containing meat)-At least $25 \%$ meat or meat food product (cooked basis) figured on total meal minus appetizer, bread, and dessert. Consumer package must weigh at least 10 ounces (284 grams).

Dumplings with Meat in Sauce-At least $18 \%$ meat.

Egg Foo Yong with Meat-At least $12 \%$ meat.

Egg Roll with Meat-At least $10 \%$ meat.

Egg Roll with Meat and Seafood-At least 5\% meat.

Eggs Benedict-At least $18 \%$ cured smoked ham.

Enchilada with Meat-At least $15 \%$ meat.

Entree: Meat or Meat Food Product and One VegetableAt least $50 \%$ meat or meat food product (cooked basis).

Frankfurter, Bologna, and Similar Cooked SausageMay contain only skeletal Meat. Mo more than $30 \%$ fat, $10 \%$ added water, and $2 \%$ corn syrup. No more than $15 \%$ poultry meat (exclusive of water in formula).

Frankfurter, Bologna, and Similar Cooked Sausage with Byproducts or Variety Meats-Same limitations as above on fat, added water, and corn syrup. Must contain at least $15 \%$ skeletal meat. These products must be specifically labeled, such as "Frankfurters with Byproducts," and each byproduct or variety meat must be specifically named in the list of ingredients. These include heart, tongue, spleen, tripe, and stomach.

Frankfurter, Bologna, and Similar Cooked Sausage with Byproducts or Variety Meats and which also Contain Nonmeat Binders-Product made with the above formulas and also containing up to $31 / 2 \%$ nonmeat binders (or $2 \%$ isolated soy protein). These products must be distinctively labeled, such as, "Frankfurters with Byproducts, Nonfat Dry Milk Added," The binders my be named in their proper order in the list of ingredients. 
Fried Rice with Meat-At least $10 \%$ meat.

Fritter-At least $35 \%$ meat; no more than $65 \%$ breading.

German Style Potato Salad with Bacon-At least $14 \%$ bacon (cooked basis).

Goulash-At least $25 \%$ meat.

Gravy-At least $25 \%$ meat stock or broth, or at least $6 \%$ meat.

Gravy and Sauerbraten-35\% meat (cooked basis).

Gravy and Swiss Steak-At least 35\% meat (cooked basis).

Gravy and Yankee Pot Roast-At least $35 \%$ meat (cooked basis).

Gravy with Beef-At least $35 \%$ beef (cooked basis).

Ham (canned)-Limited to $8 \%$ total weight gain after processing.

Ham, Cooked or Cooked and Smoked (not canned)Must not weigh more after processing than the fresh ham weights before curing and smoking, if contains up to $10 \%$ added weight, must be labeled, "Ham, Water Added,"

Ham a la King-At least $20 \%$ ham (cooked basis).

Ham and Cheese Spread-At least 25\% ham (cooked basis).

Ham Chowder

Ready-to-Eat-At least 5\% ham (cooked basis)

Condensed-At least $10 \%$ ham (cooked basis).

Ham Salad-At least $35 \%$ ham (cooked basis).

Ham Spread-At least 50\% ham.

Hamburger, Hamburg, Burger, Ground Beef, or Chopped Beef-No more than $30 \%$ fat; no extenders.

Hash-At least $35 \%$ meat (cooked basis).

Hors d'oeuvre-At least $15 \%$ meat (cooked basis) or $10 \%$ bacon (cooked basis).

Jambalaya with Meat-At least $25 \%$ meat cooked basis).

Knish-At least $15 \%$ meat (cooked basis).

Kreplach-At least $20 \%$ meat.

Lasagna with Meat and Sauce, or Cheese Lasagna with Meat-At least $12 \%$ meat.

Lasagna with Meat Sauce-At least $6 \%$ meat.

Lasagna with Sauce, Cheese, and Dry Sausage-At least $8 \%$ dry sausage.
Lima Beans with Ham or Bacon in Sauce-At least $12 \%$ ham or bacon (cooked basis).

Liver Products, such as Liver Loaf, Liver Paste, Liver Pate, Liver Cheese, Liver Spread, Liverwurst, Braunschweiger, and liver Sausage-At least $30 \%$ liver.

Macaroni and Beef in Sauce-At least $12 \%$ beef.

Macaroni and Cheese with Ham-At least 12 ham (cooked basis).

Macaroni and Meat-At least 25\% meat.

Macaroni Salad with Ham or Beef-At least $12 \%$ meat (cooked basis).

Manicotti with Meat in Sauce (contains a meat filling)At least $10 \%$ meat.

Margarine or Oleomargarine-If product is entirely of animal fat or contains some animal fat, it is processed under Federal inspection. Must contain-individually or in combination-pasteurized cream, cow's milk, skim milk, combination of nonfat dry milk and water or finely ground soybeans and water. May contain butter, salt, artificial colorings, vitamins $\mathrm{A}$ and $\mathrm{D}$, and permitted functional substances. Finished product must contain at least $80 \%$ fat from animal or vegetable sources. Label must clearly state which types of fat are used.

Meat and Dumplings in Sauce-At least 25\% meat.

Meat and Vegetables-At least $50 \%$ meat.

Meat Casserole-At least 25\% fresh, uncooked meat or $18 \%$ cooked meat.

Meat Curry-At least 50\% meat.

Meat Loaf (baked or oven-ready)-At least 65\% meat and no more than $12 \%$ cereal products.

Meat Pasty-At least 25\% meat.

Meat Pie or Vegetable Meat Pie-At least 25\% meat.

Meat Ravioli-At least $10 \%$ mean in ravioli.

Meat Ravioli in Sauce-At least $10 \%$ meat in ravioli; at least $50 \%$ ravioli in total product.

Meat Salad-At least 35\% meat (cooked basis).

Meat Sauce-At least $6 \%$ meat.

Meat Soup

Ready-to-Eat-At least 5\% meat.

Condensed-At least $10 \%$ meat.

Meat Spread-At least 50\% meat. 
Meat Stew-At least 25\% meat.

Meat Taco-At least $15 \%$ meat.

Meat Taco Filling-At least $40 \%$ meat.

Meat Turnover-At least $25 \%$ meat.

Meat Wellington-At least 50\% cooked tenderloin spread with liver pate or similar coating and covered with not more than $30 \%$ pastry.

Meatballs-No more than $12 \%$ extenders, including textured vegetable protein. At least $65 \%$ meat.

Meatballs in Sauce-At least $50 \%$ meatballs (cooked basis).

Meatball Stroganoff-At least $45 \%$ meatballs (cooked basis).

Mince Meat-At least $12 \%$ meat.

Mousaka-At least $25 \%$ meat. Must be qualified on label as "Eggplant and Meat Casserole."

New England Boiled Dinner-At least $25 \%$ cooked corned beef.

Omelet with Bacon-At least $9 \%$ bacon (cooked basis).

Omelet with Dry Sausage-At least $12 \%$ dry sausage.

Omelet with Ham-At least $18 \%$ ham (cooked basis).

Omelet with Meat Food Product, such as Creamed Chipped Beef or Corned Beef Hash-At least $25 \%$ meat food product.

Omelet, Western-At least $18 \%$ cooked ham. Contains onions and green and/or red bell peppers.

Pate de Foie-At least $30 \%$ liver.

Pepper Steak (Chinese)-At least 30\% thin, braised strips of beef (cooked basis).

Peppers and Italian Sausage in Sauce-At least $20 \%$ sausage (cooked basis).

Pizza with Meat-At least $15 \%$ meat.

Pizza with Sausage-At least $12 \%$ sausage (cooked basis) or $10 \%$ dry sausage, such as pepperoni.

Pork Sausage-Nor more than $50 \%$ fat or $3 \%$ water; may contain no byproducts or extenders.

Pork with Barbecue Sauce-At least $50 \%$ port (cooked basis).

Pork with Dressing-At least 50\% pork (cooked basis).
Pork with Dressing and Gravy-At least $30 \%$ pork (cooked basis).

Proscuitto-A flat, dry-cured ham coated with spices.

Quiche Lorraine-At least $8 \%$ bacon or ham (cooked basis) and $10 \%$ swiss or gruyere cheese.

Rice with Meat-At least $12 \%$ meat.

Salisbury Steak-At least $65 \%$ meat and no more than $12 \%$ extenders, including textured vegetable protein.

Sandwich Meat-At least 35\% meat in total sandwich; bread component may not exceed $50 \%$ of the sandwich.

Sauerbraten-At least $50 \%$ beef (cooked basis).

Sauerkraut Balls with Meat-At least $30 \%$ meat.

Sauerkaraut with Wieners and Juice-At least $20 \%$ wieners.

Sausage with Sauerkraut in Sauce-At least $40 \%$ sausage (cooked basis).

Scalloped Potatoes and Ham or Sausage-At least 20\% ham or sausage (cooked basis).

Scallopini ("Veal Scallopini," for example)-At least $35 \%$ meat (cooked basis).

Scrambled Eggs with Ham in a Pancake-At least $9 \%$ ham (cooked basis).

Scrapple-At least $40 \%$ meat and/or meat byproducts.

Shepherd's Pie-At least $25 \%$ meat; no more than $50 \%$ mashed potatoes.

Sloppy Joe-At least $35 \%$ meat (cooked basis). Must be qualified with true product name, "Barbecue Sauce with Beef."

Snack-At least $15 \%$ meat (cooked basis) or $10 \%$ bacon (cooked basis).

Spaghetti Sauce with Meat-At least $6 \%$ meat.

Spaghetti with Meat or Meatballs in Sauce-At least $12 \%$ meat.

Spanish Rice with Meat-At least $20 \%$ meat (cooked basis).

Stuffed Cabbage with Meat in Sauce-At least $12 \%$ meat.

Stuffed Pepper with Meat in Sauce-At least $12 \%$ meat.

Sukiyaki-At least $30 \%$ meat.

Sweet and Sour Meat-At least $25 \%$ meat and at least $16 \%$ fruit. 
Swiss Steak with Gravy-At least 50\% meat (cooked basis).

Tamale-At least $25 \%$ meat.

Tamale with Sauce or Gravy-At least $20 \%$ meat.

Tamale Pie-At least $20 \%$ meat; filling must be at least $40 \%$ of total product.

Taquito-At least $15 \%$ meat.

Tongue Spread-At least 50\% tongue.

Tortellini with Meat-At least $10 \%$ meat.

Tortellini with Meat in Sauce-At least $50 \%$ cooked meat tortellini.

Veal and Peppers in Sauce-At least 30\% meat (cooked basis).

Veal Bird-At least $60 \%$ meat and no more than $40 \%$ stuffing.
Veal Cordon Bleu-At least $60 \%$ veal, $5 \%$ ham, and containing swiss, gruyere, mozzarella, or pasteurized process swiss cheese.

Veal Fricassee-At least $40 \%$ meat.

Veal Parmigiana-At least $40 \%$ breaded veal in sauce.

Veal Scallopini-At least $35 \%$ veal (cooked Basis).

Veal Steak-Chopped, shaped, cubed, frozen. Beef can be added up to $20 \%$ with product name shown as, "Veal Steaks, Beef Added, Chopped, Shaped, and Cubed," If more than $20 \%$ beef, must be labeled," "Veal and Beef Steak, Chopped, Shaped, and Cubed," No more than $30 \%$ fat in total product.

Vegetable and Meat Casserole-At least 25\% meat.

Vegetable and Meat Pie-At least 25\% meat.

Won Ton Soup-At least $5 \%$ meat.

\section{Poultry Products}

All percentages of poultry are on cooked, deboned basis unless otherwise indicated. When standard indicates poultry meat, skin, and fat, the skin and fat are in proportions normal to poultry.

\section{Baby Food}

High Poultry Dinner-At least 18 3/4\% poultry meat, skin, fat, and giblets.

Poultry with Broth-At least $43 \%$ poultry meat, skin, fat, and giblets.

Beans and Rice with Poultry-At least $6 \%$ poultry meat.

Breaded Poultry-No more than $30 \%$ breading.

\section{Canned Boned Poultry}

Boned (kind) Solid Pack-At least 95\% poultry meat, skin, and fat.

Boned (kind)-At least $90 \%$ poultry meat, skin, and fat. Boned (kind), with Broth-At least $80 \%$ poultry meat, skin, and fat.

Boned (kind), with Specified Percentage of Broth-At least $50 \%$ poultry meat, skin, and fat.

Cannelloni-At least $7 \%$ poultry meat.

Chicken Cordon Bleu-At least $60 \%$ boneless chicken breast (raw basis), 5\% ham, and either swiss, gruyere, or mozzarella cheese. (If breaded, no more than $30 \%$ breading).

Creamed Poultry-At least $20 \%$ poultry meat. Product must contain some cream.

Egg Roll with Poultry-At least $2 \%$ poultry meat.
Eggplant Parmigiana with Poultry-At least $8 \%$ poultry meat.

Entree: Poultry or Poultry Food Products and One Vegetable-At least $37 \frac{1 / 2}{\%}$ poultry meat or poultry food product.

Gravy with Poultry-At least $15 \%$ poultry meat.

Noodles or Dumplings with Poultry-At least $6 \%$ poultry meat.

Poultry a la Kiev-Must be breast meat (may have attached skin) stuffed with butter and chives.

Poultry a la King-At least $20 \%$ poultry meat.

Poultry Almandine-At least $50 \%$ poultry meat. Product must contain almonds.

Poultry Brunswick Stew-At least $12 \%$ poultry meat. Must contain corn.

Poultry Burgers-100\% poultry, with skin and fat not in excess of natural proportions.

Poultry Burgundy-At least $50 \%$ poultry meat; enough wine to characterize the product.

Poultry Burrito-At least $10 \%$ poultry meat. 
Poultry Cacciatore-At least $20 \%$ poultry meat, or $40 \%$ with bone.

Poultry Casserole-At least $18 \%$ poultry meat.

Poultry Chili-At least $28 \%$ poultry meat.

Poultry Chili with Beans-At least $17 \%$ poultry meat

Poultry Chop Suey-At least $4 \%$ poultry meat.

Poultry Chow Mein (without noodles)-At least $4 \%$ poultry meat.

Poultry Creole with Rice-At least $35 \%$ cooked meat in poultry and sauce portion. Not more than $50 \%$ rice in total product.

Poultry Croquette-At least $25 \%$ poultry meat.

Poultry Croquette with Macaroni and Cheese-At least $29 \%$ croquettes.

Poultry Dinner (a frozen product)-At least $18 \%$ poultry meat, figured on total meal menu minus appetizer, bread, and dessert.

Poultry Empanadillo (a poultry turnover)-At least $25 \%$ poultry meat.

Poultry Fricassee-At least $20 \%$ poultry meat.

Poultry Fricassee of Wings-At least $40 \%$ poultry wings (cooked basis, with bone).

Poultry Hash-At least $30 \%$ poultry meat.

Poultry Lasagna-At least $8 \%$ poultry meat (raw basis).

Poultry Livers with Rice and Gravy-At least $30 \%$ livers in poultry and gravy portion, or $17 \frac{1}{2} \%$ in total product.

Poultry Meat Loaf-A minimum of $65 \%$ raw poultry or $50 \%$ poultry meat, and a maximum of $12 \%$ extenders.

Poultry Paella-At least $35 \%$ poultry meat or $35 \%$ poultry meat and other meat (cooked basis); no more than $35 \%$ cooked rice. Must contain seafood.

Poultry Parmigiana-At least $40 \%$ breaded poultry.

Poultry Pie-At least $14 \%$ poultry meat.

Poultry Ravioli-At least $2 \%$ poultry meat.

Poultry Roll-No more than $3 \%$ binding agents, such as gelatin, in the cooked product; no more than $2 \%$ natural cooked-out juices.

Poultry Roll with Broth-Contains more than $2 \%$ poultry broth in addition to natural cooked-out juices.
Poultry Roll with Gelatin-Gelatin exceeds $3 \%$ of cooked product.

Poultry Roll with Natural Juices-Contains more than $2 \%$ natural cooked-out juices.

Poultry Salad-At least $25 \%$ poultry meat (with normal amounts of skin and fat).

Poultry Scallopini-At least $35 \%$ poultry meat.

Poultry Soup

Ready-to-Eat-At least $2 \%$ poultry meat.

Condensed-At least $4 \%$ poultry meat.

Poultry Stew-At least $12 \%$ poultry meat.

Poultry Stroganoff-At least $30 \%$ poultry meat and at least $10 \%$ sour cream or a "gourmet" combination of at least $71 / 2 \%$ sour cream and $5 \%$ wine.

Poultry Tamale-At least $6 \%$ poultry meat.

Poultry Tetrazzini-At least $15 \%$ poultry meat.

Poultry Turnover-At least $14 \%$ poultry meat.

Poultry Wellington-At least $50 \%$ boneless poultry breast spread with a liver or similar pate coating and covered in not more than $30 \%$ pastry.

Poultry with Gravy-At least $35 \%$ poultry meat.

Poultry with Gravy and Dressing-At least $25 \%$ poultry meat.

Poultry with Noodles au Gratin-At least $18 \%$ poultry meat.

Poultry with Noodles or Dumplings-At least $15 \%$ poultry meat, or $30 \%$ with bone.

Poultry with Rice-At least $15 \%$ poultry meat.

Poultry with Vegetables-At least $15 \%$ poultry meat. Sauce with Poultry or Poultry Sauce-At least $6 \%$ poultry meat.

Stuffed Cabbage with Poultry-At least $8 \%$ poultry meat.

Stuffed Peppers with Poultry-At least $8 \%$ poultry meat.

Turkey Ham-A product made with cured turkey thigh meat only. 


\section{Definitions}

Some terms used throughout this document are defined below:

Binders, Extenders-Binders and extenders help to hold a meat or poultry product together, and also aid in retaining product moisture. Sometimes, these ingredients are used to supplement the required minimum amount of meat or poultry present in a product.

Cure-Curing ingredients are used to preserve such products as ham, frankfurters, and bacon. They also give these products their characteristic taste and color. Today, almost all curing of meats is done by adding limited amounts of nitrite in combination with salt during processing. If nitrite-cured products are stored are the proper temperature, the presence of nitrite prevents the growth of organisms that cause botulism in humans.

Meat-Meat comes from the muscles of cattle, sheep, swine, and goats. "Skeletal" meat refers to the muscular cuts which were attached to the animal's bone structure. Muscle found in the tongue and heart is also defined as "meat," but is permitted only in some meat products. Regulations require that all meats be identified by species (type) of animal, and, if meat from the tongue or heart is used, it must be named in the list of ingredients.

Meat Byproducts (sometimes known as "variety meats")These terms refer to the edible and wholesome parts of cattle, sheep, swine, and goats, other than skeletal meat. Whenever byproducts are added to meat products, each specific byproduct must be named in the list of ingredients.

Meat Food Product (also known as "meat product")-Any food suitable for human consumption made from cattle, sheep, swine, or goats, containing more than 3 percent meat.

Poultry-All domesticated birds (chickens, turkeys, ducks, geese, guineas).
Poultry Byproducts-All edible parts of poultry other than sex glands and "poultry meat."

Poultry Food Product (also known as "poultry product"Any food suitable for human consumption made from any domesticated bird, containing more than 2 percent poultry meat.

Poultry Meat-This term refers to the white and dark meat portions of deboned poultry, excluding fat, skin, and other edible poultry parts.

Vegetable (Plant) Protein-Vegetable protein products derived from soybeans may be used as binders or extenders in such meat and poultry products as sausages, luncheon meats, soups, sauces, and gravies. Sometimes, they are the main ingredients in meat and poultry product substitutes. Soybeans are processed into three basic soy protein products: soy flour, soy protein concentrate, and isolated soy vegetable protein. Whenever soy protein is added to a meat or poultry product, its presence is noted in the ingredient statement on the label. In some instances, it is also included in the product name, e.g., "Beef and Textured Vegetable Protein Burritos." 


\title{
Appendix D
}

\section{Test Method for Compressed Gases}

\author{
for inclusion into Handbook 133
}

4.6.4. Method D: Determining the Net Contents of Compressed Gas in Cylinders. These procedures are for industrial compressed gas.

Compressed gas may be labeled by weight (for example, LP gas or carbon dioxide) or by volume. Acetylene, liquid oxygen, nitrogen, nitrous oxide, and argon are filled by weight, but sold by cubic feet (acetylene) or by liters (for the other products listed). Helium, gaseous oxygen, nitrogen, air, and argon are filled following pressure and temperature tables. Checking the net contents of compressed gas cylinders depends on the method of fill; those filled by weight may be checked by weight. It is unnecessary to connect the cylinder to anything, but it may be necessary to move the cylinder to weigh it. In addition, it may be necessary to schedule testing over a 2-day period if acetylene is one of the products to be checked; it takes from 10 to 12 hours to fill acetylene cylinders. Once the tare weight has been determined, it will require another day to test filled cylinders for which the tare weight is known.

Those cylinders filled by using pressure and temperature charts must be tested by connecting a pressure gauge to the cylinder and determining the pressure and temperature.

Safety is a primary concern with all testing procedures.

\section{A.Safety}

Anyone handling a compressed gas cylinder must be made aware of the hazards of high pressures found with any compressed gas. Untrained or partially trained individuals should not be allowed to handle compressed gas.

It is essential that anyone handling a cylinder of gas or cryogenic liquid be certain of the contents before the cylinder is connected to anything. Discharging a gas or cryogenic liquid through a system for which the material is not intended could result in damage due to the incompatibility of the system and the product. A fire and/or explosion could be the result of such a mistake.

Before connecting a cylinder to anything, be certain of the following:

1. The cylinder is clearly marked or labeled with the name of the contents and that there are no conflicting marks or labels. Do not rely on the color of the cylinder to identify the contents of a cylinder.

2. The marked or labeled contents are all correct.

3. The cylinder is provided with the correct Compressed Gas Association (CGA) connection(s) for the product.

4. The connection(s) on the cylinder properly fits the system. A proper connection will go together smoothly. Do not use excessive force. Do not use an adaptor to connect oxygen to non-oxygen cleaned equipment.

5. Personnel moving or using cylinders are trained and knowledgeable regarding the product, cylinder, fittings, and proper procedures. See CGA pamphlet P-1 "Safe Handling of Compressed Gases in Containers," for additional information.

Warning! Failure to observe the precautions above is reported to have caused fatalities. 


\section{B. Additional Safety Warnings}

1. The inspector must have a thorough knowledge of the procedure, with emphasis on safety precautions, before attempting any tests. Charts referred to in the procedure should not be furnished to inspectors until the necessary training has been completed.

2. The inspector must be extremely careful with all gases since some react violently when mixed or when coming in contact with other substances. For example, oxygen reacts violently when it comes in contact with hydrocarbons.

3. Always wear safety glasses when testing cylinders by the temperature-pressure method.

4. When moving a cylinder, always place the protective cap on the cylinder. Do not leave spaces between cylinders when moving them. This can lead to a "domino" effect if one cylinder is pushed over.

5. When a cylinder valve is opened to measure the internal pressure, position your body away from the pressure gage blowout plug or in front of the gauge if the gauge has a solid cast front case. If the bourdon tube should rupture, you do not want to be in a position to receive serious injuries from gas pressure or fragments of metal.

6. Open all valves slowly. A failure of the gauge or other ancillary equipment can result in injuries to nearby persons. Remember: high gas pressure can propel objects with great force. Gas ejected under pressure can also cause serious bodily injuries if someone is too close during release of pressure.

7. One of the gauges shall be reserved for testing oxygen only and shall be prominently labeled "For Oxygen Use Only." See 4.6.4. (A) 2. This gauge must be cleaned for oxygen service and maintained in that "clean" condition.

8. The other gauge(s) may be used for testing a variety of gases if they are compatible with one another.

9. Special precautions must be observed with flammable gas in cylinders, in addition to the several precautions necessary for the safe handling of any compressed gas in cylinders.

Contrary to general practice with other gas cylinders, do not "crack" cylinder valves of flammable gas before connecting them to a regulator or test gauge. This is extremely important for hydrogen or acetylene.

10. Additional precautions necessary for personal safety are described in the Handbook of Compressed Gases. All personnel testing compressed gases should have this manual for reference and be familiar with its contents.

C. Equipment

1. Scale, calibrated weights, and ramp.

2. Two (2) calibrated precision bourdon tube gauges or any other approved laboratory-type pressure-measuring device that can be accurately read within plus or minus 5 psi. A gauge having scale increments of 25 psi or smaller shall be considered as satisfactory for reading within plus or minus 5 psi. The range of both gauges shall be a minimum of 0 to 5000 pounds per square inch when testing cylinders with standard industrial cylinder valve connections. Standard industrial cylinder connections are those connections listed in CGA Standard V-1, Standard for Compressed Gas Cylinder Valve Outlet and Inlet Connections, ${ }^{1}$ for use with gas pressures up to $3000 \mathrm{psig}$ $(20680 \mathrm{k} \mathrm{Pa}$ ). For testing cylinders with cylinder valve connections rated for over $3000 \mathrm{psig}$, the test gauge and its inlet connection must be rated at 2000 psig over the maximum pressure that the connection is rated for in CGA V-1. (Note that there are standard high pressure industrial connections on the market that are being used up to their maximum pressure of 7500 psig.)

Any gauge or connectors used with oxygen cylinders must be cleaned for oxygen service, transported in a manner which will keep them clean and never used for any other gas including air or oxygen mixtures. Oxygen will react with hydrocarbons and many foreign materials and can result in fire or explosion.

3. An approved and calibrated electronic temperature measuring device or three calibrated mercury-in-glass thermometers having either a digital readout or scale division of no more than 1 degree. The electronic device equipped with a surface temperature sensor is preferred over a mercury-in-glass thermometer because of its shorter response time. 
4. Safety glasses.

5. Two wrenches. Box wrenches of $11 / 8$ inch for oxygen, nitrogen, carbon dioxide, argon, helium, and hydrogen and $7 / 8$ inch for some sizes of propane. All industrial CGA connections are limited to these two hex sizes. Use of an adjustable wrench should be avoided because of the tendency to round the edges of the fittings which can lead to connections not being tightened properly.

6. It is best to use a separate gauge and fitting for each gas to be tested. If adaptors must be used, be sure that they are never used on oxygen systems.

\section{D.Procedure}

Containers must be labeled in compliance with NIST Handbook 130 requirements. Containers which do not bear a labeled statement of net quantity will be marked "off sale" until the containers are brought into compliance.

\section{Testing by Weight}

(a) The cylinder is stamped or stenciled with a tare weight. This is a safety feature that assists the filling plant in many of its filling operations. It may or may not be the weight used by the filling plant when determining the net weight of those cylinders sold or filled by weight. If there is a tare weight marked on the net contents tag or directly on the cylinder, then an actual tare weight was determined at the time of fill. If there is no tare weight marked on a tag or on the cylinder, then the stamped or stenciled tare weight was used to determine the net contents. When the stamped or stenciled tare weight is used in net contents determinations, the inspector should check the accuracy of the stamped tare weights. The actual tare weight must be within

(1) $1 / 2$ percent of the stamped tare weight for $20 \mathrm{lb}$ tare weights or less, or

(2) $1 / 4$ percent of the stamped tare weight for greater than $20 \mathrm{lb}$ tare weights.

(b) Place cylinder on scale.

(c) Remove protective cap. The cap is not included in the tare weight. The tare does include acetone when acetylene cylinders are tested.

(d) Weigh the cylinder and determine net weight. Compare actual net weight with labeled net weight or use the actual net weight to look up the correct volume declaration and compare that with the labeled volume.

(e) The acetone in acetylene cylinders is included in the tare weight of the cylinder. Therefore, as acetylene is withdrawn from the cylinder, some acetone will also be withdrawn, changing the tare weight. Most producers will replace acetone in the cylinder before the cylinder is refilled, filling the cylinder with acetone to the stamped tare weight. Other producers, although not following recommended procedures, do not replace the acetone until it drops to a specified weight. In the latter situation, the refilling plant must note the actual tare weight of the cylinder and show it on the tag containing the net content statement or on the cylinder itself.

(f) Refer to tables for acetylene gas if necessary (that is, if the acetylene is billed by the cubic foot). See (d) above.

\section{Volumetric Testing}

(a) Thermometers or temperature sensors used for measuring temperatures during testing of cylinder gases shall be in contact with the outside surface of the cylinder approximately at the midpoint of the longitudinal axis.

(b) The cylinders to be tested for quantity shall be taken from a lot that has had time to stabilize at the ambient temperature. Normally, the outside row of cylinders should not be selected for testing since they may be of a different temperature. The temperature used shall be an average taken from three cylinders selected at random. Cylinders that are exposed to heat or sunlight shall not be chosen for test unless an electronic heat sensor is used to measure the temperature of each cylinder. This is the preferred method of measuring the cylinder temperature because there can be differences in temperature from cylinder to cylinder, and the electronic sensors will stabilize within a few seconds. It is not practical to measure the temperature of each cylinder with a mercury-in-glass thermometer due to the time required for the thermometer to stabilize. 
(c) Measure the pressure of each cylinder in the sample selected.

(d) Determine the temperature of the cylinders in the sample selected.

(e) Determine the cylinder nominal capacity from cylinder data table.

(f) Refer to NIST Tech Note 1079 and compute the actual net content. ${ }^{2}$

1."Standard For Compressed Gas Cylinder Valve Outlet and Inlet Connections," Compressed Gas Association, 1235 Jefferson Davis Highway, Arlington, VA 22202.

2."NBS Technical Note 1079," U.S. Department of Commerce, National Institute of Standards and Technology, Gaithersburg, MD 20899. 


\title{
Report of the Specifications and Tolerances Committee
}

\author{
David Watson, Chairman \\ Consumer Products Supervisor \\ City of Fort Worth, Texas
}

This is the Final Report of the Committee on Specifications and Tolerances for the 75th Annual Meeting of the National Conference on Weights and Measures. This report is based on the Interim Report offered in the Conference "Program and Committee Reports" (NCWM Publication 16), the Addendum Sheets issued at the Anuual Meeting, and actions taken by the membership at the Voting Session of the Annual Meeting.

Table A identifies the items in the Report by Reference Key Number, Item Title, and Page Number. Table B reports the voting results. Voting items are indicated with a " $\mathrm{V}$ " after the item number. At the Annual Meeting, the committee grouped the less controversial voting items into a consent calendar. These are marked with "VC." Items marked with an "I" after the reference key number are information items. The items marked with a "W" were withdrawn by the Committee.

The attached Report contains many revisions and amendments to the National Institute of Standards and Technology (NIST) Handbook 44, 1991 Edition, "Specifications, Tolerances, and other Technical Requirements for Weighing and Measuring Devices." Revisions to the handbook are shown in bold face print by crossing out what is to be deleted, and underlining what is to be added. Requirements that are proposed to be nonretroactive are printed in italics. Entirely new paragraphs or sections proposed for addition to the handbook are designated as such and shown in bold face print.

Table A

Index to Reference Key Items

Reference

Key No.

Title of Item

Page

\section{General Code}

$310-1$

$310-2$

$310-3$

$310-4$

$310-5$

$310-6$

$310-7$

I G-S.1. Identification; NTEP Certificate of Conformance . . . . . . . . . . . 134

W G-S.1. Identification; Year of Manufacture ................... 136

W G-S.8. Provision for Sealing Electronic Adjustable Components; Terminology . . . . . 136

I G-S.8. Provision for Sealing Electronic Adjustable Components; Scope . . . . . . . . 136

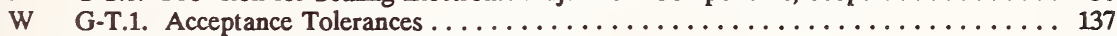

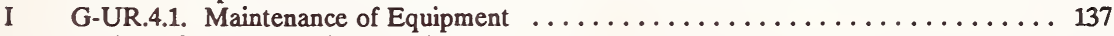

VC Review of Nonretroactive Requirements . . . . . . . . . . . . . 138 
Table A (Continued)

Reference

Key No.

Title of Item

Page

\section{Scales Code}

320-1 VC S.1.7. Capacity Indication, Weight Ranges, and Unit Weights; Initial Zero-Setting

Mechanism ..................................... 138

$320-2$

$320-3$

$320-4$

$320-5$

$320-6$

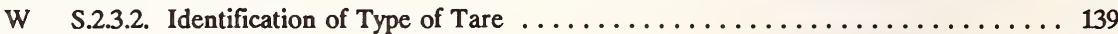

VC S.6. Marking Requirements; Table Format . ................... 139

VC S.6.11. Marking Requirements; Load Cells ...................... 145

VC N.3.1. Minimum Test-Weight Load for Railway Track Scales ................. 145

V Proposed Test Procedures and Tolerances for Coupled-In-Motion Railway Track

Scales .................................. 146

320-7 I Weighing Individual Railroad Cars for Custody Transfer; Liquids in Tank Cars ..... 151

320-8 I Weighing Individual Railroad Cars for Custody Transfer; Mixed Manifest Trains ..... 152

320-9 V T.1. Tolerances for Unmarked Scales; Reorganization . . . . . . . . . . . . . . 153

320-10 V T.1. Tolerances for Unmarked Scales; Revision . . . . . . . . . . . . . . . . 156

320-11 V T.N.1. Principles; Multiple-Weighing Devices Interfaced with a Single Indicator ..... 157

320-12 V T.N.8.1.3. Temperature Effect on Zero-Load Balance . . . . . . . . . . . . . . . . . 159

320-13 I UR.1.1. Selection Requirements; Suitability of Equipment $\ldots \ldots \ldots \ldots \ldots \ldots \ldots \ldots$

320-14 I UR.1.1. Selection Requirements; On-Board Weighing Systems . . . . . . . . . . 161

320-15 VC UR.3.1. Recommended Minimum Load; Weight Classifiers . . . . . . . . . . . . 162

320-16 I UR.3.1.1. Minimum Load, Grain Dockage Determination; Value of the Scale

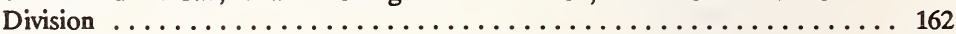

320-17 I T.1. Tolerance Values; In-Motion Weighing, Monorail Scales ................ 163

\section{Belt-Conveyor Scale Systems}

321-1 VC $\quad$ N.3.3. Simulated Load Tests ........................... 163

\section{Liquid-Measuring Devices}

330-1 I S.3. Discharge Lines and Valves ......................... 164

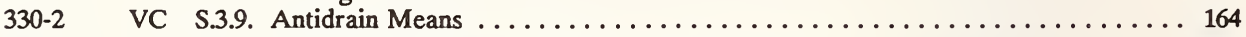

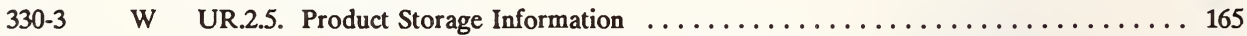

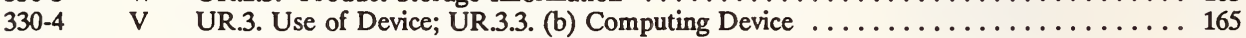

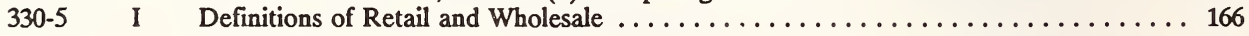

\section{Liquefied Petroleum Gas and Anhydrous} Ammonia Liquid-Measuring Devices

\section{Hydrocarbon Gas Vapor-Measuring Devices}

333-1 VC N.4.2.2. Low-Flame Test ............................ 168

333-2 VC LPG Vapor Meters Installed Adjacent to Heaters Vaporizing LP Gas $\ldots \ldots \ldots \ldots \ldots 169$

\section{Water Meters}


Table A (Continued)

Reference

Key No.

\section{Odometers Code}

353-1 VC S.1.6. Digital Indications and Representation

Taximeters

354-1 VC S.1.3.2. Lighting of Indications ......................... 170

354-2 VC S.6. Short-Term Power Interruption, Electronic Taximeters . . . . . . . . . . . . 171

354-3 I T.1.2.2. On Average Time Interval Computed After Excluding the Initial Interval .... 172

354-4 VC S.2.1. Initial Time and Distance Interval; UR.3. Statement of Rate . . . . . . . . 173

Other Items

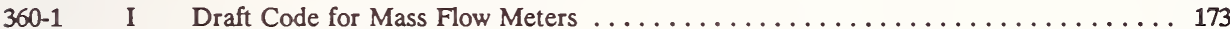

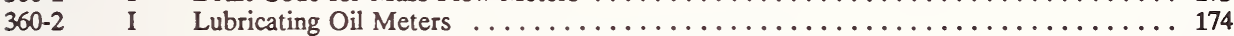

360-3 I Draft Carbon Dioxide Liquid-Mieasuring Devices Code $\ldots \ldots \ldots \ldots \ldots \ldots \ldots \ldots$

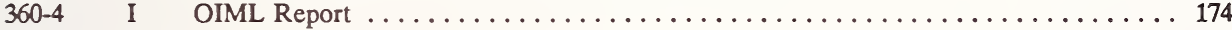

\section{Order of Presentation}

The Report was presented to the membership for voting as follows:

1. A single vote was taken on the consent calendar.

2. A separate vote was taken on each of the separate voting items listed in Table C.

3. A vote was taken on the entire Report with editorial privileges accorded to the Executive Secretary. 
Table C

Voting Results

\begin{tabular}{lllllll}
\hline $\begin{array}{l}\text { Reference } \\
\text { Key No. or } \\
\text { Subject }\end{array}$ & $\begin{array}{l}\text { House of State } \\
\text { Representatives }\end{array}$ & & & $\begin{array}{l}\text { House of } \\
\text { Delegates }\end{array}$ & Results \\
\cline { 2 - 3 } \cline { 5 - 6 } & Yes & No & & Yes & No & \\
\hline Consent Calendar & 44 & 0 & 77 & 0 & Passed \\
$320-6$ & 34 & 8 & 63 & 2 & Passed \\
$320-9$ & 42 & 3 & 68 & 3 & Passed \\
$320-10$ & 44 & 0 & 69 & 1 & Passed \\
$320-11$ & 40 & 2 & 66 & 1 & Passed \\
$320-12$ & 44 & 0 & 68 & 0 & Passed \\
$330-4$ (Item 1) & 17 & 27 & 42 & 34 & Failed \\
$330-4$ (Item 2) & 42 & 2 & 54 & 16 & Passed \\
Entire Report & 44 & 0 & 34 & 0 & Passed \\
\hline
\end{tabular}

\section{Details of All Items}

\section{0-1 I G-S.1. Identification; NTEP Certificate of Conformance}

Discussion: A significant number of States require a device to have an NTEP Certificate of Conformance before it may be used in commercial applications, and generally want the certificate number indicated on the device to aid the enforcement official in determining whether or not a device has received a Certificate of Conformance. In earlier Conferences, weights and measures officials had proposed that noncommercial devices be marked "Not Legal For Trade" so that devices not designed to meet Handbook 44 requirements would not be used in commercial applications. These proposals had been opposed by industry and some weights and measures officials because the statement "Not Legal For Trade" has a negative connotation. Some officials questioned whether they had jurisdiction over noncommercial devices to require this marking. The Committee believes that marking the NTEP Certificate of Conformance number will serve as a positive indication that a device meets Handbook 44 requirements.

The Committee originally recommended that a mark of "NTEP Pending" be used on a device for which a type evaluation has been requested but not yet completed. This recommendation appeared to create more problems than it solved, so the proposed marking of "NTEP Pending" is withdrawn. Therefore, only the marking of the NTEP Certificate of Conformance number is recommended.

The proposal to include the marking of the Certificate number as part of the General Code paragraph G-S.1. was opposed by many Conference members as being too broad. Generally, it appears that weights and measures officials want the Certificate number marked on scales and liquid measuring devices, which represent the largest number of 
devices falling under routine weights and measures enforcement. The Certificate of Conformance number is not believed to be necessary on equipment such as linear measures, berry baskets, and other categories of devices that have not posed significant enforcement problems. Consequently, the Committee recommends that the requirement to mark the Certificate of Conformance number be placed directly into the Scales Code and the Liquid-Measuring Devices Code (Handbook 44 Sections 2.20 and 3.30, respectively). These are the main areas in which there is a problem of determining whether or not a device has a Certificate of Conformance. The marking of other types of devices will be considered on a case by case (code by code) basis.

It is emphasized that the proposed requirement would not permit the installation of a device in those States that require an NTEP Certificate of Conformance until after the NTEP Certificate of Conformance number has been issued. Weights and measures officials are advised that NTEP does not perform type evaluations on all types of weighing or measuring equipment; consequently, not all devices will have Certificate of Conformance numbers. Manufacturers are encouraged to use one of the prefixes NTEP, NTEP No., or NTEP \# to identify the NTEP Certificate of Conformance number if the requirement is adopted by the Conference.

In general, the industry is opposed to this marking requirement, stating that:

1. it will create an administrative problem for the industry in the production process;

2. the marking will have limited benefit;

3. the Certificate of Conformance marking by itself does not assure that a device meets all the requirements of Handbook 44 or that it is suitable for the application for which it has been installed; and

4. the delays in obtaining a type evaluation can interfere with the marketing of a device.

The marking of the NTEP certificate number will not eliminate the need for the inspector to determine that the device is the correct model listed on the Certificate of Conformance and that theHP LaserJet Series IIt feed)HPLASEII.PRSvalue, accuracy, and other characteristics are suitable for the application. Even if a device has a Certificate of Conformance, new production devices must comply with any new or amended requirements of Handbook 44 when the date of manufacture is after the effective date of the new requirement.

Although this proposal will place an additional marking requirement on the manufacturers of devices, the Committee believes that the marking of the NTEP Certificate of Conformance number will result in substantial benefits to device users and enforcement officials. The selling and placing into commercial service of devices that have not been designed to meet Handbook 44 requirements has been a long-standing and continuing problem. Marking with the NTEP number should aid potential purchasers to obtain devices that are suitable for commercial use.

The Committee has concluded that many aspects of this issue must be studied further before the NTEP Certificate of Conformance number can be required to be marked on devices. Issues that must be addressed include which devices, main elements, and components of both scales and liquid-measuring devices must be marked, what markings are required when the same hardware (computer model) is used in different applications with different software, the process of incorporating updated Certificate numbers into production, and if office computers used as part of loading rack meter systems must be marked with Certificate numbers. Consequently, the S\&T Committee has changed this item from a voting item in 1990 to an information item with the intent to present the item for a vote in 1991. The Committee appreciates the strong support and desire among weights and measures officials for this marking requirement.

Committee Recommendation: To aid in further study and development of this issue, the Committee is making the following changes to this item.

The Committee recommends additions to the Scales Code and the Liquid-Measuring Devices Code to require that the NTEP (National Type Evaluation Program) Certificate of Conformance number be marked on devices and associated equipment after the number has been issued. The marking requirement also applies to all equipment, that is, to each part of a device that receives a separate Certificate of Conformance. Examples of equipment that, if evaluated separately, will be required to be marked with the NTEP Certificate number include scales, indicating elements, scales without indicating elements, load cells, retail motor fuel dispensers, loading rack meters, measuring elements evaluated separately, service station consoles, and any other device or equipment that is evaluated separately and falls under the requirements of these two Codes. A point-of-sale systems is not required to have the Certificate of Conformance number unless it serves as the primary indicating element for a scale or measuring device.

The Committee recommends that a marking requirement S.6.12. be added to the Scales Code to read: 
S.6.12. NTEP Certificate of Conformance Number. - The NTEP Certificate of Conformance number shall be marked on load cells with an NTEP Certificate of Conformance, scales in a single enclosure, separate indicating elements, and scales without indicating elements.

[Nonretroactive as of January 1, 199x]

If this recommendation and the table format for marking requirements (Item 320-3) are adopted, this marking requirement will be included as part of the table of marking requirements.

The Committee recommends the addition of a similar requirement to the Liquid-Measuring Devices Code as paragraph S.4.5. to read:

\section{S.4.5. NTEP Certificate of Conformance Number. - The NTEP Certificate of Conformance number shall be marked on retail motor fuel dispensers, loading rack meters, measuring elements evaluated separately, and service station consoles.}

[Nonretroactive as of January 1, 199x]

\section{0-2 W G-S.1. Identification; Year of Manufacture}

(This item was withdrawn.)

Discussion: This item proposed marking the year of manufacture on devices to assist the weights and measures official in the proper application of nonretroactive requirements. It is often very difficult for the enforcement official to determine if a nonretroactive requirement applies to a specific device. The proposal also suggested establishing a task force to explore the possibility of encoding the year of manufacture and other required marking information to reduce the cost of marking this information on the device.

The Committee received comments in strong opposition to this proposal. Many manufacturers believe that the benefits of this marking requirement are minimal and do not justify the cost of complying with the requirement. Additionally, manufacturers anticipate marketing difficulties because customers may object to the installation of new equipment marked with a prior year of manufacture even if the product is of the latest design. The Committee also recognizes that the year of manufacture is only one of the criteria to determine if a nonretroactive requirement applies to the device. Consequently, the Committee has withdrawn this item.

Committee Recommendation: Withdrawn.

\section{0-3 W G-S.8. Provision for Sealing Electronic Adjustable Components; Terminology}

(This item was withdrawn.)

Discussion: The proposal suggested changing the term "metrological integrity" to "metrological characteristics" in an effort to state more clearly the scope of the sealing requirement. However, there was a lack of support for the proposal. Additionally, industry comments supported the understanding that metrological integrity includes more than just performance requirements, but does not extend to every programmable or selectable characteristic in a device. See Item 310-4 for further information on this subject.

Committee Recommendation: Withdrawn.

\section{$310-4$ \\ I G-S.8. Provision for Sealing Electronic Adjustable Components; Scope}

Discussion: There is no uniform understanding and acceptance of the types of features and adjustments to be sealed as a result of the change to G-S.8. The Committee intended the scope of the provision for sealing to include more than just performance criteria. (When the 1989 changes to G-S.8. were adopted, the features listed as examples in the 1988 and 1989 Reports of the S\&T Committee were to have provision for sealing.) There are still significant 
differences among industry representatives, weights and measures officials, and the S\&T Committee regarding the specific features that are required to have provision for sealing based upon the changes adopted in 1989. The S\&T Committee requests the assistance of the three Sectors of the NTEP Technical Committee to establish guidelines for judging what must be sealed and to define the features and characteristics that shall have provision for sealing.

The device adjustment mechanisms, features, and characteristics under review can be divided into at least the following categories:

1. Provision for sealing required. Access to electronic adjustment mechanisms that affect the performance characteristics of a device has been required since G-S.8. was adopted in 1985.

2. Provision for sealing not required. Access to operator files, such as shift totals, unit prices, and price-look-up files is generally accepted as not requiring provision for sealing.

3. Provision for sealing not expected. The setting of device configuration parameters, such as programming the number of hoses on a retail motor fuel dispenser, the types of product dispensed, whether or not a card reader is provided, and whether or not the dispenser is programmed for multi-tier pricing is generally not expected to have provisions for sealing.

The main areas of disagreements on which features and characteristics should have provision for sealing are:

1. the selection of operating parameters that can affect device compliance with Handbook 44; and

2. the selection of device features that are operational during commercial use and which can affect the suitability of a device for use in a commercial application.

It is unrealistic to require every minor characteristic of a device to be sealed. Judgments will be required as to what must be sealed, based on the difficulty of changing a setting and the potential for fraudulent use of a selectable feature. Discussions should address whether or not provision for sealing should be required on the access to settings for which, once an operating parameter or feature is selected at the time of installation, there is no reason for that feature or parameter to change during the normal use of the device in that installation. Comments from weights and measures officials are encouraged regarding their understanding of the intent of the 1989 change and the features and device characteristics that should have provision for sealing.

Committee Recommendation: The Committee emphasizes that interpretation of Handbook 44 is the purview of the S\&T Committee. The NTEP Technical Committee Sectors are requested to develop guidelines and lists of characteristics to be sealed and to submit their recommendations to the S\&T Committee by November 1, 1990. The S\&T Committee will review the recommendations and, if they agree with the interpretations, modify them as deemed necessary and present the results to the Conference for a vote. The industry is reminded that, when new features or device characteristics are incorporated in new devices, the NTEP laboratories will make the type evaluation decisions on an "ad hoc" basis to determine whether or not these new features must be sealed.

\section{0-5 W G.T.1. Acceptance Tolerances}

(This item was withdrawn.)

Discussion: This item proposed applying acceptance tolerances to a device whenever the security seal is broken. The Committee concluded that the broad coverage of the proposed change would create unreasonable accuracy requirements when a seal is broken due to service or maintenance for operations unrelated to performance (accuracy), e.g., ticket jammed in the printer of a meter. The proposal would require acceptance tolerances to apply whenever the security seal has been changed. The application of this requirement to a device utilizing an audit trail, as compared to a physical security seal being broken, would have to be studied. The possible ramifications of this proposal have not been sufficiently developed to evaluate the proposal.

Committee Recommendation: Withdrawn.

\section{0-6 I G-UR.4.1. Maintenance of Equipment}

Discussion: This item is based on a request to develop guidelines to assist in the uniform application of G-UR.4.1. and is not a proposal to change the language of Handbook 44. The Committee supports the concept of developing 
guidelines for the enforcement of this requirement; however, this would take considerable time and study. Because of the great variety of situations that arise in the enforcement process and conditions influencing the decision in a specific instance, it may not be possible to develop universally applicable guidelines. Judgment on the part of the enforcement official will still be necessary.

Committee Recommendation: Continue to study this proposal.

\section{VC Review of Nonretroactive Requirements}

(This item was adopted as part of the consent calendar.)

Discussion: It is the Conference policy to review nonretroactive requirements periodically to determine if they should be made retroactive. Based upon the comments received, it appears that virtually all devices currently in commercial use comply with G-S.5.3.1. and G-S.5.6. Making these requirements retroactive should have very little impact on existing devices. The Committee reviewed the General Code paragraphs G-S.1. and G-S.6, and the Scales Code paragraphs S.2.1.3., S.2.3., and T.5., but decided to retain them as nonretroactive requirements. The comments on these latter paragraphs indicated that a considerable number of older devices are still in the field. If these paragraphs were made retroactive, extensive modification would often be required to bring the devices into compliance.

Committee Recommendation: The Committee recommends making the General Code paragraphs G-S.5.3.1. and G-S.5.6. retroactive.

\section{Scales Code}

$320-1$

\section{VC S.1.7. Capacity Indication, Weight Ranges, and Unit Weights; Initial Zero-Setting Mechanism}

(This item was adopted as part of the consent calendar.)

Discussion: An initial zero-setting mechanism allows a manufacturer to electronically and automatically compensate for the variation in the dead load of scale platforms instead of manually adjusting the weight of platforms or adjusting the electronics to satisfy S.1.7. These changes would be consistent with the OIML (International Organization of Legal Metrology) draft International Recommendation for Non-Automatic Weighing Instruments.

Permitting the use of an initial zero-setting mechanism will allow scales to zero up to 20 percent of the scale capacity when the unit is first connected to its power supply without the need for any additional testing during type evaluation. The scale would still be required to indicate up to 100 percent of its capacity and be accurate. No special testing would be required during type evaluation if the maximum amount of weight that can be zeroed when power is supplied does not exceed 20 percent.

A scale will be permitted to zero more than 20 percent when power is first supplied; however, additional testing must be performed during type evaluation to verify that the scale can satisfy the influence factors requirements when the maximum range of the initial zero-setting mechanism is utilized. If a scale is able to zero more than 20 percent of capacity, then the maximum amount of weight that can be zeroed must be zeroed during the type evaluation process and the complete set of type evaluation tests must be run to verify that the performance requirements are still satisfied.

The Committee believes this feature is appropriate on class I, II, and III scales. However, it does not seem appropriate or necessary to allow this feature on vehicle scales or other class III $\mathbf{L}$ scales.

Committee Recommendation: The Committee recommends permitting an initial zero-setting mechanism on class I, II, and III scales to automatically zero any dead load up to 20 percent of the scale capacity at the time the scale is switched on. A larger range is permitted if the scale is tested and found to be accurate. Any device that has an initial zero-setting mechanism must be accurate after it is placed into commercial service. The recommended changes to the Scales Code are listed below. 
Add a definition to read:

initial zero-setting device. Automatic means provided to set the indication to zero at the time the instrument is switched on and before it is ready for use.

Amend S.1.7. to read:

S.1.7. Capacity Indication, Weight Ranges, and Unit Weights. - An indicating or recording element shall not display nor record any values when the gross platform load (not counting initial dead load that has been cancelled by an initial zero-setting device) is in excess of 105 percent of the capacity of the system. The total value of weight ranges and of unit weights in effect or in place at any time shall automatically be accounted for on the reading face and on any recorded representation.

This requirement does not apply to: (1) single-revolution dial scales, (2) multi-revolution dial scales not equipped with unit weights, (3) scales equipped with two or more weighbeams, and (4) devices that indicate mathematically-derived totalized values.

Add a new paragraph S.2.1.5. to read:

\section{S.2.1.5. Initial Zero-Setting Mechanism. -}

(a) Scales of accuracy classes I, II, and III may be equipped with an initial zero-setting device.

(b) An initial zero-setting mechanism shall not zero a load in excess of 20 percent of the maximum capacity of the scale unless tests show that the scale meets all applicable tolerances for any amount of initial load compensated by this device within the specified range.

$320-2$

W S.2.3.2. Identification of Type of Tare

(This item was withdrawn.)

Discussion: This item proposed establishing a nonretroactive requirement to identify the type of tare (e.g., keyboard, push-button, or programmed tare) to be identified on the display of a scale, and with the printed tare value when more than one type of tare capability exists in a system. Although this additional definition of values is considered beneficial to tracing the actions of a transaction and may aid in determining if the appropriate type of tare has been taken, it does not guarantee the accuracy of the tare that was taken. Moreover, the abbreviations for the type of tare entry probably would not be meaningful to consumers. Consequently, this item is withdrawn.

Committee Recommendation: Withdrawn.

$320-3$

VC S.6. Marking Requirements; Table Format

(This item was adopted as part of the consent calendar.)

Discussion: At least 14 paragraphs in the General and Scales Codes require the manufacturer to mark specific information on a scale, a main element, or a component of a scale or weighing system. Both the manufacturer and enforcement official have difficulty in identifying the required markings applicable to a specific device or a specific part of a weighing system. The Scale Manufacturers Association (SMA) evaluated the many marking requirements and suggested that a table format, supplemented by additional notes as necessary to specify the applicability of specific requirements, would be a better reference source for the marking requirements. The Committee agrees with the SMA suggestion. The proposed table consolidates all of the marking requirements of the General Code and the Scales Code. The text of the General Code marking requirements would still be retained since they continue to apply to all of the other codes in Handbook 44. The marking requirements from the General Code must be satisfied as they are written there. The proposed summary information in the tables is simply an aid to locating the applicable requirements. 
Some changes were made when consolidating the text into abbreviated statements; however, they are considered minor and should not present problems in either device design or weights and measures enforcement. These are listed below to alert all interested parties to the effect of these changes.

1. The marking of the "scale without indicating element" with the serial number along with an identifying symbol is new. A serial number is not currently required on weighing elements because S.6.8. supersedes G-S.1. and does not specifically require a serial number. However, it is believed that most, if not all, weighing elements not permanently attached to indicating elements are already given a serial number. Moreover, the addition of this requirement has been supported by the Scale Manufacturers Association.

2. A scale normally consists of a digital indicating element, a weighing element, and a load-receiving element. The term "scale without indicating element" refers to the weighing element with the load-receiving element. The "scale without indicating element" is the portion of the scale that is "not permanently attached to an indicating element" as referenced in S.6.8.

3. The marking of the nominal capacity is summarized as applying to any device where the capacity is not immediately apparent. This one statement is to apply to those devices specifically identified in S.6.2.1.

4. A weight classifier has been added as an example for special marking restricting its application in order to draw attention to its special design. The special design of weight classifiers makes them inappropriate for many applications where scales are required to round to the nearest scale division. See note 13 in Tables $4 \mathrm{a}$ and $4 \mathrm{~b}$.

5. The interpretation of G-S.1. as it has been applied in the National Type Evaluation Program has been incorporated into notes 10 and 16 in Table $4 b$.

6. The marking requirements for load cells as proposed for amendment in Item 320-4 are included in the table and note 11. If Item $320-4$ is not adopted, note 11 will be changed accordingly.

In an effort to standardize the symbols used in marking devices, main elements, and components for the maximum number of scale divisions and the minimum verification value, the use of the following symbols is recommended (but is not required, except where already specified in Handbook 44):

n represents the number of scale divisions in a weighing system or in a weighing range for a multi-ranging scale (variable division-value scale).

$\mathrm{n}_{\max }$ represents the maximum number of scale divisions for which a main element or load cell complies with the applicable requirements of Handbook 44. Scales and other weighing systems may be installed to have fewer scale divisions $(\mathrm{n})$ than $\mathrm{n}_{\max }$. The maximum number of scale divisions permitted for an installation is limited to the lowest $\mathrm{n}_{\max }$ marked on the scale, indicating element, weighing element, or load cell.

e declares the verification scale division on a scale when e is different from the displayed scale division, $d$.

$\mathrm{e}_{\min }$ states the smallest scale division for which a weighing element complies with the influence factors requiremęnts of Handbook 44 (S.6.8.(f)).

$\mathrm{v}_{\min }$ marks the verification interval on load cells.

To assist in the review of the consolidation of the marking requirements into Table $4 \mathrm{a}$ and to aid in tracing the history of the marking requirements, a table titled "Code References for Proposed Table $4 a^{\text {" }}$ is included in this discussion to show the Handbook 44 references. 
Table 4a

S.6. Marking Requirements

\begin{tabular}{|c|c|c|c|c|c|c|}
\hline $\begin{array}{l}\text { Weighing } \\
\text { Equipment } \\
\text { Marked With }\end{array}$ & $\begin{array}{c}\text { Scale } \\
\text { Single } \\
\text { Enclosure }\end{array}$ & $\begin{array}{l}\text { Scale } \\
\text { Without } \\
\text { Indicating } \\
\text { Element }\end{array}$ & $\begin{array}{l}\text { Indicating } \\
\text { Element } \\
\text { Separate }\end{array}$ & $\begin{array}{l}\text { Load } \\
\text { Receiving } \\
\text { Element } \\
\text { (9) }\end{array}$ & $\begin{array}{l}\text { Other } \\
\text { Equipment } \\
\text { or Device } \\
\text { (10) }\end{array}$ & $\begin{array}{c}\text { Load } \\
\text { Cell } \\
\text { w/COC } \\
\text { (11) }\end{array}$ \\
\hline Manufacturer's ID & G-S.1. & G.S.1. & G-S.1. & $x$ & G-S.1. & $x$ \\
\hline Model Designation & G.S.1. & $x$ & G.S.1. & $x$ & G.S.1. & $x$ \\
\hline Serial Number and Prefix (2) & G.S.I. & $x$ & G-S.1. & $x$ & G-S.1. (16) & $x$ \\
\hline Accuracy Class & $x$ & $x$ & $x(8)$ & $x$ & & $x$ \\
\hline Nominal Capacity & $\mathbf{x}$ & $x$ & $x$ & $x$ & & \\
\hline Value of Scale Division (3) & $x$ & & $x$ & & & \\
\hline Value of "e" & $\mathbf{x}$ & & $x$ & & & \\
\hline Temperature Limits (5) & $x$ & $x$ & $x$ & & & $x$ \\
\hline $\begin{array}{r}\text { Concentrated Load Capacity } \\
\text { (12) }\end{array}$ & & & $\mathbf{x}$ & $x$ & & \\
\hline Special Application & $x$ & $x$ & $x$ & & & \\
\hline $\begin{array}{l}\text { Maximum Numbet of Scale } \\
\text { Divisions }\end{array}$ & & $x$ & $x$ & & & $x$ \\
\hline $\begin{array}{l}\text { Minimum Verification Scale } \\
\text { Division }\end{array}$ & & $\mathbf{x}$ & & $x$ & & \\
\hline "S" or "M" & & & & & & $x$ \\
\hline Direction of Loading (15) & & & & & & $x$ \\
\hline Minimum Dead Load & & & & & & $x$ \\
\hline Maximum Capacity & & & & & & $x$ \\
\hline Safe Load Limit & & & & & & $x$ \\
\hline $\begin{array}{l}\text { Load Cell Verification } \\
\text { Interval }\left(v_{\min }\right)\end{array}$ & & & & & & $x$ \\
\hline Section Capacity & & & $x$ & $x$ & & \\
\hline
\end{tabular}

For applicable notes, see Table, $4 b$. 
Committee Recommendation: The Committee recommends that the following paragraphs be deleted: S.6.1., S.6.2.1., S.6.3., S.6.4., S.6.5., S.6.6., S.6.7., S.6.7.1., S.6.7.2., S.6.8., S.6.10., and S.6.11.

The Committee recommends that paragraphs S.6.2.2. and S.6.9. be renumbered as S.6.1. and S.6.2., respectively, and that the marking requirements of the deleted paragraphs be consolidated into a table, supplemented by notes, providing the specific information needed to apply the marking requirements to scales. The General Code paragraph references and the " $\mathrm{x}$ " markings in the table indicate which requirements are applicable to the various weighing equipment; the subsequent tables in the Scales Code will be renumbered.

The Committee recommends that the S.6. section of Handbook 44 be amended to read:

\section{S.6. Marking Requirements [See also G-S.1., G-S.4., G-S.6., G-S.7., G-UR.2.1.1., and UR.3.4.1.]}

S.6.222 S.6.1. Nominal Capacity; Vehicle, Axle-Load, and Livestock Scales. For all vehicle, axle-load, and livestock scales, the marked nominal capacity shall not exceed the concentrated load capacity times the quantity of the number of sections in the scale minus 0.5. As a formula, this is stated as

nominal capacity $\leq$ concentrated load capacity $x(N-0.5)$

where $N=$ the number of sections in the scale.

(See N.1.3.4., T.1.3, and T.N.3.1.)

[Nonretroactive as of January 1, 1989.]

(Added 1988)

5.6.9. S.6.2. Location Of Marking Information. - Scales that are not permanently attached to an indicating element and for which the load-receiving element is the only part of the weighing/loadreceiving element visible after installation, may have the marking information required in G-S.1. of the General Code and S.6. of the Scales Code located in an area that is accessible only through the use of a tool, provided that the information is easily accessible (e.g., the information may appear on the junction box under an access plate). The identification information for these scales shall be located on the weighbridge (load-receiving element) near the point where the signal leaves the weighing element or beneath the nearest access cover.

(Added 1989)

S.6.3. Scales, Main Elements, and Components of Scales or Weighing Systems - Scales, main elements of scales when not contained in a single enclosure for the entire scale, load cells for which Certificates of Conformance (COC) have been issued under the National Type Evaluation Propram, and other equipment necessary to a weighing system, but having no metrological effect on the weighing system. shall be marked as specified in Table $4 a$ and explained in the accompanying notes (Table $4 \mathrm{~b})$. 
Code References For Proposed Table 4a

Marking Requirements

\begin{tabular}{|c|c|c|c|c|c|c|}
\hline $\begin{array}{l}\begin{array}{r}\text { Weighing } \\
\text { Equipment }\end{array} \\
\text { To Be } \\
\text { Marked With }\end{array}$ & $\begin{array}{c}\text { Scale } \\
\text { Single } \\
\text { Enclosure }\end{array}$ & $\begin{array}{c}\text { Scale } \\
\text { Without } \\
\text { Indicating } \\
\text { Element }\end{array}$ & $\begin{array}{c}\text { Indicating } \\
\text { Element } \\
\text { Separate }\end{array}$ & $\begin{array}{c}\text { Load } \\
\text { Receiving } \\
\text { Element } \\
(9)\end{array}$ & $\begin{array}{l}\text { Other } \\
\text { Equipment } \\
\text { or Device } \\
(10)\end{array}$ & $\begin{array}{c}\text { Load } \\
\text { Cell } \\
\text { W/COC } \\
\text { (11) }\end{array}$ \\
\hline Manufacturer's ID & G.S.1. & G.S.1. & G.S.1 & S.6.9. & G-S.1. & S.6.11. \\
\hline Model Designation & G.S.1. & S.6.8. & G.S.1. & S.6.9. & G-S.1. & S.6.11. \\
\hline Serial Number and Prefix (2) & GS.1. & new & G.S.1. & S.6.9. & $\begin{array}{l}\text { G.S.1. } \\
\text { NTEP }\end{array}$ & S.6.11. \\
\hline Accuracy Class & S.6.1. & S.6.8. & S.6.10 & S.6.9. & & S.6.11. \\
\hline Nominal Capacity & S.6.2.1. & S.6.8. & S.6.2.1. & $\begin{array}{l}\text { S.6.9. } \\
\text { S.6.2.1. }\end{array}$ & & \\
\hline Value of Scale Division (3) & S.6.3. & & S.6.3. & & & \\
\hline Value of "e" & S.6.4. & & S.6.4. & & & \\
\hline Temperature Limits & S.6.5. & S.6.5. & S.6.5. & & & S.6.11. \\
\hline $\begin{array}{r}\text { Concentrated Load Capacity } \\
\text { (12) }\end{array}$ & & & S.6.7.2. & S.6.72. & & \\
\hline Special Application (13) & S.6.6. & S.6.6. & S.6.6. & & & \\
\hline $\begin{array}{l}\text { Maximum Number of Scale } \\
\text { Divisions }\end{array}$ & & S.6.8. & s.6.10. & & & s.6.11. \\
\hline $\begin{array}{l}\text { Minimum Verification Scale } \\
\text { Division }\end{array}$ & & S.6.8. & & $\begin{array}{l}\text { S.6.8. } \\
\text { S.6.9. }\end{array}$ & & \\
\hline "S" or "M" & & & & & & S.6.11. \\
\hline Direction of Loading (15) & & & & & & S.6.11. \\
\hline Minimum Dead Load & & & & & & S.6.11. \\
\hline Maximum Capacity & & & & & & S.6.11. \\
\hline Safe Load Limit & & & & & & S.6.11. \\
\hline $\begin{array}{l}\text { Load Cell Verification } \\
\text { Interval }\left(\mathrm{v}_{\min }\right)\end{array}$ & & & & & & S.6.11. \\
\hline Section Capacity & & & $\begin{array}{l}\text { S.6.7.1 } \\
\text { S.6.7.2. }\end{array}$ & $\begin{array}{l}\text { S.6.7.1 } \\
\text { S.6.7.2. }\end{array}$ & & \\
\hline
\end{tabular}




\section{Notes For Table 4a}

1. Manufacturer's identification and model designation (See G-S.1.)

2. Serial number [Nonretroactive as of January 1, 1968] and prefix [Nonretroactive as of January 1, 1986]. (See G-S.1.)

3. The nominal capacity and value of the scale division shall be shown together (e.g., 100,000 $10 \mathrm{lb}$ or $30 x$ $0.01 \mathrm{lb}$ ) adjacent to the weight display when the nominal capacity and value of the scale division are not immediately apparent. Each scale division value or weight unit shall be marked on variable-division value or division-unit scales. [Nonretroactive as of January 1, 1983]

4. Required only if different from "d." [Nonretroactive as of January 1, 1986]

5. Required only on class III, III L, and IIII scales if other than $14^{\circ} \mathrm{F}$ to $104^{\circ} \mathrm{F}$. [Nonretroactive as of January 1, 1986]

6. This value may be stated on load cells in units of 1,$000 ;$ e.g., $n: 10$ is 10,000 divisions. [Nonretroactive as of January 1, 1988]

7. Denotes compliance for single or multiple load cell applications. [Nonretroactive as of January 1, 1988]

8. Can have dual compliance and marking; i.e., III/III L mark with the maximum number of scale divisions for each class. [Nonretroactive as of January 1, 1988]

9. For vehicle, axle load, and livestock scales only. Markings must be added to any scale not previously marked, at the time of modification. [Nonretroactive as of January 1, 1989]

10. Necessary to the weighing system but having no metrological effect, e.g., auxiliary remote display, keyboard, etc.

11. The markings may be either on the load cell or in an accompanying document; except that, if an accompanying document is provided, the serial number shall appear both on the load cell and in the document. [Nonretroactive as of January 1, 1988] The manufacturer's name or trademark, the model designation, and identifying symbol for the serial number shall also be marked both on the load cell and in any accompanying document. [Nonretroactive as of January 1, 1991]

12. Required on the indicating element and the load-receiving element of vehicle, axle load, and livestock scales; may be abbreviated CLC. [Nonretroactive as of January 1, 1989]

13. A scale designed for a special application rather than general use shall be conspicuously marked with suitable words visible to the operator and customer restricting its use to that application, e.g., postal scale, prepack scale, weight classifier, etc. [Nonretroactive as of January 1, 1986]

14. Required on the indicating element of railway track scales only. When marked on vehicle, axle load, and livestock scales manufactured before January 1, 1989, it may be used as the CLC.

15. Required if the direction of loading the load cell is not obvious. [Nonretroactive as of January 1, 1988]

16. Serial number [Nonretroactive as of January 1, 1968] and prefix [Nonretroactive as of January 1, 1986]. (See G-S.1.) Modules without "intelligence" on a modular system (e.g., printer, keyboard module, cash drawer, and secondary display in a point-of-sale system) are not required to have serial numbers. 
(This item was adopted as part of the consent calendar.)

Discussion: S.6.11. could be interpreted to mean that the information specified therein need only be provided in an accompanying document, and that the load cell need not be marked with a serial number or any other required information. The Committee believes that the manufacturer's name or trademark, model designation, and serial number are the minimum information that must be marked on a load cell that has received an NTEP Certificate of Conformance. The document accompanying the load cell is often misplaced and not available at the time of inspection to weights and measures officials or to a service technician. This information must be available to both parties to permit verification that the load cells are appropriate for the application and to trace the load cell back to the manufacturer. The service technician also needs the information if repairs require replacing the load cell with a metrologically equivalent or better load cell.

This marking requirement applies only to load cells for which Certificates of Conformance have been issued. If Items 320-3 and 320-4 are adopted, the text proposed in this recommendation will not appear in the Scales Code; instead, the marking requirements will be incorporated into Table $4 a$ and the notes of Table $4 b$.

Committee Recommendation: The Committee recommends that load cells be physically marked with the manufacturer's name or trademark, the model designation, and the serial number prefaced by an appropriate abbreviation or symbol. The following changes are recommended.

Amend S.6.11.(f) and the last paragraph to read:

(f) the name and address of the manufacturer or the manufacturer's trademark, model designation, serial number, minimum dead load, maximum capacity, safe load limit, and load cell verification interval $\left(v_{\min }\right)$.

Amend and editorially revise the last paragraph of S.6.11. to read:

The requined information may be given on a data ptate attached to the toot cell or, altematively, in an wcompanying document. If the document is the sounce of the information the seriat number of the toad cell shell be manked on the toad cell and atso given in the document.

The name of the manufacturer or the manufacturer's trademark, the model designation, and a nonrepetitive serial number of the load cell shall be marked on the load cell and given in an accompanying document if the latter is provided. The serial number shall be prefaced by words, an abbreviation, or a symbol that clearly identifies the number as the required serial number. The other required information may be marked on the load cell or be included in an accompanying document containing all of the required information. [Nonretroactive as of January 1, 1988]

* The markings required on load cells are nonsetroactive as of January 1. 1991, except that the serial number marking is nonretroactive as of January 1, 1988. I

\section{0-5 VC N.3.1. Minimum Test-Weight Load for Railway Track Scales}

(This item was adopted as part of the consent calendar.)

Discussion: Due to the large capacity of railway track scales and the potential for errors, and to promote an adequate test of railway track scales, a larger known test load is required whenever a railway track scale is to be certified. Current testing practices are often inadequate to ensure accuracy of coupled-in-motion (CIM) weighing over extended periods of time. The Association of American Railroads Scale Handbook requires a minimum test-weight load of $80,000 \mathrm{lb}$. The Committee agrees that a known test-weight load larger than the $30,000 \mathrm{lb}$ currently specified in N.3.1. is needed to perform an adequate test on a railway track scale. The availability of a minimum known test-weight load of $80,000 \mathrm{lb}$ could be a problem for a weights and measures jurisdiction to conduct enforcement tests on railway track 
scales and for service companies to place a scale back into service after emergency repairs. Consequently, provision is made to test these scales using less than $80,000 \mathrm{lb}$ of known test load if the scale is found to be inaccurate or if the scale is returned to service on an interim basis until a more thorough test can be performed.

A special meeting of the S\&T Committee was held October 12, 1989, to discuss the railroad issues on the agenda. Based on the comments made at the October 12 meeting and letters received, the current S\&T Committee position is summarized below:

1. The initial test of a railway track scale shall be conducted with a minimum test load of $80,000 \mathrm{lb}$. A strain-load test to the used capacity of the scale is recommended. These criteria apply to tests used to certify a railway track scale.

2. A minimum test load of $30,000 \mathrm{lb}$ may be used to return a scale into service on an interim basis. A strain-load test to $25 \%$ of the scale capacity is mandatory (whenever the scale design permits a strain-load test to be performed) if the test load is less than $80,000 \mathrm{lb}$. The strain-load test to the used capacity of the scale is recommended if the known test load is at least $80,000 \mathrm{lb}$.

3. The length of time that a scale may be used based on the interim test is left to the discretion of the official with statutory authority.

4. A scale may be tested using a minimum test load of $30,000 \mathrm{lb}$ and rejected if found to be out of tolerance.

Committee Recommendation: The Committee recommends that N.3.1. be amended to (1) require that a minimum known test load of $80,000 \mathrm{lb}$ be used to approve a railway track scale; (2) require conduct of a strain-load test to the used capacity of the railway track scale under specified conditions; (3) recognize the use of a lower known test load in combination with a strain-load test to the used capacity of the scale to perform a weights and measures enforcement test or to return a scale to service on an interim basis after a repair; and (4) state that a minimum test load of $30,000 \mathrm{lb}$ is required to take enforcement action on a scale that is found to be inaccurate.

The Committee recommends that N.3.1. be replaced with:

\section{N.3.1. Minimum Test-Weight Load and Recommended Strain-Load Test for Railway Track Scales.}

N.3.1.1. Approval. - The test-weight load shall be not less than $80,000 \mathrm{lb}$. A strain-load test conducted up to the used capacity of the weighing system is recommended.

N.3.1.2. Interim Approval. - A test-weight load of not less than $30,000 \mathrm{lb}$ and a strain-load test up to at least 25 percent of scale capacity may be used to return a scale into service following repairs.

Note: The length of time the scale may be used following an interim test is at the discretion of the official with statutory authority.

N.3.1.3. Enforcement Action for Inaccuracy. - To take enforcement action on a scale that is found to be inaccurate, a minimum test load of $30,000 \mathrm{lb}$ must be used.

\section{Proposed Test Procedures and Tolerances for Coupled-In-Motion Railway Track Scales}

(This item was adopted.)

Discussion: The discussion and recommendation contained in this item do not address, nor do they finalize, the required test procedure for CIM scales used to weigh individual tank cars containing liquids or mixed merchandise trains (referred to in previous years as mixed manifest trains) when the individual weights are used for custody transfer of the individual cars. These issues of CIM weighing of liquids in tank cars and mixed merchandise trains are addressed in Items 320-7 and 320-8. The current position of the S\&T Committee is reported for further consideration in the first point " $\mathrm{C}$ " that follows, as well as in Items 320-7 and 320-8. This item (320-6) proposes the minimum test procedure that may be used on CIM scales and describes the "as used" test procedures for CIM scales. 
The S\&T Committee has addressed the procedures for testing coupled-in-motion railway track scales over the last several years. The Committee believes that the 10-car minimum test specified in NIST Handbook 44 has resulted in installations where the scales do not generate accurate weights in normal use. The Committee believes that the most accurate method of testing coupled-in-motion scales are to test them "as used" with train lengths reflecting those normally weighed. However, the Committee realizes that the cost of testing CIM scales "as used" is usually much higher than the minimum 10-car test. The Committee has also received many letters and comments from owners and users of CIM scales stating that they have not had any problems with the accuracy of weights obtained from scales that have been tested using the 10-car train.

The proposed changes specify a minimum 10-car/5-times test but provides the option, at the discretion of the official with statutory authority, to test a scale with "as used" procedures if there is reason to believe that it is necessary to determine the accuracy of the weighing system under "as used" conditions. These procedures will apply to both the existing CIM scales and to new installations. The "as used" test procedures, if adopted, will be described in the Note section of the Scales Code. The proposed changes do not "grandfather" existing scales that have been tested up until the time of this proposal using the 10-car test. The decision of whether a scale must be tested using the minimum test or the "as used" test procedures is left to the discretion of the official with statutory authority. New N.4.2. language will allow the official with statutory authority to test existing scales as used; however, it will also open the door to testing new scales using shorter trains. The Committee believes that it is important to indicate in Handbook 44 the test the Committee believes will provide the best determination of the accuracy of the scale, that is, the "as used" test procedures, while considering the costs of the tests.

The following explanation is provided in an effort to state clearly how these changes apply to CIM scales used to weigh unit trains as defined in Handbook 44.

A. Where CIM scales are used for the assessment of freight charges only, the $10 \mathrm{car} / 5$ times minimum test applies; however, the "as used" test procedures may be required at the discretion of the official with statutory authority.

B. Where CIM scales are used for the custody transfer of unit trains only, the $10 \mathrm{car} / 5$ times minimum test applies; however, the "as used" test procedure may be required at the discretion of the official with statutory authority.

C. It is the position of the S\&T Committee that the "as used" test procedures shall be followed where CIM scales are used to determine individual car weights for custody transfer of liquids and mixed merchandise trains. Note that shorter trains may be used if test results are shown to agree with the results for longer trains.

The tolerance paragraphs for CIM weighing are revised slightly in an effort to clarify the application of the tolerances. Additional explanations to clarify the application of the tolerances to scales used to weigh trains used for different purposes are given below.

A.T.N.3.6.3. requires that the sum of the weights for a unit train (a group of contiguous cars carrying a single commodity from one consignor to one consignee, with the same commodity on the same type of car) must be within the sum of the maintenance static tolerances applicable to the weights in the group. The individual car tolerance distribution does not apply when only unit train weights are used for custody transfer. A train may consist of more than one unit train.

B. Both T.N.3.6.1. and T.N.3.6.2. apply to unit trains consisting of the same commodity on the same type of car when the individual car weights are to be used for the assessment of freight charges and for custody transfer. The S\&T Committee has not finalized its position regarding the appropriateness of CIM weighing of mixed merchandise (mixed manifest) trains or the tolerances to be applied to them. The CIM weighing of mixed merchandise trains and liquids in tank cars for the custody transfer of individual cars will be addressed again in 1991.

C.T.N.3.6.1. also requires that the sum of car weights for each run of a test train be within the sum of the maintenance static tolerances applicable to the weights in the group.

The Committee is still considering the extent of agreement required between test results from a long train test and a shorter train test for "as used" test procedures: 0.15 percent may be too large a deviation (see proposed N.4.2.1.1.). If the test results of a long and a short train have shown reasonable agreement and a shorter train is used to test a CIM scale, should the results for the short train be adjusted in subsequent tests to have an offset from zero error so that the errors presumed to exist for the long train will be zero? Comments are requested on this particular point. 
The Committee is also considering proposing a requirement that the weights from CIM scales used for the custody transfer of individual cars shall identify that the car(s) were weighed on a CIM scale. A requirement for identifying the specific scale is also being considered. Comments are requested on this point, but a recommendation for this requirement is not planned for the 1990 National Conference.

The changes recommended in this item are intended to remove some of the uncertainty surrounding the use of CIM scales, but are not intended to end the discussion of these issues. The issues will continue to be studied and, if warranted, further action may be proposed.

The S\&T Committee has requested and continues to request that the industry notify the Committee when tests to collect data on this issue for S\&T consideration are scheduled for CIM scales. So far the Committee has been notified only twice, limiting the opportunity to work with the industry. Whenever possible, the Committee members would like to observe the test process when collecting data to be submitted to the Committee in order to gain a better understanding of the many considerations and difficulties involved. The Committee encourages weights and measures officials to work with the industry whenever a CIM scale is tested in their jurisdiction to better understand CIM weighing and the testing of CIM scales.

Committee Recommendation: In an effort to reach a consensus on the issue, but still address the comments and concerns that have been raised, the Committee recommends that the following changes be made to the Scales Code. The crossing out and underlining of text is not included in this item because of the extensive changes. The proposals should be studied in their entirety. Paragraph T.N.3.7. is included for reference although the content is not changed from the current language in Handbook 44.

It is the perception of many in the railway industry that a separate paragraph addressing scales installed prior to January 1, 1991, improves the negotiating position of the railroads to interact with weights and measures officials who want to test existing scales with the "as used" test procedures. They believe the revised language places a responsibility on the weights and measures official to provide justification in the form of possible problems concerning installation or operating conditions, or complaints concerning the accuracy of weights in order to change the test procedure for existing scales from the 10-car/5-times test that the S\&T Committee is proposing as the minimum test that is acceptable. The S\&T Committee requests the assistance of the railroad industry, owners of coupled-in-motion scales, scale manufacturers, shippers, utilities, and industry associations to develop guidelines to aid weights and measures officials in determining when the as used test procedures should be used.

It is emphasized that the test procedure specified in the proposed N.4.2. is the minimum test procedure and minimum length of test train allowed to be used to test scales installed before January 1, 1991; N.4.2. should not be construed as being sufficient to conduct an adequate test for all installations. The minimum test does not only address the number of times a test train is passed over a scale or the minimum number of cars used to test a scale, it also addresses the minimum length of train that may be used to test the scale. 


\section{PROPOSED TEST PROCEDURES \& TOLERANCES FOR COUPLED-IN-MOTION RAILWAY TRACK SCALES}

Add the following definitions:

Test car. A railroad car weighed on a reference scale for use in a test train.[Added editorially.]

Test train. A train consisting of cars weighed on a reference scale and used to test coupled-in-motion railway track scales. The test cars may be placed consecutively or distributed in different places within a train.

Consecutive-car test train. A train consisting of cars weighed on a reference scale, then coupled consecutively and run over the coupled-in-motion railway track scale under test.

Distributed-car test train. A train consisting of cars weighed first on a reference scale, cars coupled consecutively in groups at different locations within the train, then run over the coupled-in-motion railway track scale under test. The groups are typically placed at the front, middle, and rear of the train.

Delete the existing N.3.1.1. and renumber the existing N.4. as N.5.

Add the following paragraphs:

\section{N.4. COUPLED-IN-MOTION RAILWAY TRACK SCALES}

N.4.1. SCALES USED TO WEIGH TRAINS OF LESS THAN 10 CARS.- These scales shall be tested using a consecutive-car test train consisting of the number of cars weighed in the normal operation run over the scale a minimum of five times in each mode of operation following the final calibration.

N.4.2. Scales Placed In Service Prior To January 1, 1991, And Used To Weigh Trains of 10 Or More Cars.- The minimum test train shall be a consecutive-car test train of no less than $\mathbf{1 0}$ cars run over the scale a minimum of five times in each mode of operation following final calibration.

N.43. Scales Placed In Service On Or After January 1, 1991, And Used To Weigh Trains of 10 Or More Cars.-

(a) These scales shall be tested using a consecutive-car test train of no less than $\mathbf{1 0}$ cars run over the scale a minimum of five times in each mode of operation following final calibration; or

(b) if the official with statutory authority determines it necessary, the AS USED TEST PROCEDURES outlined in N.43.1. shall be used.

N.43.1. AS USED TEST PROCEDURES - A scale shall be tested in a manner that represents the normal method of operation and length(s) of trains normally weighed. The scales may be tested using either:

a consecutive-car test train of a length typical of train(s) normally weighed; or

a distributed-car test train of a length typical of train(s) normally weighed.

However, a consecutive-car test train of a shorter length may be used provided that initial verification test results for the shorter consecutive-car test train agree with the test results for the distributed-car or full-length consecutive-car test train as specified in N.4.3.1.1.

The official with statutory authority shall be responsible for determining the minimum test train length to be used on subsequent tests. 
N.43.1.1. INITIAL VERIFICATION.- Initial verification tests should be performed on any new scale and whenever either the track structure or the operating procedure changes. If a consecutive-car test train of length shorter than trains normally weighed is to be used for subsequent verification, the shorter consecutive-car test train results shall be compared to either a distributed-car or consecutive-car test train of length(s) typical of train(s) normally weighed.

The difference between the total train weight of the train(s) representing the normal method of operation and the shorter consecutive-car test train shall not exceed 0.15 percent. If the difference in test results exceeds 0.15 percent, the length of the shorter consecutive-car test train shall be increased until agreement within 0.15 percent is achieved.

N.43.1.2. SUBSEQUENT VERIFICATION.- The test train may consist of either a consecutive-car test train with a length not less than that used in initial verification, or a distributed-car test train representing the number of cars used in the normal operation.

\section{N.4.3.1.3. DISTRIBUTED CAR TEST TRAINS.-}

(a) The length of the train shall be typical of trains that are normally weighed.

(b) The test cars shall be split into three groups, each group consisting of 10 cars or 10 percent of the train length, whichever is less.

(c) The test groups shall be placed near the front, around the middle, and near the end of the train.

(d) Following the final adjustment, the distributed-car test train shall be run over the scale at least three times or shall produce 50 weight values, whichever is greater.

(e) The scale shall be tested in each mode of operation.

\section{N.43.1.4. CONSECUTIVE-CAR TEST TRAINS.-}

(a) A consecutive-car test train shall consist of at least $\mathbf{1 0}$ cars.

(b) If the consecutive-car test train consists of between 10 and 20 cars, inclusive, it shall be run over the scale a minimum of five times in each mode of operation following the final calibration.

(c) If the consecutive-car test train consists of more than 20 cars, it shall be run over the scale a minimum of three times in each mode of operation.

The proposed section T.N.3.6. is revised to provide the tolerances for coupled-in-motion weighing as stated below. T.N.3.6.4. is not changed from its current language, but is renumbered as T.N.3.7. so that it does not fall under the T.N.3.6. heading for coupled-in-motion weighing. The current T.N.3.7. and T.N.3.8. would be renumbered as T.N.3.8. and T.N.3.9., respectively.

T.N.3.6. COUPLED-IN-MOTION WEIGHING, RAILWAY TRACK SCALES. - Tolerances for the group of weight values appropriate to the application must satisfy the following conditions: 
T.N.3.6.1. - For any group of weight values, the difference in the sum of the individual inmotion car weights of the group as compared to the sum of the individual static weights shall not exceed two tenths of one percent $(0.2 \%)$.

T.N3.6.2. - If a scale is used to weigh trains of five or more cars, and if the individual car weights are used, any single weight value within the group must meet the following criteria:

$$
\text { no single error may exceed three times the static maintenance tolerance; }
$$

$$
\text { not more than } 5 \text { percent of the errors may exceed two times the static maintenance }
$$
tolerance; and not more than 35 percent of the errors may exceed the static maintenance tolerance.

T.N3.63. - For any group of weight values wherein the sole purpose is to determine the sum of the group, T.N3.6.1. alone applies.

T.N3.6.4. - For a scale used to weigh trains of less than five cars, no single car weight within the group may exceed the static maintenance tolerance.

T.N3.7. UNCOUPLED-IN-MOTION WEIGHING, RAILWAY TRACK SCALES. - For any single weighment within a group of non-interactive (i.e., uncoupled) loads, the weighment error shall not exceed the static maintenance tolerance.

A new User Requirement UR.5. will be added to impress upon the scale owner/user that a scale is to be tested in the manner in which it is normally used and that the proper test procedures must be followed for coupled-in-motion scales.

UR.5. RAILWAY TRACK SCALES WEIGHING COUPLED-IN-MOTION.- A coupled-in-motion scale placed in service on or after January 1, 1991, should be tested in the manner in which it is operated, with the locomotive either pushing or pulling the cars at the designed speed and in the proper direction. The cars used in the test train should represent the range of gross weights that will be used during the normal operation of the scale. Except as provided in N.4.2. and N.4.3.(a), normal operating procedures should be simulated as nearly as practical. Approach conditions for a train length in each direction of the scale site are more critical for a scale used for individual car weights than for a unit-train-weights-only facility, and should be considered prior to the installation of the coupled-in-motion weighing system.

\section{Weighing Individual Railroad Cars for Custody Transfer; Liquids in Tank Cars}

Discussion: The CIM weighing of liquids in tank cars introduces another set of variables into the process of weighing the cars. The liquid may be moving inside the tank; some tank cars may have internal baffles to reduce the effect of moving liquid; the cars may not be completely filled; the liquids in different cars may be of significantly different densities; and the car couplers are often safety couplers to reduce danger in the event of a railroad accident.

The Committee has received data from a company that weighs several different liquids in tank cars. This company now has a program of testing the scale "as used," continually monitors the performance of the scale by weighing a monitor car in many of its trains, maintains a control chart on the performance of the scale, and conducts comparison testing of CIM weights by weighing the same train twice. This type of process control information is believed to be very effective to determine the accuracy of a scale. The data provided by the user of the scale demonstrates that, with the proper testing of the scale and continually monitoring its performance, liquids in tanks cars can be weighed accurately over a CIM scale. The statistical process control together with the "as used" test procedures used by this company exceeds the controls contained in the recommended test procedures for CIM scales in Item 320-6. It is the view of the S\&T Committee that, as a minimum, CIM scales used to weigh liquids in tank cars for custody transfer (as distinguished from weighing for the purposes of freight charges) should be required to be tested with the "as used" test procedures. 
The Railroad Advisory Committee has recommended adding the following two user requirements to address the weighing of liquids in tank cars.

UR.3.8. IN-MOTION WEIGHING OF TANK CARS ON RAILWAY TRACK SCALES.- Weighing tank cars (liquids) on a multi-draft in-motion railway track scale when the lading is of an unstable nature is acceptable provided that tests between a static scale and the in-motion scale are comparable. The test must employ the same types of loaded tank cars and commodities that are intended to be weighed in the normal operation.

\section{UR.3.9. MANUALLY CONTROLLED STATIC WEIGHING DEVICES ON RAILWAY TRACK SCALES.-}

The indication of a manually controlled static weighing device must be stable within plus or minus three graduations before the weight is recorded.

The Committee is also considering proposing a requirement that the weights from CIM scales used for the custody transfer of individual cars shall identify that the car(s) were weighed on a CIM scale. Identifying the specific scale is also being considered. Comments are requested on this point, but a recommendation for this requirement is not planned for the 1990 National Conference.

The S\&T Committee has requested and continues to request that the industry notify it when tests are scheduled for CIM scales. So far the Committee has been notified only twice, limiting the opportunity to work with the industry. Whenever possible, the Committee members would like to observe the test process in order to gain a better understanding of the many considerations and difficulties involved. The Committee encourages weights and measures officials to work with the industry to better understand CIM weighing and the testing of CIM scales.

Committee Recommendation: The items addressing the custody transfer of liquids and mixed merchandise (mixed manifest) trains are information items in 1990. The Committee plans to present recommendations for vote in 1991. The recommendation is expected to be that the CIM scales used to determine individual car weights for custody transfer shall be tested with the "as used" test procedures. Presenting these items as information this year will permit further study of the S\&T proposals and provide additional time to resolve some remaining concerns on these issues.

\section{0-8 I Weighing Individual Railroad Cars for Custody Transfer; Mixed Manifest Trains}

Discussion: The CIM weighing of mixed merchandise trains (mixed manifest trains) introduces even more variables into the weighing process than does the weighing of liquids in tank cars. While trains dedicated exclusively to weighing tank cars will generally have cars of very similar design, a mixed merchandise train may have empty and loaded cars, cars of differing design, cars with different types of couplers, and loaded cars of widely differing weights. Each of these variables introduces an additional source of potential errors. Unit trains have the advantage that the summed weight for groups of cars from one consignor to one consignee can have errors on adjacent cars which will cancel to some degree, hence the group weight may be accurate even though there are errors in the weights of individual cars.

The data provided to the Committee up to this time have nct convinced the Committee that CIM weighing is appropriate for determining the weight of individual cars for custody transfer when weighed as part of a mixed merchandise train. Even if the Committee were ultimately convinced of the appropriateness of CIM weighing for this purpose, it is the view of the S\&T Committee that, as a minimum, CIM scales used to weigh mixed merchandise trains. for the custody transfer of individual cars (as distinguished from weighing for the purposes of freight charges) shoulc be required to be tested with the "as used" test procedures. Efforts would have to be made to test CIM scales witl a train with as many different types of cars as possible and, if possible, in a variety of car combinations to determin the performance of the scale.

The Committee is considering proposing a requirement that the weights from CIM scales used for the custod transfer of individual cars identify that the car(s) were weighed on a CIM scale and identify the specific scale (se Item 320-7).

Data received by the S\&T Committee indicate that cars with rotary couplers may not be suitable for CIM weighin when individual cars in mixed merchandise trains are to be used for custody transfer. Additionally, changes in trac configuration may have a significant effect on weights obtained from CIM scales. All of these issues must b considered as more variables are introduced for CIM weighing for custody transfer of individual cars. 
The S\&T Committee has requested and continues to request that the industry notify Committee members when tests are scheduled for CIM scales. The Committee has so far been notified only twice, limiting the opportunity to work with the industry. Whenever possible, the Committee members would like to observe the test process in order to gain a better understanding of the many factors and difficulties involved. The Committee encourages weights and measures officials to work with the industry to better understand CIM weighing and the testing of CIM scales.

Committee Recommendation: The items addressing the custody transfer of liquids and mixed merchandise (mixed manifest) trains are information items in 1990. The Committee plans to present recommendations for vote in 1991. The recommendation is expected to be that the CIM scales used to determine individual car weights for custody transfer shall be tested with the "as used" test procedures. Presenting these items as information items this year will permit further study of the S\&T proposals and provide additional time to resolve some remaining aspects of these issues.

\section{T.1. Tolerances for Unmarked Scales; Reorganization}

(This item was adopted.)

Discussion: The organization and structure of the T.1. tolerance section of the Scales Code have resulted in different interpretations as to whether or not the subparagraphs T.1.1.1., T.1.1.2. and T.1.1.3. apply to those scales that are referred to the T.N. section for their tolerances. It is the view of the industry members who participated in the SMA Technical Subcommittee that led to the current tolerances in Handbook 44 that the subparagraphs T.1.1.1., T.1.1.2. and T.1.1.3. do not apply to those devices. The S\&T Committee agrees that unmarked devices that were referred to the tolerances for marked scales by paragraph T.1. should have the same tolerances applied as to marked scales. The Committee also believes that the tolerances for unmarked scales can be better understood by placing the bulk of the tolerance requirements into a table format.

The recommendations in this item do not change the tolerances that are to apply to unmarked scales; however, the reorganization will change the way the tolerances are applied by many weights and measures officials. Many weights and measures officials have been adding one-half scale division to digital scales and have been using the 1.5 multiplier for the decreasing load test for automatic indicating scales. The minimum tolerance specified in T.1.1.3. is not of significance to this issue since the minimum tolerance for marked scales is incorporated into Table 6 under T.N.3.1.

Committee Recommendation: The Committee recommends the current T.1. section be deleted and the tolerance requirements restated as follows.

T.1. Tolerance Values.

T.1.1. General. - The tolerances applicable to devices not marked with an accuracy class shall have the tolerances applied as specified in Table $\mathbf{X}$.

T.1.1.1. Decreasing-Load Tests on Automatic Indicating Scales. - One and one-half

(1.5) times the tolerance values shall be applied.

[Editor's Note: Paragraph T.1.1.1. was deleted from the Scales Code since the decreasing load multiplier is included in Table $\mathbf{X}$ for the specific devices to which it applies.] 
Specifications and Tolerances Committee

T.1.1.2. To Tests Involving Digital Indications or Representations. - To the tolerances that would otherwise be applied, there shall be added an amount equal to one-half the minimum value that can be indicated or recorded. This does not apply to digital indications or recorded representations that have been corrected for rounding error using error weights.

T.1.1.3. Minimum Tolerance. - When not otherwise specified, the minimum tolerance to be applied shall be $0.05 \%(1 / 2000)$ of scale capacity or one-half " $d$ ", whichever is less.

T.1.2. Postal and Parcel Post Scales. - The tolerances for postal and parcel post scales are given in Table $X$ and in the following table.

Table 5

Maintenance and Acceptance Tolerances for Postal and Parcel Post Scales

\begin{tabular}{|c|c|c|c|c|c|}
\hline \multirow[t]{2}{*}{$\begin{array}{l}\text { Scale } \\
\text { capacity }\end{array}$} & \multirow[t]{2}{*}{$\begin{array}{l}\text { Test } \\
\text { loads }\end{array}$} & \multicolumn{2}{|c|}{$\begin{array}{c}\text { Maintenance } \\
\text { tolerance }\end{array}$} & \multicolumn{2}{|c|}{$\begin{array}{l}\text { Acceptance } \\
\text { tolerance }\end{array}$} \\
\hline & & \multicolumn{2}{|c|}{$( \pm)$} & & $( \pm)$ \\
\hline Pound & Pound & Ounce & Pound & Ounce & Pound \\
\hline 0 to 4 , inclusive & $\begin{array}{l}0 \text { to } 1 \text {, inclusive } \\
\text { over } 1\end{array}$ & $\begin{array}{l}1 / 32 \\
1 / 8\end{array}$ & $\begin{array}{l}0.002 \\
0.008\end{array}$ & $\begin{array}{l}1 / 32 \\
1 / 16\end{array}$ & $\begin{array}{l}0.002 \\
0.004\end{array}$ \\
\hline over $4^{*}$ & $\begin{array}{l}0 \text { to } 7 \text {, inclusive } \\
7+\text { to } 24 \text {, inclusive } \\
24+\text { to } 30 \text {, inclusive } \\
\text { over } 30\end{array}$ & $\begin{array}{l}3 / 16 \\
3 / 8 \\
1 / 2 \\
0.1 \%\end{array}$ & $\begin{array}{c}0.012 \\
0.024 \\
0.030 \\
\text { est Load }\end{array}$ & $\begin{array}{l}3 / 16 \\
3 / 16 \\
1 / 4 \\
0.05 \%\end{array}$ & $\begin{array}{l}0.012 \\
0.012 \\
0.015 \\
\text { est Load }\end{array}$ \\
\hline
\end{tabular}

*See Table X for scales designed and/or used to weigh loads less than 2 lbs. 
Specifications and Tolerances Committee

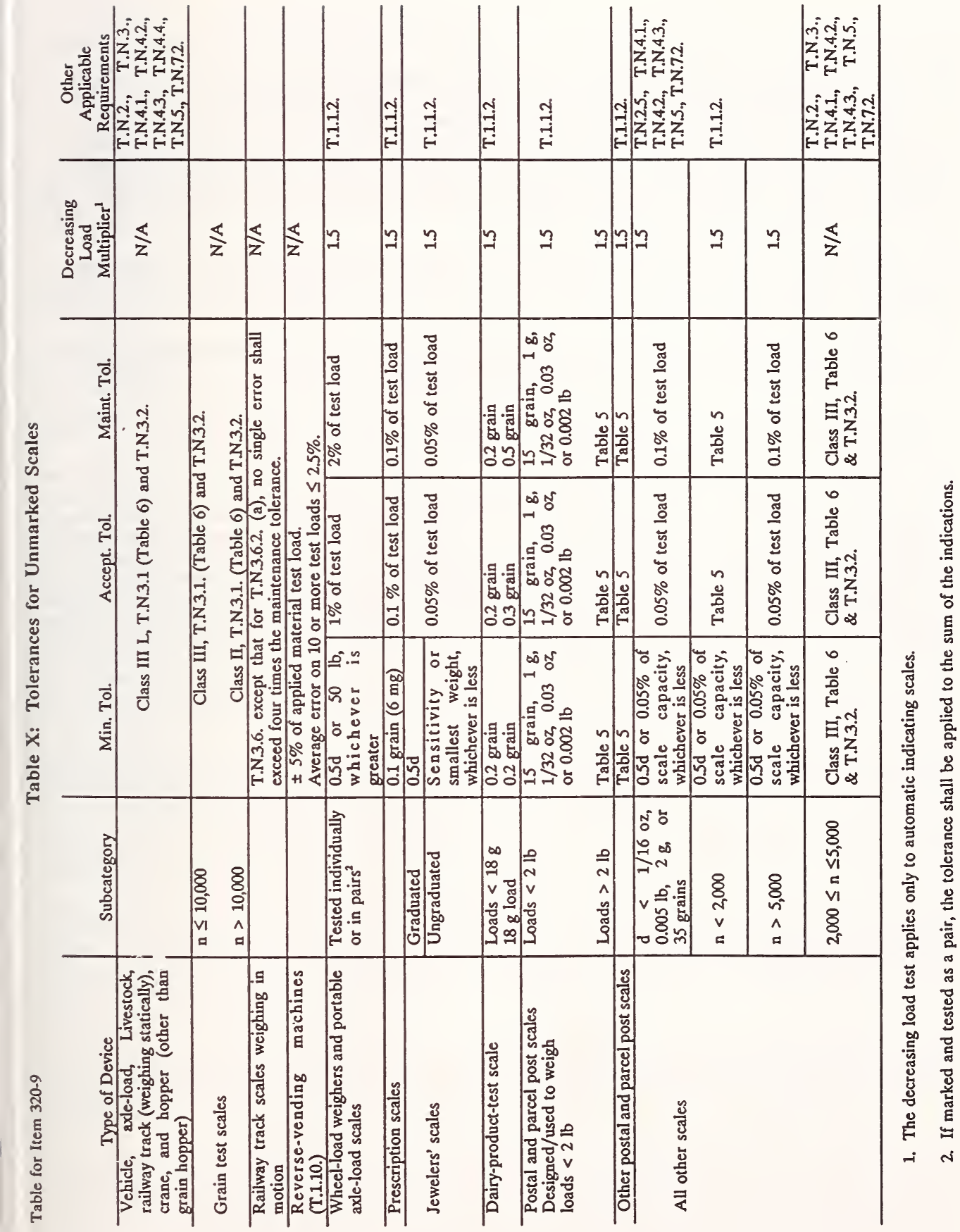




\section{0-10 V T.1. Tolerances for Unmarked Scales; Revision}

(This item was adopted.)

Discussion: The Committee received one request in 1987 and three requests in 1988 to modify T.1.1., T.1.1.1., T.1.1.2., and T.1.1.3. to simplify the tolerance application to unmarked scales with less than 2,000 and more than 5,000 divisions. In 1989 the Committee reported Item 320-5 as information to provide an opportunity for further review of its proposal to simplify the tolerances for unmarked scales.

The Committee believes that it is better to substantially simplify the tolerance application for unmarked scales by making the tolerances for unmarked scales with less than 2,000 divisions the same as those for class III scales, although this simplification will result in significantly larger tolerances for some scales. The Committee recommends:

1. that the tolerances for all unmarked scales with 5,000 scale divisions or less, except those with tolerances specified in the current T.1.3. through T.1.11., be the tolerances in Table 6; and

2. further simplifying the tolerances and offsetting some of the increased tolerances for some scales, by dropping the additional one-half scale division tolerance given to digital indicating scales as specified in T.1.1.2.

In general, the effect of the additional 0.5 division tolerance on scales with less than 2,000 divisions is small on unmarked scales because fractions of a division are truncated when the tolerance is applied. For scales with more than 5,000 scale divisions, the additional one-half division tolerance represents only a very small part of the tolerance applied to the scale and can be considered negligible. The extra tolerance for the decreasing-load test would be retained for scales with more than 5,000 scale divisions. Scales with less than 5,000 scale divisions would lose the 1.5 multiplier for the decreasing-load test; however, the increase in the tolerances resulting from applying Table 6 to these scales would adequately compensate for the elimination of the decreasing-load test multiplier for scales with less than 2,000 divisions. Scales with 2,000 to 5,000 divisions, inclusive, already have the tolerances specified in Table 6 as their tolerances. The minimum tolerance for scales with more than 5,000 divisions is included in the amended T.1.2. Table 5 would remain in the Scales Code, but it would apply only to postal and parcel post scales (T.1.8.). The tolerances for the unmarked scales that have specific tolerances given in section T.1. would not be affected by this change, i.e., wheel-load weighers and portable axle-load scales, prescription scales, jewelers' scales, dairy-product-test scales, and postal and parcel post scales.

There has been general support for the proposed revision. Some comments oppose the change, primarily due to the larger tolerances that would apply to some scales with less than 2,000 scale divisions. It was stated that these larger tolerances would prolong the use of older scales that may not be suitable for today's commercial needs.

The Committee received another suggestion to delete the special tolerances established for postal and parcel post scales to further simplify the tolerances. This suggestion states that there are relatively few postal and parcel post scales that would be affected, and that the impact would be within acceptable limits.

The examples given in the 1989 S\&T report of scale capacities by scale divisions that would be most significantly affected by this change are listed below.
$9 \times 0.005 \mathrm{lb}$
$2 \mathrm{lb} \times 1 / 4 \mathrm{oz}$
$10 \mathrm{lb} \times 1 \mathrm{oz}$
$18 \mathrm{lb} \times 1 \mathrm{oz}$
$24 \mathrm{lb} \times 1 \mathrm{oz}$
$30 \mathrm{lb} \times 1 \mathrm{oz}$
$1 \mathrm{lb} \times 1 / 8 \mathrm{oz}$
$15 \mathrm{lb} \times 1 / 4 \mathrm{oz}$
$15 \mathrm{lb} \times 1 \mathrm{oz}$
$6 \times 0.01 \mathrm{lb}$
$4 \mathrm{lb} \times 1 / 4 \mathrm{oz}$
$20 \mathrm{lb} \times 1 / 2 \mathrm{oz}$
$390 \times 0.2 \mathrm{lb}$
$5 \mathrm{lb} \times 1 \mathrm{oz}$
$5 \mathrm{lb} \times 1 / 2 \mathrm{oz}$
$60 \mathrm{lb} \times 1 \mathrm{oz}$ 
Committee Recommendation: Change T.1.2. as follows.

T.1.2. SCALES WITH EESS THA 2000SEALE BHASHONS-OR MORE THAN 5000 SCALE DIVISIONS. - Except for scales specified in paragraphs T.1.3. through T.1.11, the maintenance and aceptance tolerances shall be as-strow- in Table 5 (next page) 0.1 percent of an applied test load; the acceptance tolerance shall be 0.05 percent of the applied test load. In any case, the tolerance shall not be less than 0.5 scale division. Paragraphs T.N.2.5., T.N.4.1., T.N.4.2., T.N.4.3., T.N5., and T.N.7.2. also apply.

If Item 320-9 is not accepted by the Conference, then as part of this item, the Committee recommends that: (1) the heading for Table 5 be changed to:

\section{Maintenance and Acceptance Tolerances for Postal and Parcel Post Scales}

and (2) T.1.1.2. and T.1.1.3. be deleted.

If Item 320-9 is adopted, then consistent with the table format for the tolerances recommended in Item $320-9$, the text of T.1.2. would not appear in Handbook 44. Instead, the tolerance change would affect Table X as shown in the table headed Item 320-10: Revised Tolerances for Unmarked Scales.

\section{0-11 V T.N.1. Principles; Multiple-Weighing Devices Interfaced with a Single Indicator}

(This item was adopted.)

Discussion. The number of vehicle scales consisting of three or more individual weighing elements used simultaneously to obtain a gross weight for commercial transactions is increasing. The individual weighing elements are used to obtain axle-load weights to determine compliance with highway laws and, because the entire vehicle is weighed as a single draft, the summed weight may be used for commercial transactions. The classification of the system as a single scale would mean that the entire system shall not exceed the maximum number of scale divisions for the application. A vehicle scale consisting of three weighing devices would then also have to meet T.N.4.4. across all of the sections.

This approach to weighing has raised the question of how the number of scale divisions permitted in class III or III L scales should be applied. For example, a vehicle scale may have three platforms with the following capacities: 100,000 $\times 20 \mathrm{lb}, 100,000 \times 20 \mathrm{lb}$, and $60,000 \times 20 \mathrm{lb}$. The sum of these scale capacities is $260,000 \mathrm{lb}$ for a total of 13,000 divisions. Should the maximum number of divisions for class III scales apply to the summed indication? An argument can be made that the total is only the sum of digital indications, hence the 10,000 division limitation should not apply. However, a request had been received to permit four 20,000-lb $\times 5$-lb capacity scales to be used in combination to provide a scale with a capacity of $80,000 \times 5 \mathrm{lb}$, essentially to circumvent the class III L limit on the number of scale divisions. Consequently, the 10,000-division limit should apply to the summed indication, which is being used as the basis for commercial trade.

There is a similar situation in railroad weighing when rail cars are weighed in motion in multiple drafts. Each set of axles is weighed separately and combined to obtain the total weight of the car. It is the industry practice and the position of the Office of Weights and Measures that the capacity of the scale is the summed total of the anticipated maximum weights of the axles of the rail cars intended to be weighed on the scale. The 10,000 division limitation applies to the capacity rating of the scale although the static weighing capacity of the scale is a fraction (usually onehalf) of the capacity rating of the scale.

Committee Recommendation: Multiple weighing elements (e.g., three axle-load scales permanently installed adjacent to one another or with a dead space between the weighing elements) used simultaneously to obtain a single weight in commercial applications shall be deemed to be a single system which shall meet the requirements of the applicable accuracy class.

The classification of a scale or weighing system into an accuracy class should be based upon its application and method of use, not on the design of the device. Although this item does not contain a recommendation for change to Handbook 44, this interpretation is presented to the Conference for a yote to obtain a clear statement of the requirements that are to apply to these weighing systems. The Committee is aware that a number of jurisdictions test each scale as an independent scale, not as a single weighing system. The significance of this interpretation is that not only must each independent weighing device meet the requirements of Handbook 44, but the entire weighing system must meet all requirements that would apply if the device were a single scale. 


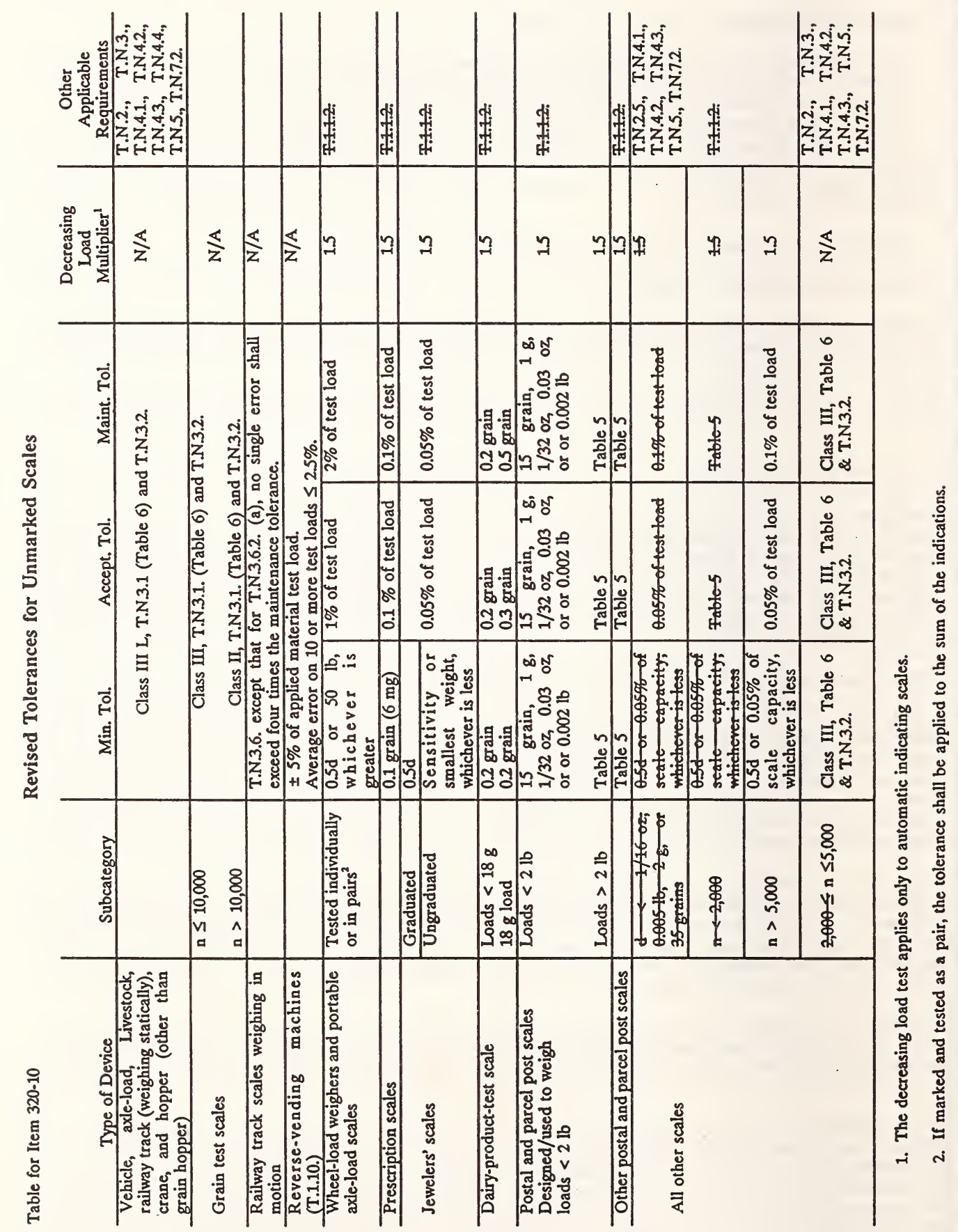


The Committee recommends that the following criteria be applied to multiple-weighing devices interfaced with a single indicating element:

1. The number of divisions in the weight indicator displaying the summed weight of all weighing elements of a scale consisting of multiple weighing elements (weighing simultaneously) shall not exceed the maximum permitted for the accuracy class (10,000 for class III and III L). The capacity by division must be marked on the weight display of the summing indicator.

2. Separate weight displays for individual weighing elements must have separate capacity statements. The number of divisions for each weighing element must satisfy the requirement for the number of scale divisions for the accuracy class. The scale division values for each weighing element and the weight display that is summing the weight values must be the same.

3. The capacity of the summed weight display shall not exceed the sum of the capacities of the individual weighing elements.

4. If one weighing element is overloaded and blanks out, then the summing weight display must also blank out.

5. All scale sections in the multiple weighing elements used simultaneously must agree within the absolute value of the maintenance tolerances (T.N.4.4.) as if the scale had a single weighing element.

Multiple weighing devices that are independent and used separately to weigh components that are mixed to obtain a final product shall be treated as separate scales, and each scale must meet the requirements of the applicable accuracy class.

[Editor's Note: The failure to reference specific paragraphs as a basis for these interpretations was identified as a deficiency in this item. For reference purposes, the applicable paragraphs are General Code G-S.1. Identification; G-S.5.2.2. Digital Indication and Representation; Scales Code S.1.7. Capacity Indication, Weight Ranges, and Unit Weights; S.5. Design of Weighing Devices, Accuracy Class; Table 3; T.N.1. Principles; and T.N.4.4. Shift or Section Tests.]

(This item was adopted.)

Discussion: Competition in the marketing of large capacity scales is driving scale manufacturers to offer vehicle scales with the maximum number of scale divisions $(10,000)$ permitted for class III $\mathrm{L}$ scales. This, in turn, pushes load cell manufacturers to offer class III L load cells with 10,000 verification intervals. The requirement of T.N.1.8. becomes very stringent when a load cell has 10,000 verification intervals.

The National Type Evaluation Program has provided some relief to load cell manufacturers by recognizing the cancellation of random errors on the temperature effect on minimum dead load output of the load cells, but at the same time introduced a technical inconsistency into the process. This technical inconsistency stems from permitting a 1.0 multiplier to be used when applying the scale tolerances to load cells (a separate main element falling under T.N.3.5.) and applying the same concept when requiring the minimum verification scale interval of the load cell $\left(\mathrm{v}_{\min }\right)$ to be less than or equal to the verification scale division of the scale (e) divided by the square root of the number of load cells $(\mathrm{N})$ used in the scale $\left(\mathrm{v}_{\min } \leq \mathrm{e} / \sqrt{ } \mathrm{N}\right)$.

To correct this technical inconsistency and to provide a less stringent performance requirement on class III $\mathrm{L}$ load cells with 10,000 verification intervals, the Committee recommends a change in the performance requirement for class III $\mathrm{L}$ devices. This change is expected to have only a small impact on class III $\mathrm{L}$ scales used commercially because most of them are equipped with an automatic zero-setting mechanism (AZSM). The greatest effect of this change will be on class III L hopper scales, which are not permitted to have AZSM. These scales are normally under load for long periods of time; a significant temperature change when a load is on the scale could change the scale indication, but if the weight of interest is a net weight determined by measuring the difference between two weights over a short period of time, even a change in the indication will not be significant because the difference will still be correct. 
Committee Recommendation: The Committee recommends that T.N.1.8.3. be replaced by the following:

T.N.8.1.3. Temperature Effect on Zero-Load Balance. - The zero-load indication shall not vary by more than:

(a) three divisions per $9{ }^{\circ} \mathrm{F}\left(5^{\circ} \mathrm{C}\right)$ change in temperature for class III $\mathrm{L}$ devices; and

(b) one division per $9{ }^{\circ} \mathrm{F}\left(5^{\circ} \mathrm{C}\right)$ change in temperature for all other devices.

\section{0-13 I UR.1.1. Selection Requirements; Suitability of Equipment}

Discussion: The S\&T Committee has expanded a table (see next page) submitted by a regional weights and measures association to propose some initial criteria to be used to determine the suitability of equipment for various applications. Many of the requirements for various applications were extracted from existing requirements in Handbook 44; others were included for discussion purposes. The table includes a listing for on-board weighing systems because it is a separate item in the report (Item 320-14). The inclusion of on-board weighing systems is for the purpose of discussion and is not to be interpreted as acceptance by the S\&T Committee in any accuracy class other than class III or III $\mathbf{L}$.

Committee Recommendation: Guidelines to determine the suitability of equipment for different applications should be established. The Committee recommends that these guidelines be discussed, revised, and expanded at the meetings of the regional weights and measures associations to establish suitability of equipment criteria. A table listing possible categorization for scales is given below. Entries with question marks are main points of discussion.

These guidelines should be based upon the accuracy required for transactions which may include the cost of the commodity, the accuracy of the devices available for the measurement, the quantity division that will relate to the minimum quantity to be measured, and the minimum quantity that is normally measured. Several items in this report involve these concepts, namely, 320-12, 320-14, 320-16, 330-5, and 360-1. These issues are suggested for discussion at the meetings of the regional weights and measures associations. 


\section{Suitability of Equipment Criteria}

$\underline{\text { Scales }}$

\section{Device and \\ Commodity}

Digital computing scale or POS scale

Animal scale

Livestock Scales

Grain hopper scales

\section{Hopper scales (not \\ grain) \\ Vehicle scale Grain}

Sand and gravel Solid waste

\section{On-Board \\ weighing systems}

Railway track $\geq 50,000 \mathrm{lb}$ scales
Belt-conveyor scales

Grain-test scale

$\geq 100 \mathrm{lb}$
$\geq 250 \mathrm{lb}$
$\geq 5,000 \mathrm{lb}$
$\geq 10,000 \mathrm{lb}$

\section{Loads or Deliveries}

Up to $50 \mathrm{lb}$

Up to $2,500 \mathrm{lb}$

$1 \mathrm{lb}$

$2 \mathrm{lb}$

$5 \mathrm{lb}$

$10 \mathrm{lb}$

$20 \mathrm{lb}$

$10 \mathrm{lb}$

$\geq 20 \mathrm{~d} \mathrm{~b}$
$50,000 \mathrm{lb}$

over $50,000 \mathrm{lb}$

$\geq 50 \mathrm{~d}$

$\geq 1000 \mathrm{lb}$

$\geq 100,000 \mathrm{lb}$

$\geq 50 \mathrm{~d}$

$\geq 50 \mathrm{~d}$

$\leq 500 \mathrm{lb}$

$>500 \mathrm{lb}$

1,000

$\mathrm{scale}$

divisions

$\leq 500 \mathrm{~g}$
$>500 \mathrm{~g}$

$50 \mathrm{lb}$

?

?

$0.5 \mathrm{~g}$
Maximum

Division Value

$0.01 \mathrm{lb}$

20d

20d

$50 \mathrm{~d}$

$50 \mathrm{~d}$

$500 \mathrm{~d}$

$500 \mathrm{~d}$

$20 d$

20d

$50 \mathrm{~d}$

$50 \mathrm{~d}$

$100 \mathrm{lb}$

$100 \mathrm{lb}$

$200 \mathrm{lb}$

$50 \mathrm{~d}$

$1000 \mathrm{~d}$

$50,000 \mathrm{lb}$ ?

$5,000 \mathrm{lb}$

$5,000 \mathrm{lb}$

?

?

class III L

$0.2 \mathrm{~g} ?$
$20 \mathrm{~d}$

20d
$0.5 \%$

\section{Accuracy (Tol.)}

Required

class III

class III

class III L

class III

class III L

class III L

$?$

class III

class III

\section{$320-14$}

UR.1.1. Selection Requirements; On-Board Weighing Systems

Discussion: The Committee has been requested to establish unique tolerances for on-board weighing systems. The argument for unique tolerances is based on the extensive abuse these devices must withstand due to highway travel, bumps, and other types of shock loading to the system. A tolerance larger than class III or III L, but still within the accuracy needed for the intended application, is requested. On-board weighing systems could be used effectively in some commercial applications, such as weighing liquid feed and fertilizers, solid waste products, and LP gas. These weighing devices are suitable for weighing some commodities based upon the tolerances permitted for particular commodities.

The Committee is opposed to creating a separate accuracy class for these devices. The Committee continues to study the proposal that suggests revising the tolerances for class IIII scales and then permitting class IIII scales to be used for some commercial applications. The suitability of equipment issue is critical to this discussion. 
Committee Recommendation: This issue should be studied further through the regional weights and measures associations. These discussions should address the suitability of equipment for the commodities being weighed, the accuracy required to weigh the commodities, and the potential impact of competition with class III L where suitability of equipment has dictated that class III L scales be used in specific applications. Manufacturers of on-board weighing systems are requested to submit test data obtained in cooperation with weights and measures officials to document the performance of the devices that have been permitted for use by individual States. This information could then be used as a basis to further analyze the request to establish different tolerances for on-board systems.

\section{0-15 VC UR.3.1. Recommended Minimum Load; Weight Classifiers}

(This item was adopted as part of the consent calendar.)

Discussion: A scale must perform within tolerance at any test load. The tolerance for any scale includes error resulting from scale rounding, the internal resolution of the scale, and the weighing error in the scale. Weight classifiers are programmed to round weight indications up to the next higher digit once the nominal value of an indication is exceeded. This approach reduces the round-off error at the points where postal and rate charts change from one rate to another. The remaining primary sources of error in weight classifiers at the weights at which rates change are (1) the internal resolution of the scale and (2) the weighing error of the scale. Although the acceptance tolerance of any marked scale is $0.5 \mathrm{~d}$ at $10 \mathrm{~d}$ and $20 \mathrm{~d}$, the inherent weighing error of the scale must be much less to enable the scale to be within tolerance at $500 \mathrm{~d}$.

Because weight classifiers eliminate the round-off error for small loads, the S\&T Committee recommends that a minimum load of $10 \mathrm{~d}$ be recognized for these types of scales. The effect of this change is that scales intended for use in postal applications may have divisions of $0.1 \mathrm{oz}$ instead of $0.05 \mathrm{oz}$. This slightly larger division value makes it easier for the scale manufacturer to produce a scale with a higher capacity at lower cost for the postal and parcel post applications. Although it has been cited that West Germany has accepted a minimurn load of $10 \mathrm{~d}$ for weight classifiers, apparently they have not accepted the minimum load of $10 \mathrm{~d}$ for weighing letters.

The Committee has some concerns about recommending a minimum load of $10 \mathrm{~d}$ for weight classifiers. These are that:

1. it sets a precedent of a $10 \mathrm{~d}$ minimum load for a class III scale;

2. these scales will have double the tolerance for larger loads than a scale that rounds off to the nearest division; and

3. this smaller minimum load appears to give weight classifiers a competitive advantage in postal and parcel applications.

In any event, the Committee has not received comments against this proposal. Consequently, the Committee is recommending the change in the recommended minimum load for weight classifiers.

Committee Recommendation: The Committee recommends that a foutnote be added to Table 8 for class III scales:

A minimum load of $10 \mathrm{~d}$ is recommended for a weight classifier marked in accordance with a statement identifying its use for special applications.

\section{UR.3.1.1. Minimum Load, Grain Dockage Determination; Value of the} Scale Division

Discussion: The Committee was asked to specify the maximum value of a scale division that is suitable for use on grain-test and grain-dockage scales. In general, two types of scales used for these applications appear to present problems. Both are fan-type automatic-indicating scales; one has a 5-g division, and the other has a 2.5-g division. The errors resulting from the lack of resolution may have a significant effect on the final price paid to the farmer. The value of the scale division permitted on grain-test scales was specified in the 1979 edition of Handbook 44, but the values were dropped after the 1985 edition when Tables $7 \mathrm{a}$ and $7 \mathrm{~b}$ were adopted as part of the revised Scale Code. 
For Handbook 44 applications, the NTEP type evaluation checklist permits percent calculations to be displayed only when the value of the scale division is less than or equal to $0.2 \mathrm{~g}$ for loads up to $500 \mathrm{~g}$ and less than or equal to $0.5 \mathrm{~g}$ for loads greater than $500 \mathrm{~g}$. For FGIS applications, the following requirements must be satisfied:

1. To calculate and display percent values, the verification scale division shall not exceed $0.01 \mathrm{~g}$ for loads up to 120 $\mathrm{g}$ and $0.5 \mathrm{~g}$ for loads in excess of $120 \mathrm{~g}$ through $1000 \mathrm{~g}$.

2. The percent values shall be rounded and displayed to at least 0.1 percent.

3. To calculate and display test weight values, the verification scale division shall not exceed $0.5 \mathrm{~g}$.

4. For official weighing, the FGIS has three categories of electronic laboratory scales used as grain test scales: precision, moisture, and general. The accuracy classes and scale divisions used for these scale categories shall not exceed those given in the following table.

\begin{tabular}{lcl}
\hline Category & Accuracy Class & Scale Division \\
\hline \hline & II & $\mathrm{e} \leq 0.01 \mathrm{~g} ; \mathrm{d} \leq 0.01 \mathrm{~g}$ \\
Precision & II, III & $\mathrm{e} \leq 0.1 \mathrm{~g} ; \mathrm{d} \leq 0.1 \mathrm{~g}$ \\
Moisture & II, III & $\mathrm{e} \leq 0.5 \mathrm{~g} ; \mathrm{d} \leq 0.5 \mathrm{~g}$ \\
General & & \\
Note: For Class III scales, $\mathrm{e} \leq \mathrm{d}$. & & \\
\hline \hline
\end{tabular}

More study is required before maximum division values can be specified for these scales.

Committee Recommendation: Study this issue.

\section{0-17 I T.1. Tolerance Values; In-Motion Weighing, Monorail Scales}

Discussion: In 1985 the Tolerances Section of the Scales Code was separated into sections for marked and unmarked scales. Due to an oversight, there is no reference to unmarked monorail scales that weigh while the carcass is moving across the scale; this tolerance is expressed in the paragraph T.N.3.7. Assuming that Item 320-10 is adopted, an entry in the table in Item 320-10 will be added editorially to specify the tolerance for these scales as the tolerances in T.N.3.7.

Belt-Conveyor Scale Systems

$321-1$ VC N.3.3. Simulated Load Tests

(This item was adopted as part of the consent calendar.)

Discussion: The number of required simulated load tests and the agreement required among these tests were deleted from the Note paragraph N.3.3. last year when simulated load tests as recommended by the manufacturer were specified. Requirements are needed to specify a minimum level of testing and performance. The Committee recommends establishing a requirement on the repeatability of the simulated load test. This recommendation would require a simulated load test to be run shortly after the material test to establish the factor that relates the results of the simulated load test to the results of the material test.

Committee Recommendation: The Committee recommends that N.3.3. be amended to read: 


\section{N.3.3. Simulated Load Tests. -}

(a)

(b)
As required by the certifying authority, simulated load tests as recommended by the manufacturer are to be conducted between material tests to monitor the system's operational performance, but shall not be used for official certification.

A simulated load test consisting of at least three consecutive test runs shall be conducted as soon as possible, but not more than 12 hours after the completion of the material test, to establish the factor to relate the results of the simulated load test to the results of the material tests.

The results of the simulated load test shall repeat within 0.1 percent.

Discussion: Stage II vapor recovery is required in more cities and States. The S\&T Committee has been asked to provide a statement that nothing in Handbook 44 prevents the use of a single delivery hose on a multi-product dispenser. A single delivery hose on a multi-product dispenser reduces the cost of a dispensing system and reduces customer difficulty in handling a heavy hose if no other hoses interfere. The sampling method established in 1989 by the Laws and Regulations (L\&R) Committee for the octane level of product dispensed by blend dispensers shall also be used for multi-product dispensers using a single delivery hose. Device manufacturers are considering using one delivery hose on multi-product dispensers because they can meet the octane requirements when a minimum of 0.3 gallon product is delivered before the sample is taken for the octane test.

See Item 237-1 in the 1989 L\&R Committee report for further information on this issue.

Committee Recommendation: After having reviewed the issue, the Committee has concluded that nothing in Handbook 44 prevents a single delivery hose from being used on a multi-product dispenser; however, a single delivery hose cannot be used for dissimilar products, such as gasoline and diesel fuel.

\section{2}

\section{VC S.3.9. Antidrain Means}

(This item was adopted as part of the consent calendar.)

Discussion: The National Fire Protection Association requires that the nozzle on a wet-hose device used in selfservice applications cannot be opened unless there is pressure on the hose. Nozzle manufacturers have designed a nozzle that cannot be opened unless there is pressure on the hose. It is possible to release a very small amount of liquid if the liquid in the hose expands when the hose is in the sunlight on a hot day, but the quantity is very small and the design of the nozzle prevents the draining of the hose.

A manufacturer provided the S\&T Committee with a cut-away example of this type of nozzle. The Committee is convinced that the nozzle appears to be as effective as an antidrain valve to prevent the draining of the hose. Consequently, the Committee recommends permitting this type of nozzle to be used instead of requiring an antidrain valve in the nozzle.

Committee Recommendation: To be more general and recognize methods other than an antidrain valve to prevent draining of the hose, the Committee recommends amending S.3.9. to read:

S.3.9. Antidrain Vatve Means. - In a wet hose, pressure-type device, an-antidrain valve means shall be incorporated in or immediately-adjacent to the-diseharge-vatve to prevent the drainage of the discharge hose. 
(This item was withdrawn.)

Discussion: This item proposed requiring the fill pipes for product storage tanks be marked as to the product contained by means of a color code that complies with the codes outlined in the American Petroleum Institute (API) Recommended Practice 1637 and API Bulletin No. 1542. Uniform coding would reduce the potential of contaminating fuel supply tanks with the wrong product and increase the confidence of the weights and measures official that the product is being returned to the correct storage tank after a test of the dispensers. This proposal was submitted to the S\&T Committee in 1987 (Item 330-17) and was not proposed for adoption because the Committee believed weights and measures jurisdictions could require the fill lines to be marked, but that it was inappropriate for Handbook 44 to specify the markings or codes that must be used. The position of the Committee has not changed.

Committee Recommendation: Withdrawn.

\section{$330-4$}

\section{V}

\section{UR.3. Use of Device; UR.3.3. (b) Computing Device}

(Voting item 1 failed, voting item 2 was adopted.)

Discussion: In 1989 the Conference adopted changes to require that:

1. after January 1, 1990, any dispenser (with limited exceptions) placed into a multi-tier pricing (typically cash/credit pricing) application must either compute the sales price for all unit prices for which the product is offered for sale or be dedicated to those sales for which it can compute (UR.3.3.);

2. effective January 1, 1991, a new computing device shall compute the total sales price at any single-purchase unit price (with limited exceptions) for which the product is offered for sale (S.1.6.5.); and

3. effective January 1, 1991, new computing devices used in multi-tier pricing applications shall have controls on the device or other user-activated controls to select the unit price for the transaction (S.1.6.5.4.).

The Conference adopted policy to require dispensers to compute the sales price at which the product is offered for sale, but did not agree upon a date by which single unit price dispensers used in multi-tier pricing applications prior to January 1, 1990, must either (1) be modified or replaced to be able to compute at all of the unit prices for which product is sold through the device or (2) be dedicated to those sales for which the dispenser can compute the sales price. Three regional weights and measures associations have suggested a cutoff date of January 1, 1995, and one association has suggested January 1, 1999. It is clear to the Committee that the Conference wants to establish a cutoff date by which all devices used in multi-tier pricing applications must be able to compute the sales price for which the product is being sold.

The Committee has debated the many facets to this issue and is well aware of the impact on the industry. The Committee supports January 1, 1999 as a final date for dispensers to compute at the unit price or prices at which the product is offered for sale. Thereafter, all devices would either (1) be able to compute at all of the unit prices for which product is sold through the device or (2) be dedicated to those sales for which the dispenser can compute the sales price. It is emphasized that this would not require that dispensers be converted; however, some stations may choose to discontinue the marketing practice of multi-tier pricing if it is not economically practical to convert to multitier pricing equipment or to dedicate dispensers or hoses to sales at a single unit price.

As part of this issue, the Committee received some comments suggesting that the January 1, 1990 date stated in UR.3.3. be changed to coincide with the final date by which all dispensers must compute the sales price for the unit prices at which product is offered for sale through the device. The motivation behind the UR.3.3. requirement adopted in 1989, was to prevent an increase in the number of devices that the Conference considers not suitable for multi-tier pricing applications. The Committee does not support a change in the January 1, 1990 date, and is not aware of sufficient support within the Conference to reconsider the 1989 decision. 
Committee Recommendation: The S\&T Committce is offering the Conference the selection of the effective date of this requirement as either January 1, 1995 or January 1, 1999, as scparate voting items. Based upon economic and other factors, the Committec believes the January 1, 1999 date is the most realistic choice of dates. The January 1, 1995 date will be presented first. If it is accepted, the vote on the January 1, 1999 date will be withdrawn. If neither the January 1, 1995 date nor the January 1, 1999) date are adopted, the proposed addition of UR.3.3.(b) will fail and a final date for the implementation of this deadline will not be established at this Annual Meeting.

\section{Voting Item 1:}

The Committce recommends that a part (b) be added to UR.3.3. to read:

(b) A computing device shall be used only for sales for which the device computes and displays the sales price for the transaction. (Effective and retroactive as of January 1, 1995)

(This voting item failed.)

\section{Yoting Item 2;}

The Committec recommends that a part (b) be added to UR.3.3. to read:

(b) A computing device shall be used only for sales for which the device computes and displays the sales price for the transaction. (Effective and retroactive as of January 1, 1999).

(This voting item was adopted.)

Discussion: The S\&T Committee has expanded a table, submitted by a regional weights and measures association, proposing some initial critcria for determining the suitability of equipment for various applications. Many of the requirements for various applications come from Handbook 44; others were included for discussion purposes. The Committee recommends that these tables (see also Item 320-13) be discussed, revised, and expanded at the meetings of the regional weights and measures associations to establish suitability of equipment criteria. A table listing possible categorization for liquid-measuring devices follows. 


\section{Suitability of Equipment Criteria}

\section{Liquid-Measuring Devices}

\section{Device and}

Commodity

Motor-fuel device

Analog

Digital

Either

Loading rack

VTM

gas, fuel

Agri-chem

Milk

LPG \& $\mathrm{NH}_{3}$

Agri-chemical
Loads or

\section{Deliveries}

$$
\leq 100 \text { gallon }
$$$$
\leq 100 \text { gallon }
$$

$>100$ gallon

$$
\begin{aligned}
& \leq 1,000 \text { gallon } \\
& >1,000 \text { gallon }
\end{aligned}
$$

\author{
Maximum \\ Division Value
}

\section{1 gallon}

0.01 gallon

0.1 gallon

0.1 gallon

1 gallon

0.1 gallon

$\geq 100$ but $\leq 1000$

gallons

$>1,000$ gallons

$\begin{array}{ll}\leq 1,000 \text { gallon } & 0.1 \text { gallon } \\ >1,000 \text { gallon } & 1 \text { gallon } \\ \text { See below } & \text { See below } \\ \leq 1,000 \text { gallon } & 1 \text { pint } \\ >1,000 \text { gallon } & 1 \text { gallon }\end{array}$

0.01 gallon

\section{$\leq 100$ gallon}

1 gallon

\author{
Minimum Load \\ or Delivery
}

?

$100 d$

$500 \mathrm{~d}$

$500 \mathrm{~d}$

$500 \mathrm{~d}$

$0.3 \%$

$0.3 \%$

$\begin{array}{ll}500 \mathrm{~d} & 0.22 \% \\ 500 \mathrm{~d} & 0.22 \% \\ \text { See below } & 1.0 \% \\ ? & 0.2 \% \\ 1000 \mathrm{~d} & 0.2 \% \\ & -1.5 \% /+1.0 \% \\ 500 d^{*} & -1.5 \% /+1.0 \% \\ 500 \mathrm{~d} & 1.0 \% \\ & 1.0 \% \\ 500 \mathrm{~d} & \end{array}$

$0.3 \%$

$1.0 \%$

$0.2 \%$

$-1.5 \% /+1.0 \%$

$-3.0 \% /+1.5 \%$

Mass Flow Meters

gas, fuel oil

Agri-chemical

Milk

LPG $/ \mathrm{NH}_{3}$

Hydrocarbon

vapor

\section{"Italics means nonretroactive}

Committee Recommendation: The terms "retail" and "wholesale" should be removed from the code and criteria for suitability of equipment be established. However, terms are needed to replace "retail" and "wholesale" before their removal, since those terms are used to delineate specific requirements applying to certain devices. The regional weights and measures associations are requested to discuss these issues and to recommend terminology.

Guidelines for suitability of equipment for different applications should be based upon the accuracy required for transaction, which may include the cost of the commodity, the accuracy of the devices available for the measurement, the quantity division that will relate to the minimum quantity to be measured, and the minimum 'quantity that is normally measured. Several items in this report involve these concepts, namely 320-12, 320-14, 320-16, 330-5, and 3601. These issues are suggested for discussion at the meetings of the regional weights and measures associations. 


\section{Liquefied Petroleum Gas and Anhydrous Ammonia Liquid-Measuring Devices}

\section{$332-1$}

\section{VC S.1.4.2. Return to Zero}

(This item was adopted as part of the consent calendar.)

Discussion: Stationary retail devices other than retail motor-fuel devices are used commercially. The return-tozero requirement should apply to all stationary retail devices, not just retail motor-fuel devices. A change of language was made to S.1.1.5. in 1988 and S.4.2. in 1989, but this paragraph was overlooked. The proposed change would be consistent with the language of the other paragraphs.

Committee Recommendation: Reorganize S.1.4.2., delete the reference to retail motor-fuel device, and replace the words with stationary retail device so S.1.4.2. will read as follows:

\section{S.1.4.2. Return to Zero. -}

(a) Primary indicating elements shall be readily returnable to a definite zero indication. Means shall be provided to prevent the return of primary indicating elements, and of primary recording elements if these are returnable to zero, beyond their correct zero position.

(b) Primary recording elements on a retail motorfuel stationary retail device, if the device is equipped to record, shall be readily returnable to a definite zero indication.

This will be a retroactive requirement.

\section{Hydrocarbon Gas Vapor-Measuring Devices}

$333-1$

\section{VC N.4.2.2. Low-Flame Test}

(This item was adopted as part of the consent calendar.)

Discussion: It takes 8 hours to perform the low-flame test on smaller meters, using a draft of 2 cubic feet as required by N.3. and a flow rate of $0.25 \mathrm{ft}^{3}$ as prescribed by Table 1 . This is an unnecessarily long test period when defects can be identified within an hour using the proposed procedure. The Committee believes that this procedure can be shortened to as little as 60 minutes without significant deterioration of the quality of the test results. The 60 -minute test is already recognized in NBS Handbook 117, "Examination of Vapor-Measuring Devices for Liquefied Petroleum Gas," but Handbook 117 references the tolerances currently specified in T.1.1.

The Committee has been advised that the meter performance for the low-flame test is typically a pass or fail situation. Either the meter registers quantity throughout the test cycle or it ceases to operate at some point in the test. Consequently, the tolerances specified for the low-flame test (T.1.1.) are not needed; the proposal substitutes a performance requirement for the low-flame test that looks for continuous registration of flow at a very low pressure to determine if the meter ceases to register at some point during the test. At least one revolution of the tangent arm is needed to test the meter performance throughout one measurement cycle of the meter. All vapor meters will make one complete cycle of the tangent arm within 60 minutes. This is ample time to demonstrate any mechanical binds or internal leakage within the meter housing.

\section{Committee Recommendation: Amend N.3. to read:}

N3. Test Drafts. - Except for low-flame tests, test drafts should be at least equal to one complete revolution of the largest capacity proving indicator, and shall in no case be less than 2 cubic feet or 0.05 cubic meter. All now rates shall be controlled by suitable outlet orifices.

Amend N.4.2.2. to read: 
N.4.22. Low-Flame Test. - The device shall be tested at an extremely low-flow rate as given in Table 1. The test shall consist of passing air at a pressure of 1.5 inches water column through the meter for not less than 60 minutes. The quantity of air registered by the meter shall be determined at a minimum of three approximately equal time intervals. (See T.1.1. for the performance requirement for this test.)

Delete the existing text of T.1.1. and replace it with the following:

T.1.1. On Low-Flame Test. - The-maintenanee-and-aceptamee-toleranees-shall-be-20-pereent-on underregistration and 10 pereent on-overregistration. The quantity registered during the time intervals for the low-flame test shall agree within 30 percent.

\section{3-2 VC LPG Vapor Meters Installed Adjacent to Heaters Vaporizing LP Gas}

(This item was adopted as part of the consent calendar.)

Discussion: A gas-fired heater is sometimes used to vaporize LPG prior to metering the vapor. A vaporizer may be used to generate a higher pressure to overcome the use of undersized piping in the vapor distribution system when the system is unable to supply adequate product to meet the demand. The vapor discharged from the vaporizers can be very warm $\left(70^{\circ} \mathrm{F}\right.$ to $\left.90^{\circ} \mathrm{F}\right)$. A customer purchasing gas through a gas-fired vaporizer/metering system will pay for more gas than if the product were metered at ambient temperature.

The National Propane Gas Association (NPGA) has stated that LPG tanks are located at least 50 feet from the nearest building or property line for safety and operational reasons. Thus, in most cases the vapor will have cooled to ambient temperature before it is measured. In those instances where the vapor meter is located close to the vaporizer, the NPGA agrees that the vapor should be temperature-compensated to $60^{\circ} \mathrm{F}$.

The Committee recommends that when vaporizers are used and vapor meters are installed close to the vaporizers such that the product does not cool to the ambient temperature, then the meter shall automatically temperaturecompensate the product. Additionally, a thermometer well to measure the temperature of the product being metered may be required if deemed necessary by the weights and measures official.

The NPGA has provided a detailed analysis of the heat loss from vapor through bare steel pipe of various sizes buried underground. This information may assist the weights and measures official to determine when an automatic temperature compensation system may be needed. The analysis shows that, for a vaporizer load of 80 gallon/hour being converted to $2909 \mathrm{ft}^{3}$ of LP gas vapor heated to $120^{\circ} \mathrm{F}$, the length of pipe needed to cool the vapor to the ground temperature of $55^{\circ} \mathrm{F}$ ranges from 24 to 41 feet. The length of pipe needed will depend upon the load on the vaporizer, the temperature to which the vapor is heated, and the size and type of pipe. Copies of the equations and the analysis are available from the Office of Weights and Measures.

Committee Recommendation: The Committee recommends adding a new paragraph UR.2.5. to read:

UR.2.5. Use of Auxiliary Heated Vaporizer Systems. - Automatic temperature compensation shall be used on hydrocarbon gas vapor meters equipped with an auxiliary heated vaporizer system unless there is sufficient length of underground piping to provide gas at a uniform temperature to the meter inlet. When required by weights and measures officials, a thermometer well (appropriately protected against freezing) shall be installed immediately up-stream of the meter.

Water Meters

(This item was adopted as part of the consent calendar.)

Discussion: Some water meters are rated for flow rates higher than those shown in Table 1. Some meters pass the tolerance requirements when tested at the Table 1 values, but fail when tested at the manufacturer's rated capacity. 
These meters shall be accurate over the range of flow rates specified by the manufacturer. Whenever possible, these meters should be tested at flow rates above the Table 1 ratings, but not to exceed the meter rating.

Committee Recommendation: The Committee recommends that N.4.1. be amended to read:

N.4.1. Normal Tests. The normal test of a meter shall be made at the maximum discharge rate developed by the installation. Meters with maximum gallon per minute ratings higher than Table 1 values may be tested up to the meter rating.

\section{Odometers Code}

\section{3-1 VC S.1.6. Digital Indications and Representation}

(This item was adopted as part of the consent calendar.)

Discussion: A digital odometer submitted for type evaluation was found to truncate the mileage values (drop any fraction of a mile until the nominal distance was actually reached). These odometers may be used on rental cars and are commercial devices when used to determine mileage charges. Odometers that truncate mileage values currently violate the General Code requirement G-S.5.2.2.(c).

The Committee believes that odometers that truncate values are appropriate for car rental use because most mileage charges are for a sizable number of miles, hence the error due to rounding down is relatively small as a percentage of the total miles driven. Moreover, the truncation always favors the customer when the trip odometer is used. The Committee has been advised that digital odometers are commonly designed to truncate the mileage. Consequently, the Committee recommends adopting a new requirement in the Odometers Code to supersede G-S.5.2.2.(c) for digital odometers.

Committee Recommendation: The Committee recommends adding a new paragraph S.1.6. to the Odometers Code to read:

S.1.6. Digital Indications and Representation. - Digital indicating odometers (discontinuous registration) shall "round ofr" indications to the nearest minimum division or truncate indications to the lower minimum division.

\section{Taximeters}

\section{4-1 VC S.1.3.2. Lighting of Indications}

(This item was adopted as part of the consent calendar.)

Discussion: Based upon the current language of S.1.3.2., taximeters are required to provide illumination of fare indications, the operational controls of the taximeter, and other indications of passenger interest. The "other indications of passenger interest" referenced in S.1.3.2. includes the operating status of the taxicab, that is, whether or not the taxicab is vacant, hired, or operating in the time-off mode. The lighting of these various indications and controls must be integral to the meter. The requirement that the lighting be integral to the meter developed from the design of some taximeters that were to have a light source mounted on the meter to illuminate the indications and controls (as specified in UR.2.), but frequently the light source was not supplied.

Taximeter manufacturers generally design meters to have the fare indications illuminated, but the operational controls are usually not illuminated. It has been argued that there is little justification to require lighting of operator controls, such as the print key, keys to recall operator information (totals and other operator statistics), the credit card reader, and keys for tip entry. Additionally, the phrase "other indications of passenger interest" in S.1.3.2. is vague and open to subjective interpretation. The Committee recommends that S.1.3.2. be amended to delete the requirement to illuminate the operator controls and to specify which indications must be illuminated. 
Committee Recommendation: The Committee recommends that S.1.3.2. be amended to read:

S.1.3.2 Lighting of Indications. Integral lighting shall be provided for illuminating the fare extras, the nate or rate code, and the taximeter status indications, operationat controts, and other indications of passenger interest (i.e.n. vacant, hired, and time off,etc:).

[Nonretroactive as of January 1, 1989]

\section{4-2 VC S.6. Short-Term Power Interruption, Electronic Taximeters}

(This item was adopted as part of the consent calendar.)

Discussion: In some municipal areas, taximeters are mounted on slide mounts to permit the taxicab operator to remove the taximeter from the cab to discourage theft of the meter. These meters can be easily disconnected and reconnected in 3 seconds. Municipal areas with heavy taximeter use can have passenger turnover in 5 to 7 seconds. The 10-second time period for power interruptions allows these slide-mounted meters to be disconnected at the termination of one fare and reconnected as the initiation of the next fare, thereby defrauding a passenger. A shorter time period for a power interruption while still permitting the taximeter to advance would reduce the potential for fraud.

The acceptable methods of taximeter operation after short and long term power interruptions are specified in paragraphs S.6 and S.7. A proposal was made to establish a shorter time period (3 seconds) for the power interruption as it applies to removable taximeters as compared to a 10-second time period for permanently-installed taximeters.

The Committee concluded that no distinction in the duration of the power interruption requirement should be made based upon the method of mounting the meter; the power interruption criterion should be the same for permanently installed and removable taximeters. Consequently, the Committee recommends combining S.6. and S.7. into one paragraph consisting of two parts. Taximeter manufacturers have also stated through the NTEP type evaluation laboratories that they need more time to incorporate the design change of S.6. into their taximeters. Many models of taximeters do not meet the S.6. requirement. To afford more time for manufacturers to change the design of their taximeters, the Committee recommends that the requirements of S.6. and S.7. (as modified by the following recommended change to the Conference) become effective and nonretroactive on January 1, 1994. The changes are to become retroactive on January 1, 1999.

Committee Recommendation: The Committee recommends amending S.6. and S.7. by:

(1) combining paragraphs S.6. and S.7. into a single paragraph;

(2) making the requirement of S.6. nonretroactive and effective on January 1, 1994, but to become retroactive on January 1, 1999; and

(3) base the acceptable meter operations upon power interruptions of three seconds.

The following language is recommended.

S.6. Short Term Power Interruption, Electronic Taximeters.

(a) After a power intermuption of $7 \theta 3$ seconds or less, the fare and extras indications shall retum to the previously displayed indications and may be susceptible to advancement without the taximeter being cleared.

f.7. Long Ferm Power Interntption Etectronic Faximeters.

(b) After a power internuption exceeding 703 seconds, the fare and extras indications shall retum to the previously displayed indications and shall not be susceptible to advancement until the taximeter is cleared.

[Effective and nonretroactive as of January 1, 1994. Retroactive after January 1, 1999.] 

Interval

Discussion: Although the electronic timing devices used in taximeters are quite accurate, errors of either overregistration or underregistration may occur. The electronic timing devices usually do not have any adjustment mechanism for accuracy, consequently the zero tolerance on overregistration is not practical. All devices, no matter how accurate, will have some overregistration or underregistration error. The tolerance for a device must also recognize the uncertainty in the test process used to test the time feature on taximeters.

In its Interim Report, the Committee recommended establishing a small fixed tolerance on overregistration consistent with the tolerance in the Timing Devices Code.

Committee Recommendation: The Committee recommends amending T.1.2.2. to read:

T.1.2.2. On Average Time Interval Computed After Excluding the Initial Interval. - Maintenance and acceptance tolerances on the average time interval excluding the initial interval shall be as follows:

(a) On Overregistration: $-\underline{5 \text { seconds for any time interval of } 1 \text { minute of more; and }}$

(b) On Underregistration: 3 seconds per minute (5 percent).

Change in Proposed Committee Action:

The Committee has received a more detailed explanation of the objection to this item from the State of California. Based upon the explanation and further analysis, the Committee has concluded that the change recommended in the Committee report is inappropriate and would need modification before a change should be made to T.1.2.2. Consequently, the Committee requests the permission of the Conference to change this item to an information item. As an information item, no change is made to T.1.2.2. at this time.

The Committee adds the following explanation of this item so any future proposal can consider the problem that has been brought to the attention of the Committee.

The request to recognize a tolerance for overregistration for the timers used in taximeters is based upon the desire to recognize that the timing mechanisms used in electronic taximeters are probably typical off-the-shelf mechanisms for which the manufacturing process targets zero error in timing as the optimum. Assuming that a normal distribution applies to the manufacturing process means that some production devices will overregister and some will underregister, although the overall accuracy of the timing mechanisms may be very good. If a tolerance of zero applies to overregistration, then timing mechanisms would have to be sorted to select only those timing mechanisms that underregister to be used in taximeters, or the manufacturing process would have to be changed to target production to underregister slightly. Since off-the-shelf timing mechanisms are probably used in many applications where it is best to target zero error in the operation of the timing mechanism, it appears reasonable to recognize a small tolerance for overregistration. A small tolerance for overregistration would have the additional benefit of addressing the small uncertainty in the test process that can affect the test on timing devices.

The Committee based its recommendation for the tolerance on overregistration on the tolerance expressed in the Timing Devices Code. It was the intent of the Committee that the overregistration tolerance of 5 seconds applies to the test of any time period regardless of length. However, the use of the term "time interval" in the Taximeter Code differs from the use in the Timing Devices Code.

The time intervals in the Taximeter Code address the intervals of the money drops based upon time, whereas the time intervals in the Timing Devices Code apply to any time interval selected for a test which can be long periods of time up to the capacity of the timing device. The Taximeter Code Note N.2. specifies that the time test of a taximeter consist of the following.

1. Check the initial time interval for the initial time drop. 
2. Check at least four individual time intervals (time drops) after the initial time interval. Normally the first four consecutive time intervals following the initial time interval are tested for the accuracy of the individual interval. The tolerances stated in T.1.2.1. apply, which includes a nonzero tolerance for overregistration.

3. At least four consecutive time intervals after the initial time interval are tested and the average time for these four time intervals is computed. The four time intervals used to compute the average time for the time interval are usually the four time intervals checked for individual accuracy. The tolerance for the average time interval stated in T.1.2.2. applies. The overregistration tolerance on the average time for a time interval is zero.

Based upon the use of "time interval" in the Taximeter Code as the time interval of the taximeter time drop, which may be relatively short, the tolerance of 5 seconds for overregistration on the average time interval is excessive and undesirable. Consequently, the Committee recommends that the tolerances expressed in T.1.2.2. remain unchanged until the issue receives further study.

(This item was adopted as part of the consent calendar.)

Discussion: The programming of rates in some of the new types of electronic taximeters is very flexible. The programming permits the cost for the initial time interval to differ from the cost for the initial distance interval. In addition, the cost of the initial distance interval (or the initial time interval) may be different from the cost for subsequent distance (or time) intervals. The rates for these initial intervals are usually not posted.

The Committee recommends requiring the ratio of the initial time interval to the subsequent intervals to be equivalent to the ratio of the distance of the initiai mileage interval to the subsequent intervals. It is recommended that paragraph UR.3. also be amended to require the rates for the initial time interval and the initial distance interval to be posted. If adopted, these changes will take effect on January 1, 1991.

Committee Recommendation: The Committee recommends adding a new subparagraph S.2.1. and amending UR.3. to read:

S.2.1. Initial Time and Distance Intervals. - The time and distance intervals of a taximeter shall be directly proportional as expressed in the following formula:

\section{$\frac{\text { Seconds of Initial Time Interval }}{\text { Seconds per Non-Initial Time Interval }}=$}

\section{Distance of Initial Mileage Interval Distance per Non-Initial Mileage Interval}

UR.3. Statement of Rates. - The distance and time rates for which a taximeter is set, including the initial distance interval and the initial time interval, and the schedule of extras when an extras indication is provided, shall be conspicuously displayed inside the front and rear passenger compartments. The words "Rate," "Rates," or "Rates of Fare" shall precede the rate statement. The rate statement shall be fully informative, selfexplanatory, and readily understandable by the ordinary passenger, and shall either be of a permanent character or be protected by glass or other suitable transparent material.

\section{Other Items}

\section{0-1 I Draft Code for Mass Flow Meters}

Discussion: A separate code for mass flow meters is still under development. The draft code will be based upon the draft OIML recommendation and requirements for mass flow meters already in Handbook 44. Copies will be available from the Office of Weights and Measures upon request after the draft is completed. 


\section{0-2 I Lubricating Oil Meters}

Discussion: The use of meters to sell lubricating oils is increasing. Special field standards and test procedures are needed to facilitate the testing of meters used in these applications.

Information has been submitted to the S\&T Committee from the Measuring Industry Sector of the Technical Committee on National Type Evaluation and by the State of California. This information will be sent to the regional weights and measures associations for study. The S\&T Committee requests comments and recommendations for uniform standards and test procedures to test lubricating oil meters.

\section{0-3 I Draft Carbon Dioxide Liquid-Measuring Devices Code}

Discussion: Delivery of liquid carbon dioxide to restaurants is increasing. The code is needed to provide adequate regulation of measuring devices for this product. The Office of Weights and Measures has not been able to do additional work on this code. A brief comparison of the draft code to the Cryogenics Liquid-Measuring Devices Code indicates many similarities. The Committee will continue to explore the possibility of incorporating the differences required for liquid carbon dioxide meters into a separate set of requirements within the Cryogenic Meter Code. Comments and the rationale regarding the unique requirements for liquid carbon dioxide meters and the justification for a separate code for these devices are requested.

\section{0-4 I OIML Report}

The following information was provided by Mr. O. K. Warnlof, Standards Management, NIST.

Discussion: The OIML schedule of activities for $1989 / 1990$ has been extremely heavy and is expected to continue for the next several years, primarily because of "EC'92." The cooperation and interest of members of the NCWM is appreciated and your continued participation is encouraged. The following is an outline of activities for 1989/1990.

OIML WORK PROGRAM - 1989/1990

\section{PS5D "Dynamic Measurement of Liquids"}

RS1 "Meters With Measuring Chambers or Turbines"

Pre-Draft International Recommendation (IR) " Combined Document" circulated to National Working Group (NWG) - 6/21/89

Comments on 1st Pre-Draft "Combined Document" due Reporting Secretariat (RS) - 10/89

Comments received on 1st Pre-Draft and sent

2nd Pre-Draft "Combined Document" to be circulated by RS - 3/15/90

2nd Pre-Draft "Combined Document" received and circulated to NWG - 7/7/90

Meeting of NWG - 8/13-15/90, NIST, Gaithersburg, MD (Lecture Room D)

Comments on 2nd Pre-Draft due RS - 8/90

Meeting of International Working Group (IWG) - 10/24-26/90. NIST Gaithersburg. MD (Lecture Rooin A)

RS3 "Water Mèters"

2nd Pre-Draft Revision R49 circulated to NWG - 8/17/89

Comments due to RS - $12 / 31 / 89$

Comments received on 2nd Pre-Draft from AWWA, Badger Meter and sent - 1/90

Meeting of IWG - Late 1990

RS6 "Electronic Devices"

1st Draft IR "Electronics" circulated to NWG - 6/21/89 
Comments and vote due to RS - $9 / 15 / 89$

U.S."no" vote and comments sent $-9 / 7 / 89$

RS7 "Methods \& Devices for Verification" \& RS9 "Vortex Meters"

Meeting of IWG - 11/6-10/89. Japan

(a) 2nd Pre-Draft "Test Procedures, Gas Pumps"

(b) 2nd Pre-Draft "Pipe Provers"

(c) 1st Pre-Draft "Vortex Meters"

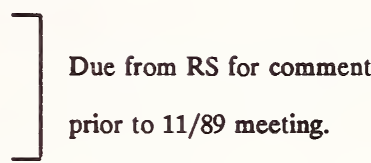

Received \& Circulated to NWG - 9/20 for comments by 10/27/89

Comments Received - (a), API, Gilbarco; (b) and (c), NIST; comments sent to RS - 11/14/89

RS10 "Direct Mass Flow Meters"

Meeting of NWG - 10/23-24/89; NIST, Gaithersburg. MD (Metrology, A-340) to develop 2nd Pre-Draft. Meeting of NWG - 3/20/90; NIST, Gaithersburg, MD (Lec A) to finalize 2nd Pre-Draft.

2nd Pre-Draft circulated to IWG $3 / 22 / 90$ for comment by $8 / 1 / 90$

Meeting of NWG - 8/15-16/90 NIST, Gaithersburg. MD, to review comments received.

Meeting of IWG - 10/22-23/90 NIST, Gaithersburg MD (Lec A)

\section{PS5S "Static Measurement of Liquids"}

RS12 "Static Direct Mass Measurement of Quantities of Liquids"

1st Pre-Draft IR received from RS - 12/27/89

Comments due to RS - $7 / 1 / 90$

\section{PS6 "Measurement of Gas"}

RS4 "Measurement of Hydrocarbon Gases Distributed by Pipe-Line"

2nd Pre-Draft IR circulated to NWG - 8/8/89

Comments due to RS - 9/15/89; delay requested.

Comments received from AGA \& API, 10/3/89; sent 10/10/89

\section{PS7 "Measurement of Mass"}

RS2 "General Problems. Electronic Devices"

R74 comments for revision to IWG - 7/31/89

Response from IWG due - 11/1/89

Responses received: CECIP, U.K., Switzerland, Finland, Australia, Netherlands, Belgium, Canada, Sweden \& Hungary

NWG Meeting - $1 / 17 / 90$, Scottsdale, AZ

Ballot to IW' $-2 / 2 / 90$

IWG Meetin - 7/16-19/90, NIST, Gaithersburg, MD

RS4 "Non-Automatic Weighing Instruments"

R76 comments of IWG on proposed revisions due RS - 5/31/89. Sent.

R76 Revision to be circulated by RS - 10/31/89 (received 12/10/89); circulated to USNWG.

R76 Revision comments of IWG due to RS - 1/20/90 (U.S., 3/10/90)

NWG Meeting - 2/27 - 3/1/90 (Tu-Th) NIST, Gaithersburg, MD

R76 Collated comments and responses of RS - (received 4/8/90); circulated 4/9/90 to U.S. delegation to IWG meeting.

Weighing Seminar - 5/15-18/90, PTB, Braunschweig. (Tu-Fr)

IWG Meeting - 5/21-23/90, PTB, Braunschweig. (M-W) 
NWG Meeting 12/5-7/90, NIST, Gaithersburg, to develop comments on 3rd Pre-Draft Revision of R76 IWG Meeting, 1/91, PTB, Braunschweig, to discuss 3rd Pre-Draft revision of R76

RS5 "Automatic Weighing Instruments"

1st Draft IR "Hoppers" circulated to PS \& NWG for vote - 11/1/89 vote: Yes - 10, No - 0, Comments - 5. (Members - 11) Edited version sent to RS - $1 / 5 / 90$

1st Draft IR "RR Track" circulated to PS \& NWG for vote - 11/1/89 Vote: Yes - 7, No - 2 (U.S.,USSR,) Abs - 1 (Austria).

3rd Pre-Draft Revision R50 "Belt Weighers" - received 11/7/89, circulated to NWG 11/20/89 Comments due to RS - 2/19/90. Sent.

1st Pre-Draft Revision R61 "Gravity Filling Machines" - 9/30/89 (due from RS) Actually received - $1 / 5 / 90$; comments due RS - $3 / 23 / 90$

1st Pre-Draft proposed IR "Catchweighers" - received 4/2/90.

NWG Meeting Beltweighers \& Gravity Filling Machines - 1/18-19/90, Scottsdale, AZ

IWG Meeting - 5/7-11/90, NWML, U.K. (M-F)

NWG Meeting - 3/91, NIST, Gaithersburg, MD, to review succeeding Draft Documents on Belt Weighers, Catchweighers, etc.

IWG Meeting - 5/91. NWML, U.K. - to discuss succeeding Draft Documents

\section{RS8 "Load Cells"}

Revised R60 submitted to CIML for vote. Results: 30 yes, 1 no (FRG), with comments from 6 Countries, Australia, Japan, France, Norway, FRG, Finland \& CECIP

RS response to comments sent - 12/1/89.

Test procedures and report forms for certificate system.

Revised R60 to be voted on by CIML at meeting in Paris, 9/91.

\section{PS8 "Weights"}

Combined Document received from Belgium - 10/10/89

Circulated to NWG - 10/11/89

Comments due to RS - $12 / 31 / 89$

Comments sent 12/21/89

Revised Combined Document received from Belgium 6/20/90 and circulated to NWG for comment 6/22/90.

IWG Meeting - Combined Document on Weights - NIST 7/19/90 (Th).

David Watson, City of Fort Worth, Texas, Chairman

Charles Carroll, Massachusetts

Ray Helmick, Arizona

Jack Jeffries, Florida

James Truex, Ohio

Henry Oppermann, NIST, Technical Advisor

\section{Specifications and Tolerances Committee}




\title{
Report of the Committee on \\ Education, Administration, and Consumer Affairs
}

\author{
G.W. Diggs, Chairman \\ Supervisor, Weights and Measures \\ State of Virginia
}

\begin{abstract}
REFERENCE
KEY NO.
\end{abstract}

Introduction

This is the Final Report of the Committee on Education, Administration, and Consumer Affairs for the 75th Annual Meeting of the National Conference on Weights and Measures. The Report consists of the Interim Report offered in the Conference "Program and Committee Reports" as amended by the Addendum Sheets issued during the Annual Meeting.

Table A identifies all of the items contained in the Report by Reference Key Number, Item Title, and Page Number. Item $402-7$ (identified in the table by the suffix "V") was the Committee's only voting item. It was adopted by a separate vote of the membership as follows: House of State Representatives - 44 yea, 0 nay ; House of Delegates 64 yea, 0 nay. Item 402-8, which is marked with a "W," was withdrawn. All other items, which are marked with an "I" after the Reference Key No., were informational and required no formal action by the membership. The membership adopted the report in its entirety as follows: House of State Representatives - 44 yea, 0 nay; House of Delegates - 62 yea, 0 nay.

Table A

Reference Key Items and Index

\section{Reference}

Key No.

Title of Item

Page

401 I Regional Weights and Measures Activities $\ldots \ldots \ldots \ldots \ldots \ldots \ldots \ldots \ldots$

$402 \quad$ National Training Program (NTP) $\ldots \ldots \ldots \ldots \ldots \ldots \ldots \ldots \ldots \ldots \ldots \ldots \ldots \ldots \ldots$

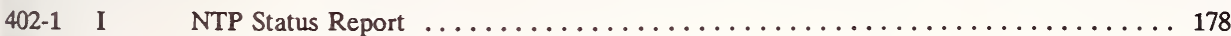

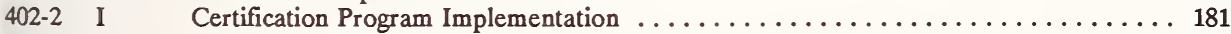

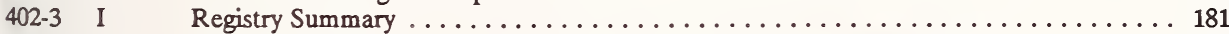

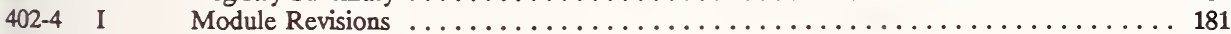

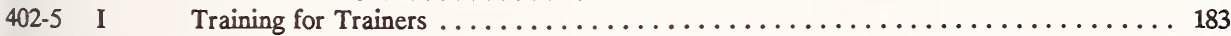

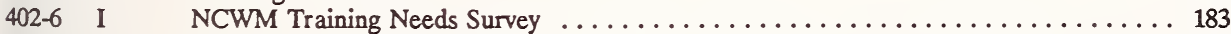

402-7 V Awarding of Continuing Education Units to Associate and Advisory Members ...... 184

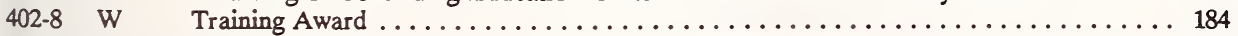

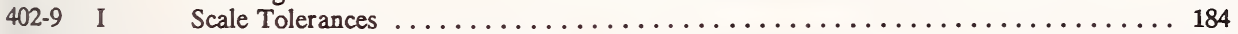

402-10 I Certification of NTP Instructors . . . . . . . . . . . . . . . . . . . 184

402-11 I Identification of Supplemental Visual Aids Used with NTP Modules . . . . . . . 185

402-12 I Development of Policy on Review of Comments on Published Modules ......... 185

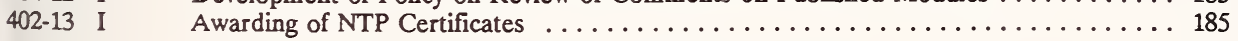

403 I Review of Recommendations of the Task Force on Fraud . . . . . . . . . 185

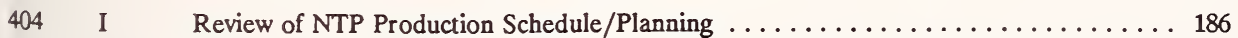


In addition, the Report contains four appendices that are related to specific Reference Key Numbers as follows:

\title{
Table B \\ Appendices
}

\begin{tabular}{llll}
\hline App. & \multicolumn{1}{c}{ Title } & Reference Key No. & Page \\
\hline A. & NTP Certification Summary & $402-2$ & 187 \\
B. & NTP Registry Summary of Activity & $402-3$ & 191 \\
C. & Excerpts From: The NCWM Training Needs & $402-6$ & 197 \\
D. $\quad$ Survey Summary of Responses & Outlines of Parts I and II of Module 23 & 404 & 205 \\
\hline
\end{tabular}

\author{
Details of All Items \\ (in order of Reference Key Number)
}

401

I Regional Weights and Measures Activities

The Committee reviewed and discussed the following:

1. The final report of the Education and Consumer Affairs Committee to the 32nd Annual Technical Conference of the Western Weights and Measures Association (August 1989).

2. The final report of the Education Committee to the 44th Annual Conference of the Southern Weights and Measures Association (October 1989).

3. A letter from Bill Slamon, Chairman of the Northeastern Weights and Measures Association (NEWMA), on issues proposed at NEWMA's Interim Meeting for inclusion on the Education Committee's agenda.

4. The final report of the Committee on Education, Administration, and Consumer Affairs to the 18th Annual Conference of the Northeastern Weights and Measures Association (May 1990).

The Committee thanks the regional weights and measures associations for their input. Items that were raised by these groups prior to the 1990 Interim Meeting are covered in separate items in this report. Two new proposals included in the NEWMA report will be discussed at the Committee's 1991 Interim Meeting.

The status of the National Institute of Standards and Technology (NIST) grants to the NCWM as of June 30, 1990, was as follows: 


\section{Grant 1 - NB83NAHA4003}

Net outlays to date:

$\$ 472,231.66$

Total unliquidated obligations:

$3,500.00$

(money committed to contractors)

Total outlays \& unliquidated obligations:

$475,731.66$

Total grant funds authorized:

$515,189.00$

Unobligated balance of funds:

$39,457.34$

(money available for future module development)

\section{Grant 2 - 70NANB8H0869}

Net outlays to date:

$\$ 31,868.13$

Total unliquidated obligations: (money committed to contractors)

Total outlays \& unliquidated obligations:

Total grant funds authorized:

Unobligated balance of funds:

(money available for future module development)

Total funds available for future module development (grants 1 \& 2):

In January 1990, the NCWM requested the third and final $\$ 60,000$ increase in Grant 2 from NIST. David Edgerly, Deputy Director of Technology Services, announced at the Interim Meeting that NIST had approved this request. This brings the total funds available under Grant 2 to $\$ 180,000$ and the total funds allocated by NIST for the development of training modules to $\$ 695,189$. NIST's continued generous support of the NCWM's National Training Program is greatly appreciated by the Committee.

The status of all training modules under development as of June 30, 1990, is given in Table C. 


\section{Table C \\ Training Module Status Report \\ (As of 6/30/90)}

\section{Module No.}

1

2

4

5

6

7

8

10

13

19

20

21 $\underline{\text { Subject }}$

Mechanical Computing Scales

Electronic Computing Scales

Medium-Capacity Scales

Vehicle and Axle-Load Scales

Monorail Scales

Livestock and Animal Scales

Retail Motor-Fuel Dispensers

Package Checking

Hopper Scales

Loading-Rack Meters

Vehicle-Tank Meters

LPG Liquid Meters

Commodity Regulations

Weights and Measures Admin.

Introduction to Handbook 44

Electronic Weighing and

Measuring Systems

\section{$\underline{\text { Status }}$}

Project completed.

Project completed.

Project completed.

Project completed.

Project completed.

Project completed.

Project completed.

Project completed.

The working group is developing a new draft of the module.

The contractor delivered the final version of the module. Copies will be mailed to the States in summer 1990.

Project completed.

Project completed.

Project completed.

The Education Committee met in March 1990 to develop an outline of this module. Plans are being made to assign topics listed in the outline to volunteer individuals and groups for development.

Project completed.

Project completed. 


\section{Certification Program Implementation}

As of June 30, 1990, the following 52 jurisdictions had signed Letters of Agreement with the NCWM and had been accepted as participants in the NTP Certification Program:

Alabama
Alaska
Arizona
Arkansas
California
Colorado
Connecticut
Delaware
District of Columbia
Florida
Georgia
Hawaii
Idaho
Illinois
Indiana
Iowa
Kansas

\author{
Kentucky \\ Louisiana \\ Maine \\ Maryland \\ Massachusetts \\ Michigan \\ Minnesota \\ Mississippi \\ Missouri \\ Montana \\ Nebraska \\ Nevada \\ New Hampshire \\ New Jersey \\ New Mexico \\ New York \\ North Carolina \\ North Dakota
}

Ohio
Oklahoma
Oregon
Pennsylvania
Puerto Rico
South Carolina
South Dakota
Tennessee
Texas
Utah
Vermont
Virginia
Virgin Islands
Washington
West Virginia
Wisconsin
Wyoming

Information summarizing participation in the NTP Certification Program is provided in Appendix A.

\section{Registry Summary}

A summary of information in the NTP Registry as of June 30,1990, is found in Appendix B. The Registry serves as a permanent record of NCWM courses successfully completed and Continuing Education Units (CEUs) earned under the NTP.

\section{Module Revisions}

The revision status of all published NCWM training modules as of June 30,1990, is shown in Table D. The Education Committee and the NIST Office of Weights and Measures (OWM) are dedicated to maintaining the usefulness of the modules by keeping them up to date through regular revisions.

OWM, which provides administrative and technical support for module revisions, has put a great deal of effort into the revision process and, as indicated in Table D, has made excellent progress despite the fact that major Handbook changes adopted by the Conference membership over the past several years have unavoidably delayed several important revisions and have resulted in a whole series of modules needing of revision at the same time. An example is the major restructuring of the Liquid-Measuring Devices Code in Handbook 44 in 1989 that resulted in extensive wording and numbering changes affecting the modules based on that code. Another example is the changes to the tolerances in the Scales Code of Handbook 44 that were adopted at the 75th NCWM. Consideration of these changes delayed publication of the revision of Module 2, and now their adoption will necessitate major revisions to all six of the published scales modules. The Education Committee and OWM are planning how to proceed now that the tolerances have been changed (see Item 402-9). OWM has been advocating a 2-year revision cycle for the major handbooks adopted by the Conference, partly to allow more time for module revisions. 


\section{Table D \\ Module Revision Status \\ (As of $6 / 30 / 90$ )}

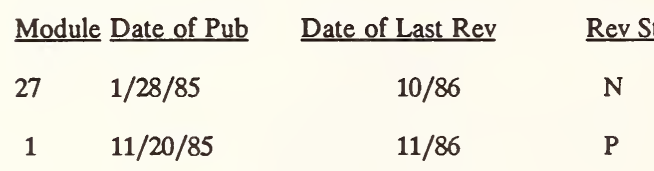

$10 \quad 11 / 29 / 85$

$2 \quad 2 / 26 / 86$

$9 / 89$

$5 \quad 10 / 17 / 86$

$20 \quad 10 / 31 / 86$

$6 \quad 4 / 3 / 87$

$7 \quad 5 / 27 / 87$

$21 \quad 8 / 5 / 87$

$4 \quad 6 / 22 / 88$

$24 \quad 5 / 18 / 89$
$\mathbf{P}$

$\mathrm{U}$

U

P

U

$\mathrm{N}$

$\mathbf{P}$

$\mathrm{N}$

P

U

\section{Comments}

This module will be affected by proposed changes to the tolerances in the Scales Code of Handbook 44.

This module is currently being revised by OWM staff. The revision is scheduled for completion in September 1990.

This module will be affected by proposed changer to the tolerances in the Scales Code of Handbook 44.

This module is being revised by a contractor The scheduled completion date is August 1990

The Committee will be issuing a contract to complete the revision of this module.

This module will be affected by the propose tolerance changes in the Scales Code.

This module will be affected by the propose tolerance changes in the Scales Code.

This module will be affected by the propose tolerance changes in the Scales Code.

This module is being revised to be consistent wit the 1990 edition of Handbook 44. The projecte completion date for the revision is August 199

*Key to module revision status abbreviations: $\mathrm{N}=$ No revision planned in $1990, \mathrm{U}=$ Revision is underway, $\mathrm{P}$ Partial revision is planned for 1990 if NCWM members approve the changes to the tolerances in the Scales Code c Handbook 44 that are being proposed. 
OWM has also put a lot of effort into improving the efficiency of the revision process. Revisions have been somewhat complicated by the fact that development of the NCWM training modules was begun long before computer technology had stabilized to the point that the NCWM could select the best computer hardware and software for the modules. Consequently, many modules were developed in formats that were not completely compatible with today's equipment and software. Over the past year, OWM has used in-house staff and outside contractors to convert modules to a standard format so that they can be revised more quickly and easily and so that changes to the handbooks can be readily incorporated in the modules. In its joint meeting with the NCWM Executive Committee at the Interim Meetings, the Education Committee requested that the Conference make funds available in 1990/1991 to facilitate the rapid completion of this conversion process.

In an effort to ensure that all suggested changes to the modules are given full consideration and that appropriate action is taken on them as quickly as practical, the Education Committee is taking steps to formalize the review of module comments (see item 402-12). All members of the Conference can help speed the revision process and improve the modules by providing feedback on them. Both weights and measures officials and industry members who teach the modules and must update them for presentation to a class could help the NCWM by sending copies of their marked modules to the Committee's Technical Advisor.

\section{2-5 I Training for Trainers}

In 1989, the Committee purchased a comprehensive videotape program on Training the Trainer using $\$ 10,000$ that the Executive Committee had allocated specifically for training trainers. This program, consisting of $141 / 2$-hour tapes and accompanying student work books, is now available for loan to NCWM members for use in in-house training programs. Each State was sent a letter announcing the availability of the program and a preview tape of the program. In 1990 , the Committee also made a special mailing to county and city weights and measures groups to describe the program and provide reservation forms.

At the Interim Meeting, possible uses for a second $\$ 10,000$ allocation made by the Executive Committee for training trainers were discussed. The Education Committee recommended that funds up to $\$ 2,500$ be made available to any regional weights and measures association planning to sponsor a train-the-trainer course. The funds could be used to pay the expenses of an instructor for the course, but not to pay travel costs of the participants. After the Interim Meeting, detailed information on how to obtain these funds was sent to each regional group.

\section{2-6 I NCWM Training Needs Survey}

The Committee would like to thank everyone who responded to the NCWM's Training Needs Survey. The information obtained from the survey will be useful in planning future training. Excerpts from a summary of the responses to the survey are provided in Appendix C. 


\title{
Awarding of Continuing Education Units to Associate and Advisory Members
}

(This item was adopted)

At the present time, only State and local weights and measures officials are eligible to receive Continuing Education Units (CEUs) for successfully completing NCWM training module courses. The rules for awarding CEUs require that permanent records be kept of all credits given. In order to meet this requirement, the NCWM uses The American College Testing Program (ACT) National Registry Service in Iowa City, Iowa. The ACT Registry Service currently charges $\$ 3$ to process each Registry entry. This fee is paid by the Conference. To date, the NCWM has spent over $\$ 10,000$ on the processing of Registry information (see Appendix B graph on NTP Registry Costs). It has been suggested that NCWM Associate and Advisory Members should also be able to receive credit for the NCWM courses they successfully complete. The Committee feels it would be appropriate to award CEUs to all individuals who successfully complete official NCWM module courses and, therefore, proposes the following:

\begin{abstract}
That, beginning on August 1, 1990, the National Conference on Weights and Measures expand its Continuing Education Units program by awarding such units to any individual who successfully completes an NCWM training module course sponsored by a group participating in the NCWM's National Training Program (NTP) Certification Program; and that the NCWM pay the cost of recording the CEU information in the NTP Registry for all weights and measures officials and NCWM Associate and Advisory Members and permit individuals who are not weights and measures officials or members of the NCWM to receive CEUs and be entered in the NTP Registry if they pay the fee charged by the Registry.
\end{abstract}

\section{W Training Award}

In 1989, the Committee proposed the initiation of an NCWM Award for Training Achievements. (For details on this award, see item 402-8 in the Committee's Report to the 74th NCWM, 1989.) Due to lack of support for this item by the regional weights and measures associations, the Committee has decided to withdraw the item; however, other ways of collecting and disseminating information on innovative approaches to implementing the National Training Program will continue to be explored.

\section{Scale Tolerances}

The changes to the tolerances for unmarked scales being considered by the Specifications and Tolerances Committee were reviewed by the Committee at the 1990 Interim Meeting. Because these changes were adopted by the Conference at the 75th NCWM, extensive revisions will have to be made to all of the existing NCWM training modules on scales. Due to the length of time it will take to revise all of the scales modules, the Committee is considering interim measures to permit the modules to be used during the revision period. One proposal is to publish updated EPOs and tolerance work sheets for each scale module before beginning a comprehensive revision of any one module. The Committee would appreciate other suggestions on how to deal with this problem.

\section{2-10}

\section{Certification of NTP Instructors}

The Committee requests information from the regional weights and measures associations or from any group or individual on the pros and cons associated with establishing a certification program for individuals who teach NCWM training modules. 
The Committee would like to compile a list of supplemental visual aids developed by State and local jurisdictions for use with NTP training modules so that this information can be shared. If you have materials that you are willing to share with other jurisdictions, please contact the Education Committee's Technical Advisor.

\section{2-12 I Development of Policy on Review of Comments on Published Modules}

In an effort to ensure careful consideration of all comments received on the training modules, the Committee is establishing the following policy on the submittal and handling of comments:

1. All proposed changes to a module that are of a technical nature must be submitted in writing.

2. Copies of all such proposals will be distributed to members of the Education Committee by the Committee's Technical Advisor.

3. The Technical Advisor will review the comments with technical experts as directed by the Committee.

4. A response will be sent to each individual who submits comments even if an issue cannot be addressed immediately.

5. Issues involving the interpretation of NIST Handbooks adopted by the NCWM will be referred to the appropriate NCWM Standing Committee for an official response.

The Committee received two separate requests regarding the awarding of NTP certificates. The first request was that Associate Members who successfully complete NTP training modules be given some type of certificate as a record of their achievement. At present, Associate Members are not eligible to receive either certification by the NCWM for completing classroom and field training or Continuing Education Units (see item 402-7 for proposed change in the CEU policy); consequently, they have not received any documentation from the NCWM to indicate that they have successfully completed an NCWM course. The Committee agrees that such documentation should be provided and therefore plans to give certificates of completion to Associate Members who successfully complete training sponsored by participants in the NCWM's NTP Certification Program.

The second request was that certificates of completion be given to all weights and measures officials who successfully complete an NCWM module training course for which Conference certification is not available, for example, Module 22. Commodity Regulations; Module 24, Introduction to NIST Handbook 44; and Module 27, Introduction to Electronic Weighing and Measuring Systems. The Committee has developed a Certificate of Training that can be used for both of the purposes mentioned above. Copies will now be provided upon request for associate members taking any NCWM module or for weights and measures officials taking Module 22, 24, or 27.

This is a carryover item from last year. Recommendations of the NCWM Task Force on Fraud that were directed to the Education Committee were discussed. These recommendations included the following:

Develop a uniform definition of fraudulent activities, Develop a uniform method of classifying types of fraudulent activities, Establish a mechanism by which information on fraudulent activities could be collected and made available at the national level.

Because of limited time and resources available to undertake a project such as this at the present time, the Committee is postponing action on this item. 
Education Committee

\section{I Review of NTP Production Schedule/Planning}

Due to the continuing interest shown by Conference members in the development of a training module on Weights and Measures Administration, the Committee met in March 1990 to develop an expanded outline of the contents of the module (see Appendix D). The Committee is asking for volunteers to write sections of the module. Anyone who would like to volunteer should contact the Committee's Technical Advisor.

G. W. Diggs, Virginia, Chairman

M. Gray, Florida

C. Greene, New Mexico

R. Kalentkowski, Connecticut

S. Malone, Nebraska

J. Koenig, NIST, Technical Advisor

Committee on Education, Administration, and

Consumer Affairs 
Education Committee

Appendix A 


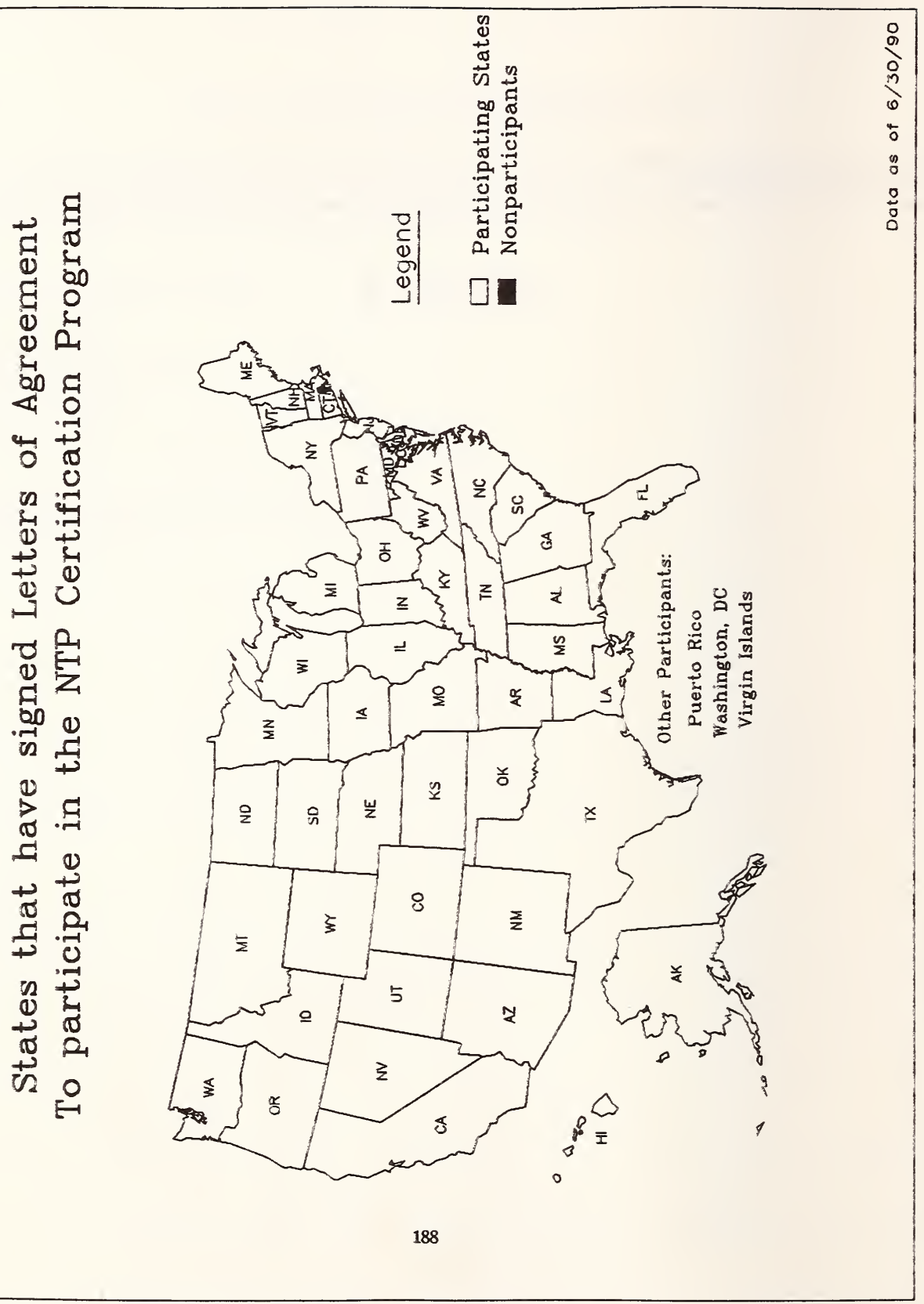


Education Committee

\section{Certification Summary}

As of June 30, 1990

\begin{tabular}{|c|c|c|c|c|c|c|c|c|c|c|c|}
\hline State & $\begin{array}{l}\text { Total No. } \\
\text { of Certif, }\end{array}$ & $\begin{array}{l}\text { Total No. } \\
\text { of People }\end{array}$ & 1 & $\underline{2}$ & 4 & $\begin{array}{l}\text { Modi } \\
5\end{array}$ & 7 & 8 & 10 & $\underline{20}$ & $\underline{21}$ \\
\hline AL & 35 & 18 & & 15 & 12 & & 4 & 4 & & & \\
\hline AK & 10 & 10 & & & & & & 10 & & & \\
\hline$A Z$ & 28 & 28 & & 28 & & & & & & & \\
\hline AR & 121 & 38 & 20 & 20 & & 8 & 4 & 37 & 12 & 17 & 3 \\
\hline $\mathrm{CO}$ & 7 & 7 & & & & & 7 & & & & \\
\hline CT & 56 & 22 & & 15 & 19 & 2 & & & 15 & 3 & 2 \\
\hline DC & 3 & 3 & & & & & & 3 & & & \\
\hline FL & 32 & 22 & 6 & 8 & 2 & 4 & & & 12 & & \\
\hline GA & 29 & 24 & & & & 8 & 4 & 17 & & & \\
\hline ID & 9 & 9 & & & & & & 9 & & & \\
\hline IL & 17 & 17 & & 8 & & 9 & & & & & \\
\hline IN & 30 & 30 & & & & 30 & & & & & \\
\hline XS & 21 & 9 & 7 & 7 & & 4 & & 1 & 2 & & \\
\hline LA & 1 & 1 & & & & & & & 1 & & \\
\hline MD & 28 & 28 & & & & & & 28 & & & \\
\hline MI & 42 & 14 & & & & 9 & 12 & & & 14 & 7 \\
\hline $\mathbf{M N}$ & 15 & 15 & & & & & & 15 & & & \\
\hline MO & 24 & 23 & & & & & & 5 & 19 & & \\
\hline NE & 24 & 12 & & 2 & & & & 12 & 10 & & \\
\hline NH & 32 & 8 & 6 & 5 & 5 & 2 & & 6 & & 8 & \\
\hline NM & 8 & 8 & & 1 & & & & 7 & & & \\
\hline NC & 19 & 19 & & & & & & & 19 & & \\
\hline ND & 3 & 3 & & & & & & 3 & & & \\
\hline $\mathrm{OH}$ & 75 & 46 & & 26 & & 5 & & 35 & 5 & & 4 \\
\hline OR & 54 & 16 & 16 & 15 & & 6 & & 10 & 6 & & 1 \\
\hline P\&S & 14 & 14 & & & & & 14 & & & & \\
\hline PA & 11 & 11 & & & & & & & 11 & & \\
\hline PR & 80 & 47 & & 32 & & & & 33 & 15 & & \\
\hline SD & 27 & 12 & & & 7 & 12 & & 7 & 1 & & \\
\hline TN & 41 & 30 & & & & 5 & 6 & 30 & & & \\
\hline UT & 72 & 16 & 15 & 15 & 2 & 11 & 4 & 12 & 12 & & 1 \\
\hline VA & 2 & 2 & & & & & & & & & 2 \\
\hline WA & 21 & 16 & & 5 & & & & 16 & & & \\
\hline WI & 4 & 4 & & & & & & & & & 4 \\
\hline$\overline{34}$ & $\overline{995}$ & $\overline{582}$ & $\overline{70}$ & $\overline{202}$ & $\overline{47}$ & $\overline{115}$ & $\overline{55}$ & $\overline{300}$ & $\overline{140}$ & $\overline{42}$ & 24 \\
\hline
\end{tabular}




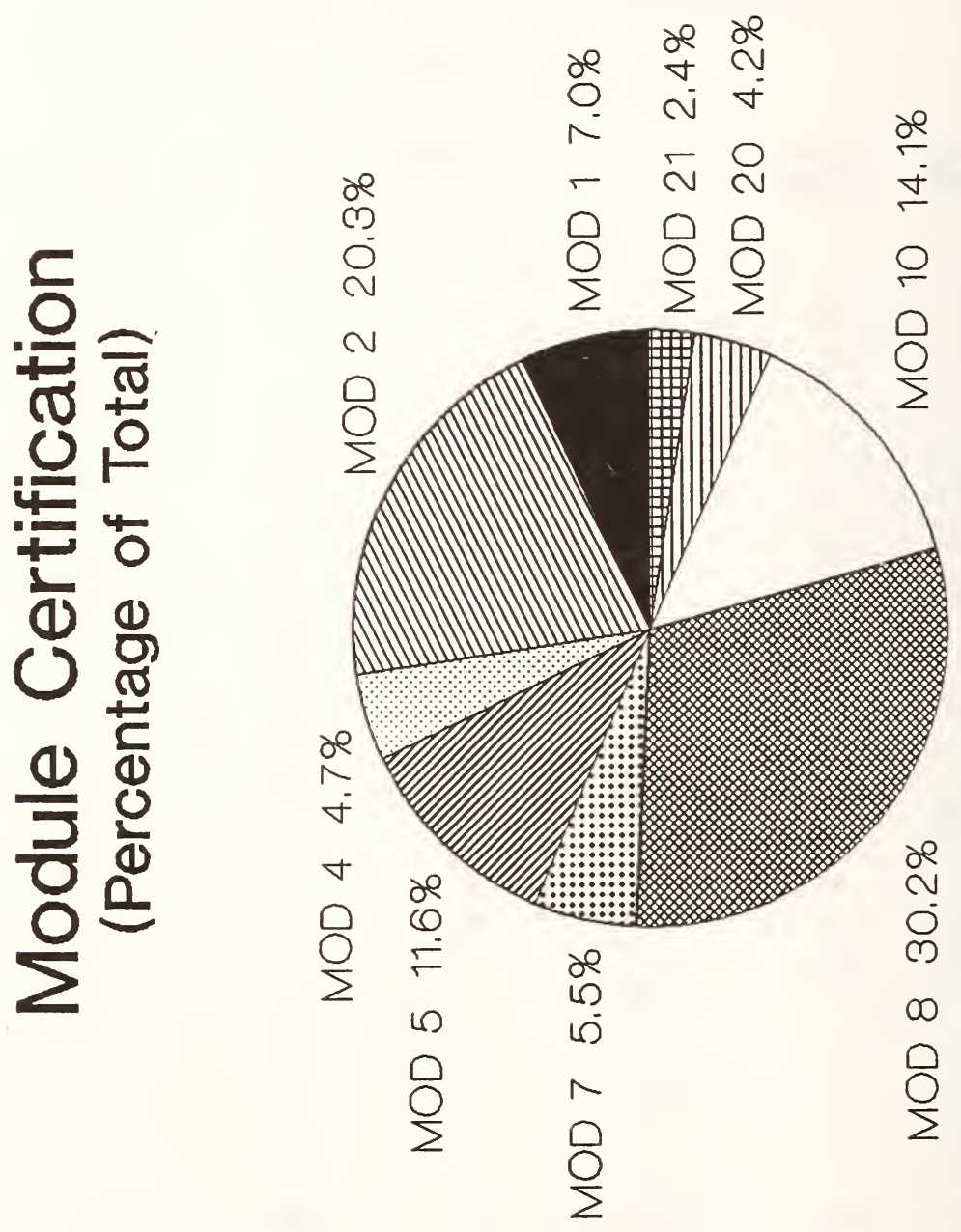

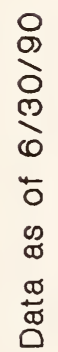




\section{Appendix B}

\section{NATIONAL TRAINING PROGRAM REGISTRY \\ SUMOMARY OF ACTIVITY}

(As of June 30, 1990)

Courses Listed in Registry:

Module 1, Retail Computing Scales - Mechanical

Module 2, Retail Computing Seales - Electronic

Module 4, Medium-Capacity Seales

Module 5, Vehicle and Ade-Load Scales

Module 6, Meat Beams and Monorail Scales

Module 7, Livestock and Animal Scales

Module 8, Retail Motor-Fuel Dispensers and Consoles

Module 10, Checking the Net Conteats of Packaged Goods

Module 20, Vebicle-Tank Meters

Module 21, LPG Liquid-Measuring Devices

Module 22, Commodity Regulations

Module 24, Introduction to NIST Handbook 44

Module 27, Introduction to Electronic Weighing the Measuring Systems

INDIMIDUALS TRAINED - BY MODULE

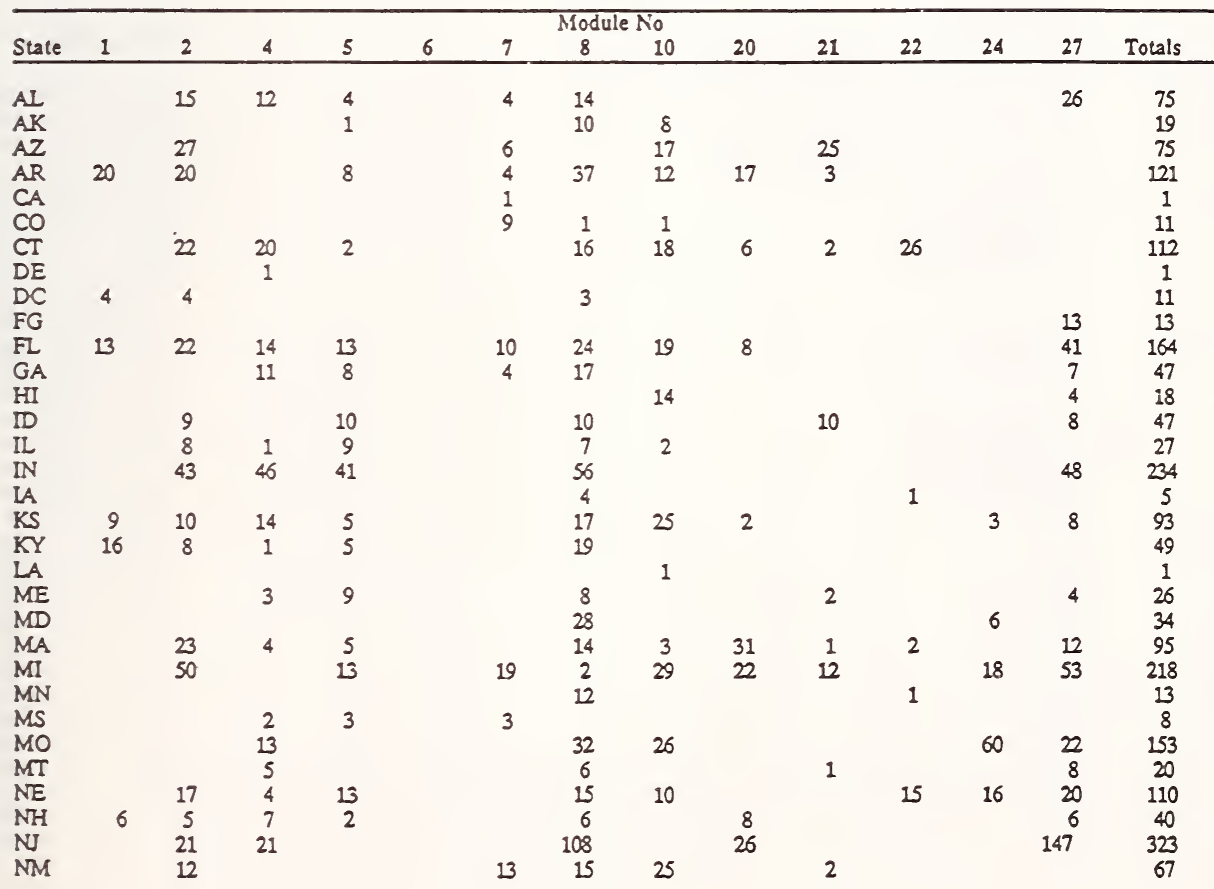




\section{Education Committee}

\begin{tabular}{|c|c|c|c|c|c|c|c|c|c|c|c|c|c|c|}
\hline & & & & & & & Mod & & & & & & & \\
\hline State & 1 & 2 & 4 & 5 & 6 & 7 & 8 & 10 & 20 & 21 & 22 & 24 & 27 & Totals \\
\hline$N Y$ & & 74 & & & & & & 92 & & 9 & & & & 175 \\
\hline NC & & & & & & & & 19 & & & & & & 19 \\
\hline ND & & & & & & & 3 & & & & & & 12 & 15 \\
\hline $\mathrm{OH}$ & & 40 & & 13 & 4 & 8 & 42 & 14 & & 9 & 2 & 29 & 58 & 219 \\
\hline OK & & & 2 & & & & 5 & 22 & & & & & 2 & 31 \\
\hline OR & 18 & 17 & & 8 & & & 12 & 16 & & 16 & & 17 & 16 & 120 \\
\hline PS & & & & 2 & & 14 & & & & & & & 3 & 19 \\
\hline PA & 34 & 69 & 51 & & & & 56 & 39 & & 1 & 13 & & 82 & 345 \\
\hline PR & & 32 & & & & & 33 & 15 & & & & 27 & & 107 \\
\hline RI & & 1 & & 1 & & & & & 1 & & & & & 3 \\
\hline SC & & 25 & & & & 2 & 28 & & & & & & & 55 \\
\hline SD & & & 7 & 12 & & & 7 & 10 & & & 10 & & 10 & 56 \\
\hline TN & & 27 & & 6 & & 6 & 32 & & & & & & 5 & 76 \\
\hline TX & & & & & & $\delta$ & 24 & & & 4 & & 5 & & 41 \\
\hline UT & 16 & 15 & & 11 & & 4 & 12 & 13 & & 1 & & & 16 & 88 \\
\hline VT & 5 & & 3 & 2 & & & 7 & 1 & & & 2 & & 5 & 25 \\
\hline VA & & & 24 & 16 & & 2 & 9 & 38 & 25 & 4 & & 5 & 43 & 166 \\
\hline WA & 13 & $\delta$ & & 16 & & & 16 & & & 1 & & 6 & 16 & 76 \\
\hline WV & & & & & & 3 & & & & & & & & 3 \\
\hline WI & 56 & 53 & & 13 & & & 28 & & 26 & 5 & & & 65 & 246 \\
\hline WY & & & 11 & & & & 16 & & & 10 & & & 3 & 40 \\
\hline Total & 210 & 677 & 277 & 251 & 4 & 120 & 811 & 489 & 172 & 118 & 72 & 192 & 763 & 4156 \\
\hline
\end{tabular}


Education Committee

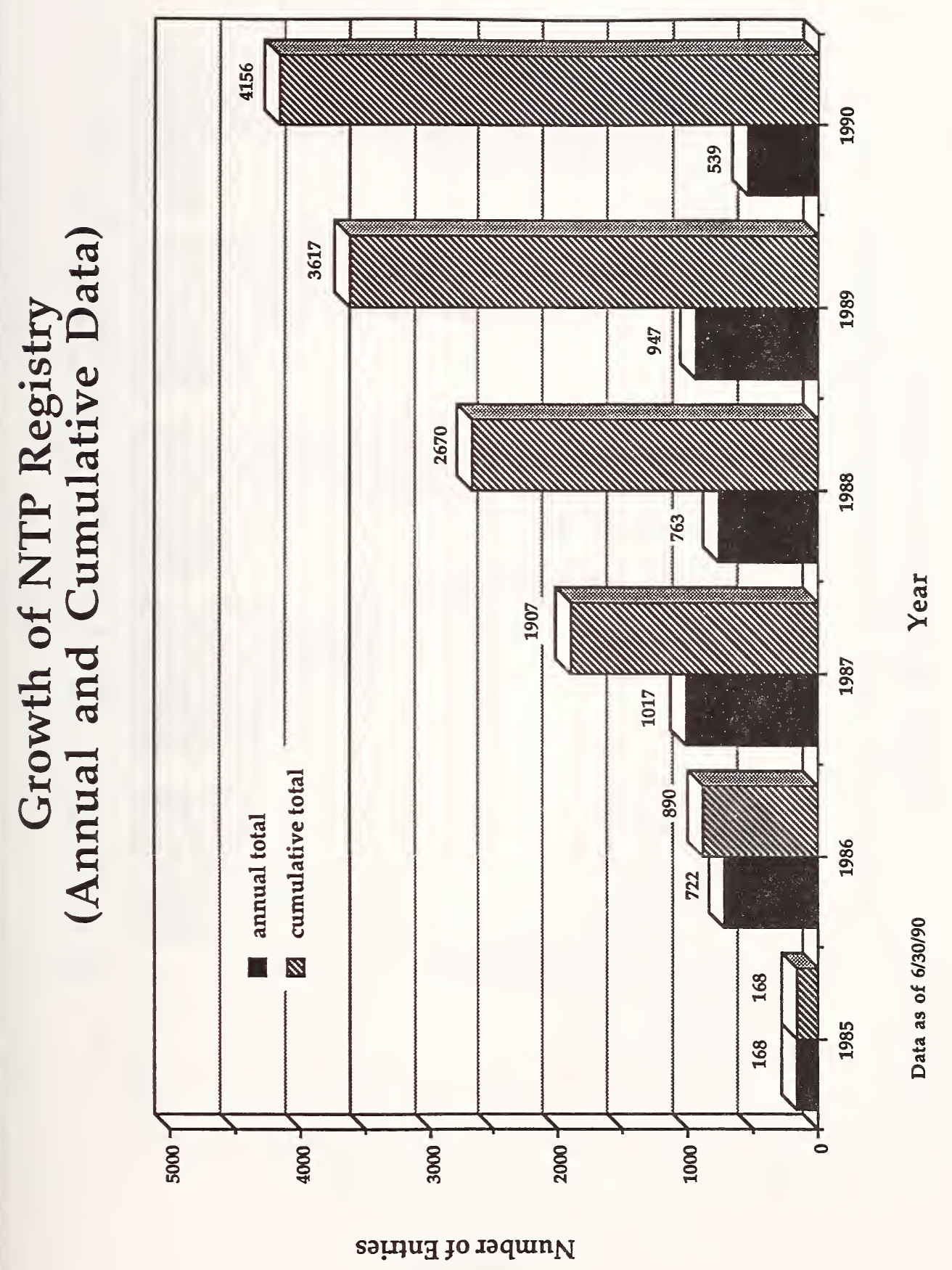




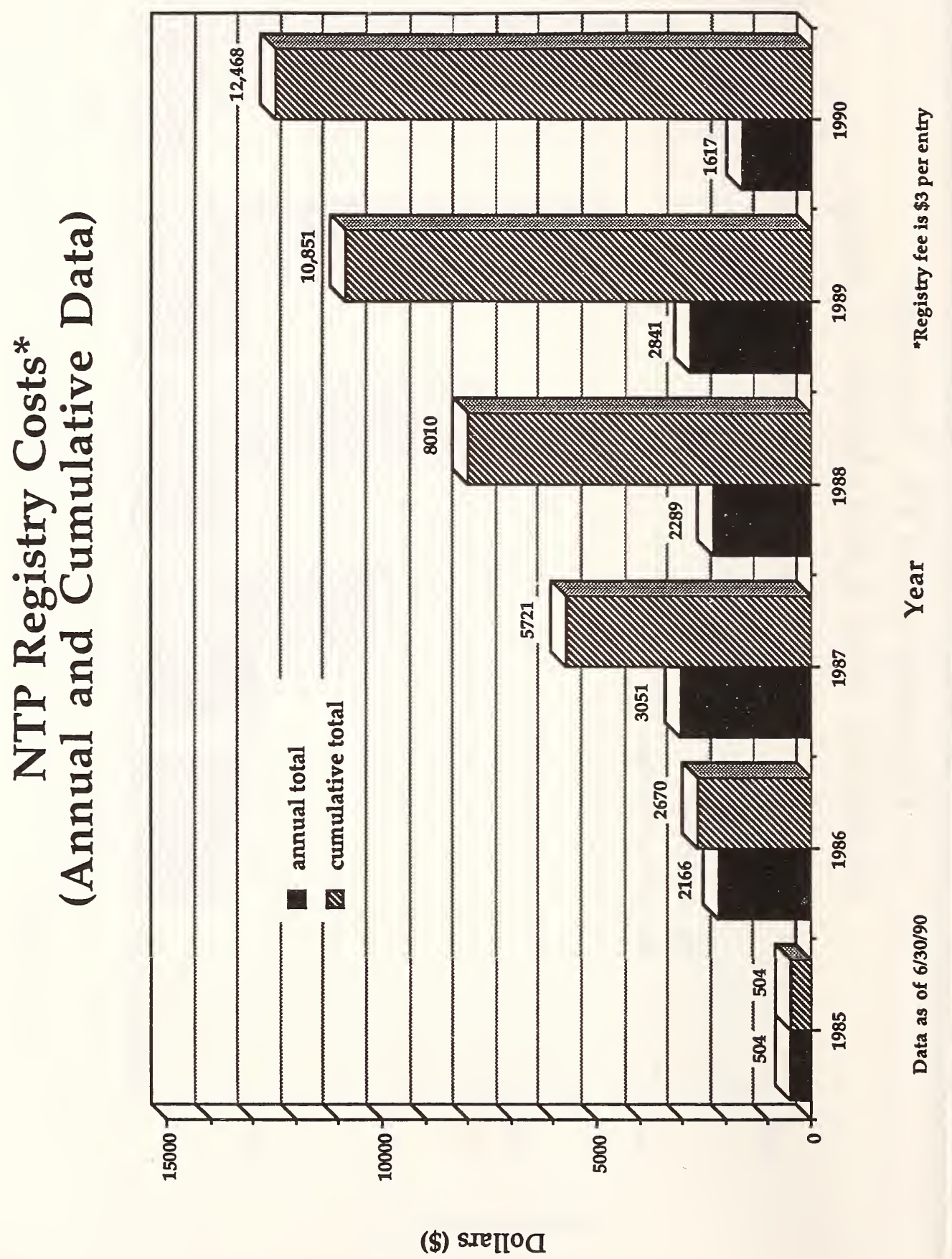


Education Committee

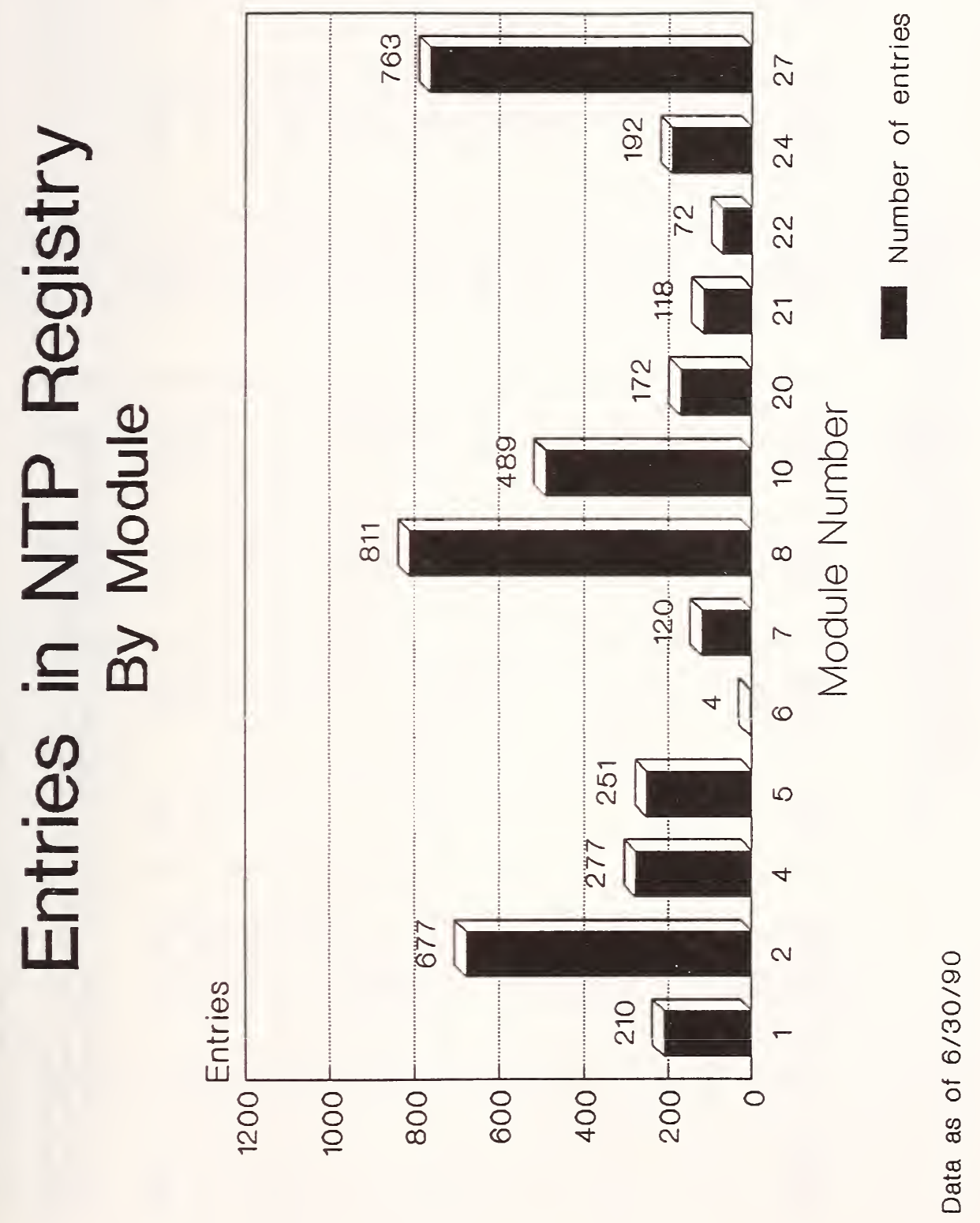


Education Committee

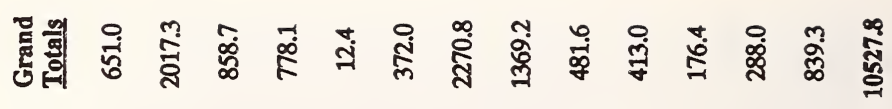

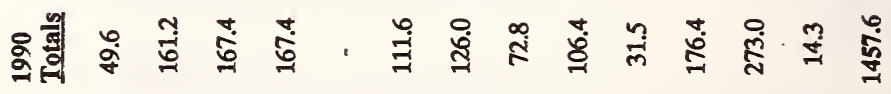

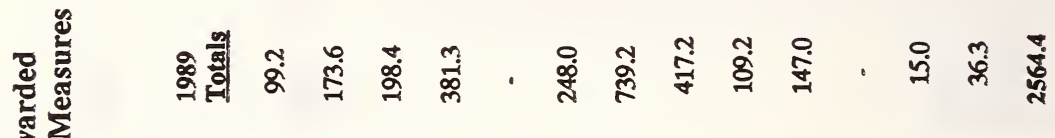

合

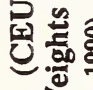

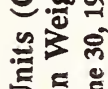

5.

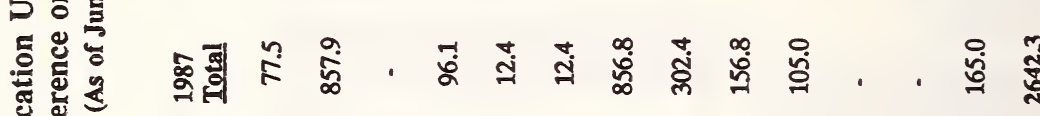

䪭

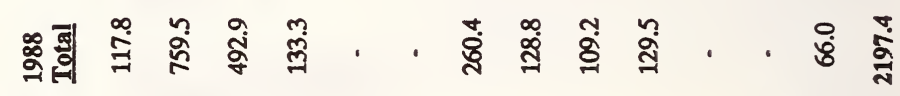

政

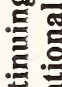

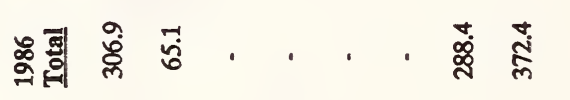

)

를

造娄

른

ले

嗞部

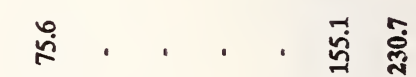

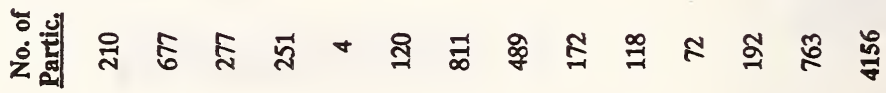

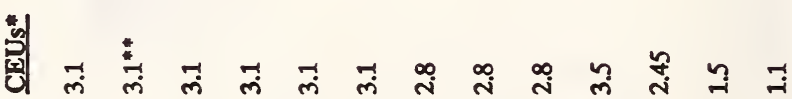

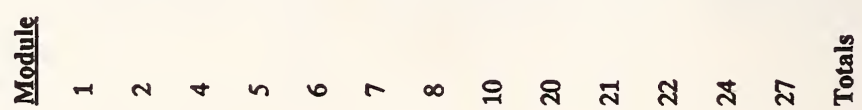




\section{Appendix C \\ Excerpts From: \\ THE NCWM TRAINING NEEDS SURVEY \\ Summary of Responses \\ January 3, 1990}

In mid-September, 1989, a Training Needs Survey was sent to 775 heads of State, county, and city weights and measures agencies aiong with a request for compietion and return to NCWM. A total of 89 surveys has been received from 39 State, 28 county, and 22 city officials. A summary of some of the responses to the survey is given below.

1. Provide the following demographic information regarding your agency:

Number of personnel

$\begin{array}{lrrrr} & \text { State/County/City } & \text { State } & \text { County } & \text { City } \\ \text { Total } & 3,051 & 2,072 & 151 & 828 \\ \text { Range } & 1 \text { to } 750 & 5 \text { to } 580 & 1 \text { to } 53 & 1 \text { to } 750 \\ \text { Average } & 34 & 53 & 5 & 38\end{array}$

Number of weights and measures personnel (including petroleum quality/quantity)

$\begin{array}{lrrrr} & \text { State/County/City } & \text { State } & \text { County } & \text { City } \\ \text { Total } & 1,381 & 1,189 & 127 & 65 \\ \text { Range } & <1 \text { to } 120 & <1 \text { to } 120 & 1 \text { to } 44 & 1 \text { to } 23 \\ \text { Average } & 16 & 30 & 5 & 3\end{array}$

What is your annual training budget?

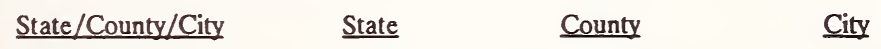

$\begin{array}{lrrrr}\text { Total } & \$ 182,046.00 & \$ 129,495.00 & \$ 10,751.00 & \$ 41,800.00 \\ \text { Range } & \$ 0.00-\$ 31,500.00 & \$ 0.00-\$ 31,500.00 & \$ 0.00-\$ 2,500.00 & 0.00-\$ 17,000.00 \\ \text { Average } & \$ 2,045.00 & \$ 3,320.00 & \$ 384.00 & \$ 1,900.00\end{array}$

When does your fiscal year commence?

$\begin{array}{lrrrr} & \underline{01 / 01} & \underline{07 / 01} & \underline{10 / 01} & \text { Other } \\ \text { State } & 0 & 35 & 3 & 1 \\ \text { County } & 19 & 8 & 0 & 0 \\ \text { City } & 4 & 14 & 1 & 2\end{array}$


2. In which NTP modules have your personnel received training (city/county officials only)?

\begin{tabular}{lccccccrr} 
& County & City & Total & & \multicolumn{2}{c}{ County } & City & Total \\
Module 2: & 58 & 49 & 107 & & Module 20: & 10 & 12 & 22 \\
Module 1: & 51 & 42 & 93 & & Module 4: & 10 & 8 & 18 \\
Module 8: & 62 & 26 & 88 & & Module 24: & 11 & 7 & 18 \\
Module 10: & 48 & 9 & 57 & & Module 21: & 4 & 1 & 5 \\
Module 27: & 14 & 41 & 55 & & Module 6: & 1 & 0 & 1 \\
Module 5: & 12 & 12 & 24 & & Module 7: & 1 & 0 & 1
\end{tabular}

3. In which NTP modules will you want to train your personnel within the next three years?

\begin{tabular}{|c|c|c|c|c|}
\hline & $\underline{\text { State }}$ & County & City & Total \\
\hline Module 24: & 530 & 76 & 56 & 662 \\
\hline Module 2: & 481 & 46 & 14 & 541 \\
\hline Module 4: & 413 & 63 & 16 & 492 \\
\hline Module 10: & 365 & 35 & 53 & \\
\hline Module 8: & 401 & 31 & 12 & 44 \\
\hline Module 20: & 337 & 56 & 5 & \\
\hline Module 27: & 168 & 76 & 13 & \\
\hline odule 6: & 190 & 43 & 0 & \\
\hline
\end{tabular}

State County City Total

Module 1: $187 \quad 33 \quad 10 \quad 230$

Module 5: $113 \quad 60 \quad 5 \quad 178$

Module 7: $125 \quad 5 \quad 500130$

Module 21: $57 \quad 64 \quad 3 \quad 124$

$\begin{array}{lllll}\text { Module 22: } & 85 & 0 & 2 & 87\end{array}$

Module 13: $20 \quad 1 \quad 21$

Module 19: $\begin{array}{llll}15 & 0 & 2 & 17\end{array}$

4. Which of the modules under development will be of interest when available (shown in order of interest):

Module 22: Commodity Regulations

Interested

State

County

City

Total

69

Module :13: Hopper Scales

Interested

State
County
City

Total

32
15
5

52
No Interest

6

3

18

No Interest No Response

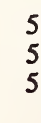

15
No Response

2
1
2
6

6

2
8
12
22


Module 19: Loading-Rack Meters

\begin{tabular}{|c|c|c|c|}
\hline & Interested & No Interest & No Response \\
\hline State & 29 & 10 & 0 \\
\hline County & 7 & 19 & 2 \\
\hline City & 6 & 14 & 2 \\
\hline Total & 42 & 43 & 4 \\
\hline
\end{tabular}

5. In what subject areas do you need weights and measures training that is not provided by current or planned training modules?

Weights \& measures administration

Taximeters and mileage inspections

Investigative techniques, evidence collection

Weights \& measures violations, legal aspects,

fines, court procedures, case studies

Grain moisture meters

Petroleum quality testing/sampling

Safety procedures

Electric, vapor, and water meter testing

$\begin{array}{llll}\text { State } & \text { County } & \text { City } & \text { Total } \\ 4 & 2 & 4 & 10 \\ 3 & 3 & 2 & 8 \\ 4 & 2 & & 6 \\ 4 & 1 & & 5 \\ 4 & 1 & & 4 \\ 2 & 1 & 1 & 3 \\ 1 & 2 & & 2 \\ & 2 & 2 & 2 \\ & 1 & 1 & 2 \\ & 1 & 1 & 2 \\ & 1 & & 2 \\ 1 & 1 & & 2 \\ 2 & & & 1 \\ 1 & 1 & & 1 \\ 1 & 1 & 1 & 1 \\ 1 & 1 & & 1 \\ & 1 & & 1 \\ & 1 & & 1 \\ 1 & & & 1 \\ 1 & & & 1 \\ & & & \end{array}$

Introduction to weights \& measures

Linear measuring devices

Test equipment

Timing devices

UPC scanning

Weights \& measures communications

Belt conveyor scales

Bulk meters

Combined cash register, UPC pricing, open pricing

Developing professionalism

Handbook 44 update

Metric measurement

Metrology

Milk tanks

Railroad track scales

Retail motor fuel dispensing

Train-the-trainer

7. Although training modules have been designed for beginning inspectors, most jurisdictions have found it beneficial to deliver modules to their entire staff. Suggestions have been made to the Conference to develop more advanced modules for more experienced inspectors and develop short courses that update inspectors on changes, for example, to Handbook 44, that impact the testing and inspection of a given type of device or class of devices. In light of your near-term (next 3 years) training needs, how would you rank the following $(1=$ highest priority). (The responses have been listed in the order of how many ranked the item number 1 priority.) 
The NCWM should complete development of the modules next on the list of priorities (namely Weights and Measures Administration and Communications) before tackling other new tasks ( 1 = highest priority):

$\begin{array}{lllr}\text { State } & \text { Total Responses: } 39 & \text { Ranking 1: } & 26 \\ & & \text { Ranking 2: } & 5 \\ & & \text { Ranking 3: } & 8 \\ \text { County } & \text { Total Responses: } 18 & \text { Ranking 1: } & 11 \\ & & \text { Ranking 2: } & 3 \\ & & \text { Ranking 3: } & 4 \\ \text { City } & \text { Total Responses: } 15 & \text { Ranking 1: } & 5 \\ & & \text { Ranking 2: } & 2 \\ & & \text { Ranking 3: } & 3\end{array}$

The NCWM should develop short courses, $1 / 2$ to 2 -day duration ( $1=$ highest priority):

State $\quad$ Total Responses: 32

$\begin{array}{lr}\text { Ranking 1: } & 12 \\ \text { Ranking 2: } & 17 \\ \text { Ranking 3: } & 2 \\ \text { Ranking 5: } & 1\end{array}$

County Total Responses: $16 \quad$ Ranking 1: 5

Ranking 2: 6

Ranking 3: 5

City Total Responses: $12 \quad$ Ranking 1: 6

Ranking 2: 5

Ranking 3: 1

The NCWM should develop advanced modules in selected areas:

$\underline{\text { State }}$

Total Responses: 29

Ranking 1: $\quad 4$

Ranking 2: $\quad 10$

Ranking 3: 13

Ranking 5: 1

Ranking 10: 1

County Total Responses: 16

Ranking 1: $\quad 6$

Ranking 2: 4

Ranking 3: 5

Ranking 8: 1

City

Total Responses: 8

Ranking 1: $\quad 3$

Ranking 2: 2

Ranking 3: 2

Ranking 6: 1

Ranking 10: 1 
8. Are you able to meet all of your current training needs with in-house training staff?

$\begin{array}{llll}\text { State } & \text { Yes } 12 & \text { No } 26 & \text { No response } 1 \\ \text { County } & \text { Yes } 3 & \text { No } 23 & \text { No response } 2 \\ \text { City } & \text { Yes } 5 & \text { No } 17 & \text { No response } 0 \\ \text { Total } & \text { Yes } 19 & \text { No } 66 & \text { No response } 3\end{array}$

9. If no, do you get help from outside organizations?

Note: Contradictory information is contained in this response (i.e., some respondents indicated "Yes" they are able to meet current training needs with in-house staff but do receive help from other organizations).

$\begin{array}{llll}\text { State } & \text { Yes } 27 & \text { No } 7 & \text { No response } 6 \\ \text { County } & \text { Yes } 24 & \text { No } 2 & \text { No response 2 } \\ \text { City } & \text { Yes } 15 & \text { No } 5 & \text { No response 2 } \\ \text { Total } & \text { Yes } 66 & \text { No } 14 & \text { No response } 10\end{array}$

$\underline{\text { State }}$

$\begin{array}{lcccc}\text { OWM } & \text { Yes } 23 & \text { No } 7 & \text { No response } 9 \\ \text { IWM } & \text { Yes } & 4 & \text { No } 9 & \text { No response } 25\end{array}$

Other Yes $10 \quad$ No $17 \quad$ No response 11

County

OWM Yes 9 No 10

IWM Yes 4 No 13

Other Yes 18

No 5

City

$\begin{array}{llll}\text { OWM } & \text { Yes } 9 & \text { No } 10 \\ \text { IWM } & \text { Yes } & 4 & \text { No } 15\end{array}$

No 15

No 8

$\begin{array}{ll}\text { No } & 27 \\ \text { No } & 37 \\ \text { No } & 30\end{array}$

No response 21

No response 18

No response 18

Man-hours per year Man-hours per year

Man-hours per year

No response 9

No response 11

No response 5

No response 3

No response 3

No response 3

Total

OWM Yes 41

Other Yes 39
Man-hours per year

Man-hours per year

Man-hours per year

Man-hours per year

Man-hours per year

Man-hours per year

Man-hours per year Man-hours per year Man-hours per year

\section{"Other" training sources include:}

USDA Packers and Stockyards

Private industry

Other States

State or regional associations

Other departments within the agency

State or county weights and measures jurisdictions 


\section{Education Committee}

10. Is training from outside organizations sufficient?

$\begin{array}{lllll}\text { State } & \text { Yes } 17 & \text { No } 12 & \text { No response } 10 \\ \underline{\text { County }} & \text { Yes } 13 & \text { No } 12 & \text { No response } 3 \\ \text { City } & \text { Yes } 11 & \text { No } 8 & \text { No response } 3 \\ \text { Total } & \text { Yes } 41 & \text { No } 32 & \text { No response } 16\end{array}$

12. I would like to see the NCWM sponsor/provide training packages which would incluc providing the trainer (not just furnish modules). There may be a cost associated.

$\begin{array}{llll}\text { State } & \text { Yes } 31 & \text { No } 4 & \text { No Response } 4 \\ \text { County } & \text { Yes } 15 & \text { No } 9 & \text { No Response } 4 \\ \text { City } & \text { Yes } 13 & \text { No } 4 & \text { No Response 5 } \\ \text { Total } & \text { Yes } 59 & \text { No } 17 & \text { No Response 13 }\end{array}$

13. A. If the Conference arranged for the presentation of a Train-the-Trainer course at : acceptable location, would you send any of your trainers?

$\begin{array}{llll}\text { State } & \text { Yes } 34 & \text { No } 4 & \text { No Response } 1 \\ \underline{\text { County }} & \text { Yes } 13 & \text { No } 5 & \text { No Response 10 } \\ \text { City } & \text { Yes } 9 & \text { No } 6 & \text { No Response 7 } \\ \text { Total } & \text { Yes } 56 & \text { No } 15 & \text { No Response } 18\end{array}$


E. Location - For each of the locations listed below, please indicate "Yes" if you could send a trainer for training or "No" if you could not:

Within your region:

$\begin{array}{lllc} & \text { Yes } & \text { No } & \text { No Response } \\ \text { State } & 35 & 1 & 3 \\ \text { County } & 10 & 7 & 11 \\ \text { City } & 11 & 3 & 8\end{array}$

Within your State:

Yes $\quad$ No $\quad$ No Response

$\begin{array}{llrr}\text { State } & 30 & 2 & 7 \\ \text { County } & 16 & 1 & 11 \\ \text { City } & 10 & 5 & 7\end{array}$

At NIST in Gaithersburg, MD:

$\begin{array}{lccc} & \text { Yes } & \text { No } & \text { No Response } \\ \text { State } & 21 & 11 & 7 \\ \text { County } & 2 & 16 & 10 \\ \text { City } & 3 & 9 & 10\end{array}$

At another location in the central United States:

$\begin{array}{lccl} & \text { Yes } & \text { No } & \text { No Response } \\ \text { State } & 13 & 16 & 10 \\ \text { County } & 1 & 16 & 11 \\ \text { City } & 2 & 10 & 10\end{array}$

15. What weights and measures magazines, periodicals, and newsletters do you presently read on a regular basis?

The publications mentioned most frequently were:

Publication

Weighing \& Measurement Magazine

Weights \& Measures Today Newsletter

Southern Weights \& Measures Assn Newsletter

Western Weights \& Measures Assn Newsletter

New York State W \& M Assn Newsletter

Northeastern Wts \& Measures Assn Newsletter

IWM Newsletter

NCWM Publications

NIST Publications

SMA's Newsletter

Massachusetts Wts \& Measures Assn Newsletter
Number of Responses

32

21

17

16

16

13

11

10

9

9

9 



\section{Weights and Measures Administration}

\section{Part I - An Introduction to Weights and Measures \\ For New Weights and Measures Officials}

I. Introduction
A. Description of the purpose and significance of weights and measures activities

B. Objectives of the module

II. Historical Background
A. History of standards
B. Hierarchy of standards
C. History of weights and measures legislation

III. Weights and Measures in the United States
A. Structure
B. Description of weights and measures regulatory groups in the United States
1. USDA
a. Packers and Stockyards
b. Federal Grain Inspection Service
2. FDA
3. FTC
4. BATF
5. EPA
C. NIST
D. NCWM
1. Background and purpose
2. Activities
a. Uniform laws and regulations
b. National Type Evaluation Program
c. National Training Program
d. Liaison with other groups
3. Input to the NCWM
a. Regional and State Associations, local jurisdictions, NASDA, individuals
b. Industry
c. Consumers
d. Federal agencies
e. International (Canada, OIML)

IV. Legal Basis for Weights and Measures
A. State laws and regulations
B. Relationship between State law and uniform laws
C. Local ordinances (counties and cities)
D. Jurisdiction specific information
E. Federal preemption 
Education Committee

V. State and Local Weights and Measures Programs

A. Organization - first model law identified three types of W\&M organizations:

1. State only

2. State and some local groups under State control

3. State and a number of local groups that are largely independent

B. Funding

C. Scope of operations - types of activities performed by W\&M programs

D. Jurisdiction specific information

VI. Role of the Weights and Measures Official

A. Device inspection vs. process verification (e.g., checking gasoline pumps vs. checking packages)

B. Fundamental considerations

1. Regulatory actions (approval, rejection, condemnation)

2. Penalties

3. Documentation and records

4. Chain of evidence

C. Education/communication

1. Public

2. Industry

D. Professionalism

1. Attitude

2. Training

3. Appearance (of official and equipment)

4. Safety

E. Jurisdiction specific information 


\section{Weights and Measures Administration}

\section{Part II - Organization and Management of Weights and Measures Programs For Weights and Measures Supervisors and Administrators}

I. Introduction
A. Scope of Part II (who and what does it cover)
B. Purpose and significance of weights and measures activities

II. Functions of a Weights and Measures Program
A. Maintain traceability of State standards
1. Test secondary standards annually
2. Assist industry
B. Device regulation
C. Quantity control
D. Adopt rules and regulations
1. Labeling
2. Method of sale
3. Weighmaster
4. NTEP
5. Open dating
6. Unit pricing
7. Registration of W\&M servicepersons and service agencies
8. Motor fuel
E. Conduct investigations
F. Enforce laws and regulations
G. Perform other functions assigned by law

III. Structure
A. Types
1. State only
2. State and local
a. State supervised
b. Local independent
B. Placement
1. State
a. Department of Agriculture
b. Department of Commerce
c. Department of Labor
d. Department of Consumer Protection
e. Other

2. Local
a. Department of Agriculture
b. Department of Consumer Protection
c. Permits and Inspections
d. Other

C. Philosophy of Organization

1. Organization by geographical areas or by specialty areas

2. Sample organizational charts 


\section{Education Committee}

IV. Metrology

A. Introduction - What every Director should know.

1. Components
a. Facility
b. Standards
c. Personnel

2. Purpose

a. Support W\&M field program
(1) relation to national standards
(2) effects of international trade

b. Support Industry with calibration services

B. The State Standards Program from NIST

1. Standards

2. Measuring equipment

3. Additional equipment purchased by State

C. The Hierarchy of Standards

1. Definitions

2. Measurement accuracy and the Transfer Ratio

3. The hierarchy
a. International Standards (BIML)
b. National Standards (NIST)
c. State Primary Standards
(1) calibration certificates
(2) proper usage as reference standards
(3) appropriate use as working standards

d. State Working Standards

e. Field Standards

f. Commercial devices

4. General capabilities - relative accuracies
a. Mass
b. Volume
c. Length
d. Other measurements

D. Training, Certification and the LAP Program

1. Training
a. Basic Seminar
b. Intermediate Seminar
c. NCWM Metrology Workshops
d. Continuing Training through RMAP's

2. Certification by measurement area

3. The Laboratory Auditing Program (LAP)

E. The Metrologist

1. Function - job description

2. Exercise discretion
a. Choice of appropriate test procedure
b. Choice of standard
c. Choice of test equipment

3. Good Laboratory Practices
a. Follow standard operating procedure

b. Provide necessary documentation

F. Quality Assurance (use Chap. 3 of HB 145)

1. Quality Assurance

2. Quality Control

3. Quality Assessment 
G. Regional Measurement Assurance Programs (RMAP's)

1. Description

2. Functions
a. Quality circle organizations
b. Training provided by NIST OWM
c. Round Robin testing

H. Conclusions and Summary

V. Program Planning
A. Program definition
1. Identify activities for which the program is responsible
2. Decide on the relative importance of each activity

B. Program philosophy

1. Device inspection vs. process control

2. Administrative compliance vs. judiciary compliance

C. Establishment of goals and objectives

1. Statistics/Demographics (define the scope of the work)
a. Number of devices to be checked
b. Number of servicepeople
c. Number of businesses conducting commercial weighing and measuring
d. Geographic distribution of population

2. Long range

3. Short range

4. Periodic reevaluation

D. Program Justification

1. Output measures
a. Number of devices inspected
b. Number of packages inspected
c. Reinspection rate
d. Compliance rate
e. Number of complaints
f. Judiciary actions
g. Other

2. Cost/benefit assessment
a. Tangible benefits
b. Intangible benefits

E. Establishment of policies and procedures to help achieve goals and objectives

F. Program evaluation

VI. Budgeting and Funding

A. Funding sources and alternatives

1. Fees, licenses, permits

2. General fund

3. Grants and contracts

B. Funding philosophy

1. Use of cash funds (limit to weights and measures use)

2. Total funding from general fund (pluses and minuses)

3. Fee systems (pluses and minuses)

4. Using the budget process to achieve program goals

C. Typical budget categories

1. Personnel

2. Operating expenses
a. Travel
b. Postage
c. Telephone
d. Repairs
e. Oil, gas
f. Vehicle rental 
g. Training

3. Equipment and facilities

D. Assessment of personnel needs

VII. Legislation
A. Law vs. regulation vs. policy
B. Adoption by reference
C. Interactions with the Legislature

VIII. Personnel
A. Position descriptions (describe why they are needed)
1. Job duties
2. Qualifications
B. Selection Process
1. Recruiting
2. Physical requirements
3. Examinations
C. Agency personnel policies
1. Unions
2. EEO/AA
D. Performance evaluation - establish standards
E. Administrative control
1. Establish itineraries
2. Require reports of activity
a. Number of miles driven
b. Number of devices checked
F. Motivation (use of quality circles)

IX. Training

A. Planning, organization, and scope of the training program

B. Sources of training and information

1. NCWM National Training Program
a. Modules
b. Trainers List

2. Department/Agency

3. State W\&M Association

4. Regional W\&M Association

5. NIST Office of Weights and Measures

6. Institute of Weights and Measures

7. Federal agencies

a. USDA
(1) P\&S
(2) FGIS
(3) USDA Graduate School

C. Scope of training

1. Training for Trainers (NCWM tapes and other sources)

2. Safety training

X. Safety

A. Establish safety policy/coordinator 
B. Evaluation

1. Data collection
a. Accident reports
b. Medical testing

2. Data review

3. Recommendations for change

C. Training sources

1. National Safety Council

2. Occupational Safety and Health Administration

D. Resource library

E. Equipment

XI. Communications

A. Internal (staff/management)

B. External

1. Public relations

2. Public education

3. Publicity

4. Education
a. Device owner
b. Packager
c. Service agency

5. Methods and tools

6. Interactions with other agencies
a. State
b. Federal

XII. Obtaining Compliance

A. Voluntary compliance

B. Adjudicatory Process
1. Administrative procedures
2. Penalty Assessment
3. Criminal vs. civil penalties
4. Notice of violation
5. Rights of accused
6. Appeals process

XIII. Investigations
A. Chain of evidence
B. Complaint handling
C. Investigations initiated by W\&M office
D. Cooperation/coordination with local authorities
E. Undercover and out-of-hours investigations
F. Development of policies/procedures
G. Equipment

XIV. Records Management

A. Determine the type of information needed

B. Types of records

1. Inspection reports

2. Complaint logs

3. Correspondence logs

4. Personnel records

5. Training records

6. Business records
a. Expense accounts
b. Purchase orders
c. Attendance reports
d. Mileage reports 


\section{Education Committee}

\section{e. Itineraries}

7. Subject reference files

8. Safety records (accident reports)

9. Certificates of Conformance (NTEP)

10. Case files

11. Laboratory records

C. Data processing

1. Manual

2. Electronic

3. Coordination and sharing of data

D. Records retention policies

E. Organization of records (e.g., by device type, by towns, by inspector, by jurisdiction)

F. Analysis of data

XV. Equipment
A. Adequacy of test equipment
1. Handbook 44
2. Handbook 133
3. Handbook 105 series
B. Maintenance of equipment
C. Scheduling replacement of equipment

XVI. Professionalism

A. Conflict of interest

B. Setting an example for staff to follow

XVII. Reference Materials

A. Publications

1. OWM

2. NCWM

3. Other

B. Safety 


\title{
Report of the Committee on Liaison
}

\author{
Peggy H. Adams, Chairman \\ Chief Sealer, Bucks County \\ Pennsylvania Department of Consumer Protection
}

Reference

Key No.

500

\section{Introduction}

This is the final report of The Committee on Liaison for the 75th Annual Meeting of the National Conference on Weights and Measures. This report results from the Interim Report, the Addendum Sheets issued at the meeting, and the actions taken by the membership at the meeting.

Reference Key Numbers, Item Titles, and Page Numbers are identified in Table A. Voting items are identified in boldface print, as well as by the suffix "V." Information items are identified by the suffix "I." Withdrawn items are identified by the suffix "W."

(This report was adopted in its entirety by a hand vote of the membership.)

Table A

Reference Key Items and Index

Reference

Key No.

Title of Item

Page

501

Federal Agency Activities . . . . . . . . . . . . 214

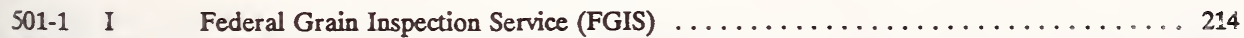

501-2 I Federal Role in Net Content Compliance: USDA .................. 215

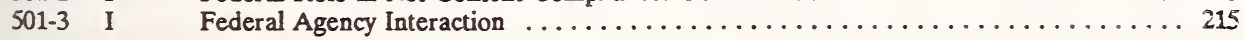

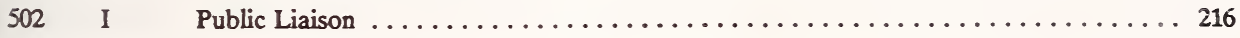

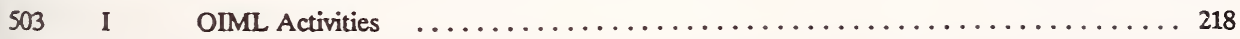

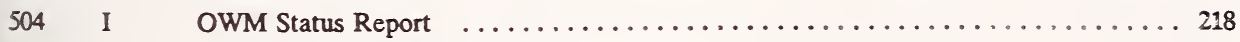

505 I Railroad Freight Car Stenciled Tare Weights $\ldots \ldots \ldots \ldots \ldots \ldots \ldots \ldots \ldots \ldots \ldots \ldots$

506 I The 75 th Annual Meeting of the NCWM $\ldots \ldots \ldots \ldots \ldots \ldots \ldots \ldots \ldots \ldots \ldots \ldots \ldots$ 
Table A (Continued)

\section{Reference}

Key No.

Title of Item

Page

507 I Liaison with Regional Associations ........................ 219

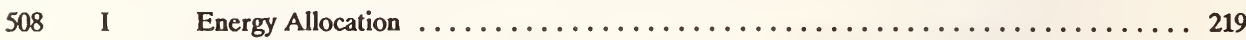

509 I Weights and Measures Week ............................... 219

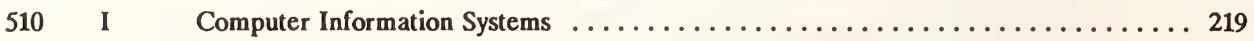

511 I Liaison with Other NCWM Organizations and Committees $\ldots \ldots \ldots \ldots \ldots$

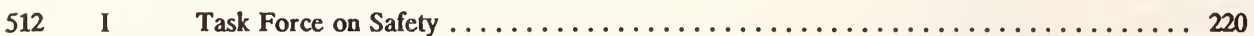

\section{Details of All Items}

501

Federal Agency Activities

\section{1-1 I Federal Grain Inspection Service (FGIS)}

\section{Railroad Track Scale Testing}

Mr. Richard Pforr, Chief Weighing and Equipment Branch, Field Management Division, FGIS, reported the following activities for 1989:

1. All master scales (13) in service were tested during the year and test results were submitted to the American Association of Railroads (AAR), State Weights and Measures, and the appropriate railroad. State Weights and Measures Officials generally attended when the tests were conducted.

2. The master scale removed from Martinsburg, West Virginia, is being installed at Barboursville, West Virginia.

3. Two testing circuits were completed, during which approximately 90 tests were conducted on official railroad track scales.

4. FGIS continued the tolerance testing of standards owned by local scale companies at the Master Scale Depot in Chicago on a request basis. Reports of tests were provided to the owner of the standards and the State of Illinois.

5. The "Belt Line" railroad, which owns the railroad yard where the FGIS Master Scale Depot is located, has informed FGIS that it is in receivership and is reorganizing. Only minor delays of test car movement are expected because of the reorganization.

6. The Oregon Public Utilities Commission (OPUC) and the Washington Public Utilities Commission (WPUC), which have been responsible for testing railroad track scales in those States, will transfer testing responsibility to the Weights and Measures Departments of those States in the near future. We anticipate no change in FGIS service provided to the Oregon master scale. 
7. FGIS continues to operate this program at capacity. Requests have been received from a number of agencies to have a third car built. To date, these requests have not been seriously considered.

\section{Grain Quality}

Mr. David Funk and Mr. Richard Pierce with the Quality Assurance Research and Development (QARD) Branch, FGIS, Kansas City, Missouri, met with the Committee to discuss the work done by their branch.

QARD, a branch of FGIS that checks quality of official grain samples, moisture meters, and protein measurement of grain samples, wanted to make NCWM members aware of this program and the possibility that Weights and Measures may become involved in these areas.

Mr. Funk was asked to continue to keep the Committee aware of FGIS activities and how NCWM could help them.

The U.S. Department of Agriculture (USDA) published a proposal to change its net weight regulations, with a comment period that ended in May, 1989. The draft proposal, developed with close NCWM cooperation and support, seeks to adopt Handbooks 133 and 44 to provide mandatory procedures for Federal inspectors in net content compliance determinations. The adoption of these handbooks should enable Federal, State, and local weights and measures officials to strengthen enforcement and compliance. Work on the analysis of the comments by the Food Safety Inspection Service (FSIS) of USDA has been completed. A final rule has been reviewed by the agency and will soon be going to OMB for policy review. It is hoped that the final rule will be published by October, 1990.

A problem with the labeling of hamburgers was brought to the attention of the Committee. Some boxes of hamburgers do not have a net weight statement on them, but only a designation of "Spec. 40-4." This designation is intended to indicate that the box contains 40 quarter pound hamburgers. Examination revealed that only 9-1/2 pounds of product was in each box. The USDA reports that it permits the above labeling because its meat regulations do not require a total net weight declaration. In contrast, Federal poultry regulations do require a complete net weight statement. The Committee recommended to the Executive Committee that the NCWM petition USDA to change its regulation to require a complete net weight declaration by adopting the requirements in the poultry regulations as requirements in the meat regulations. The Executive Committee agreed with the recommendation from the Liaison Committee and a petition has been sent to USDA.

$501-3$

I Federal Agency Interaction

\section{Ofice of Metric Programs}

The Office of Metric Programs (OMP), U.S. Department of Commerce, reported that most Federal Government departments are implementing plans to comply with requirements of the Metric Conversion Act of 1975 as amended in the 1988 Trade Act. The Amendment requires Federal agencies to convert to metric when feasible by 1992.

The OMP urged NCWM to continue to focus on metric issues as part of a public awareness program. The office urged NCWM to take a stand on metrication in all weights and measures areas.

Mr. Jerry Underwood of the U.S. Dept. of Commerce Office of Metric Programs updated the Conference on the federal activities toward Federal procurement in metric by 1992.

Federal Trade Commission (FTC)

Mr. Bret Smart, representing the FTC, discussed the Conference's concern with metric labeling. The Fair Packaging and Labeling Act (FPLA) requires that packages have inch-pound net content statements. It permits the addition of metric statement, but not metric statements alone. In order for Federal agencies to change their regulations to permit metric only statements, Congress would have to change the FPLA. Mr. Smart indicated that FTC is not in a position to lobby Congress for a law change and suggested that members of the Conference might contact members 
of Congress to gain interest in changing the Act.

\section{U.S. Postal Service (USPS)}

Mr. Theodore H. Yaffee, USPS, Program Manager, Postal Service Engineering Division, reported on recent USPS scale activities. 30,000 integrated retail terminals which can weigh and calculate the proper postage for any single piece of first, third, or fourth class mail weighing between $1 / 2$ ounce and 70 pounds have been installed in post offices throughout the country. A total of $45,000-50,000$ terminals will be installed nationwide by the time USPS finishes this project. The scales will be used in all offices that have 2 or more postal windows.

The 25-pound electronic bulk mail acceptance scales are being updated as computing scales which calculate the weight of a single piece when a known number of identical pieces are added. If a bundle is weighed, the scale will tell how many pieces are in the bundle.

\section{Food and Drug Administration (FDA)}

The FDA indicated that work on the Conference's early petition to change requirements for aerosol net weigh labeling has not progressed due to the need for additional information. FDA requested the Conference to include an economic and environmental impact statement with its petition. The Liaison Committee has prepared these materials and submitted them to FDA for the Conference.

Ms. Janice Oliver, FDA, discussed issues of concern to the National Conference. The FDA has had four hearing on labeling issues around the country. The agency has completed its hearings and is reviewing the comments. FDA was not ready to give any policy position at this time, but will do so after analyzing comments. The Committer requested that FDA review the food and nutrition labeling bills which have been introduced in Congress concerning the possibility of preemption of State regulations. This issue may also affect Handbook 130.

The Fair Packaging and Labeling Act was discussed as part of the FDA presentation. FDA, like FTC, must follor the requirements of the Act. FDA is not in a position to get Congress to change the Act, but recommended tha members of the Conference might contact members of Congress directly.

\section{U.S. Office of Consumer Affairs}

Mr. Howard Selzer, U.S. Office of Consumer Affairs, met with the Committee and discussed their office prioritie: They included privacy, more media coverage, and issues affecting senior citizens. Mr. Selzer meets with the 41 member Consumer Affairs Council which is comprised of representatives of Federal agencies and department: National Consumer Week, traditionally held at the end of April each year may be moved to the fall in 1991. NCWI members will be encouraged to participate in activities in their area. The Conference will send "Weights an Measures Today" to the Office of Consumer Affairs to keep them informed.

\section{National Industrial Scales Association (NISA)}

Mr. Bill Gemeiner, president of NISA, outlined the organization of the Association and presented its goals ar objectives. NISA, a group of users and manufacturers of heavy industrial scales, was organized in 1987 as an offsho of the Railroad Division of the International Society of Weighing and Measurement (ISWM.) Currently, there at 190 members from the United States, Canada, and China. Two technical seminars are conducted each year. Sever publications provide membership contact. NISA hopes to work with NCWM in its area of expertise and provide united voice where applicable. Anyone interested in membership may contact NISA, c/o Mr. Max Casanor Secretary/Treasurer, 1853 West County Road-C, St. Paul, Minnesota 55113.

\section{Canada}

Mr. Gilles Vinet, Program Officer, Weights and Measures, Legal Metrology Branch, attended the Interim Meeti to learn about the work of the Conference as a means of coordinating Canadian and U.S. weights and measur 
issues. He indicated that the contact was useful and his office intends to have someone attend Conference activities on a regular basis. Anyone with weights and measures issues concerning trade with Canada should contact Mr. Vinet by telephone (613) 952-2628, or in writing at 207 Queen Street, Ottawa, Ontario K1A 0C9 Canada, or call the Canadian Consumer Products Office (819) 997-1177.

\title{
International Association of Wiping Cloth Manufacturers (IAWCM)
}

Mr. Stuart Daniels, President of the LAWCM reported to the Committee that IAWCM wants to work with NCWM to resolve the industry's problems in selling wiping cloths by gross weight and to clear up any misunderstanding by either the industry or the Conference. He is going to take the Laws and Regulations Committee's comments back to the industry representatives and work toward resolution.

\section{U.S. Metric Association}

Mr. Louis Sokol, U.S. Metric Association, addressed the Committee concerning recent activities in the conversion towards and acceptance of metrication in the United States. The greatest activity within the Federal agencies is with the General Services Administration (GSA). A Federal Register notice for metrication programs has been published and no negative comments have been received. The U.S. Metric Association (USMA) and the American National Metric Council (ANMC) conducted a well-attended metric conference in October. A second National Metric Conference sponsored by the U.S. Metric Association, the American National Metric Council and the Department of Commerce Metric Program Office will be held October 29-30, 1990 in Arlington, Virginia. All members of the Conference are invited to attend.

Mr. Sokol stated that the Fair Packaging and Labeling Act (FPLA) provides a stumbling block for metrication. He has marked up a copy of the package labeling section (Section 4) to require that the contents be expressed in SI metric units and has forwarded it to Mr. James H. Turner, staff counsel of the Committee on Science, Space, and Technology, U.S. House of Representatives, Washington, DC.

Mr. Sokol has prepared and presented to the Executive Committee a mark-up of Appendixes B and C of H-44 to put the proper use of "mass" and "weight" into effect.

Mr. Sokol has also responded to FDA on nutritional labeling requesting the term calorie be changed to kilojoule.

Removal of Trade Barriers inside the European Community by 1992 (EC-92)

The Committee has sent to each State Director and officer of the NCWM an update of activities concerned with the 1992 deadline to remove barriers to free trade with the European Community (EC-92). The update included the following contacts: the Office of European Community Affairs, International Trade Administration, U.S. Department of Commerce, Room 3036, Washington, D.C. 20230 (202) 377-5279 or 377-5823; Ms. Debra Miller, Office of Industrial Trade Administration, U.S. Department of Commerce, Washington, DC. 20230 (202) $377-3703$.

Task Force on Fraud

The report of the Task Force on the Prevention of Fraud is being reprinted. A copy of the publication and condensed information will be sent to the following organizations including:

\author{
U.S. Office of Consumer Affairs \\ National Association of District Attorneys \\ National Association of Attorneys General \\ National Association of Consumer Agency Administrators \\ International Association of Chiefs of Police \\ National Institute of Municipal Law Offices \\ International Society of Weighing and Measuring \\ Scale Manufacturers Association \\ American Petroleum Institute \\ Gasoline Pump Manufacturers Association
}

Discussions with these groups have revealed that they would like to receive materials for their newsletters as well 
as copies of final reports. The Committee will place these and other associations interested in interacting with the Conference on the Weights and Measures Today mailing list.

Mr. Sam Chappell (NIST) described the OIML activities of interest to the NCWM. See the report of the Executive Committee for details.

\section{OWM Status Report}

Mr. Albert Tholen, Chief, OWM, reported on the status of the OWM in terms of staffing and program changes. See the report of the Executive Committee for details.

Mr. John J. Robinson, Senior Assistant Vice President, Association of American Railroads (AAR), reported that during 1989 , a total of 86,719 railroad freight cars were weighed and restenciled. The total represents 42,564 nonexempt (general service) cars and 44,155 exempt (specially equipped) cars. This was approximately 8 percent of the total serviceable fleet. Almost 14,000 covered hoppers and 24,000 open top hopper cars were restenciled. This is a substantial reduction from the 1988 total of over 141,000 cars restenciled.

The reduction is attributed in large part to a change in the railroad industry's Interchange Rule 70 governing the lightweighing/restenciling of freight cars made during the first half of 1989. The existing tolerances remain unchanged; however, the 60 -month time limit for lightweighing non-exempt cars was eliminated, along with the authority for a car owner to weigh another's cars when the 60-month limit was exceeded. Accordingly, the responsibility for maintaining accurate tare weights now rests solely with the car owner.

In taking this action, the rail carriers noted the continuing trend in the railroad industry toward per-car rates and weight agreements. It was concluded that, where tare weights are still used, the individual railroads have sufficient incentive to maintain the necessary tare weight accuracy.

The AAR field force continues to spot check over 2,000 stenciled tare weights monthly for comparison with the applicable UMLER (computer based) tare weight. The AAR will continue to furnish each freight car owner a summary of its annual restenciling activity and will urge all railroads to continue their efforts in this area.

Due to the special significance of the 75th Annual Meeting and the Conference's relationship with the National Institute of Standards and Technology (formerly the National Bureau of Standards), Washington, DC., has been selected as the site of the 1990 meeting.

In 1904, an invitation was sent to the Governor of each State by the Director of the National Bureau of Standards to send a representative to attend a meeting. The proposal was to effect a "close cooperation" between the State weights and measures inspectors and the National Bureau of Standards. The Conference was held in Washington, DC., January 16 and 17, 1905. This was the first National Conference on Weights and Measures. A videotape of the First National Conference was made under the direction of the Committee and shown as part of the opening ceremonies of the 75th Annual Meeting. Anyone who would like a copy of the tape should contact Karl Newell at (301)9754013 for information and cost.

A souvenir program containing the proceedings from the First Conference and a letter of congratulations signed by President Bush was given out at the 75th Conference. 
The Committee heard a report from Mr. Ray Elliott, past President, for Mr. Bill Eldridge, President of the Southern Weights and Measures Association, on their activities. They are working on a history of the Association. Concern was expressed over the liaison and education role Dick Smith played with the regional associations and what the future direction of NIST may be in this area following Mr. Smith's retirement. The timeliness of getting information regarding the theme for Weights and Measures Week was discussed. The next Southern meeting will be held October 28 through November 1, 1990 in Jackson, Mississippi.

The report on the Western Weights and Measures Association was given by Mr. Pat Nichols, President. Plans for the 1990 meeting include participation of representatives from the United Kingdom. The meeting is scheduled for August, 1990 in Phoenix, Arizona.

Ms. Peggy Adams gave the report for the Northeast Weights and Measures Association for Chairman William Slamon. The Northeast's concern over the current NIST information distribution practice of sending policy letters only to State Directors, but not to major city and county jurisdictions, was discussed. Mr. Ronald Crust, Chairman of the Northeast Weights and Measures Association, reported that their Interim Meeting will be held on October 24 and 25 in Cromwell, Connecticut, and their Annual Meeting will be held at the Royce Hotel, Langhorn, Bucks County, Pennsylvania, May 20-24, 1991.

The Central Weights and Measures Association report was given by Mr. Jim Akey for Mr. Don Soberg, Chairman. The Central region also voiced concern over Dick Smith's retirement and its impact on interaction between the regionals and NIST. The Central region has forwarded its concerns regarding petroleum products (oxygenated additives) labeling to the Conference. Michelle Phillips, President of the Central Weights and Measures Association, reported that their Annual Meeting will be held in Indianapolis, Indiana, April 14-18, 1991.

\section{Energy Allocation}

Representatives of the Task Force on Energy Allocation and the National Utilities Allocation Association (NUAA) met with the Committee to target national governmental, consumer, landlord/tenant, and technical organizations who should receive the "Recommended Regulation for Energy or Utilities Allocation Systems" (see 1989 Report of the NCWM, p. 92). A NUAA plan of action is in the process of implementation. NUAA's toll free number is $1(800)$ 525-1124.

All jurisdictions and members of NCWM received the third printing of NCWM Publication \#7, "Weights and Measures Week Guide." All local and State jurisdictions received the 1990 Weights and Measures Week mailing. The theme was "Progress Through Consensus Among Consumers, Regulators and Industry."

Weights and Measures Week packets for 1991 were distributed to all delegates during the 75th Annual Meeting. The theme for 1991 is "Weights and Measures for the 21st Century." Any jurisdiction not receiving the packet should contact Peggy Adams, Box E, Bedminster, Pennsylvania 18910; (215)795-2149.

The need for computer information users groups at the regional meetings was reaffirmed. The Committee recommends that each regional association have a computer users meeting as part of its annual meeting; the meeting should be scheduled so as not to conflict with other meetings and should include a demonstration of a successful program by one of its members and used by that member's jurisdiction. The WAMIS electronic bulletin board will continue to be updated by OWM. 


\section{Industry Committee on Packaging and Labeling (ICPL)}

Mr. Chip Kloos and Mr. Irving Bell conducted a discussion of accuracy regarding labeling requirements and weights and measures practices. A letter from ICPL was presented concerning sampling plans and the use of sampling variations. ICPL is planning a request and proposal to the NCWM for the addition of a sampling variation provision to the Category B sampling plans similar to the Category A plans. Discussion was held on the accuracy and equity in the package filling process and how Category B, without an allowance for sampling variation, forces overfilling for assurance of compliance. Accuracy is required in packaging and labeling regulations. Category A sampling plans in $\mathrm{H}-133$ provide for sampling variation. This will be incorporated into the Laws and Regulations Committee report as an informational item.

\section{Associate Membership Committee}

Chairman Bill Braun reported that the Committee's Vice Chairman, Max Casanova, had resigned due to other job responsibilities not allowing him time to complete his duties for the Committee. Ms. Dawn Brydon has been appointed to replace Mr. Casanova. Mr. Chip Kloos was elected as Secretary. Plans are proceeding smoothly for the industry reception in Washington, DC., for the 75th Annual Meeting. Mr. Braun commented that he had attended Module 22 (Commodity Regulations) training in South Dakota and found it to be excellent. He recommended that other industry personnel attend training of this nature as soon as they can.

\section{Retiree's Group}

Mr. Ray Wells reported on the activities of the retirees at the Regional Meetings and the National Conference. He is looking for a retired person to take over the organization of the groups. Retiree groups are active in the Western and Southern Associations, but more work is needed in the Central and Northeast. He hopes for a large turnout at the National Conference in Washington.

\section{2}

\section{Task Force on Safety}

Members of the Task Force on Safety met with the Committee to discuss ways the Committee can provide assistance to the Task Force (see also the Executive Report). Task Force technical advisor, Ms. Tina Butcher, presented a list of goals and objectives of the Task Force. The Task Force wants to explore ways of working with the Occupational Safety \& Health Administration, OSHA, loss control agencies, safety educational groups, and others to address the broad areas of safety programs. The Committee will contact Consumer Product Safety Commission, Federal agencies, industrial groups, loss control agencies, and others to determine resources for the Task Force.

The Committee and the Chairman of the Task Force on Safety met with Mr. Al Abadir, of the Directorate of Technical Support at OSHA. A good liaison was established. Future meetings will establish how the NCWM will interact with OSHA. Several possibilities were discussed including OSHA review of NCWM publications, particularly EPOS's, use of OSHA libraries and technical centers, and use of the OSHA Training Center in Chicago, Illinois.

\section{P. Adams, Bucks County, Pennsylvania, Chairman}

J. Akey, Wisconsin

R. Davis, James River Corporation

J. McCutcheon, USDA

K. Thuner, San Diego County, California

K. Newell, NIST, Technical Advisor

\section{Committee on Liaison}


Annual Committee Reports 



\title{
Report of the Resolutions Committee
}

\author{
O. R. Elliott, Chairman \\ Director, Agricultural Products Division \\ Oklahoma Department of Agriculture
}

\section{REFERENCE KEY}

700

\section{GENERAL}

The resolutions committee wishes to express the appreciation of the members of the National Conference on Weights and Measures to those who contributed their time and talents toward the arrangements for the conduct of, and the success of this 75 th Annual Meeting. Special votes of thanks are extended:

(1) to President George Bush for his letter of greeting to Conference participants and his praise for Conference efforts toward the growth of American commerce from the time of the first meeting in 1905 until this Diamond Anniversary meeting;

(2) to Representative Tim Valentine, Jr., of North Carolina for his gracious welcome to the conference members and guests and his laudatory remarks regarding the activities of the National Institute of Standards and Technology and, since its inception, the splendid accomplishments of the National Conference on Weights and Measures;

(3) to Dr. John Lyons, the Director of the National Institute of Standards and Technology (NIST), for his continuing the custom of addressing the membership, and for perpetuating the NIST partnership with the NCWM; to Dr. Lyons for his vision for the future of weights and measures and commitment to maintaining the NIST traditional function of support of the states, business and the Conference; to Dr. Lyons for his appointment of Dr. Edward C. Heffron, State of Michigan, to the NIST Visiting Committee;

(4) to Dr. Don Johnson, Director, NTST Technology Services, for his attendance at the annual meeting and his presentation of this year's President's and Honor Awards;

(5) to officers and appointed officials of the National Conference on Weights and Measures for their assistance and service toward progress on national issues;

(6) to committee members for their efforts throughout the past year preparing and presenting their reports; to the subcommittees and task forces for their discerning and appropriate recommendations;

(7) to regulatory officials of State and local jurisdictions for the advice, interest, and support of weights and measures administration in the United States;

(8) to representatives of business and industry for their cooperation and assistance in committee and Conference work; to the associate membership organization for the hospitality exhibited in sponsored social functions;

(9) to the staff of the J. W. Marriott Hotel for their assistance and courtesies, all of which contributed to the enjoyment and comfort of the delegates within their fine facilities; and 
to the National Institute of Standards and Technology and the Office of Weights and Measures for their outstanding assistance in planning and conducting the work and program of the National Conference on Weights and Measures, especially to Ann Heffernan-Turner and Terry Grimes for their professional and hospitable operation of the administrative operations of the meeting; to the Liaison Committee, the actors, NIST staff, and all those involved in the recreation on videotape of the first meeting of the Conference of 85 years past.

The following resolution is presented in its entirety for consideration of the members of the Conference:

\section{NEWSLETTER EDITORS} and

Whereas, weights and measures newsletters are a professional and informative source of communication;

Whereas, weights and measures publishers and editors through their dedication, research, and personal attention bring knowledge and information to those weights and measures enforcement personnel unable to attend seminars and conferences; and

Whereas, weights and measures publishers and editors through their services aid and enhance the professional and technical expertise of weights and measures personnel in the performance of their assignments in respective jurisdictions; and

Whereas, weights and measures publishers and editors of newsletters represent a valuable means of communication on laws and regulations, type approval of devices, inspection and testing procedures of devices set forth by the National Institute of Standards and Technology to be administered throughout the United States of America; Therefore, be it

Resolved by the 75th Annual Conference that recognition be given to publishers and editors of weights and measures newsletters for the donation of their time, talent, and expertise in assembling, validating, and publishing items of interest and importance to members of the weights and profession.
O. R. Elliott, Chairman
D. Ely, Pennsylvania
S. McFarlane, Washington
S. McGuire, Illinois
C. Pittman, Tennessee
A. Thompson, Alaska
J. Mindte, NIST, Coordinator

Resolutions Committee 


\title{
Report of the Nominating Committee
}

\author{
John J. Bartfai, Chairman \\ Director, Bureau of Weights and Measures \\ State of New York
}

\section{REFERENCE}

KEY NO.

800

The Nominating Committee met during the Interim Meeting at the SunBurst Resort Hotel and Conference Center, Scottsdale, Arizona, and nominated the persons named below to be officers of the 76th Conference. In the selection of nominees from active membership, consideration was given to professional experience, qualifications of individuals, prior Conference attendance and participation, regional representation, and other factors considered to be important.

CHAIRMAN-ELECT:

VICE-CHAIRMEN:

EXECUTIVE COMMITTEE:

TREASURER:

John J. Bartfai, New York, Chairman

F. Clem, Columbus, $\mathrm{OH}$

L. DeGrange, Maryland

C. Greene, New Mexico

D. Guensler, California

E. Keeley, Delaware

T. Kelly, New Jersey

\section{Nominating Committee}

On motion of Mr. Bartfai, Chairman, the report of the Nominating Committee, voting key item 800 , was adopted in its entirety by the Conference.
Sidney A. Colbrook, Illinois

Kenneth S. Butcher, Maryland

Lynda Maurer, Rhode Island

Glen H. Jex, Idaho

Mike Deisley, Nebraska

Patrick E. Nichols, California

Ross J. Andersen, New York

Charles Gardner, Jr., Suffolk County, NY 


\title{
Report of the Auditing Committee
}

\author{
Gerald Hanson \\ Director of Weights and Measures, San Bernardino County, California
}

Reference

Key No.

900

The Auditing Committee met on Tuesday afternoon, July 10, 1990, for the purpose of reviewing the financial reports of the Conference Treasurer, Charles A. Gardner, Jr. Committee members S. Casto and E. Murphy were unable to attend the annual meeting. Carol P. Fulmer, South Carolina, and Richard L. Davis, James River Corporation, Neenah, Wisconsin, were appointed on-site to serve in their absence. The gentlemen graciously accepted.

The Auditing Committee finds the financial reports of the Conference Treasurer to be in accordance with Conference procedure and correct.

G. Hanson, San Bernardino, California, Chairman

C. Fulmer, South Carolina

R. L. Davis, James River Corporation, Neenah, Wisconsin

J. Mindte, NIST, Coordinator

\section{Auditing Committee}

(On motion of Mr. Hanson, the Report of the Auditing Committee, Reference Key Item 900, was adopted by the Conference.) 
National Conference On Weights and Measures

July 11, 1990

Listing of Expenses

FY 74 (1989 - 1990)

2.0 Annual Meeting

$2.1 \mathrm{Hotel} /$ Food Services

$\$ 9,659.79$

750.00

2.2 Audio/Visual

2.3 Personnel

1169.00

2.4 Printing

592.03

2.5 Photos

415.00

2.9 Miscellaneous

$\underline{12,766.72}$

3.0 Interim Meeting

3.1 Hotel/Food Service

$6,301.86$

701.43

3.3 Personnel

$1,172.26$

$\underline{8,175.55}$

4.0 Committee Operations

4.1 Executive

4.2 Laws and Regulations

$7,376.10$

$2,843.13$

$7,806.88$

4.3 Specifications and Tolerances

$5,152.17$

4.4 Education

$2,100.57$

4.5 Liaison

502.21

$3,742.20$

$\underline{29,523.26}$

4.8 Printing

$8,284.30$

645.67

$4,772.65$

$4,734.86$

$1,282.70$

$\underline{19,720.18}$

6.0 Chairman's Expenses

6.1 Chairman

6.2 Chairman-Elect

6.3 Annual Reception

6.4 Regional Breakfasts

$4,272.68$

$2,757.12$

4417.22

881.25

$\underline{12,328.27}$

7.0 Membership Programs

7.2 Contract Work

2,131.03

7.3 Banners

$2,525.15$

817.00

7.5 Invoices

347.03

$\underline{5,820.21}$ 
8.0 Printing and Publications

8.1 Annual Meeting

8.3 Letterhead

$9,633.56$

8.4 Membership

245.00

8.9 Miscellaneous

120.00

104.00

$\underline{10.102 .56}$

9.0 Administration

9.1 Equipment

1509.00

9.2 Services/Contract 2434.26

9.3 Mailing

82.50

9.4 Supplies

76.60

9.5 Bank Charges

7.00

159.00

.6 P.O. Box Rental

$4,024.45$

9.8 Travel

158.00

9.9 Miscellaneous

155.14

$\underline{8.605 .95}$

10.0 Special Events

$10,722.72$

$10,722.72$

11.0 Promotional Items

$3,667.42$

$3,667.42$

12.0 Training Modules

$14,914.15$

$14,914.15$

TOTAL DISBURSEMENTS

$\$ 136.346 .99$ 
Treasurer's Report Fiscal Year 74 (1989-1990)

July 11,1990

\section{National Conference on Weights and Measures}

\section{Grant Account}

Start

$\$ 5082.89$

Deposits

Grant \#1 HA 4003

Grant \#2 8H 0869

$\$ 30,570.20$

$3,000.00$

Total

$\underline{33.570 .20}$

Interest

Grant \#1 HA 4003

136.81

Grant \#2 8H 0869

103.64

Total

$\underline{240.45}$

Total

$\$ \underline{38,893.54}$

Payments

Grant \#1 HA 4003

$\$ 25,241.77$

Grant \#2 8H 0869

$6,871.77$

Total

$\underline{32,113.54}$

Close

$\$ \underline{\underline{6.780 .00}}$

Date Submitted: July 13, 1990

(signed) Charles A. Gardner

Charles A. Gardner, Treasurer 
Treasurer's Report

National Conference on Weights and Measures

Treasurer's Report

July 11, 1990

Fiscal Year 74 (1989-1990)

CASH

$\$ 90,942.70$

(BUDGET)

RECEIPTS:

$\begin{aligned}(\$ 30,000) & 1.1 \text { Registrations } \\ (67,550) & 1.2 \text { Memberships } \\ (6,500) & 1.3 \text { Training Modules } \\ (3,000) & 1.4 \text { Interest } \\ (1,000) & 1.5 \text { Promotional } \\ (5,000) & 1.6 \text { Special Events } \\ (300) & 1.9 \text { Miscellaneous }\end{aligned}$

$(113,350)$

$\frac{\frac{25,315.00}{96,883.50}}{\frac{8,667.00}{5,064.40}} \frac{\frac{-0-}{14,174.71}}{\underline{115.00}}$

TOTAL RECEIPTS $\underline{150,219.61}$

TOTAL INCOME $241,162.31$

DISBURSEMENTS:
$(14,000)$
$(4,000)$
$(20,000)$
$(18,000)$
$(12,550)$
$(6,000)$
$(6,000)$
$(12,500)$
$(5,000)$
$(1,300)$
$(14,000)$

$(113,350)$
2.0 Annual Meeting

3.0 Interim Meeting

4.0 Committee Operations

5.0 Special Programs

6.0 Chairman's Expense

7.0 Membership Expense

8.0 Printing \& Publications

9.0 Administration

10.0 Special Events

11.0 Promotions

12.0 Training Modules
12.766 .72

8.175 .55

$29,523.26$

$19,720.18$

$\underline{12,328.27}$

5.820 .21

$\frac{5.820 .21}{10,102.56}$

$8,605.95$

$\underline{10.722 .72}$

3.667 .42

$\underline{14.914 .15}$

TOTAL DISBURSEMENTS

$\underline{136,346.99}$

BALANCE

$\underline{104,815.32}$

\section{BANKS}

European American (New York)

Signet (Maryland)

$\frac{49,260.18}{314.24}$

$\underline{314.24}$

Certificate of Deposit \#1 (6 Mo.)

Certificate of Deposit \#2 (3 Mo.)

Certificate of Deposit \#3 (3 Mo.)

23.374 .94

$11,088.46$

$\underline{20.777 .50}$

BALANCE

$104,815.32$

Date Submitted: $7 / 12 / 90$

Date Audited: $7 / 10 / 90$

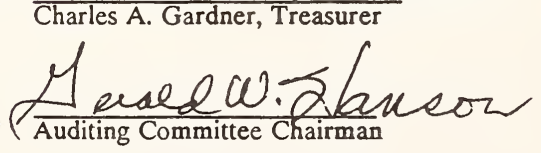

JOAN MINDTE

Staff Advisor 


\title{
New Chairman's Message
}

\author{
July 12,1990
}

\author{
N. David Smith \\ Director, Standards Division, North Carolina Department of Agriculture
}

I am the first Chairman-elect to have had the privilege of accompanying the Chairman to the regional meetings. From close, personal observation, I can say that Fred Gerk has been a tremendous Chairman.

Fred has been a great friend and advisor. As Chairman, you have certain perks, one of which is to create awards. Thus, I am giving Fred a personal award - The Great Example Award.

Fred and I have a great working relationship. The same will continue with me and Sid Colbrook, your Chairman-elect. We have known each other for several years and share many common philosophies. I hope you will give Sid and me your advice and criticism.

The earliest record I have of the National Conference is the report of the 10th Annual Conference which was held in Washington, DC in 1915. From that report, I have found some interesting information.

During a discussion of when and where to schedule future conferences, the delegate from the District of Columbia made the following declaration. "The only reduced rate at this season of the year that can be counted on, year by year, is the reduction that comes on all trips to Washington around Decoration Day. There is the prime argument for setting the date in the month of May. The summer rates go in effect in June, but if you come here once in June you will never come again. There is no one who spends a week here in Washington after June if they can help it."

Mr. L.A. Fischer, Chief, Division of Weights and Measures, NBS, reported that "at the last conference, the committee on tolerances and specifications was given authority to reword the tolerances and specifications without changing their meaning, and the committee promptly set about carrying out the instructions of the conference. After carefully studying the subject, the committee found it highly desirable and necessary to make amendments involving some changes in the meaning of the original tolerances and specifications." Today, we know that changes to meaning are the result of granting "editorial privilege".

The delegate from New York offered a resolution to expand the committee on tolerances from 3 to 5 members and change the committee's name to the board of control. Thankfully, the resolution was defeated.

Lastly, in the comments of William C. Redfield, Secretary of Commerce, he noted the following, "nearly half of the world is on fire. The citizens of Europe, of Africa, of Asia, and of Australia are engaged in destruction. I wonder if you have ever thought, as I used to think, that now is a very ordinary time in which to live, that all the interesting things happened in the time about which the books were written, and that this was a very humdrum day. We, none of us, think so now, for America is the only continent in which a great many people are not trying to destroy one another. Neither your fathers nor yourselves ever saw such a condition as we face every time we pick up our morning newspaper. Men's lives, men's property are being destroyed at a rate which is appalling. Sciences are being utilized to produce disaster on a scale which we have never know. Nothing could be more contrasted than the spirit in which we meet here to help one another and the spirit with which, across the sea, men are trying to destroy one another. there can be no sharper difference made between the spirit of America and spirit of militancy than that."

As we meet in 1990, the citizens of Europe are again engaged in destruction, but this time they are destroying a form of government while throwing out the welcome mat to the citizens of the world. 
In preparing my remarks, I decided to review the annual conference reports at the beginning of each decade since 1920. In each of those reports, there are pleas for national uniformity of weights and measures requirements, for agreement on device type evaluation, and for more help from the Bureau in the area of training. Weights and measures officials complained about the lack of staff and resources and the imposition of fees. The integrity of the $S \&$ T Committee was called into question in virtually every report. Has anything changed? Yes, great problems have been solved and much progress has been made. Yet, the National Conference continues to be a much undervalued organization and one that perhaps consciously avoids publicity. As we prepare for the 21st Century, I feel that the National Conference must take stock of itself and plot a course of where we want to go or others will surely plot that course for us.

If being President of the United States means that George Bush doesn't have to eat broccoli, then being chairman of the National Conference means I can exercise a moment of personal privilege. At this time, I want my son, Eric, to come forward. Eric is 10 years old and is a rising fifth grader at Lead Mine Road Elementary School. However, I want us to examine Eric as he will be in the year 2000. In 10 years, Eric will be 20 years old and if everything goes according to plan, he will be out of college and ready to support his parents.

Let's look at Eric at the beginning of the 21st Century and what weights and measures may mean to him.

First, Eric the weights and measures inspector. After graduating from college with a degree in computer science, engineering, statistics, accounting, or mathematics, now the required degrees for a weights and measures position, Eric begins his career in weights and measures. However, things are different for Eric since he spends the majority of his time auditing weights and measures transactions. From his office, he plugs into the quality control program of a major packager and audits production runs from several day's production. There is no longer a need for the weights and measures inspector to weigh individual packages since each package is weighed separately by the manufacturer and is given a unique number. When Eric detects a short weight lot or even individual short weight packages, a notice of violation is electronically transmitted to the manufacturer. Settlement of the shortweight discovery is immediate since according to prior agreement, the results of electronic auditing are not contestable. You ask, "What about testing weighing and measuring devices"? This practice has been virtually eliminated due to the introduction of devices which are self calibrating. Eric needs only to audit a company's calibration schedule. For the few devices which are not self calibrating, Eric relies on a sampling plan which targets troublesome devices. The remainder of Eric's time? Weights and measures has broadened its scope to include many areas of consumer fraud such as travel promotions and rent of leisure property. In addition, Eric is responsible for monitoring compliance with product safety laws and for providing assistance to firms interested in introducing new products to the international market.

Now, Eric the weights and measures device manufacturer. Eric's company competes freely in Europe and is a major supplier of weighing systems. Regardless of the country, the system is exactly the same, save for an interchangeable key pad which is available in 15 languages. Eric's current assignment is to analyze the domestic market and make recommendations to upper management on how to improve U.S. profitability. Armed with facts on the high cost of making 6 different versions of the same model to satisfy domestic weights and measures requirements, Eric is prepared to recommend that his company join a growing list of firms advocating that Congress enact a national weights and measures law. This law will move NTEP from voluntary to mandatory status, but will also standardize equipment design and requirements and require that the states recognize an NTEP certified device.

A look at Eric the packager. With the ability to weigh and identify each package, Eric regards the quarterly weights and measures audit as routine. At the appointed time, the weights and measures inspector accesses Eric's computer system. Eric already knows which lots will be questioned and he is prepared to offer a $0.01 \%$ overfill for the next 3 months to compensate customers in Wake County, North Carolina who purchased short measure product. This is easy to do since a record is maintained on where each package is sold, and if the purchase is by credit card or debit card, the name and address of the purchaser is known. The weights and measures official agrees to this approach and, after verifying that production computers have been reprogrammed, he signs off the system.

What about Eric the consumer? Eric is concerned with health care costs, the environment, and food and product safety. When asked about weights and measures issues, Eric explains that accurate measurement is 
important, but its importance is down the list. His thinking simply means that in 10 years, consumer concerns have not changed. In the Fall, 1989, issue of MOBIUS, the Journal of the Society of Consumer Affairs Professionals in business, none of the articles in the issue, which was devoted to the consumer agenda for the 90 's, mentioned weights and measures or a concern which can be readily identified with weights and measures. Are we satisfied with the state of weights and measures because our needs are being met or is weights and measures one of those effective programs that no one knows about yet is one of the first to be found when the budget knives are being sharpened?

At this point, I must inject an editorial comment. While researching consumer trends, I found an article which dealt with Federal agencies and their consumer agenda for the next decade. According to Secretary Mosbacher, "the mission of the Department of Commerce is to encourage economic growth, promote international trade, and further technological advancement. To carry out these goals, the Commerce Department works closely with both the business and consumer communities." While I didn't expect the National Conference to be mentioned, I must wonder if the Secretary is aware that through the National Conference there is a great opportunity for the Department of Commerce to interact with consumers and industry. Better yet, cities, counties, states, and private industry are footing the lion's share of the cost. With a potential membership of 5,000 in the next 3 years, the National Conference can be a very potent force in helping the Commerce Department meet its mission.

Now for perhaps the most important Eric of all, Eric the taxpayer. On what programs will Eric demand that his tax money be spent? What level of performance will he require? Most likely, Eric the taxpayer will reflect the concerns of Eric the consumer. Remember, health costs, the environment, and food and product safety dominate his agenda. In the year 2000 , will any weights and measures program be a general fund obligation or will the programs be solely supported by inspection and registration fees or from some other imaginative means designed to separate people from their money?

In 10 short years, Eric and his classmates will be moving into these roles. The 21st Century will be here. I have chosen this year's theme to be "Weights and Measures for the 21st Century." To help plot a course, some very fine people have agreed to give freely of their time and talents.

\section{Education Committee}

Laws and Regulations Committee

Specifications \& Tolerances

Committee

Liaison Committee

Auditing Committee

Credentials Committee

Resolutions Committee

\section{Martin Coile, Georgia 5-year term}

Sharon Rhoades, Indiana 5-year term

Dick Suiter, Nebraska 5-year term

Clayton Davis, Maine 5-year term

John Lacy, Packers/Stockyards USDA 4-year term

Aves Thompson, Alaska 3-year term

Ed Hanish, Indiana 3-year term

Guy Tommasi

Middletown, Connecticut 3-year term

Michelle Phillips, Indiana 3-year term 
Nominating Committee

Budget Review Committee

Chaplain

Assistant Treasurer

Sergeants-At-Arms

Parliamentarian
Mike Grenier, New Hampshire 3-year term

Glen Jex, Idaho

2-year term

Ed Price, Texas

2-year term

Steve Malone, Nebraska 1-year term

L.F. Eason, North Carolina 1-year term

Alan Rogers, Virginia

1-year term

Don Soberg, Wisconsin

1-year term

Charlie Gardner, Suffolk County, New York 1-year term

Carl Conrad, New Jersey

1-year term

Fred Gerk, New Mexico

2-year term

Cordell Robinson, Columbus, Ohio

Gerry Hanson, San Bernadino County, California

Jim Noone, Philadelphia, Pennsylvania

Ron Roof, Pennsylvania

Clayton Davis, Maine

The Safety Task Force will continue its work. According to Chairman Gardner, the Task Force should complete its assignment and have a final report for the next conference.

I have said much about preparing for the 21st Century. We need to discuss our vision of the future. We need a plan. To put ideas on the table, I have asked Darrell Guensler of California to chair a task force of wildeyed dreamers. Their goal is to rock the boat and not be satisfied with the status quo. Among many tasks, I want the task force to:

determine the interest in including a session on motor fuel quality during the annual meeting;

make some predictions on the future of traditional weights and measures;

suggest new areas which could come under the weights and measures umbrella;

suggest how we can take the National Conference to the membership rather than the membership coming to the National Conference;

investigate avenues that will put the value of the National Conference before our political and civic "movers 
and shakers";

consider the impact of biodegradable, recyclable, and safety packaging on existing weights and measures requirements; and

be a "blue sky" committee that will cause us to engage in debate and discussion on the future of weights and measures.

Joining Darrell in this assignment are Bruce Martell of Vermont, Tom Geiler of the Town of Barnstable, Chip Kloos of Beatrice/Hunt-Wesson Foods, Inc., and a yet to be named representative from the Department of Commerce.

I look forward to serving the National Conference. As previously stated, your advice and criticism is welcomed. Just pick up the phone and give me a call.

At the conclusion of the meeting, Al Tholen is expecting me to say "Sine Die." but I feel a more appropriate ending is "Y'all Come Back." There being no further business to come before this assembled 75th Annual Meeting of the National Conference on Weights and Measures, I declare the meeting adjourned. 
Registration List for 75th Annual Meeting
Deidre Adams

700

Staff Product Planner

IBM

2020 Yonkers Road

Raleigh, NC 27604

Telephone: 919-664-5120

FAX: 919-664-5004

Michael F. Adams

Manager of Technical Support

11447

Fairbanks Scales

711 E St Johnsbury Rd

St Johnsbury, VT 05819

Telephone: 802-748-5111 x326

FAX: 802-748-5216

Peggy H. Adams

2735

Chief Sealer

Bucks County Consumer Protect.

Box 340

Bedminster, PA 18910

Telephone: 215-795-2694

FAX: 215-538-1315

James H. Akey

State Metrologist

WI Department of Agriculture

PO Box 78834702 University Ave(05)

Madison, WI 53707

Telephone: 608-267-3510

FAX: 608-266-1560

Frederick T. Allen 12094

Manager, Reg Affairs LC27-00

Pitney Bowes

Walter Wheeler Dr

Stamford, CT 06926

Telephone: 203-925-5044

FAX: 203-925-5080

Ross J. Andersen

Metrologist

NY State Bureau of Wts \& Meas

Bldg 7A State Campus

Albany, NY 12235

Telephone: 518-457-4781

FAX: $518-457-4780$

Sydney D. Andrews

Private Consultant

1133 Myers Park Dr

Tallahassee, FL 32301-4525

Telephone: 904-878-3928

Wanda E. Armstrong

Auditor

Clinton County Auditor

46 South Street

Wilmington, $\mathrm{OH} 45177$

Telephone: 513-382-2250

FAX: 513-382-7530

Ron Balaze

8988

Metrologist

Michigan Dept of Agriculture

PO Box 30017

Lansing, MI 48909

Telephone: 517-373-9897
Jerry L. Bane

10636

Acting Bureau Chief

Iowa Dept Agriculture

Henry A Wallace Bldg, E 9th

Des Moines, IA 50319

Telephone: 515-281-5716

FAX: $515-281-6236$

Salvatore A. Barbera

287

President

Digi Matex Inc

80 Oak St

Norwood, NJ 07648

Telephone: 201-784-3400

FAX: 201-784-3770

Lester H. Barrows

3926

Director

Bureau of Weights \& Measures

PO Box 630

Jefferson City, MO 65102

Telephone: $314-751-4316$

FAX: $314-751-8307$

John J. Bartfai

Director

Bureau of Weights \& Measures

Bldg 7A State Campus

Albany, NY 12235

Telephone: 518-457-3452

FAX: $518-457-4780$

Irving Bell

Senior Executive Staff Rep

Coca-Cola Co

PO Drawer 1734/One Coca-Cola Plaza

Atlanta, GA 30313

Telephone: 404-676-2623

FAX: 404-676-8265

Anthony F. Belmont

Sealer of Weights \& Measures

Town of Greenwich Con Aff

101 Field Point Road

Greenwich, CT 06830

Telephone: 203-622-7713

F. Michael Belue

President

691

Belue Associates

PO Box 701, 2004 Liberty St

Bonham, TX 75418

Telephone: 214-583-9082

Celeste Bennett

MFQ Coordinator Wts \& Meas

Michigan Dept of Agriculture

PO Box 30017

Lansing, MI 48909

Telephone: 517-373-1060

David N. Bigley

13743

Research Engineer

Consolidation Coal Co

Consol Plaza

Pittsburgh, PA 15241

Telephone: 412-831-4972
Melvin Bigthumb

4248

Weights \& Measures Inspector

The Navajo Nation

PO Box 663

Window Rock, AZ 86515

Telephone: 602-871-6714

FAX: 602-871-7381

James R. Bird

82

Deputy State Supt NJ Retired

Bella Bridge Rd, Box 194

Medford, NJ 08055

Telephone: 609-267-5520

Harold Birgy

2471

MI Dept of Agriculture

PO Box 30017

Lansing, MI 48909

Telephone: 517-373-1060

FAX: 517-335-0628

Del W. Bissett

Vice President

16251

SGS Control Services

PO Box 1328

Kenner, LA 70063

Telephone: 504-469-6401

FAX: 504-469-8485

Michael Blacik

8924

Acting Dir Weights \& Measures

State Of Minnesota

2277 Highway 36

St Paul, MN 55113

Telephone: 612-341-7200

FAX: 612-297-1659

Paul Blixt

Assistant Manager Corp QA

Camation

5045 Wilshire Blvd.

Los Angeles, CA 90036

Telephone: 213-932-6334

Barbara J. Bloch

Special Assistant

CA Div of Measurement Standard

8500 Fruitridge $R$ d

Sacramento, CA 95826

Telephone: 916-366-5119

FAX: $916-366-5179$

Roger B. Bognar

Manager Tissue Division

American Paper Institute

260 Madison Ave

New York, NY 10016

Telephone: $212-340-0618$

FAX: 212-689-2628

Harold D. Bradshaw

Inspector Weights \& Measures

Dept of Weights \& Measures

City County Bldg, Room 314

Jeffersonville, IN 47130

Telephone: 812-283-6289 
William D. Brasher

Senior Quality Control Analyst

Southem Co Services Inc

PO Box 2625 Bin B852

Birmingham, AL 35202

Telephone: $205-877-7653$

FAX: 205-877-7288

William H. Braun

Packaging Section Manager

Procter \& Gamble

5299 Spring Grove Ave

Cincinnati, $\mathrm{OH} 45217$

Telephone: 513-627-5476

FAX: 513-627-5534

Carroll S. Brickenkamp

Program Manager

Natl Institute of Stds \& Tech

A617 Admin

Gaithersburg, MD 20899

Telephone: 301-975-4005

FAX: $301-926-0647$

Robert W. Brooks

VP Administration

Colombo Inc.

3 Riverside Drive

Andover, MA 01810

Telephone: 508-682-7115

FAX: 508-685-6543

Robert Bruce

Chief Weights \& Measures

Canadian Cons \& Corp Affairs

207 Queen St, Ottawa

Canada K1A 0C9, 026

Telephone: 613-952-2625

Robert T. Brumbaugh

President

Systems Associates Inc

1932 Industrial Dr

Libertyville, IL 60048

Telephone: 708-367-6650

FAX: 708-367-6960

Dawn M. Brydon

Director of Marketing

Milk Ind Fndn/Intl IC Assn

888 16th St, NW

Washington, DC 20006

Tele phone: $202-296-4250$

FAX: 202-331-7820

Howard Burgess

Quality Assurance Manager

Friskies Petcare/Camation Co

150 Riverview Dr

Jefferson, WI 53549

Telephone: $414-674-4100 \times 139$

FAX: 414-674-5022

Charles Burns, Jr.

Chief Inspector

City of Birmingham W \& M

710 20th St No. Room 207

Birmingham, AL 35203

Telephone: 205-254-2246

PAX: 205-254-2925
Tina Gaver Butcher $\quad 8236$

Weights \& Measures Coordinator

Natl Inst of Stds \& Tech

A617 Administration Building

Gaithersburg, MD 20899

Telephone: 301-975-2196

FAX: 301-926-0647

Charles H. Carrol

Assistant Director

MA Division of Standards

One Ashburton Place

Boston, MA 02108

Telephone: $617-727-3480$

FAX: $617-227-6094$

Charles D. Carter

9838

Program Administrator W \& M

Agricultural Products Division

$2800 \mathrm{~N}$ Lincoln Blvd

Oklahoma City, OK 73105-386

Telephone: 405-521-3864 x294

FAX: 405-521-4912

16000

Max C. Casanova

Manager Technical Service

Ramsey Technology Inc

1853 W County Rd C

Saint Paul, MN 55113

Telephone: $612-638-2264 \times 264$

FAX: $612-638-2275$

H. Penny Causgrove

Retired Sealer of Wts \& Meas

City of New Haven

18 Davis $\mathrm{S}$

New Haven, CT 06515

Telephone: 203-387-4913

Darrel E. Cavender

Metrologist

Div of Measurement Standards

12050 Ind Wy Bl O/POB 111686

Anchorage, AK 99511

Telephone: 907-345-7750

FAX: 907-345-2641

Samuel E. Chappell

10610

Standards Management

Natl Institute of Stds \& Tech

Bldg 101, Room 625

Gaithersburg, MD 20899

Telephone: 301-975-4024

Barbara Chames

13800

Director

Coloradans for Clean Air

1985 Grape St.

Denver, CO 80220

Telephone: $303-388-4858$

FAX: $303-388-4858$

Phillip R. Chisholm

Executive Vice President

Petroleum Marketers Assoc.

1120 Vermont Ave. N.W.

Washington, D.C., 20005

Telephone: 202-331-1198

Richard H. Claussen

Director Rm 105

Porter County Weights \& Meas

Court House Annex $1401 \mathrm{~N}$ Calumet Av

Valparaiso, IN 46383

Telephone: $219-465-3585$
Lavar Clegg

Director of Engineering

Revere Transducers Inc

14030 Bolsa Lane

Cerritos, CA 90701

Telephone: 714-739-1991

FAX: 714-522-0931

Fred P. Clem

Weights \& Measures Inspector

City of Columbus

50 W Gay St

Columbus, OH 43215-2821

Telephone: $614-645-7144$

PAX: 614-645-6675

Martin T. Coile

State Metrologis

Georgia Dept Agriculture

Atlanta Farmers Market

Forest Park, GA 30050

Telephone: 404-363-7685

Sidney A. Colbrook

W\&M Program Manager

Illinois Dept of Agriculture

PO 19281, 801 E Sangamon Ave

Springfield, IL 62794-9281

Telephone: 217-782-3817

FAX: 217-524-4882

Robert L. Collette

Assoc Dir Science \& Technology

National Fisheries Institute

1525 Wilson Blvd Suite 500

Arlington, VA 22209

Telephone: 202-524-8883

PAX: 202-524-4619

Carl P. Conrad, Jr.

Chief Supervisor

Office of Weights \& Measures

1261 U.S. Rte 1 \& 9 South

Avenel, NJ 07001

Telephone: $201-815-4840$

FAX: 201-382-5298

Donald O. Cripe

Sealer of Weights \& Measures

9794

Madera County

332 Madera Ave

Madera, CA 93637

Telephone: 209-675-7876

FAX: 209-674-4071

Ronald R Crust

Centre County W\&M

Box 574

Milesburg, PA 16853

Telephone: $814-355-5750$

A.R. Daniels

irector Industry Stds \& $\mathrm{Re}$

NCR Corp

1700 S Patterson Blvd WHQ-S

Dayton, OH 45479

Telephone: 513-445-1310

FAX: $513-445-1418$

Gerald E. Davis

System Supvr Scale Insp

968

Conrail

6 Pen center Plaza Room 1634

Philadelphia, PA 19103-2959

Telephone: 215-977-1617 
Richard L. Davis

3806

Manager Product Compliance

James River Corporation

1915 Marathon Avenue

Neenah, WI 54957

Telephone: 414-729-8174

FAX: 414-729-8161

Mike Deisley

4428

Agric Program Supervisor

Nebraska Weights \& Measures

301 Centennial Mall S. PO Box 94757

Lincoin, NE 68509

Telephone: $402-471-4292$

FAX: 402-471-3252

R.F. Demory

8408

Weights \& Measures Bureau

State of Virginia

234 W Shirley Ave

Warrenton, VA 22186

Telephone: $703-349-8310$

FAX: 703-347-5868

G.W. (Wes) Diggs

Superv, VA Weights \& Measures

VA Weights \& Measures

PO Box 1163 Room 402

Richmond, VA 23209

Telephone: 804-786-2476

FAX: 804-371-7793

\section{Loren Dobyns}

Manager Plant \& Electrical

12941

Thunder Basin Coal Co

PO Box 406

Wright, WY 82732

Telephone: 307-939-1300

Louis D. Draghetti

Inspector of Wts \& Meas

Town of Agawam

36 Main St Town Hall

Agawam, MA 01001

Telephone: 413-786-0400 x232

Irv Dubinsky

USDA

FSIS/USDA

Washington, DC 20250

Telephone: $202-447-2378$

Clyde L. Duncan

15337

President

Deka Scale Inc

5655 Opportunity Dr, Suite 30

Toledo, OH 43612

Telephone: $419-478-5001$

FAX: $419-478-4633$

Donald S. Duncan

Deputy Sealer

Sacramento Co W \& M

4137 Branch Center Rd

Sacramento, CA 95827

Telephone: $916-366-2003$

FAX: $916-366-4150$

Michael Dynia

Metrologist

Weights \& Measures

Rm G-17 St Off BI, 165 Capitol

Hartford, CT 06106

Telephone: 203-566-5230

FAX: 203-566-7630
L.F. Eason

3886

Metrologist NC Dept of Agric

Standards Division

PO Box 27647/SD

Raleigh, NC 27611

Telephone: 919-733-4411

FAX: 919-733-0999

David E. Edgerly

2999

Acting Depty Dir/Tech Serv

Natl Instit of Stds \& Tech

Bldg 221 Room A363

Gaithersburg, MD 20899

Telephone: $301-975-4500$

FAX: 301-975-2183

William P. Eldridge

Director Wts \& Meas Division

MS Dept of Agric \& Commerce

PO Box 1609

Jackson, MS 39215-1609

Telephone: $601-354-7080$

FAX: 601-354-6001

John J. Elengo, Jr.

VP Engr, Wallinford Operations

Revere Transducers Inc

845 N Colony Rd PO Box 5041

Wallingford, CT 06492

Telephone: 203-284-5102

FAX: 203-284-5142

\section{O. Ray Elliott}

Director Agric Products Div

OK Dept of Agriculture

2800 N Lincoln Blvd

Oklahoma City, OK 73105

Telephone: 405-521-3864 x301

FAX: 405-521-4912

Dean F. Ely

District Supervisor

PA Dept of Agriculture

675 Rose St

Williamsport, PA 17701

Telephone: $717-327-3560$

Larry J. Enfield

15874

Directro Quality Control

General Mills Inc.

Number One General Mills Blvd

Minneapolis, MN 55440

Telephone: 612-540-2729

FAX: $612-540-4925$

Alexander Eska

Superintendent

City of Linden Wts \& Meas

301 N Wood Ave

Linden, NJ 07036

Telephone: $201-474-8403$

James H. Eskew

Chief Metrologist

TX Dept of Agriculture

119 Cumberland Rd

Austin, TX 78704

Telephone: $512-462-1441$

Dexter A. Fedor

11314

Director Quality Control

CA Cedar Products Co

1340 W Washington St, PO Box 528

Stockton, CA 95201

Telephone: 209-944-5800

FAX: 209-948-6758
Robert K. Feezor

11200

Superintendent Scales

Norfolk Southern Corp

Building Box 142, 99 Spring Sreet

Atlanta, GA 30303

Telephone: 404-527-2537

FAX: 404-527-2589

Sy Feinland

7048

SMTS

Pitney Bowes Inc

Parrot Dr

Shelton, CT 06484

Telephone: 203-925-5211

FAX: 203-925-5333

Catherine Finch

Food/W\&M Specialist

MI Dept of Agriculture

16615 S Harrison

East Lansing, MI 48823

Telephone: 517-373-8782

Beatrice H. Florczyk

Deputy Inspector

Dept of Weights \& Measures

City County Bldg Room 1760

Indianapolis, IN 46204

Telephone: $317-236-4272$

Robert L. Fonger

Senior Field Representative

Bennett Pump Co

PO Box 597

Muskegon, MI 49445

Tel hone: 616-733-1302

FAג: $616-739-8832$

Cleveland C. Forde

Director

Dept Weights \& Measures

1157 Scottsville Rd

Rochester, NY 14624

Telephone: $716-436-1330$

Ken L. Fraley

Metrologist

Lab Div Bur of Standards

2800 N Lincoln Blvd

Oklahoma City, OK 73105

Telephone: 405-521-3864 x370

FAX: 405-521-4912

Bob Fuehne

Sr Qual Assurance Technologist

Ralston Purina Co

Checkerboard Square - 4RN

St Louis, MO 63164

Telephone: 314-982-2916

FAX: $314-982-4072$

Carol P. Fulmer

Assistant Commissioner

SC Dept of Agriculture

PO Box 11280

Columbia, SC 29211

Telephone: 803-737-2080

FAX: 803-734-2192

James O. Funderburk

11613

Manager Regulatory Affairs

First Brands Corporation

88 Long Hill Street

East Hartford, CT 06108

Telephone: 203-728-6182

FAX: 203-728-6083 
Charles A. Gardner

3438

Director Wts \& Measures

Suffolk County Consumer Affair

County Ctr/N Bldg 340

Hauppauge, NY 11788

Telephone: 516-360-4621

FAX: $516-360-7470$

Charles H. Gardner

President

Seraphin Test Measure

30 Indel Ave

Rancocas, NJ 08073

Telephone: 609-267-0922

FAX: $609-261-2546$

Thomas F. Geiler

Sealer of Weights \& Measures

Town of Barnstable

367 Main St

Hyannis, MA 02601

Telephone: 508-790-6251

FAX: $508-775-3344$

William G. GeMeiner

Scales Engineer

Chicago \& North Westem RR

$165 \mathrm{~N}$ Canal Street

Chicago, IL 60606

Telephone: $312-559-6133$

FAX: $312-559-7185$

Victor L. Gerber

Metrologist

Wyoming Dept of Agriculture

2219 Carey Avenue

Cheyenne, WY 82002-0100

Telephone: $307-777-7324$

Fred A. Gerk

Dir Div Stds \& Consumer Sves

NM Dept of Agriculture

PO Box 30005, Dept. 3170

Las Cruces, NM 88003-0005

Telephone: 505-646-1616

FAX: 505-646-3303

Joesph A. Giannina

Manager Bulk Terminal

Port of Corpus Christi Auth

PO Box 1541

Corpus Christi, TX 78403

Telephone: 512-883-1162

FAX: 512-883-1652

Carl W. Gile

Assistant Metrologist

Kansas Weights \& Measures Lab

2016 SW 37th St

Topeka, KS 66611-2570

Telephone: 913-267-0278

Ronald M. Gilman

Agricultural Commissioner

Director of Weights \& Measures

263 Camino Del Remedio

Santa Barbara, CA 93110

Telephone: 805-681-5600

PAX: $805-681-5603$

William V. Goodpaster

Vice President

Cardinal Detecto

1610 North C St

Sacramento, CA 95814

Telephone: 916 441-0178

FAX: 916-441-5606

1607
John Gould

American Meat Institute

1700 N Moore St

Arlington, VA 22209

Telephone: 703-841-2400

Maxwell H. Gray

Chief Bureau of W\&M

FL Dept of Agric \& C S

3125 Conner Blvd

Tallahassee, FL 32301

Telephone: 904-488-9140

Richard D. Greek

Agri Commissioner/Sealer

San Luis Obispo County

2156 Sierra Way Suite D

San Luis Obispo, CA 93401

Telephone: 805-549-5910

FAX: 805-549-5911

Charles H. Greene

Director General Services

NM Dept of Agriculture

PO Box 30005, Dept 3GSD

Las Cruces, NM 88003-0005

Telephone: 505-646-2787

FAX: 505-646-3303

Terry L. Grimes

Secretary

Natl Inst of Stds \& Tech

A617 Admin Bldg

Gaithersburg, MD 20899

Telephone: 301-975-4027

FAX: $301-926-0647$

Christopher B. Guay

Regulatory Affairs

Procter \& Gamble Co

11511 Reed Hartman Highway

Cincinnati, OH 45241

Telephone: 513-626-2222

FAX: $513-626-2407$

Darrell A. Guensler

Assistant Director

CA Measurement Standards

8500 Fruitridge Rd

Sacramento, CA 95826

Telephone: 916-366-5119

FAX: $916-366-5179$

Robert Gunja

Standards Administrator

City of Kansas City W\&M

701 North 7th St

Kansas City, KS 66101

Telephone: 913-573-5080

PAX: 913-573-5005

Paul Hadyka

9402

Industrial Specialist

USDA/FGIS Room 0623-S

PO Box 964541400 Ind. Ave

Washington, DC 20250-6454

Telephone: 202-382-0262

FAX: $202-447-4628$

Wayne E. Handy

Inspector

Weights \& Measures

Johnson County Courthouse Annex

Pranklin, IN 46131

Telephone: 317-736-3909
956

Edwin M. Hanish

Inspector Laporte County

Indiana Weights \& Measures

2700 Franklin St

Michigan City, IN 46350

Telephone: $219-874-7197$

7991

Melvin C. Hankel

9094

Manager of Mechanical Engr

Liquid Controls Corp

Wacker Park

North Chicago, IL 60064-3599

Telephone: 708-689-7302

FAX: 708-689-0540

Gerald W. Hanson

116

Director

San Bernardino County Wts/Meas

777 E Rialto Ave

San Bernardino, CA 92415-0790

Telephone: 714-387-2136

FAX: 714-889-6449

James D. Harnett

7774

Agricultural Commissioner

Dept of Weights \& Measures

1010 S Harbor Blvd

Anaheim, CA 92805-5597

Telephone: 714-447-7110

FAX: 714-774-2741

Jim Harrington

Inspector Weights \& Measures

Michigan Dept of Agriculture

8918 Dolphin Drive

Kalamazoo, MI 49002-6133

Telephone: 616-323-0747

Georgia Harris

Metrologist, Office Wts \& Meas

Natl Instit Stds \& Technology

A617 Admin Bldg

Gaithersburg, MD 20899

Telephone: $301-975-4004$

FAX: 301-926-0647

Jack Harshman

Manager Measurement Eng

Daniel Flow Products Inc

9720 Katy Rd

Houston, TX 77224

Telephone: 713-827-5131

FAX: $713-827-3880$

Stephen Hasko

10707 Glenhaven Dr

Silver Spring, MD 20902

Telephone: 301-649-5163

Ronald G. Hayes

Petroleum Lab Supervisor

MO Dept of Agriculture

PO Box 630

Jefferson City, MO 65102

Telephone: 314-751-2922

FAX: $314-751-8307$

David K Heck

Coordinator-Policy Anal/Govt A

Chevron USA Inc

575 Market St, Room 966

San Prancisco, CA 94105-2856

Telephone: $415-894-0910$

FAX: 415-894-8468

109 
Edward C. Heffron

Director, Food Division

MI Dept of Agriculture

PO Box 30017

Lansing, MI 48909

Telephone: $517-373-1060$

FAX: $517-373-9146$

Sid Hejzlar

Vice President Engineering

John Chatillon \& Sons Inc

83-30 Kew Gardens Rd

Kew Gardens, NY 11415

Telephone: $718-847-5000$

FAX: $718-441-4365$

Raymond H. Helmick

Director

State of AZ Dept of W\&M

1951 W North Lane

Phoenix, AZ 85021

Telephone: 602-255-521

FAX: $602-255-1950$

Marilyn J. Herman

President

Herman \& Associates

2300 M St, NW, Suite 800

Washington, DC 20037

Telephone: 202-775-1630

FAX: 202-293-3083

Arthur Hershbein

Retired Director Dade County

Consumer Protection Division

140 W Flagler St, Ste 1605

Miami, FL 33130

Telephone: $305-375-4222$

David M. Hershberger

Load Cell Product Manager

Toledo Scale Inc.

350 W. Wilson Bridge Rd.

Worthington, $\mathrm{OH} 43085$

Telephone: $614-438-4679$

FAX: $614-438-4770$

Richard Hewitt

VP Sales \& Marketing

Ishida USA Inc.

6396 Overbrook Ave.

Philadelphia, PA 19151

Telephone: $215-879-8284$

FAX: $215-879-8238$

T.L. Hillburn

Technical Representative

Turnbow Engineering

PO Box 1604

Bartlesville, OK 74005

Telephone: 918-333-8475

FAX: 918-333-8879

Sam F. Hindsman

Director

Arkansas Bureau of Standards

4608 W 61st St

Little Rock, AR 72209

Telephone: 501-371-1750

Donald J. Hine

(Retired)

AEM Corp

$452 \mathrm{~W}$ Tenth St

Elyria, OH 44035

Telephone: 216-323-2041
Dir, Cons, Spec \& Info Service

National Forest Products Assn

1250 Connecticut Ave, NW Suite 200

Washington, DC 20036

Telephone: 202-463-2765

Herman R. Hochstetler

Inspector

Elkhart County Weights \& Meas

$117 \mathrm{~N}$ 2nd

Goshen, IN 46526

Telephone: 219-534-3541

Lee Hock

6238

Manager Field Services

BP Oil Co

$4850 \mathrm{E}$ 49th $\mathrm{S}$

Cleveland, $\mathrm{OH} 44125$

Telephone: 216-271-8211

FAX: $216-271-8717$

Frances P. Holland

15654

Authorities \& Stan Admin

Schlumberger Technologies

3601 Koppens Way

Chesapeake, VA 23323

Telephone: 804-366-4400

FAX: $804-487-7350$

Leonard T. Holtgreven

President

Loadmaster Scale Mfg

420 E Lincoln St

Findlay, $\mathrm{OH} 45840$

Telephone: $419-422-4779$

FAX: $419-422-9036$

Monty H. Hopper

Director

Dept. Of Weights \& Measures

1116 E. California Avenue

Bakersfield, CA 93307

Telephone: 805-861-2418

FAX: 805-324-0668

Richard M. Huff

10608

Vice President Electronics

Universal Epsco Inc

1494 Ellsworth Ind Dr/Bx 93544

Atlanta, GA 30318

Telephone: 404-351-2740

FAX: 404-351-2899

Clayton $\mathrm{H}$. Hughey

9618

Inspector of Weights \& Measur

Hendricks County

3421 Indiana $\mathrm{Rd}$

Plainfield, IN 46168

Telephone: $317-839-4752$

Randall L. Hutton

Associate Director/Comnty Affr

Winn-Dixie Stores Inc

5050 Edgewood Ct

Jacksonville, FL 32205-0297

Telephone: 904-783-5408

FAX: 904-783-5294

William D. Ince

Manager Unit

Wheel Abrator Coal Services

3505 Olsen

Amarillo, TX 79109

Telephone: 806-355-9253
Christopher L. Irving, Esq.

12809

Counsel

NY City Dept Consumer Affairs

80 Lafayette Street

New York, NY 10013

Telephone: $212-566-4862$

Michael T. Jackelen

Marketing Manager

Poly-Tech Inc

$1401 \mathrm{w} 94$ th St

Minneapolis, MN 55431

Telephone: $612-884-7281$

FAX: 612-884-6438

David James

9368

Program Superviso

MO Dept Agri Dev \& Comm Insp

PO Box 630

Jefferson City, MO 65102

Telephone: 314-751-5639

FAX: $314-751-8307$

W. Terry James

Vice Pres Engineering Services

Cardinal/Detecto Scale Mfg Co

203 E Daugherty PO Box 151

Webb City, MO 64870

Telephone: 417-673-4631

FAX: 417-673-5001

Jack Y. Jeffries

2199

Superviso

Division of Standards

7810 Alafia $\mathrm{Dr}$

Riverview, FL 33569

Telephone: $904-487-2634$

FAX: 813-272-2287

Glen H. Jex

Chief

Bureau of Weights \& Measures

2216 Kellogg Lane

Boise, ID 83712

Telephone: 208-334-2345

FAX: 208-334-2170

Mark R. Joeison

4238

General Counsel

Morgan Lewis \& Bockius

1800 M St, NW

Washington, DC 20036

Telephone: 202-467-7240

FAX: 202-467-7176

Jean Johnson

11232

Measurement Assistant

American Petroleum Institute

1220 L St NW

Washington, DC 20005

Telephone: $202-682-8147$

FAX: 202-682-8154

Ted F. Johnson

Director of Marketing

Sensortronics Inc

677 Arrow Grand Circle

Covina, CA 91722

Telephone: 818-331-0502 ×201

FAX: $818-332-3418$ 
Rte 3 Box $65 \mathrm{C}$

Jackson, GA 30233

Telephone: 404-775-6387

Dept of Weights \& Measures

PO Box 2100, 120 E 8th St

Anderson, IN 46011

Paul J. Klein 4468

FAX: $612-884-6438$

George E. Jones

Director Fuel \& Measures Div

Inspector Weights \& Measures

Telephone: 317-646-9839

St Joseph County

227 West Jefferson Blvd

South Bend, IN 46601

Telephone: 219-284-9751

Capital Square 19, MLK, Jr. Drive

Atlanta, GA 30334

Telephone: 404-656-3606

Harold D. Jones

C. N. Brown Co.

Chip Kloos

Lab Manager-R \& D

Beatrice/Hunt-Wesson Foods

$1645 \mathrm{~W}$ Valencia Dr

Fullerton, CA 92633-3899

Telephone: 714-680-1098 x1098

FAX: 714-449-5166

E. Jongen

Dir Gen, Int Mrkt \& Ind Affair

Joan A. Koenig

Commission of the Euro. Commu.

3, Rond Point Schuman

B-1040 Brussels Belgium

Telephone:

Raymond Kalentkowski

Supervisor

Weights \& Measures Division

State Office Bldg/Cons Prot

Hartford, CT 06106

Telephone: 203-566-4778

FAX: $203-566-7630$

Eugene Keeley

Administrator

Weights \& Measures Coordinator

Natl Inst of Stds \& Tech

Admin 101, Rm A617

Gaithersburg, MD 20899

Telephone: 301-975-4007

FAX: 301-926-0647

Willem Kool

15332

OIML SP7/SR2 Berkel

PO Box 251 NL 2280 AG Ryswyk

The Netherlands,

Telephone: 317039563000

FAX: 31703995623

Nelson Kranker

Delaware Weights \& Measures

2320 S Dupont Highway

Dover, DE 19901

Telephone: $302-736-4811 \times 37$

FAX: $302-697-6287$

Michael J. Keilty

Product Mgr-Custody Transfer

Micro Motion Inc

7070 Winchester Circle

Boulder, CO 80501

Telephone: $303-530-8400$

PAX: $303-530-8418$

Robert B. Kelley

Deputy Director

Director

Dutchess Co Dept of Cons Affrs

22 Market $\mathrm{St}$

Poughkeepsie, NY 12602

Telephone: 914-471-6322

Walter E. Kupper

Director Tech \& Reg Affairs

Mettler Instrument Corp

PO Box 71

Hightstown, NJ 08520-0071

Telephone: 609-443-8861

FAX: 609-443-5972

Dan Kushnir

Sales Manager

FAX: $317-646-5668$

Robert A. LeCaire, Jr.

Manager Quality Assurance

Presto Products Co

670 N Perkins St

Appleton, WI 54914-3133

Telephone: 414-738-1334

FAX: 414-738-1458

Walter G. Leight

Acting Deputy Director, OSS

Natl Inst of Stds \& Tech

A600 Admin

Gaithersburg, MD 20899

Telephone: $301-975-4010$

Jerry Levine

Director, Corporate Studies

Amoco Oil Co

200 E. Randolph

Chicago, IL 6060

Telephone: $312-856-2605$

FAX: $312-856-7006$

Raymond J. Lloyd

Executive Director

Scale Manufacturers Assn

932 Hungerford Dr \#36

Rockville, MD 20850

Telephone: 301-738-2448

FAX: 301-738-0076

Harvey M. Lodge

Dunbar Manufacturing Inc

307 Broadway

Swanton, $\mathrm{OH} 43558$

Telephone: 419-825-2331

FAX: $419-826-8439$

Heliodoro Lopez-Torres

Dir Weights \& Measures

Dept Of Consumer Affairs

P O Box 41059 Manillas Station

Santurce, PR 00940

Telephone: 809-721-1930

FAX: $809-726-6570$

Seraphin Test Measure

30 Indel Ave

Rancocas, NJ 08073

Telephone: 609-267-0922

FAX: 609-261-2546

John T. Lacy

246

Chief Scales \& Weighing Branch

USDA Packers \& Stockyards Adm

3414 S 14th \& Independence Ave

Washington, DC 20250

Telephone: $202-447-3140$

Steve Lambert

Corp Q A Mgr

Frigo Cheese Corporation

1088 Springhurst Dr

Green Bay, WI 54304

Telephone: 414-494-2228 x305

FAX: $414-494-7717$

Forrest Joe Loyd, Jr.

Engineer-Scales \& Weighing

CSX Transportation Inc

500 Water St, Room 907

Jacksonville, FL 32202

Telephone: 904-359-1024

FAX: 904-359-7476

David Lunceford

13791

Northeast Regional Mgr

SGS Control Services Inc

20 Lafayette St

Carteret, NJ 07008

Telephone: 201-541-7200

James F. Lyles

Retired Chief

VA Weights \& Measures Bur.

7804 Lycoming Rd.

Richmond, VA 23229

Telephone: 804-285-0559 
Supervisor, Cons. Assur. Div.

National Inst. of Stds \& Tech.

Quince Orchard \& Clopper Roads

Gaithersburg, MD 20899

Telephone: 301-975-2300

Melvin L. Lyons 8632

Asst Director LA Wts \& Measure

LA Dept of Agri and Forestry

PO Box 3098

Baton Rouge, LA 70821-3098

Telephone: 504-925-3780

FAX: 504-922-1289

John MacDonald

Vice President, Engineering

Howe Richardson

680 Van Houten Avenue

Clifton, NJ 07003

Telephone: 201-471-3400

FAX: 201-472-7851

James E. Maka

Chief Metrologist

Div Of Measurement Standards

725 Ilalo St

Honolulu, HI 96813-5524

Telephone: 808-548-7168

Steven A. Malone

Director

Weights \& Measures Division

301 Centennial Mall, S, Box 94757

Lincoln, NE 68509

Telephone: $402-471-4292 \times 208$

FAX: $402-471-3252$

Renald Marceau

Program Officer

Consumer \& Corporate Affaris

207 Queen St, Ottawa

CANADA K1A 0C9.

Telephone: 613-952-2633

Sheryl A. Marcouiller

Food \& Drug Counsel

Kraft General Foods, Inc.

Kraft Court

Glenview, IL 60025

Telephone: 708-998-7650

FAX: 708-999-6431

Patrick Marino

Technical Service Manager

New Brunswick Internatl Inc

76 Veronica Ave

Somerset, NJ 08873

Telephone: $201-828-3633$

FAX: $201-828-4884$

Alan V. Marsh

10361

Supervisor Weights \& Measures

Butler Co Wts \& Meas

130 High St

Hamilton, OH 45011

Telephone: 513-887-3157

Glen R. Marshall

Staff Engineer

Shell Oil Co

777 Walker - TSP1130

Houston, TX 77002

Telephone: 713-241-1452

FAX: 713-241-7166
Vermont Dept of Agriculture

116 State Street SOB

Montpelier, VT 05602

Telephone: 802-828-2436

FAX: 802-828-2361

Vernon Lee Massey

Sealer

Shelby County Government

157 Poplar Suite 402

Memphis, TN 38103

Telephone: 901-576-3920

Tom Masuyama

Software Engineer

TEC America Inc

19300 Hamilton Ave, Suite 200

Gardena, CA 90248

Telephone: $213-329-9600$

FAX: $213-329-1490$

George E. Mattimoe

Retired Admin Measurement Stds

953 Wainiha St

Honolulu, HI 96825

Telephone: 808-395-1492

FAX: $808-548-8524$

Arthur L. McCabe

13802

Fuel Transportation Administr

Consumers Power Co

1945 W Parnall Rd

Jackson, MI 49201

Telephone: $517-788-1388$

Robert McCarty

Systems Engineer-Industry Stds NCR Corp

PO Box 728, 800 Cochran Ave

Cambridge, $\mathrm{OH} 43725$

Telephone: $614-439-0579$

FAX: $614-439-0249$

T. B. McDonald

Manager Resale Facilities Eng. 12456

Mobil Oil Corp

8260 Willow Oaks Corp Dr Rm 2M-211

Fairfax, VA 22038

Telephone: 703-849-5320

FAX: 703-849-5074

Sterling McFarlane

Supervisor Weights \& Measures

Dept of Licenses \& Cons Aff

Room 102, 600 4th Ave

Seattle, WA 98104

Telephone: 206-386-1298

Stephen E. McGuire

Metrologist

Illinois Dept of Agriculture

801 E Sangamon Ave

Springfield, IL 62794-9281

Telephone: 217-785-8480

FAX: 217-524-5960

John R. McPherson

Senior Staff Engineer

Exxon Co USA

PO Box 4415, 1200 Smith St

Houston, TX 77210

Telephone: 713-656-7757

FAX: $713-656-7789$

3634

13726

James Melgaard

39

Director

Div Commercial Insp \& Reg

118 West Capitol

Pierre, SD 57501-2080

Telephone: $605-773-3697$

FAX: 605-773-4117

Charles W. Michell, Jr. 9082

Sr Loss Control Representative

Shell Oil Co

PO Box 2463/Rm 2286 One Shell P

Houston, TX 77001

Telephone: 713-241-0455

Stanley K. Millay

Supervisor

ME Dept Agriculture W\&M

Division of Regulations Station 28

Augusta, ME 04333

Telephone: 207-289-2751

FAX: 207-289-7161

Joan Mindte

Training Coordinator

National Inst of Stds \& Tech

A609 Admin

Gaithersburg, MD 20899

Telephone: $301-975-4003$

FAX: 301-926-0647

Daniel H. Moenter

Manager, Government Affair

Marathon Oil Company

539 South Main Street

Findlay, $\mathrm{OH} 45840$

Telephone: 419-422-2121

FAX: $419-422-2121$

Charles W. Moore

County Insfector

Weights \& Measures

Madison County Govt Center Box 15

Anderson, IN 46011

Telephone: 317-641-9662

FAX: 317-641-9486

G. E. Moore

VP Technical Liaison

Dover Corp OPW Division

PO Box 405003

Cincinnati, OH 45240-5003

Telephone: 513-870-3202

FAX: 513-874-1231

Thomas L. Morrow

Business Unit Manager

TEC America Inc

19300 Hamilton Ave Suite 200

Gardena, CA 90248

Telephone: 213-329-9600

FAX: 213-329-1490

Ronald D. Murdock

Standards Division

NC Dept of Agriculture

PO Box 27647

Raleigh, NC 27611

Telephone: 919-733-3313

Larry Murray

Chief Engineer

Wayne Div-Dresser Industries

124 W College Ave PO Box 1859

Salisbury, MD 21801

Telephone: 301-546-6690

FAX: $301-546-6888$ 
Frank Nagele

Weights \& Measures Specialist

MI Dept Of Agriculture

1006 Britten Ave

Lansing, MI 48910-1328

Telephone: $517-372-1784$

Joseph V. Nagy

Sealer of Weights \& Measures City of South Bend Indiana

701 W Sample Street

South Bend, IN 46618

Telephone: $219-284-9273$

Allan M. Nelson

Director Weights \& Measures

Dept of Consumer Protection

165 Capitol Ave, Room G17

Hartford, CT 06106

Telephone: 203-566-4778

FAX: 203-566-7630

Gerald H. Nessenson

President

Valvtect Petroleum Products

3400 Dundee Rd, \#330

Northbrook, IL 60062

Telephone: 708-272-2278

FAX: $708-272-4260$

Karl Newell

Office of Weights \& Measures

Natl Inst of Stds \& Tech

Admin 101, Rm A617

Gaithersburg, MD 20899

Telephone: $301-975-4013$

FAX: $301-926-0647$

Glen W. Newton

Manager Transportation

Arco Coal Company

55517 th St

Denver, CO 80202

Telephone: 303-293-7785

FAX: 303-293-4820

Patrick E. Nichols

Director Weights \& Measures

Dept of Weights \& Measures

333 Fifth Street

Oakland, CA 94607-4107

Telephone: $415-268-7287$

FAX: 415-444-3879

J.W. Noble

Department Engineer

Silas Mason Co Inc

PO Box 30020

Amarillo, TX 79177

Telephone: $806-477-4301$

Henry V. Oppermann

General Physical Scientist

Natl Inst of Stds \& Tech

Admin 101, Rm A617

Gaithersburg, MD 20899

Telephone: $301-975-4008$

FAX: $301-926-0647$

Victor L. Page

Director

KY Dept of Agric Wts \& Meas

106 West 2nd St

Prankfort, KY 40601

Telephone: 502-564-4870

FAX: 502-564-6527
Claude R. Parent

Consultan

Private

7 Eastwood Drive

Orinda, CA 94563

Telephone: 415-376-5697

Bill B. Paull

10650

Standards Engineer

Hobart Corp/PMI Food Equip.

World Headquarters

Troy, OH 45374

Telephone: 513-332-2651

FAX: 513-332-2142

James E. Peeples

Director Legislative Affair

Information Resources Inc

499 S. Capitol St Suite 400

Washington, DC 20003

Telephone: 202-554-0614

H.Steffen Peiser

Consultant

638 Blossom Dr

Rockville, MD 20850

Telephone: 301-762-6860

Peter R. Perino

President

Revere Transducers Inc

14030 Bolsa Lane

Cerritos, CA 90701

Telephone: 714-739-1991

FAX: 714-522-0931

Paul L. Peterson

Industrial Specialist

9664 USDA Packers \& Stockyards Adm

14th \& Independence, SW, Rm 3414 S

Washington, DC 20250

Telephone: $202-447-5841$

Richard R. Pforr

Branch Chief WEB

USDA/FGIS

1400 Independence Ave Room 1640

Washington, DC 20250

Telephone: 202-382-0262

FAX: $202-447-4628$

Richard L. Phegley

11697

Exoxon Co USA

PO Box 2180

Houston, TX 77252-2180

Telephone: 713-656-8510

DeVern H. Phillips

10619

State Seale

Kansas Div of Inspections

2016 SW 37th S

Topeka, KS 66611-2570

Telephone: 913-267-4641

FAX: 913-296-2247

Michelle I. Phillips

9076

Assistant Administ rator

Dept of Weights \& Measures

City County Bldg, Room 1760

Indianapolis, IN 46204

Telephone: $317-236-4272$
Richard L. Philmon

9168

Program Coordinator

Illinois Dept of Agric

801 E Sangamon Ave

Springfield, IL 62794-9281

Telephone: 217-782-3817

Richard Pierce

Ag Engr, Type Approval Group

USDA FGIS

Box 20285

Kansas City, MO 64195

Telephone: 816-891-8553

Allen W. Pirlot

8171

Deputy Inspector

Dept of Weights \& Measures

City County Bidg Room 1760

Indianapolis, IN 46204

Telephone: $317-236-4272$

Cathryn F. Pittman

Technologist

TN Department of Agriculture

PO Box 40627 Melrose Station

Nashville, IN 37204

Telephone: 615-360-0159

Alan Porter

8752

Technical Unit Supervisor

Wisconsin Dept of Agriculture

801 W Badger Rd, Box 8911

Madison, WI 53708

Telephone: 608-266-7244

FAX: $608-266-1300$

Marian Powell-Tyree

President

Powell All-Steel Scales Inc

Rt 8 Box 432 Curry Road Hwy 257

Jasper, AL 35501

Telephone: $205-387-8647$

FAX: 205-384-3805

Edwin J. Price

Enforcement Coordinator

Dept of Agriculture

PO Box 12847

Austin, TX 78711

Telephone: $512-463-7607$

FAX: 512-475-1618

Gale Prince

10651

Manager Regulatory Compliance

Kroger Co

1014 Vine St

Cincinnati, OH 45201

Telephone: 513-762-4209

FAX: 513-762-4372

John V. Pugh

Director Metrology Laboratory

S C Dept Of Agriculture

Po Box 11280

Columbia, SC 2921

Telephone: 803-253-4052

FAX: 803-734-2192

Patrick Quigg

11118

Director of Quality Contro

General Mills Inc

Number One General Mills Blvd

Minneapolis, MN 55426

Telephone: 612-540-2354

FAX: 612-540-2109 
David W. Quinn

Product Manager

Fairbanks Scales

69th Ave Industrial Park

Meridian, MS 39307

Telephone: $601-483-4311$

FAX: $601-483-4311$

John B. Rabb

W \& M Laboratory Supervisor

Div of Weights \& Measures

PO Box 3336

Montgomery, AL 36193

Telephone: 205-242-2652

Robert A. Reinfried

Technical Assistant

Scale Manufacturers Assn

932 Hungerford Dr, \#36

Rockville, MD 20850

Telephone: $301-738-2448$

FAX: $301-738-0076$

Robert E. Reynolds

Downstream Alternatives Inc

PO Box 190

Bremen, IN 46506

Telephone: 219-546-4204

FAX: $219-546-5845$

Sharon Rhoades

Administrator

Division of Weights \& Measures

1330 W Michigan St, Rm 136N

Indianapolis, IN 46206

Telephone: $317-633-0350$

Austin T. Rhoads

President

Northeast Ice Cream Assn

P O Box 0510

Fulton, MD 20759-0510

Telephone: 301-953-9117

Marsha L. Richardson

11136

Inspector

Gibson County Wts \& Meas

Courthouse Annex, 800 S Prince St

Princeton, IN 47670

Telephone: 812-385-2426

Richard L. Rightmyer

Senior Staff Engineer

VA Power

PO Box 26666

Richmond, VA 23236

Telephone: 804-771-3862

FAX: 804-771-3166

Gage Robertson

Senior Engineer-Performance

Southwestern Public Service Co

PO Box 1261

Amarillo, TX 79170

Telephone: 806-378-2722

John J. Robinson

Sr. Assistant Vice President

Assn of American Railroads

SO F St NW

Washington, DC 20001

Telephone: 202-639-2204

FAX: 202-639-2930
J.A. Rogers

9374

Chief

Virginia Weights \& Measures

1100 Bank St

Richmond, VA 23209

Telephone: 804-786-2476

FAX: 804-371-7793

Terry Rosfelder 9078

Manager of Engineering Project

Sun Refining \& Marketing Co

1801 Market Street 21st Floor

Philadelphia, PA 19103-1699

Telephone: 215-977-6502

FAX: $215-246-8098$

Thomas P. Ross

Retail Analyst

Mobil Oil Corp

8280 Willow Oaks Corp Dr, Rm 7W 907

Fairfax, VA 22037

Telephone: 703-849-3834

FAX: 703-849-5831

Joseph Rothleder 3495

Principal State Metrologist

CA Div of Measurement Standard

8500 Fruitridge Rd

Sacramento, CA 95826

Telephone: 916-366-5119

FAX: $9160366-5179$

Albert E. Salemo

12232

President

Syracuse Scale Co Inc

158 Solar St

Syracruse, NY 13204

Telephone: $315-476-9696$

FAX: $315-476-3743$

Martin Scanlon

13778

Sr Project Tech Specialist

Federal Express Corp

2842 Business Park Dr

Memphis, TN 38118-2822

Telephone: 901-369-3085

FAX: $901-797-5202$

Tom W. Schafer

10000

Metrologist

Idaho Weights \& Measures

2216 Kellogg Lane

Boise, ID 83712

Telephone: 208-334-2345

FAX: 208-334-2170

Dennis Schaffer

Marketing Product Manager

TEC America Inc

19300 Hamilton Ave Suite 200

Gardena, CA 90248

Telephone: 213-329-9600

FAX: $213-329-1490$

James Schnitzler

10871

Gen Mgr Milk Receiving Sym Accurate Metering Systems Inc

1651 Wilkening Court

Schaumburg, IL 60173

Telephone: 708-882-0690

FAX: 708-882-2695
Brad H. Schumacher

National Account Manage

Dresser/Wayne

8420 West Bryn Mawr Suite 950

Chicago, IL 60631

Telephone: $312-693-7400$

FAX: $312-693-3618$

H.E. Schumacher

V/P Sales \& Services

Kerr McGee Coal Corp

PO Box 25861

Oklahoma City, OK 73125

Telephone: 405-270-3735

FAX: $405-270-2490$

Richard L. Seitz

1032

Manager Mech Petro Engr

Veeder-Root Co

125 Powder Forest Dr, POB 2003

Simsbury, CT 06070-2003

Telephone: 203-651-2722

FAX: 203-651-2719

M. Richard Shockley

Program Manager

Maryland Dept of Agriculture

So Harry S Truman Parkway

Annapolis, MD 21401

Telephone: $301-841-5790$

Joseph Silvestro

Superintendent

Gloucester Co Wts \& Meas Dept

49 Wood St County Bldg

Woodbury, NJ 08096

Telephone: 609-853-3358

FAX: $609-853-2770$

Kendrick J. Simila 2510

Administrator Measmt Stds Div

Oregon Dept of Agriculture

635 Capitol St, NE

Salem, OR 97310-0110

Telephone: 503-378-3792

FAX: 503-378-5529

John C. Skuce 10442

Manager Mechanical Engineering

Smith Meter Inc

1602 Wagner Ave-PO Box 10428

Erie, PA 16514

Telephone: 814-898-5405

FAX: $814-899-8927$

Douglas C. Smith

Technical Services Rep

William M Wilsons Sons Inc

8th St \& Valley Forge Rd

Lansdale, PA 19446-0309

Telephone: $215-855-4631 \times 236$

FAX: 215-855-0341

N. David Smith

Director Standards Division

NC Dept of Agriculture

PO Box 27647, Dept SD

Raleigh, NC 27611

Telephone: 919-733-3313

FAX: 919-733-0999

Richard N. Smith

Retired Tech Coordinator

Natl Institute of Std \& Tech

1003 Windemere Rd

Inwood, WV 25428

Telephone: $304-229-5964$ 
Robert A. Smoot

Deputy Dir. Weights \& Measures

Utah Dept of Agriculture

350 North Redwood Rd

Salt Lake City, UT 84116

Telephone: 801-538-7158

FAX: 801-538-7126

Donald J. Soberg

Admin Trade \& C.P. Division

Wisconsin Dept of Agriculture

801 W Badger Rd, PO Box 8911

Madison, WI 53708

Telephone: $608-266-7220$

FAX: $608-266-1300$

Louis F. Sokol

President Emeritus and Editor

US Metric Association

255 Mountain Meadows Rd

Boulder, CO 80302-9256

Telephone: $303-443-9728$

George R Spencer

$11340 \quad \begin{array}{ll}\text { Ellen Thomas } \\ \text { Manager Regulatory Indus Relns }\end{array}$

Sales \& Distribution Mgr.

Duraflame Inc

$2005 \mathrm{~W}$ Washington St

Stockton, CA 95203

Telephone: 209-948-2515

FAX: 209-948-2862

Thomas M. Stabler

Manager-Weights \& Measures

3119

Toledo Scale Corp

PO Box 1705

Columbus, OH 43216

Telephone: $614-438-4548$

PAX: $614-438-4646$

Don E. Stagg

Director

Weights \& Measures Division

PO Box 3336

Montgomery, AL 36193

Telephone: 205-242-2613 or 2614

FAX: 205-240-3135

Fred J. Staudinger

Business Manager

Pitney Bowes

Walter H Wheeler Jr Drive Loc 2700

Stamford, CT 06926

Telephone: 203-925-5235

FAX: 203-925-5140

Michael K. Stephenson

Inspector

Michigan Dept of Agriculture

244 Marshall St

Allegan, MI 49010

Telephone: $616-673-8812$

Louis E. Straub

Program Manager

Weights \& Measures Section

SO Harry S Truman Parkway

Annapolis, MD 21401

Telephone: $301-841-5790$

FAX: 301-841-5999

East Chicago, IN 46312

San Diego, CA 92123-1292
Kraft Inc

George W. Strayer

13733

National Quality Assurance Mgr

kin Robbins USA

1201 S Victory Blvd

Burbank, CA 91502

Telephone: 818-569-3764

FAX: $818-841-6569$

Chester Szyndrowski

Inspector Weights \& Measures

City of East Chicago

1102 W 151 Street

Telephone: 219-397-3409

Albert D. Tholen 232

Chief Off of Weights \& Measure

Natl Inst of Stds \& Tech

Admin 101, Rm A617

Gaithersburg, MD 20899

Telephone: 301-975-4009

FAX: $301-926-0647$

5401 Old Orchard Rd

Skokie, IL 60077

Telephone: 708-998-2000 x2054

FAX: 708-998-7801

Aves D. Thompson

10201

Chief

Div of Measurement Standards

12050 Industry Way PO11686

Anchorage, AK 99511

Telephone: 907-345-7750

FAX: 907-345-2641

E.A. (Hap) Thompson

Marketing Department

American Petroleum Institute

1220 L Street NW

Washington, DC 20005

Telephone: $202-682-8230$

FAX: 202-682-8222

Merrill S. Thompson

Merrill S. Thompson, P.C

Arnold \& Porter

PO Box 8500

Bridgeton, IN 47836

Telephone: 317-548-2202

Kathleen A. Thuner

Agric Comm Sealer Wts \& Meas

Dept of Agric Wts \& Meas

5555 Overland Ave, Bldg 3

Telephone: 619-694-2741

FAX: 619-565-7046

Walter Tkachuk

Senior Loss Control Specialist

Shell Oil Co

17919 Fireside Dr

Spring, TX 77379

Telephone: 713-251-0327

Guy J. Tommasi

Sealer of Weights \& Measures

City of Middletown

City Hall-245 Dekoven Drive

Middletown, CT 06457

Telephone: 203-344-3492 x492

PAX: 203-344-0136
Daryl E. Tonini

1336

Technical Director

Scale Manufacturers Assn

932 Hungerford Dr, \#36

Rockville, MD 20850

Telephone: 301-738-2448

FAX: 301-738-0076

Jose A. Torres-Ferrer

11193

Metrologist/W\&M Supervisor

Department of Consumer Affairs

PO Box 41059 Minillas Station

Santurce, PR 00940-1059

Telephone: 809-721-1930

FAX: 809-726-6570

Jonas E. Townsend, Jr.

Assistant Superintendent

6068

Cumberland County

788 E Commerce St

Bridgeton, NJ 08302

Telephone: $609-453-2203 \times 2205$

FAX: $609-451-0967$

Jon C. Trejo

16247

resident

Trejo Oil Company Inc.

Po Box G

Caja Grande, AZ 85222

Telephone: $602-836-5352$

FAX: $6902-421-022$

James C. Truex

Weights \& Measures Insp Mgr

Ohio Dept of Agriculture

8995 E Main St

Reynoldsburg, OH 43068

Telephone: $614-866-6361$

FAX: $614-866-4174$

Richard Tucker

9070

Manager Customer Service

Tokheim Corp

1602 Wabash Ave

Ft Wayne, IN 46801

Telephone: 219-423-2552

FAX: 219-484-4887

Ann H. Turner

Conference Coordinator

Natl Conf on Wts \& Meas

PO Box 4025

Gaithersburg, MD 20885

Telephone: 301-975-4012

FAX: 301-926-0647

Eric A. Vadelund

Senior Standards Specialist

Natl Institute of Stds \& Tech

Admin Bldg Rm A625

Gaithersburg, MD 20899

Telephone: $301-975-4028$

Calvin F. Vance

7607

Chief Enforcement Officer

AZ Dept of Weights \& Measures

1951 W North Lane

Phoenix, AZ 85021

Telephone: 602-255-5211

FAX: 602-255-1950

Lester C. Venable

Area Supervisor

Tenn Dept Of Agriculture

4735 Waynesboro Highway

Lawrenceburg, TN 38464

Telephone: $615-360-0160$ 
Gilles Vinet

11941

Program Officer Weights \& Meas

CANADA Legal Met Branch

207 Queen St, 2nd Fl, Ottawa

CANADA K1A 0C9,

Telephone: 613-952-2632

FAX: $613-952-1736$

Robert C. Wainscott

15661

Senior Vice President

Inspectorate America Corp.

5050 Timber Creek

Houston, TX 77017

Telephone: 713-944-2000

FAX: $713-947-0300$

Doug Walker

1688

Measurement Coordinator

Marathon Petroleum Co

$425 \mathrm{~S} 20$ th St

Tampa, FL 33605

Telephone: 813-248-6730

David R. Wallace

Chief Meas Standards Section

Colorado Dept of Agriculture

3125 Wyandot St

Denver, CO 80211

Telephone: $303-866-2845$

FAX: $303-480-9236$

Irene B. Warnlof

Retired Wts \& Meas Official

9705 Inaugural Way

Gaithersburg, MD 20879

Telephone: $301-926-8155$

Otto K. Warnlof

Standards Management

Natl Inst of Stds \& Tech

Admin Bldg A625

Gaithersburg, MD 20899

Telephone: 301-975-4026

FAX: 301-926-0647

Stanley I. Warshaw

Acting Director, OSS

Natl Institute of Stds \& Tech

A603 Admin Bldg

Gaithersburg, MD 20899

Telephone: $301-975-4001$

David Watson

Consumer Products Superviso

City of Fort Worth Texas

1000 Throckmorton, 5th Floor

Fort Worth, TX 76102

Telephone: 817-870-7386

FAX: $817-870$

Steve M. Watson

Marketing Manager

Sartorius Corporation

140 Wilbur Place

Bohemia, NY 11716

Telephone: 516-563-5120

FAX: 516-563-5065

Richard H. Weber

Metrology Lab

$3 \mathrm{M} \mathrm{Co}$

Bldg 544-1-02, 3M Center

St Paul, MN 55144-1000

Telephone: $612-733-2674$

FAX: 612-736-7325
Raymond R. Wells

Sensitive Measurement Inc

200 SMI W Hampton St, PO Box 72

Pemberton, NJ 08068

Telephone: $609-894-2292$

FAX: 609-894-0387

Richard L. Whipple

3486

Senior Regulatory Engineer

Gilbarco Inc

7300 W Friendly Ave, PO Box 22087

Greensboro, NC 27420

Telephone: 919-547-5150

FAX: 919-292-8871

George Wilson

12814

Senior Science Advisor

American Meat Institute

2510 Shagbark, SE

Grand Rapids, MI 49546

Telephone: 616-956-0507

FAX: 616-956-0507

Kenneth L. Wilson

1966

Automation Specialist

Arco Products Co

8601 S Garfield Ave

South Gate, CA 90280

Telephone: $213-806-4180$

FAX: $213-806-4130$

William J. Wilson

4493

Director Of Wts \& Measures

Clinton County W \& M

137 Margaret St

Plattsburgh, NY 12901

Telephone: 518-565-4600

FAX: $518-565-4616$

Randall Wise

KY Dept of Agric Wts \& Meas

106 West 2nd Street

Frankfort, KY 40601

Telephone: $502-564-4870$

Robert Wittenberger

91

Metrologist

Weights \& Measures Laboratory

PO Box 630

Jefferson City, MO 65102

Telephone: 314-751-3440

Theodore H. Yaffe

10872

Program Manager

US Postal Service

8403 Lee Highway

Merrifield, VA 22082-8101

Telephone: 703-641-7055

FAX: $703-280-4541$

W. E. Yager

11671

Superintenden

Cabot-Tuco Inc

PO Box 9902

Amarillo, TX 79105-5902

Telephone: 806-371-7341

Arthur L. Young

4112

Supervisor

Weights And Measures Division

American Samoa Government

Pago Pago American Samoa, AS 96799

Telephone: 946-633-1663

1

Paul Zalon

7312

Director Regulatory Affairs

Nestle Foods Corp

100 Manhattanville $R$

Purchase, NY 10577

Telephone: 914-251-3487

FAX: 914-251-2961

Andrew A. Zards

1344

Specialist Facilities Engineer

Amoco Oil Co

200 E Randolph Dr

Chicago, IL 60601

Telephone: $312-856-4073$

Joel H. Zimmerman

Quality Assurance Systems Mg

ConAgra Frozen Foods Co

5 ConAgra Drive

Omaha, NE 68102

Telephone: 402-595-6433

H.G. Zinsmeyer

President

Additive Systems Inc

8500 North Mopac, \#825

Austin, TX 78759

Telephone: 512-346-8514

Harold Zorlen

Regional Supervisor

MI Dept of Agric Reg VII

23777 Greenfield, 320

Southfield, MI 48075

Telephone: $313-443-0566$ 


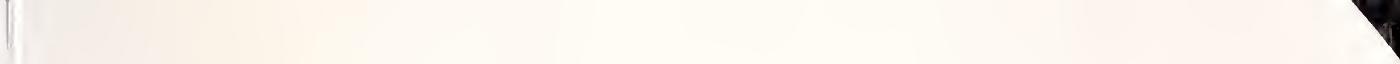



